MÁRCIA BORBA

Comportamento mecânico de cerâmicas utilizadas na confecção de próteses parciais fixas

São Paulo

2010 


\section{MÁRCIA BORBA}

Comportamento mecânico de cerâmicas utilizadas na confecção de próteses parciais fixas

Tese apresentada à Faculdade de Odontologia da Universidade de São Paulo para obtenção do título de Doutor em Ciências Odontológicas.

Área de Concentração: Materiais Dentários

Orientador: Prof. Dr. Álvaro Della Bona

São Paulo

2010 
Autorizo a reprodução e divulgação total ou parcial deste trabalho, por qualquer meio convencional ou eletrônico, para fins de estudo e pesquisa, desde que citada a fonte.

Catalogação da Publicação

Serviço de Documentação Odontológica

Faculdade de Odontologia da Universidade de São Paulo

\section{Borba, Márcia}

Comportamento mecânico de cerâmicas utilizadas na confecção de próteses parciais fixas / Márcia Borba; orientador Álvaro Della Bona. -- São Paulo, 2010.

170p. : fig., tab., graf.; $30 \mathrm{~cm}$.

Tese (Doutorado) -- Programa de Pós-Graduação em Ciências Odontológicas. Área de Concentração: Materiais Dentários -- Faculdade de Odontologia da Universidade de São Paulo.

1. Cerâmicas - Prótese parcial fixa - Propriedades mecânicas. 2. Materiais odontológicos. I. Della Bona, Álvaro. II. Título. 
Borba M. Comportamento mecânico de cerâmicas utilizadas na confecção de próteses parciais fixas. Tese apresentada à Faculdade de Odontologia da Universidade de São Paulo para obtenção do título de Doutor em Ciências Odontológicas.

Aprovado em: / /2010

\section{Banca Examinadora}

Prof(a). Dr(a). Instituição:

Julgamento: Assinatura:

$\operatorname{Prof}(a)$. $\operatorname{Dr}(a)$. Instituição:

Julgamento: Assinatura:

Prof(a). Dr(a). Instituição:

Julgamento: Assinatura:

Prof(a). Dr(a). Instituição:

Julgamento: Assinatura:

Prof(a). Dr(a). Instituição:

Julgamento: Assinatura: 


\title{
Dedicatórias
}

\author{
À Deus
}

À minha família

Mãe, você é um exemplo de determinação e força. Agradeço por ter me ensinado a ser independente e por me dar coragem. Obrigada por nunca dizer não, por patrocinar todas as minhas vontades, por acalmar minhas ansiedades, por não me deixar desistir e sempre me motivar a seguir em frente. Obrigada por ser essa super mãe e super mulher.

Pai, você é meu protetor. Obrigada por cuidar de mim, por sempre ter uma palavra sábia para resolver os meus problemas, por sempre me buscar no aeroporto com um buquê de rosas, por ser o melhor churrasqueiro do mundo, por assistir todos os programas bobos da TV só pra ficar do meu lado, por me deixar ir por mais difícil que isso seja pra ti...

Dani, meu companheiro e amigo. Agradeço por todas as risadas, comentários sarcásticos e principalmente pelo tempo que passamos juntos nos $\mathcal{E} \mathcal{A}$. Obrigada por agüentar minhas crises, por se preocupar comigo e tornar a minha vida mais leve e divertida!

Obrigada por sempre apoiarem meus sonhos, por me ajudarem a levantar todas as vezes que eu caí e por comemorarem minhas vitórias.

Essa tese eu dedico a vocês. 


\section{Agradecimentos}

Ao meu orientador Álvaro Della Bona. Para mim você é mais do que um mestre, é minha inspiração. Faltam palavras para agradecer tudo o que você tem feito por mim. Obrigada por acreditar em mim, por me dar apoio, abrir portas, caminhar ao meu lado $e$ nunca me deixar cair. Obrigada por cuidar de mim mais como filha do que como orientada.

Ao professor Paulo Francisco Cesar. Obrigada por me receber no seu grupo de cerâmicas e trabalhar comigo durante esses anos. Eu aprendi muito nesse tempo de convivência contigo, você colaborou muito para o meu amadurecimento profissional $e$ pessoal. Agradeço por sempre me incentivar a crescer e por ser mais do que um professor, um amigo.

Ao professor Jason Alan Griggs. Agradeço pela atenção e o cuidado que teve comigo durante meu período no Mississippi. Você é um exemplo para mim, a maneira como você se dedica a seus alunos é admirável. Obrigada por me receber com braços abertos não só na Universidade como também na sua família.

Ao professor Humberto Yoshimura. Agradeço por sempre ter uma resposta para todas as perguntas, a sempre nos incentivar a pensar mais, a estudar mais, a ir afém. Com certeza você é um dos maiores responsáveis pela alta qualidade de pesquisa do grupo de cerâmicas. Obrigada pelos ensinamentos e pela colaboração nesse trabalho.

À Mari, Tutty, SNá e Vivi. Minhas eternas colegas de colégio, amigas, vizinhas, companheiras, irmãs... $\mathcal{N a ̃ o}$ tem como escrever em um parágrafo minha gratidão a vocês. Vocês estiveram ao meu lado nos piores e melhores momentos, são minha coragem, minha força e minha alegria. Mesmo longe eu sempre levo um pedaço de vocês comigo.

Ao meu irmão "adotado", Arthur. Você é uma grande parte da minha vida, é muito 6om te encontrar e sentir como se ainda morássemos um do lado do outro. O tempo e a distância não são nada perto da nossa amizade.

Às minhas grandes amigas Fernanda e Karen. Ferdi, obrigada por sempre estar ao meu lado mesmo à distância, pelas horas de conversa, de conselhos, teu apoio psicológico foi muito importante para mim nesse tempo longe de casa. Karen, obrigada pela amizade, a tua companhia faz muita falta. Com certeza o meu tempo de faculdade não seria o mesmo sem vocês ao meu lado.

Às meninas do "apê 43", Tathy e Fabi. A minha transição de Passo Fundo para São Paulo jamais teria sido tão fácil se não fosse por vocês. Vocês me acolheram com carinho e sempre me ajudaram, em pouco tempo já éramos parte uma da vida da outra. Tenho muita saudade da época em que morávamos juntas. Fabi, obrigada pelo apoio, pela amizade, pela 
companhia, pelas risadas. É muito 6om ter como amiga uma pessoa tão positiva, você deixa as pessoas a sua volta mais felizes! Tathy, você me deu muita força em todos os momentos do meu doutorado, essa tese também é sua. Obrigada pelos conselhos, pelos "beijinhos", por ficar acordada comigo até tarde trabalhando, por ser minha consultora de tese online, por ouvir todas as minhas reclamações... A propósito, já fica registrado aqui o convite pra banca do meu primeiro aluno de pós-graduação, viu!

À Carol. Para mim você é uma combinação de dois extremos, delicadeza e força. Obrigada por estar ao meu lado nessa jornada, por me transformar em japa, por ter coragem de me ensinar a dirigir em SP, pelas viagens inesqueciveis, pelas conversas madrugada a dentro, por me escutar e me entender, pelo apoio e pela tua amizade. Um pedaço dessa tese também é seu.

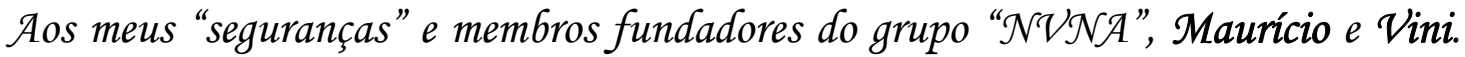
$U_{m}$ dos presentes que eu ganhei quando me mudei para São Paulo foi a amizade de vocês. Obrigada por cuidarem de mim, por ficarem comigo nos fins de semana, pelas viagens, shows, eventos culturais, pelos almoços de domingo, tardes no Ibirapuera, passeios no shopping... Obrigada por deixarem meus dias mais felizes!

À Letícia. Agradeço pela amizade nesses anos de pós-graduação, pela convivência dentro e fora da Universidade. Tenho saudades da época de "Pinguíns", em que nos divertíamos fazendo as disciplinas juntas.

À Paula Gomes. Agradeço por ser minha grande companheira, tanto no trabalho como na vida pessoal. Obrigada por ficar comigo até tarde no IPT, pelas horas intermináveis de usinagem e polimento, por tornar meu trabalho mais agradável, pelas risadas, fofocas, aventuras e, principalmente, pela tua amizade.

Agradeço aos amigos do grupo de cerâmicas. Ao Marcelo, que me acolheu no início dessa jornada e sempre me ajudou com paciência e boa vontade. À Karen, pela sua grande colaboração nessa tese, pela amizade e por ter um coração enorme. Ao Maico, pela ajuda durante meu período no exterior, sem teu esforço esse trabalho não seria possivvel. Aos alunos de iniciação científica Talita e Eric que também colaboraram para a conclusão desse estudo.

Ao Departamento de Materiais Dentários da FO-USP. Agradeço aos professores Rosa Helena Miranda Grande, Walter Gomes Miranda Junior, Igor Studart Medeiros, Fernando $\mathcal{N}$ eves $\mathcal{N}$ ogueira, Leonardo Eloy Rodrigues Filho, Roberto Ruggiero Braga, Josete Barbosa Cruz Meira, Rafael Yagüe Ballester, Antonio Muench, Carlos Eduardo Francci, Paulo Eduardo Capel Cardoso, Victor Elias Arana e Alyne Simões Gonçalves pela colaboração na minha formação profissional. Obrigada pelas lições de trabalho e de vida. Agradeço a Antonio, Silvio, Mirtes e Eli pela paciência com que me ajudaram sempre que eu precisei. À Rosa Cristina, pela dedicação com que cuida dos alunos e desse departamento. Agradeço aos demais colegas de pós-graduação pela agradável companhia nessa jornada. 
Ao Departamento de Ciências Biomédicas da Universidade do Mississippi. Agradeço aos professores Lyle Zardiackas, Kenneth St John, Amol Janorkar e Aaron Puckett pelos ensinamentos, pela dedicação e pela boa vontade com que sempre me ajudaram. A Glenn Thomas, Felícia Barnes, Nelda Moore, Joseph Thomas, Nathaniel Austin e John Neidigh por serem sempre prestativos e tornarem o ambiente de trabalho tão agradável. Aos colegas e amigos, Yuan Yuan Duan, Gaurav Joshi, Pratim Kulkarmi, Shruti Amruthwar, Minakshi Gupta, Michael Roach e Scott Williamson. Vocês fizeram a minha experiência no exterior inesquecivel, obrigada pela companhia dentro e fora da Universidade.

Agradeço a Emerson Nakao, Ricardo Tanaka e Mariane Brumatti, que colaboraram com muita boa vontade para a realização desse trabalho.

Aos professores, colegas e amigos da Vniversidade de Passo Fundo. Vocês me deram o conhecimento e o incentivo para chegar até aqui.

Aos amigos e funcionários do Instituto de Pesquisa Tecnologia (IPT) pela colaboração e por disponibilizar o seu laboratório para que essa pesquisa fosse realizada.

À USP, CAPES, CNNPq e FAPESP agradeço pelo apoio financeiro. 


\section{RESUMO}

Borba M. Comportamento mecânico de cerâmicas utilizadas na confecção de próteses parciais fixas [tese]. São Paulo: Universidade de São Paulo, Faculdade de Odontologia; 2010.

Objetivos: determinar a resistência à flexão em três pontos $\left(\sigma_{f}\right)$, módulo de Weibull $(\mathrm{m})$, coeficiente de susceptibilidade ao crescimento subcrítico de trinca $(n)$ e tenacidade à fratura $\left(K_{I C}\right)$ de três cerâmicas usadas para confecção de infraestrutura (IE) de próteses parciais fixas (PPFs) (YZ- zircônia tetragonal parcialmente estabilizada por óxido de ítrio; IZ- cerâmica a base de alumina infiltrada por vidro e reforçada com zircônia; AL- alumina policristalina) e duas porcelanas (VM7 e VM9); avaliar o efeito da configuração (uma, duas ou três camadas) nos valores de $\sigma_{f} \mathrm{e}$ modo de fratura dos corpos-de-prova (CP); avaliar a influência do material de IE, do tamanho dos conectores e da ciclagem mecânica (CM) na carga de fratura (CF) e distribuição de tensões de PPFs; relacionar o comportamento mecânico dos materiais cerâmicos testados na configuração de barra e de PPF. Material e Método: Foram produzidos três tipos de CP em forma de barra $(2 \mathrm{~mm} \times 4 \mathrm{~mm} \times 16 \mathrm{~mm})$ : monolítico, duas camadas e três camadas. As IE das PPFs foram confeccionadas utilizando o sistema CAD-CAM e recobertas com porcelana. Os ensaios de $\sigma_{f}$ foram realizados em saliva artificial a $37^{\circ} \mathrm{C}$. Os valores de $\mathrm{m}$ e $n$ foram determinados pela análise de Weibull e ensaio de fadiga dinâmica, respectivamente. As PPFs foram carregadas no centro do pôntico até a fratura. Oito PPFs de cada grupo foram submetidas a CM com freqüência de $2 \mathrm{~Hz}$ e carga de $140 \mathrm{~N}$ durante $10^{6}$ ciclos e, posteriormente, ensaiadas até a fratura. A distribuição de tensões nas PPFs foi avaliada com análise de elementos finitos (AEF). Os princípios da fractografia foram utilizados para determinar o padrão de fratura e os valores de $\mathrm{K}_{\mathrm{Ic}}$. Os dados de $\sigma_{\mathrm{f}} \mathrm{e}$ CF foram analisados estatisticamente com Kruskal-Wallis e Tukey (95\%). Resultados: A YZ obteve o maior valor de $\sigma_{f}(860 \mathrm{MPa})$ seguida dos materiais $\mathrm{IZ}$ (411 MPa) e AL (474 MPa) que não apresentaram diferença estatística. Os menores valores de $\sigma_{f}$ foram encontrados para as porcelanas (65 MPa). Os valores de $\mathrm{m}$ foram semelhantes para os materiais, com exceção dos grupos $I Z$ e VM7, que apresentaram diferença significante. Os maiores valores de $n$ foram encontrados 
para as cerâmicas $\mathrm{YZ}$ (76) e AL (72), seguidos pela IZ (54) e pelas porcelanas (40). A YZ apresentou o maior valor de $\mathrm{K}_{\mathrm{IC}}$. O material submetido à tensão de tração durante o ensaio determinou o valor de $\sigma_{f}$ das estruturas. As PPFs de YZ com conector de $16 \mathrm{~mm}^{2}$ suportaram os maiores valores de CF. Houve influência significativa do tamanho de conector para o material YZ. A CM não influenciou os valores de CF das PPFs. O padrão de distribuição de tensões foi semelhante entre as PPFs. Foi observada uma boa relação entre os valores de tensão de fratura dos materiais de IE em forma de barra e de PPF. Foram encontradas diferenças no modo de falha dos CP em forma de barra e de PPF. Conclusão: a YZ apresentou o melhor comportamento mecânico tanto na configuração de barra como de PPF.

Palavras-Chave: cerâmicas odontológicas; propriedades mecânicas; crescimento de trinca subcrítico. 


\begin{abstract}
Borba M. Mechanical behavior of ceramic materials used for fixed partial dentures [thesis]. São Paulo: Universidade de São Paulo, Faculdade de Odontologia; 2010.
\end{abstract}

Objectives: to determine the flexural strength $\left(\sigma_{f}\right)$, Weibull modulus $(m)$, slow crack growth coefficient $(n)$ and fracture toughness $\left(\mathrm{K}_{\mathrm{IC}}\right)$ of three ceramics used as framework materials for fixed partial dentures (FPDs) (YZ- yttria partially stabilized zirconia tetragonal polycrystals; IZ- alumina-based zirconia-reinforced glass infiltrated ceramic; AL- alumina polycrystals) and two veneering porcelains (VM7 and VM9); to evaluate the effect of the specimen design (one, two or three layers) in the $\sigma_{f}$ and fracture mode; to evaluate the influence of the framework material, connector size and mechanical cycling (MC) in the fracture load (FL) and stress distribution of FPDs; to relate the mechanical behavior of the ceramic materials tested using bar-shaped specimens and FPDs. Materials and Methods: Bar-shaped specimens $(2 \mathrm{~mm} \times 4 \mathrm{~mm}$ $x 16 \mathrm{~mm}$ ) were produced in three different designs: monolithic, bilayer and trilayer. FPD frameworks were built using CAD-CAM system and veneered with porcelain. Specimens were tested for three point bending in $37^{\circ} \mathrm{C}$ artificial saliva. Weibull analysis and dynamic fatigue testing were used to determine $\mathrm{m}$ and $n$ values, respectively. FPDs were tested with a load applied in the middle of the pontic. Eight FPDs of each group were subjected to MC using a frequency of $2 \mathrm{~Hz}$ and load of $140 \mathrm{~N}$ for $10^{6}$ cycles and were subsequently loaded to failure. Stress distribution for FPDs was evaluated using finite element analysis (FEA). Fractography principles were used to determine the fracture mode and $\mathrm{K}_{\mathrm{IC}}$ values. $\sigma_{f}$ and $\mathrm{FL}$ data were analyzed using Kruskal-Wallis and Tukey (95\%). Results: YZ had the highest $\sigma_{f}$ value (860 MPa) followed by IZ (411 MPa) and AL (474 MPa). Lower $\sigma_{f}$ values were observed for the porcelains (65 MPa). Except for IZ and VM7, $m$ values were similar among the ceramic materials. Higher $n$ values were found for $Y Z$ (76) and AL (72), followed by $I Z(54)$ and the veneering materials (40). YZ presented the highest $K_{I C}$ value. The $\sigma_{f}$ values were influenced by the material subjected to tensile stress during testing. YZ FPDs with $16 \mathrm{~mm}^{2}$ connector showed higher FL values. There was significant influence of the connector size on the $F L$ values for $Y Z$ material. MC had 
no influence in the FL values for the FPDs. The stress distribution was similar for all FPDs. Considering the framework material, there was a good agreement between the fracture strength values obtained for bar-shaped specimens and FPDs. Different fracture modes were observed for bar-shaped specimens and FPDs. Conclusion: YZ presented the best mechanical performance in both bar-shaped and FPD specimen configuration.

Keywords: dental ceramics, mechanical properties, slow crack growth. 


\section{LISTA DE FIGURAS}

Figura 2.1 - Desenho esquemático da superfície de fratura. Pode-se observar as três regiões características que envolvem a origem de fratura: mirror, mist e hackle (Mecholsky, 1995)

Figura 4.1 - Bloco de YZ fixado ao tubo de PVC com cera pegajosa e sendo seccionado na cortadeira. A) Vista lateral do primeiro corte sendo realizado. B) Segundo corte sendo realizado

Figura 4.2 - A) Corpos-de-prova na bandeja sobre a base de refratário do forno Zyrcomat. B) Corpos-de-prova de AL sinterizados

Figura 4.3 - A) Aplicação da pasta de vidro na barras de IZ. B) Pasta de vidro aplicada sobre a superfície do corpo-de-prova. C) Barra logo após o ciclo de infiltração do vidro. D) Barra após a remoção do excesso de vidro com pontas montadas .58

Figura 4.4 - A) Dispositivo para chanfrar os cantos das barras de cerâmica. B) Corpo-de-prova posicionado dentro do dispositivo para chanframento dos cantos.

Figura 4.5 - Corpos-de-prova monolíticos de $Y Z$ (A) e $A L$ (B): (1) antes da sinterização; (2) após sinterização; (3) após usinagem; (4) após polimento de uma das faces e chanframento dos cantos

Figura 4.6 - A) Aplicação do agente de união (Effect Bonder) com auxílio de um pincel sobre a barra de $\mathrm{YZ}$. B) barra de $\mathrm{YZ}$ com a camada de Effect Bonder.

Figura 4.7 - Corpos-de-prova de duas camadas após usinagem. A) YZ sob a VM9. B) IZ sob a VM7. C) AL sob a VM7

Figura 4.8 - Passos de confecção do corpo-de-prova de três camadas. A) Matriz metálica. B) Primeira camada de porcelana sendo aplicada. C) Inserção da barra de infra-estrutura na camada de porcelana. D) Base da matriz ajustada para receber a segunda camada de porcelana. E) Aplicação da segunda camada de porcelana. F) Remoção do excesso de porcelana com uma lâmina. G) Corpo-de-prova após remoção do excesso de porcelana. H) Corpo-de-prova extraído da matriz. I) Vista da extremidade do corpo-de-prova onde a porcelana foi removida para visualização da infra-estrutura

Figura 4.9 - Corpo-de-prova de três camadas após sinterização da porcelana. A) Vista lateral. B) Detalhe da extremidade com infra-estrutura exposta..64 
Figura 4.10 - A) Modelo em aço inox simulando dentes com preparos protéticos para receber coroas totalmente cerâmicas com término em chanfro como proposto por Sundh et al. (2005). B) Bloco de resina acrílica posicionado no modelo para simular a gengiva que fica abaixo do pôntico. C) Dimensões dos pilares protéticos: altura de $4,5 \mathrm{~mm}$, preparo com inclinação de $6^{\circ}$, término em chanfro de $120^{\circ}, 3,1 \mathrm{~mm}$ de diâmetro na área oclusal e $6 \mathrm{~mm}$ de diâmetro na área cervical ...........65

Figura 4.11 - Molde dos preparos obtido com silicone de adição. A) Vista geral. B) Detalhe.

Figura 4.12 - Modelo de gesso especial reproduzindo os preparos feitos em aço inoxidável. A) Vista lateral. B) Vista oclusal ....

Figura 4.13 - Imagem tridimensional do modelo de gesso sobre a qual a PPF foi construída. Vista oclusal (A) e vista lingual (B) do modelo com os términos dos preparos e a base do pôntico delimitados (linhas azuis) 66

Figura 4.14 - Desenho final de uma PPF de YZ com conector de $9 \mathrm{~mm}^{2}$. A) Vista oclusal. B) Vista vestibular. C) Vista interna.

Figura 4.15 - A) Bloco de YZ posicionado no CEREC inLab. B) PPF logo após a usinagem. C) PPF usinada e antes de ser separada do bloco cerâmico

Figura 4.16 - Processo de infiltração do vidro nas PPFs de IZ. A) Aplicação da pasta de vidro com pincel. B) Vista lateral da PPF logo após ciclo de infiltração do vidro. C) PPF após remoção dos excessos de vidro ......68

Figura 4.17 - Infra-estruturas com conector de $16 \mathrm{~mm}^{2}$ dos sistemas IZ (acima), YZ (centro) e AL (abaixo). A) Vista oclusal. B) Vista vestibular. C) Vista cervical. 68

Figura 4.18 - Imagem de uma PPF mostrando os pontos de controle da espessura da camada de porcelana (flechas em amarelo).

Figura 4.19 - Dispositivo para ensaio de resistência à flexão em três pontos. A) Vista lateral do corpo-de-prova posicionado sobre os dois suportes cilíndricos de apoio. Vista lateral (B) e superior (C) do corpo-de-prova dentro do dispositivo pronto para o ensaio. .73

Figura 4.20 - Vista geral da máquina de ciclagem. B) PPFs posicionadas sob os pistões esféricos

Figura 4.21 - PPF pronta para ensaio de carga de fratura .77

Figura 4.22 - Máscaras construídas a partir de cortes tomográficos. A) Vista sagital. B) Vista coronal. C) Vista axial. D) Modelo tridimensional da PPF. As máscaras de cores rosa, verde e amarelo correspondem aos pilares, infra-estrutura e camada de porcelana, respectivamente 80 
Figura 4.23 - Camadas do modelo final das PPFs com conector de $16 \mathrm{~mm}^{2}$ (A) e de $9 \mathrm{~mm}^{2}(\mathrm{~B})$ : pilares (abaixo), infra-estrutura (centro) e camada de porcelana (acima)

Figura 4.24 - A) Interface entre os pilares e a infra-estrutura. B) Interface entre a infra-estrutura e a camada de porcelana.

Figura 4.25 - Imagem de uma PPF com conector de $16 \mathrm{~mm}^{2}$ representando as condições de fixação e carregamento.A flecha indica a região e direção de carregamento e as faixas em laranja representam as regiões de fixação.

Figura 5.1 - Imagens de MEV das superfícies dos materiais de infra-estrutura. A) YZ. B) $\mathrm{AL}$

Figura 5.2 - Imagem de MEV da superfície do material IZ: as partículas mais claras correspondem aos cristais de zircônia, as partículas escuras aos cristais de alumina e a matriz cinza corresponde ao vidro de silicato de lantânio.

Figura 5.3 - Imagens de MEV das superfícies dos materiais de recobrimento. A) Porcelana VM7. B) Porcelana VM9.

Figura 5.4 - Boxplot com os dados de resistência à flexão em três pontos $\left(\sigma_{f}\right)$ dos cinco grupos experimentais.

Figura 5.5 - Gráfico de Weibull mostrando os resultados de $\sigma_{f}$ para a taxa de carregamento de $1 \mathrm{MPa} / \mathrm{s}$ .90

Figura 5.6 - Intervalos de confiança de $95 \%$ para os parâmetros $\sigma_{0}$ e $\mathrm{m}$ dos grupos experimentais

Figura 5.7 - Resultados de fadiga dinâmica, correlacionando os valores de tensão de fratura e a taxa de carregamento para os cinco materiais estudados ..93

Figura 5.8 - Curvas de tempo de vida (lifetime curve) obtidas para os cinco materiais estudados, através da correlação entre log do tempo de fratura e log da tensão de fratura. No eixo $x$ foram colocadas marcações indicando os tempo de 1 dia (1d), 1 ano (1a) e 10 anos (10a) ..............................95

Figura 5.9-Gráficos SPT para os tempos de 1 dia, 1 ano e 10 anos .96

Figura 5.10 - Imagem de esteremicroscópio da superfície de fratura dos materiais de infra-estrutura. A) YZ. B) IZ. C) AL. Pode-se observar a presença de marcas características como compression curl (CC) e hackle lines (HL). As flechas apontam para a origem de defeito .98 
Figura 5.11 - Imagens de MEV da superfície de fratura dos materiais de infraestrutura. A e B) YZ. C e D) IZ. E e F) AL. Pode-se observar a presença de marcas características como compression curl (CC) e hackle lines $(\mathrm{HL})$. As flechas indicam o defeito crítico.........................99

Figura 5.12 - Imagens de MEV da superfície de fratura das porcelanas. A e B) VM7. C e D) VM9;. Pode-se observar marcas características como compression curl (CC) e wake hackles (WH). As flechas indicam o defeito crítico. 100

Figura 5.13 - Gráficos mostrando o tamanho de defeito crítico $(\mu \mathrm{m})$ em função das taxas de tensão $(\mathrm{MPa} / \mathrm{s})$ para cada grupo experimental $(\mathrm{n}=5)$.. 101

Figura 5.14 - Corpos-de-prova de duas camadas após fratura em ensaio de flexão em três pontos com a porcelana em tração (PT). A e B) YZ-PT. C e D) IZ-PT. E e F) AL-PT. As trincas foram coradas com tinta preta para facilitar visualização. Nas imagens o material de infra-estrutura está sobre a camada de porcelana. 103

Figura 5.15 - Corpos-de-prova de duas camadas após fratura em ensaio de flexão de três pontos com material de infra-estrutura em tração. A) YZ-IT. B) IZ-IT. C) AL-IT. As flechas apontam para a origem do defeito crítico.104

Figura 5.16 - Imagem de MEV da superfície de fratura de um corpo-de-prova do grupo IZ-IT. A) Imagem geral da superfície de fratura com a flecha apontando para a origem de defeito. B) Vista ampliada da interface entre a porcelana e a infra-estrutura (ampliação do quadro marcado na imagem $\mathrm{A}$ ), as flechas pretas evidenciam a presença de cone cracks na camada de porcelana submetida às tensões de compressão.......105

Figura 5.17 - Imagem do padrão de fratura parcial de um corpo-de-prova do grupo YZ-IT. A) Vista da camada de porcelana com os pedaços fraturados reposicionados. B) Vista lateral do corpo-de-prova fraturado com os pedaços sendo reposicionados. C) Vista da superfície de fratura da porcelana com parte da infra-estrutura exposta. D) Pedaço de porcelana que delaminou após a fratura ....................................105

Figura 5.18 - Corpos-de-prova de três camadas após fratura em ensaio de flexão em três pontos. Vista superior (A) e vista lateral (B) de um corpo-de-prova do grupo YZ-TRI com fratura parcial. Superfície de fratura de corpo-deprova dos grupos IZ-TRI (C) e AL-TRI (D) que fraturaram como um corpo-único (fratura total). 106

Figura 5.19 - Imagem de MEV da superfície de fratura de um corpo-de-prova do grupo IZ-TRI. A) Vista geral da superfície de fratura. B) Vista ampliada camada de porcelana evidenciando a origem do defeito. A flecha aponta para a origem do defeito crítico 107

Figura 5.20 - Boxplot com os dados de carga de fratura $(\mathrm{N})$ dos quatro grupos experimentais 108 
Figura 5.21 - Boxplot com os dados de carga de fratura $(\mathrm{N})$ das PPFs dos grupos controle e submetidos à ciclagem mecânica $(\mathrm{CM})$ para os três materiais de infra-estrutura. 109

Figura 5.22 - Padrão de fratura macroscópica das PPFs, classificado de acordo com a origem da fratura. A) Fratura do conector. B) Fratura do pôntico. C) Fratura do retentor. As flechas apontam para o local de início da fratura

Figura 5.23 - Imagens da superfície de fratura de uma PPF do grupo YZ16 com fratura do retentor e origem do defeito na superfície interna da margem adjacente ao conector. A) Imagem de estereomicroscópio ampliada no local da origem do defeito. B) Imagem de estereomicroscópio da superfície de fratura do retentor. C) Imagem de MEV do defeito crítico. Pode-se observar marcas características como compression curl (CC) e hackles lines $(\mathrm{HL})$. As flechas indicam a origem do defeito .....

Figura 5.24 - Imagens de MEV da superfície de fratura de uma PPF do grupo YZ16 com fratura do pôntico e origem do defeito na superfície externa da porcelana. A) Imagem da região cervical do pôntico mostrando a camada de porcelana e a cerâmica de infra-estrutura, os dois defeitos estão evidenciados nas caixas pretas. B) Defeito crítico na infraestrutura. C) Defeito crítico na porcelana.................................112

Figura 5.25 - Imagens de MEV mapeando a superfície de fratura de uma PPF do grupo AL16 com fratura do pôntico e origem do defeito na interface. Pode-se perceber nas imagens ampliadas da superfície de fratura que as wake hackles apontam para a interface 113

Figura 5.26 - Imagens de estereomicroscópio da superfície de fratura de uma PPF do grupo IZ16 (A) e do grupo AL16 (C). Imagens de MEV do defeito crítico para a infra-estrutura do grupo IZ16 (B) e AL16 (D) ...............114

Figura 5.27 - Imagem lateral, cervical e oclusal das infra-estruturas dos grupos YZ9 (A) e YZ16 (B)

Figura 5.28 - Faixas de tensões na região cervical das infra-estruturas de $16 \mathrm{~mm}^{2}(\mathrm{~A})$ e $9 \mathrm{~mm}^{2}(B)$

Figura 5.29 - Imagem lateral e cervical da camada de porcelana do grupo YZ9 (A) e YZ16 (B) 116

Figura 5.30 - Imagem lateral e cervical das infra-estruturas com conector de $16 \mathrm{~mm}^{2}$ para os sistemas $I Z(A)$ e $A L(B)$.

Figura 5.31 - Imagem lateral e cervical da camada de porcelana dos grupos YZ16 (A), IZ16 (B) e AL16 (C). 


\section{LISTA DE TABELAS}

Tabela 4.1 - Descrição dos sistemas cerâmicos utilizados nesse estudo .56

Tabela 4.2 - Ciclos de sinterização dos materiais YZ e AL e ciclo de infiltração de vidro do IZ

Tabela 4.3 - Ciclos de sinterização das porcelanas VM7 e VM9 e do Effect Bonder e ciclo de glaze

Tabela 4.4 - Classificação das estruturas em forma de barra com relação ao número de camadas (uma, duas ou três) e à configuração do ensaio de flexão (porcelana em tração ou infra-estrutura em tração)

Tabela 4.5 - Classificação das PPFs com relação ao tamanho de conector $\left(9 \mathrm{~mm}^{2}\right.$ ou $16 \mathrm{~mm}^{2}$ ) e a condição experimental (com ou sem ciclagem) .78

Tabela 4.6 - Valores de módulo de elasticidade (E) e coeficiente de Poisson (v) utilizados na AEF

Tabela 5.1 - Tipo, fração volumétrica $(\%)$ e tamanho médio $(\mu \mathrm{m})$ de cristal das cerâmicas estudadas. Valores apresentados pela média \pm desviopadrão

Tabela 5.2 - Valores médios de densidade $(\rho)$, módulo de elasticidade $(E)$ e coeficiente de Poisson $(v)$ e desvio padrão para os cinco materiais estudados, além dos grupamentos estatísticos $(n=10)$.

Tabela 5.3 - Valores médios, desvio padrão (DP), coeficiente de variação (CV), mediana e valores mínimos e máximos de resistência à flexão $\left(\sigma_{f}\right)$ dos grupos experimentais (MPa), além do grupamento estatístico $(n=30) .88$

Tabela 5.4 - Valores dos parâmetros de Weibull, $\sigma_{0}$ (resistência característica) e m (módulo de Weibull), com seus respectivos intervalos de confiança de $95 \%$ e os valores de resistência para uma probabilidade de fratura de $5 \%\left(\sigma_{5 \%}\right)$, além dos grupamentos estatísticos $(n=30)$

Tabela 5.5 - Médias de tensão de fratura (MPa) em função da taxa de tensão com respectivos valores de desvio-padrão para os materiais estudados $(n=10)$

Tabela 5.6 - Parâmetros de crescimento subcrítico obtidos no ensaio de fadiga dinâmica: $n$ e $\sigma_{f 0}$, com seus respectivos valores de desvio-padrão .....94 
Tabela 5.7 - Valores de tensão de ruptura, em MPa, necessários para fratura dos cinco materiais em tempos de vida de 1 dia $\left(\sigma_{1 d}\right), 1$ ano $\left(\sigma_{1 a}\right)$ e 10 anos $\left(\sigma_{10 a}\right)$ e diferença, em $\%$, entre os valores de $\sigma_{1 \mathrm{~d}}$ e $\sigma_{10 \mathrm{a}}$. Valores obtidos a partir das curvas de regressão da figura 5.8

Tabela 5.8 - Valores de tensão necessários para fratura dos cinco materiais em tempos de vida de 1 dia $\left(\sigma_{1 \mathrm{~d}}\right), 1$ ano $\left(\sigma_{1 \mathrm{a}}\right)$ e 10 anos $\left(\sigma_{10 \mathrm{a}}\right)$ para uma probabilidade de falha de $5 \%$, obtidos através dos diagramas SPT (MPa)

Tabela 5.9 - Valores médios de tamanho crítico de defeito (c), tenacidade à fratura $\left(\mathrm{K}_{\mathrm{Ic}}\right)$ e desvio padrão para os materiais estudados, além dos grupamentos estatísticos $(n=25)$. 100

Tabela 5.10 - Valores de resistência à flexão em três pontos $\left(\sigma_{f}\right)$ para os corpos-deprova em forma de barra em função do material e da configuração da estrutura. Valores dispostos em mediana (MPa) \pm desvio padrão, e grupamento estatístico $(n=10)$. 102

Tabela 5.11 - Tipo de fratura dos corpos-de-prova em camadas em função do material e configuração da estrutura. 103

Tabela 5.12 - Valores de média, desvio padrão (DP), coeficiente de variação (CV), mediana, valores mínimos e máximos da carga de fratura $(\mathrm{N})$ para os grupos experimentais, e o grupamento estatístico* $(n=10) \ldots \ldots \ldots \ldots . . . .108$

Tabela 5.13 - Valores de média, desvio padrão (DP), coeficiente de variação (CV), mediana, valores mínimos e máximos da carga de fratura $(\mathrm{N})$ para os grupos controle e submetidos à ciclagem mecânica (CM), e o grupamento estatístico*. O valor de $n$ para os grupos ciclados foi igual a 8 109

Tabela 5.14 - Número de PPFs com padrão de fratura iniciando no conector, no pôntico e nos retentores, para cada grupo experimental, além do número de delaminações. $O$ valor de $n$ para os grupos controle e ciclado $(\mathrm{CM})$ foi 10 e 8 , respectivamente

Tabela 5.15 - Número de PPFs com origem de fratura na superfície da porcelana, na interface, na superfície interna da margem do conector e número de fraturas não identificadas para cada grupo estudado. $O$ valor de $\mathrm{n}$ para os grupos controle e ciclado (CM) foi 10 e 8 , respectivamente. 111

Tabela 5.16 Valores médios de tamanho do defeito crítico (c) e tensão de fratura $\left(\sigma_{\mathrm{f}}\right)$ das infra-estruturas dos grupos experimentais. $O$ valor de $\mathrm{n}$ para os grupos controle e ciclado $(\mathrm{CM})$ foi igual a 8 e 5 , respectivamente. Os valores estão dispostos em média \pm desvio padrão. 114

Tabela 5.17 - Valor da tensão de tração máxima principal para os modelos avaliados (MPa) 


\section{SUMÁRIO}

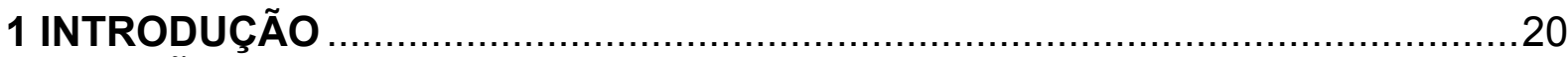

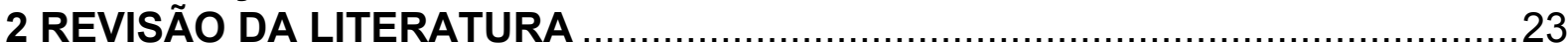

2.1 PROPRIEDADES MECÂNICAS DOS MATERIAIS CERÂMICOS ....................23

2.2 RESTAURAÇÕES METALO-CERÂMICAS E RESTAURAÇÕES

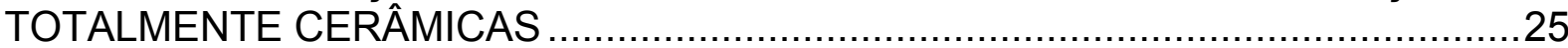

2.2.1 Zircônia tetragonal parcialmente estabilizada com óxido de ítrio - YZ ....26

2.2.2 In-Ceram Zircônia - IZ .................................................................30

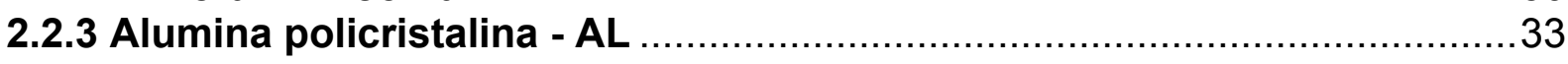

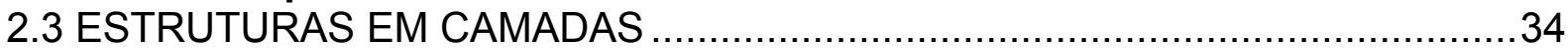

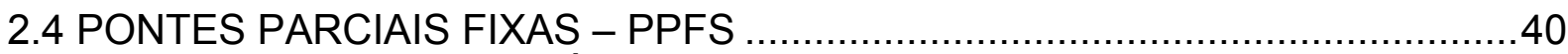

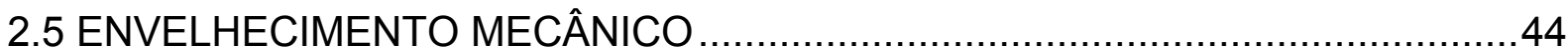

2.6 FRACTOGRAFIA DE MATERIAIS CERÂMICOS …................................47

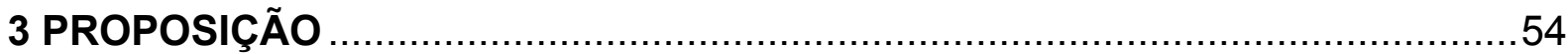

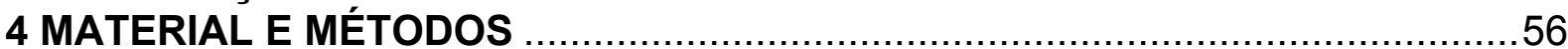

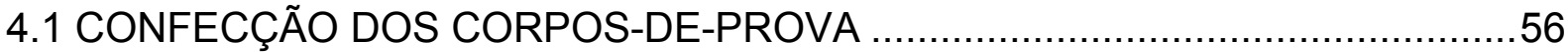

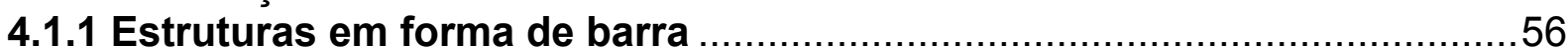

4.1.1.1 Corpos-de-prova monolíticos (uma camada) ….....................................57

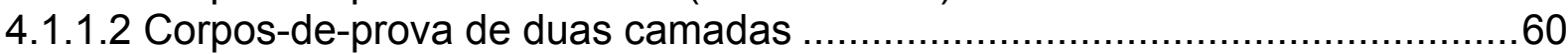

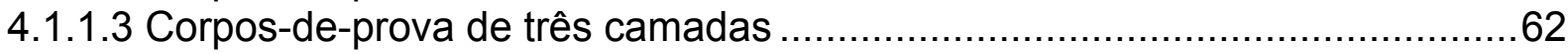

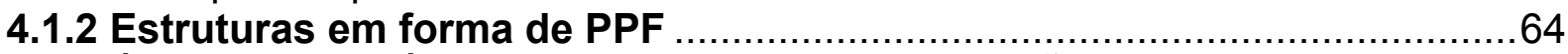

4.2 MÉTODOS ANALÍTICOS PARA A CARACTERIZAÇÃO DOS MATERIAIS ........70

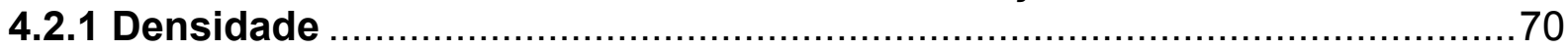

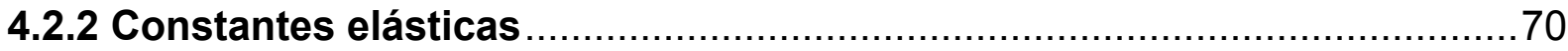

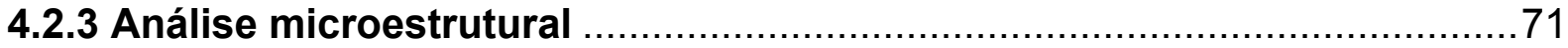

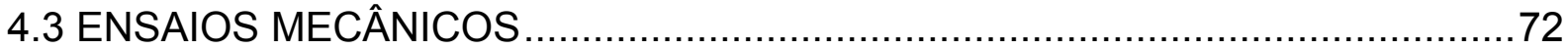

4.3.1 Análise de Weibull e comportamento de crescimento subcrítico de

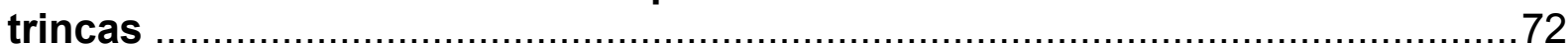

4.3.2 Resistência à flexão em função da configuração do corpo-de-prova .......75

4.3.3 Carga de fratura das PPFs em função da ciclagem mecânica e da área de seção transversal do conector. ............................................................

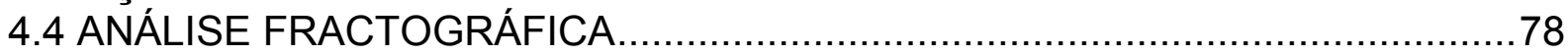

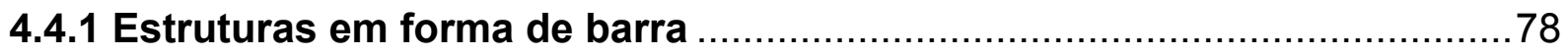

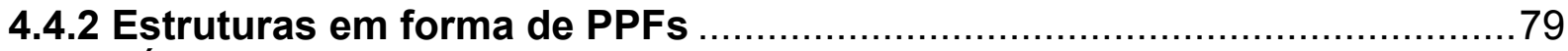

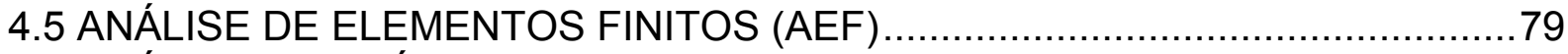

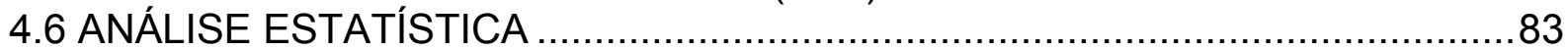

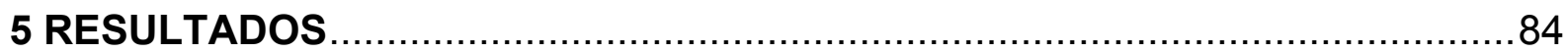

5.1 CARACTERIZAÇÃO E ANÁLISE MICROESTRUTURAL …..........................84

5.1.1 Microestrutura dos materiais de infra-estrutura ...................................8 84

5.1.2 Microestrutura dos materiais de recobrimento (porcelanas) …...............86

5.1.3 Densidade e propriedades elásticas ................................................ 86

5.2 ENSAIOS MECÂNICOS E ANÁLISE FRACTOGRÁFICA DAS

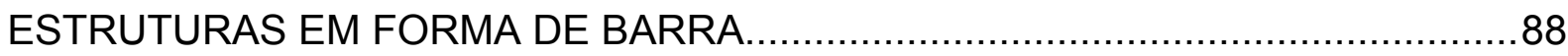

5.2.1 Ensaio de resistência à flexão em três pontos dos corpos-de-prova

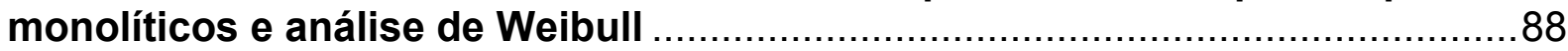

5.2.2 Determinação do coeficiente de susceptibilidade ao crescimento subcrítico da trinca $(n)$ 
5.2.3 Análise fractográfica qualitativa e quantitativa dos corpos-de-prova monolíticos

5.2.4 Efeito da configuração na resistência à flexão em três pontos e modo de fratura dos corpos-de-prova em forma de barra

5.3 CARGA DE FRATURA E ANÁLISE FRACTOGRÁFICA DE PPFS

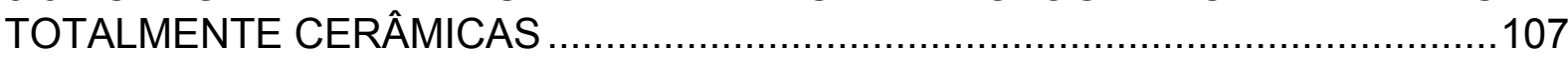

5.3.1 Influência do tipo de material e tamanho de conector ...........................107

5.3.2 Influência do envelhecimento mecânico ……......................................108

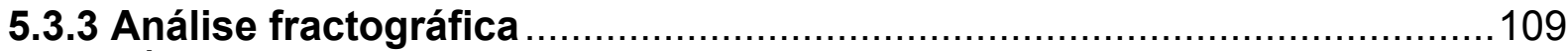

5.4 ANÁLISE DE ELEMENTOS FINITOS (AEF) _....................................114

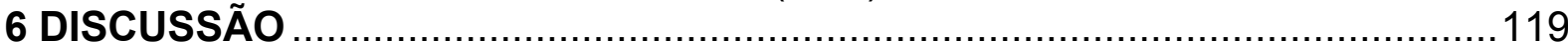

6.1 RESISTÊNCIA À FLEXÃO DE CORPOS-DE-PROVA MONOLÍTICOS ............119

6.2 CONFIABILIDADE DOS SISTEMAS CERÂMICOS ......................................123

6.3 COMPORTAMENTO DE CRESCIMENTO SUBCRÍTICO DE TRINCAS -

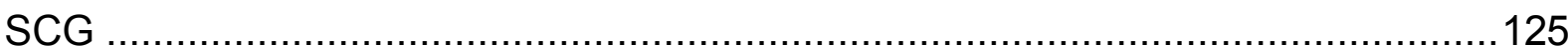

6.4 ESTIMATIVA DO TEMPO DE VIDA PARA OS MATERIAIS CERÂMICOS ......128

6.5 TENACIDADE À FRATURA DOS MATERIAIS CERÂMICOS …........................130

6.6 EFEITO DA CONFIGURAÇÃO DO CORPO-DE-PROVA NA RESISTÊNCIA

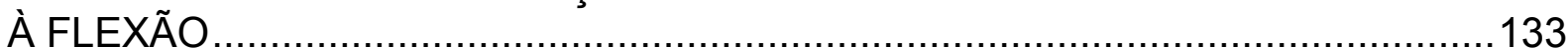

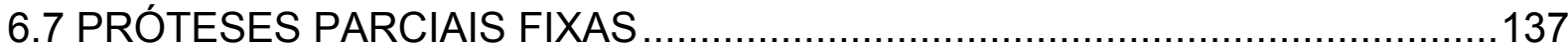

6.7.1 Efeito do tipo de material de infra-estrutura e do tamanho de secção transversal na carga de fratura das PPFs

6.7.2 Efeito da ciclagem mecânica na carga de fratura das PPFs ...................139

6.7.3 Efeito do tipo de material de infra-estrutura e do tamanho de secção transversal na distribuição de tensões das PPFs ......................................143

6.7.4 Padrão de fratura das PPFs em função do tipo de material de infraestrutura, tamanho de conector e ciclagem mecânica

6.8 RELAÇÃO ENTRE OS ENSAIOS COM CORPO-DE-PROVA EM FORMA DE

BARRA E DE PPF 


\section{INTRODUÇÃO}

O uso de materiais cerâmicos com alto conteúdo cristalino na confecção de restaurações dentárias foi impulsionado pela introdução da tecnologia CAD-CAM (computer-aided design - computer-aided manufacturing) na Odontologia. Sistemas cerâmicos à base de alumina e zircônia podem ser utilizados como material de infraestrutura de restaurações submetidas a uma alta concentração de tensões, como coroas de dentes posteriores e próteses parciais fixas (PPFs). Esses sistemas estão disponíveis no mercado como blocos pré-fabricados para processamento com a tecnologia CAD-CAM. Restaurações totalmente cerâmicas são produzidas em duas camadas. A infra-estrutura é composta por uma cerâmica com propriedades mecânicas elevadas e é recoberta por outra cerâmica (porcelana) com melhores propriedades ópticas, produzindo uma restauração com aparência semelhante à da estrutura dentária (Raigrodski, 2004; Della Bona, 2009).

A avaliação clínica das restaurações protéticas fornece informações confiáveis para determinar o prognóstico desses sistemas cerâmicos. Entretanto, é necessário um período longo de tempo para a coleta de resultados e a investigação pode ser limitada pelas variáveis relacionadas aos voluntários, tais como: número pequeno de voluntários, desistências e condições orais individuais (Hickel et al., 2007; Rosentritt et al., 2009). Portanto, os ensaios in vitro são de grande importância para se obter resultados rápidos e padronizados (Rosentritt et al., 2009). Os ensaios laboratoriais procuram simular as falhas clínicas com os objetivos de investigar as variáveis que influenciam o sucesso das próteses fixas e de avaliar novos materiais ou configurações. Porém, muitas vezes, o comportamento dos materiais submetidos a testes laboratoriais não é o mesmo observado in vivo (Kelly, 1999).

Valores de resistência à fratura são freqüentemente considerados indicadores do comportamento mecânico dos materiais dentários (Della Bona; Van Noort, 1995). Porém, a resistência é uma propriedade condicional e não inerente do material (Kelly, 1999). A resistência dos materiais cerâmicos é limitada pela presença de defeitos pré-existentes e pelo valor relativamente baixo de tenacidade à fratura. É encontrada uma grande variabilidade nos resultados como conseqüência da distribuição no tamanho dos defeitos e da susceptibilidade do material a um comportamento denominado "crescimento subcrítico de trincas". A variabilidade dos 
resultados pode ser analisada através da distribuição de Weibull e a susceptibilidade do material ao crescimento subcrítico de trincas pode ser determinada com o ensaio de resistência à flexão utilizando diferentes taxas de carregamento (fadiga dinâmica). Esses dados somados aos valores de resistência à fratura possibilitam estimativas de tempo de vida para os materiais avaliados (Kelly, 1995; Ritter, 1995a; Thompson, 2004; Salazar Marocho et al., 2010).

Algumas limitações dos testes de resistência à fratura estão relacionadas com a geometria e a confecção dos corpos-de-prova, os quais possuem forma de barra ou disco monolítico que dificilmente simulam a configuração das restaurações dentárias. Além disso, o método de confecção desses corpos-de-prova também pode ser diferente (Kelly, 1999). A avaliação de estruturas em camadas (cerâmica de infra-estrutura combinada com porcelana) pode fornecer informações importantes sobre a distribuição de tensões, modo e origem de fratura, união da interface e tensões térmicas que não são obtidas quando os materiais são avaliados separadamente (Della Bona et al., 2003; Studart et al., 2007). Entretanto, é possível prever de maneira mais confiável o comportamento dos sistemas cerâmicos utilizando corpos-de-prova na forma de restaurações. Nesse caso, são utilizados os mesmos procedimentos de confecção e a população de defeitos é semelhante à encontrada nos casos clínicos. Além disso, é possível verificar a influência da geometria na distribuição de tensões e comportamento de fratura. Análise de elementos finitos (AEF) pode ser utilizada para a avaliação da distribuição de tensões nessas estruturas mais complexas (Kelly et al., 1995).

Utilizando corpos-de-prova em forma de restaurações também é possível avaliar com maior precisão o efeito do carregamento cíclico no comportamento mecânico dos sistemas cerâmicos. Para apresentar relevância clínica, o procedimento de envelhecimento das restaurações deve simular ao máximo as condições do ambiente oral. A força e a freqüência utilizadas na ciclagem mecânica in vitro devem ser similares às que ocorrem durante a mastigação e o ensaio deve ser realizado em meio úmido (Delong; Douglas, 1983).

Outra ferramenta importante para a compreensão do comportamento mecânico dos materiais é a análise fractográfica. A fractografia é a análise da superfície de fratura que contém características resultantes da interação da trinca em propagação com a microestrutura do material e os campos de tensão. Análise fractográfica quantitativa pode ser realizada para identificar o tamanho e origem do 
defeito crítico, estimar a tensão de fratura e a tenacidade à fratura, identificar a natureza das tensões e a presença de tensões residuais ou crescimento subcrítico, e reconhecer defeitos de processamento (Mecholsky, 1995a; Quinn, 2007; Della Bona, 2009). Se houver uma boa correlação entre o padrão de fratura observado in vitro e in vivo, os resultados obtidos no ensaio laboratorial podem ser validados através dessa análise (Thompson et al., 1994; Kelly et al., 1995).

Portanto, é necessária uma caracterização completa do comportamento mecânico dos materiais cerâmicos para estimar o prognóstico clínico dessas restaurações. Essa caracterização pode ser realizada utilizando ferramentas como o ensaio de resistência à flexão, a análise de Weibull, o ensaio de fadiga dinâmica e a análise da superfície de fratura. Em corpos-de-prova em forma de restaurações também pode-se avaliar a susceptibilidade dos materiais ao crescimento subcrítico de trincas através do envelhecimento mecânico, simulando as condições clínicas, e a distribuição de tensões pode ser observada com AEF. Além disso, é importante avaliar a relação entre os resultados obtidos com os diferentes tipos de corpo-deprova (estrutura monolítica ou em camadas, restaurações) e com diferentes metodologias de ensaio. O ideal é que exista uma boa concordância entre esses resultados e que eles simulem adequadamente as condições clínicas e o comportamento mecânico in vivo. 


\section{REVISÃO DA LITERATURA}

\subsection{PROPRIEDADES MECÂNICAS DOS MATERIAIS CERÂMICOS}

Materiais cerâmicos são friáveis, ou seja, possuem pouca ou nenhuma capacidade de deformação plástica. Portanto, eles são sensíveis à concentração de tensões ao redor de defeitos pré-existentes. O campo de tensões na ponta da trinca pode ser descrito pelo fator de intensidade de tensão $(K)$ que, no caso dos materiais friáveis, como as cerâmicas, é controlado pelo modo I de fratura ou modo de tração $\left(\mathrm{K}_{\mathrm{I}}\right)$. A trinca irá se propagar quando a intensidade de tensão na ponta da trinca alcançar uma condição crítica, $\mathrm{K}_{\mathrm{lc}}$, que é o fator de intensidade de tensão crítico ou tenacidade à fratura (Irwin, 1957; Callister Jr, 2002; Della Bona, 2009). A tenacidade à fratura caracteriza a resistência do material à propagação instável de defeitos préexistentes, sob uma determinada tensão (Thompson; Anusavice, 1994). Os defeitos são gerados durante o processamento (poros, inclusões) ou após a manipulação, acabamento, ou uso clínico (Quinn, 2007). Portanto, a resistência à fratura dos materiais cerâmicos é limitada pelos defeitos pré-existentes associados a um baixo valor de tenacidade à fratura (Ritter, 1995a; Della Bona, 2009).

A resistência à fratura pode ser considerada uma propriedade condicional do material porque é dependente de fatores como as condições de carregamento do ensaio, concentração de tensões, geometria e volume do corpo-de-prova (Kelly, 1995). Por causa da grande sensibilidade aos defeitos pré-existentes, os materiais cerâmicos são mais resistentes ao ensaio de flexão do que ao ensaio de tração. Em tração, um volume maior de material é submetido ao nível máximo de tensão. Por outro lado, em flexão, uma pequena camada da superfície (um pequeno volume relativo) é submetida à máxima tensão de tração. Portanto, geralmente são

utilizados ensaios de flexão para determinar as propriedades mecânicas das cerâmicas. No ensaio de flexão em três pontos um corpo-de-prova em forma de barra é apoiado em dois suportes inferiores e a carga é aplicada no centro. A desvantagem desse método é que uma pequena superfície ou volume do corpo-deprova é submetida à máxima tensão de tração. Portanto, maiores valores de resistência à fratura podem ser obtidos. Além disso, o ensaio de flexão em três 
pontos é sensível ao acabamento de superfície e a presença de ângulos (cantos) no corpo-de-prova (Ritter, 1995b; Zeng et al., 1996; Della Bona, 2009).

A variabilidade nos valores de resistência dos materiais cerâmicos está relacionada com a distribuição do tamanho e posicionamento dos defeitos e pode ser analisada utilizando a estatística de Weibull (Ritter, 1995a). Essa análise relaciona a probabilidade de falha de um volume ou área submetido a tensões de tração a dois parâmetros, o módulo de Weibull e a resistência característica, m e $\sigma_{0}$, respectivamente. A resistência característica ou parâmetro escalar $\left(\sigma_{0}\right)$ representa o valor no qual a probabilidade de ocorrer fratura do corpo-de-prova é de 63,21\%. 0 módulo de Weibull $(\mathrm{m})$ está relacionado com a dispersão dos resultados de resistência na distribuição assimétrica. A distribuição normal (gaussiana) favorece a seleção de materiais com a maior média de resistência. Entretanto, o valor médio subestima a influência dos corpos-de-prova que possuem baixos valores de fratura. O módulo de Weibull compensa os baixos valores de resistência que são típicos da distribuição assimétrica encontrada para os materiais cerâmicos. Um valor alto de $\mathrm{m}$ assegura um erro menor na estimativa de resistência e maior confiabilidade estrutural (Weibull, 1939; Tinschert et al., 2000; Della Bona et al., 2003; Thompson, 2004).

As cerâmicas são susceptíveis a um fenômeno denominado crescimento subcrítico de trincas (subcritical crack growth - SCG). Esse fenômeno é caracterizado por um processo de corrosão sob tensão, envolvendo o crescimento estável de trincas pré-existentes até um tamanho crítico que, para um determinado nível de tensão, origina a fratura catastrófica (Michalske; Freiman, 1983). O SCG resulta da combinação de tensões na ponta da trinca com a presença de moléculas de água ou fluidos corporais (Chevalier et al., 1999). Esse tipo de crescimento é extremamente sensível às cargas aplicadas na estrutura, porém também depende da concentração da solução de imersão, temperatura do ambiente, e outras variáveis externas (De Aza et al., 2002). O comportamento de SCG pode ser determinado pela avaliação direta da velocidade de propagação da trinca em função do fator de intensidade de tensão. Também podem ser feitas inferências sobre o comportamento de propagação da trinca utilizando métodos indiretos como testes de fadiga dinâmica, cíclica e estática (Thompson, 2004). O método da fadiga dinâmica utiliza os dados obtidos através do ensaio de resistência à flexão com diferentes taxas de tensão constante para determinar os parâmetros de SCG (Ritter, 1995b). 
Esses parâmetros podem ser calculados seguindo a norma ASTM C 1368-00 (2001). O coeficiente de crescimento subcrítico de trincas, $n$, é adimensional e representa a susceptibilidade de um material ao SCG em um determinado ambiente. Portanto, altos valores de $n$ correspondem a uma baixa susceptibilidade ao SCG (Morena et al., 1986).

A estimativa da confiabilidade de um material é sensível às incertezas na determinação experimental dos parâmetros de Weibull e SCG. A reprodutibilidade estatística desses parâmetros depende da variabilidade nos valores de resistência, número e intervalo das taxas de tensão utilizadas no ensaio de fadiga dinâmica, e número de corpos-de-prova. Além disso, as condições do teste devem ser semelhantes às condições de serviço, e a população de defeitos deve ser a mesma responsável pela falha clínica (Ritter, 1995b; Della Bona, 2009). Para obter um valor confiável de $\mathrm{m}$ recomenda-se um número mínimo de 30 corpos-de-prova (Ritter, 1995b; Cattell et al., 1997).

\subsection{RESTAURAÇÕES METALO-CERÂMICAS E RESTAURAÇÕES TOTALMENTE CERÂMICAS}

Sistemas cerâmicos com alto conteúdo cristalino foram introduzidos na Odontologia com o objetivo de substituir infra-estruturas metálicas em coroas e próteses parciais fixas (PPFs). As PPFs totalmente cerâmicas são confeccionadas, tradicionalmente, em duas camadas, sendo que a camada de infra-estrutura é constituída de uma cerâmica de maior tenacidade, enquanto que a camada de cobertura (porcelana) é construída com uma cerâmica de melhor qualidade óptica e com propriedades térmicas compatíveis com a infra-estrutura (Della Bona, 2009).

As infra-estruturas utilizadas em PPFs totalmente cerâmicas apresentam vantagens em relação às infra-estruturas metálicas, como a possibilidade de posicionar o término cervical do preparo na mesma altura da margem gengival livre, levando a um melhor resultado estético e evitando a invasão do espaço biológico (Raigrodski; Chiche, 2001). Além disso, estruturas cerâmicas apresentam maior translucidez do que as metálicas, produzindo restaurações com aparência mais natural (Heffernan et al., 2002a, b). As cerâmicas ainda apresentam baixa 
condutividade térmica, diminuindo o risco de irritação pulpar (Sorensen et al., 1999), e são altamente biocompatíveis, o que evita problemas de hipersensibilidade como aqueles observados quando são utilizadas algumas ligas metálicas (Lucas; Lemons, 1992; Raigrodski; Chiche, 2001; Uo et al., 2003).

As limitações das PPFs totalmente cerâmicas estão relacionadas com a natureza frágil dos materiais cerâmicos. A alta concentração de tensões na região do conector da PPF pode levar à fratura catastrófica da estrutura (Kelly et al., 1995; Magne et al., 2002; Fischer et al., 2003). Portanto, o conector da peça deve ter altura e espessura suficientes para resistir à fratura. As dimensões do conector variam conforme a cerâmica utilizada (Raigrodski; Chiche, 2001; Raigrodski, 2004). Esses sistemas são contra-indicados para situações em que os pilares estejam comprometidos periodontalmente. Também existem restrições em relação aos casos de pacientes com hábitos parafuncionais (Sorensen et al., 1998; Sorensen et al., 1999).

Sistemas cerâmicos à base de alumina e zircônia foram introduzidos no mercado com o objetivo de disponibilizar materiais com melhores propriedades mecânicas que pudessem ser utilizados para a construção de restaurações extensas como PPFs. Alguns exemplos desses sistemas são a cerâmica à base de zircônia tetragonal parcialmente estabilizada por ítrio $(\mathrm{YZ})$, a cerâmica à base de alumina infiltrada por vidro e reforçada com zircônia (IZ) e a cerâmica policristalina de alumina $(A L)$.

\subsubsection{Zircônia tetragonal parcialmente estabilizada com óxido de ítrio - YZ}

As cerâmicas policristalinas à base de zircônia podem ser classificadas em três tipos de acordo com a sua microestrutura: FSZ (fully stabilized zirconia), PSZ (partially stabilized zirconia) e TZP (tetragonal zirconia polycristals). Na FSZ, a zircônia se encontra em sua forma cúbica, sendo geralmente obtida adicionando-se grandes quantidades de estabilizadores (mais de $8 \mathrm{~mol} \%$ de óxido de ítrio). A PSZ é constituída de partículas nanométricas nas formas monoclínica ou tetragonal que são precipitadas na matriz de zircônia cúbica. Esses materiais são geralmente obtidos por meio de adição de óxido de cálcio ou magnésio. A TZP é constituída 
predominantemente pela fase tetragonal, embora possa conter pequenas quantidades de fase cúbica secundária, e geralmente é estabilizada com óxido de ítrio (3\%-6\% em peso) (Chevalier; Gremillard, 2009).

A cerâmica policristalina à base de zircônia tetragonal parcialmente estabilizada com óxido de ítrio (YZ - Yttria stabilized tetragonal zirconia polycristals) foi inicialmente introduzida na área médica para a construção de próteses ortopédicas devido a seu excelente desempenho mecânico e biocompatibilidade (Christel et al., 1989; Piconi; Maccauro, 1999). A confecção de próteses dentárias utilizando a cerâmica $Y Z$ foi impulsionada pela introdução da tecnologia CAD-CAM na Odontologia. Esse material é indicado para a construção de infra-estruturas de coroas e PPFs em todas as regiões da cavidade oral. Em comparação com outros sistemas cerâmicos, a $Y Z$ requer uma área de secção transversal do conector relativamente pequena, cerca de $9 \mathrm{~mm}^{2}$ para uma PPF com distância entre pilares de aproximadamente 12 mm (Raigrodski, 2003; Raigrodski, 2004). Luthy et al. (2005) concluíram que a cerâmica YZ também pode ser indicada para PPF de 4 elementos desde que seja utilizado um conector maior que $7,3 \mathrm{~mm}^{2}$ (distância entre pilares de 15,7 mm). Além disso, a $Y Z$ também pode ser utilizada na confecção de pinos intra-radiculares, bráquetes ortodônticos e implantes dentários (Meyenberg et al., 1995; Raigrodski, 2004).

As restaurações de $Y Z$ são confeccionadas utilizando sistemas CAD-CAM por meio da usinagem de: (1) blocos pré-fabricados parcialmente sinterizados ou (2) blocos densamente sinterizados por meio de prensagem isostática a quente (hot isostatic pressing - HIP) (Sjolin et al., 1999; Filser et al., 2001). A usinagem de blocos densamente sinterizados pode produzir restaurações com melhor adaptação, porém esse processo é demorado e envolve grande desgaste dos instrumentos. Já o uso de blocos parcialmente sinterizados aumenta a eficiência do processo de usinagem. Nesse caso, o sistema CAD-CAM produz peças maiores para compensar a contração de sinterização, garantindo a precisão das restaurações (Tinschert et al., 2004).

O comportamento mecânico dos materiais à base de zircônia está associado com um aumento de tenacidade por transformação de fase (transformation toughening). A zircônia pode assumir três formas cristalográficas dependendo da temperatura. A estrutura é monoclínica desde a temperatura ambiente até $1170^{\circ} \mathrm{C}$, tetragonal entre $1170^{\circ} \mathrm{C}$ e $2370^{\circ} \mathrm{C}$ e cúbica acima de $2370^{\circ} \mathrm{C}$ até o ponto de fusão. A 
transformação da fase tetragonal para monoclínica durante o resfriamento é acompanhada de uma expansão volumétrica $(\sim, 5 \%)$ e de uma deformação em cisalhamento ( 0,16\%) (Hannink et al., 2000; Chevalier; Gremillard, 2009). A associação da zircônia pura com óxidos estabilizantes como óxidos de cálcio ( $\mathrm{CaO})$, de magnésio $(\mathrm{MgO})$, de ítrio $\left(\mathrm{Y}_{2} \mathrm{O}_{3}\right)$ ou de cério $\left(\mathrm{CeO}_{2}\right)$ permite a estabilização da fase tetragonal à temperatura ambiente. Quando este material estabilizado é submetido a tensões (ex: mastigação, desgaste e polimento), ocorre a transformação da fase cristalina tetragonal para monoclínica, o que resulta na geração de tensões compressivas e nucleação de micro-trincas (microcrack toughening) que se opõem às tensões de tração que levariam à propagação dos defeitos. O resultado final é uma melhora das propriedades mecânicas do material (Heuer et al., 1986). Essa transformação de fase ocorre por meio de nucleação e crescimento dos cristais, iniciando-se geralmente na superfície de cerâmicas policristalinas. É dependente da composição, tamanho e forma das partículas de zircônia, do tipo e quantidade dos óxidos estabilizantes, da interação da zircônia com as outras fases e do processamento (Witek; Butler, 1986; Piconi; Maccauro, 1999; Della Bona et al., 2007).

Para aplicação odontológica, a microestrutura da cerâmica YZ é composta por cristais eqüiaxiais com diâmetro entre 0,2 a 0,5 $\mu \mathrm{m}$, dependendo da temperatura de sinterização (Denry; Kelly, 2008). Esse sistema cerâmico apresenta valores médios de resistência à flexão variando entre 700 e 1500 MPa e tenacidade à fratura entre 4,4 e 9,4 MPa.m ${ }^{1 / 2}$ (Liu; Chen, 1991; Kosmac et al., 1999; Tinschert et al., 2000; Luthardt et al., 2002; Guazzato et al., 2004a; Tinschert et al., 2007; Yilmaz et al., 2007; Oilo et al., 2008; Taskonak et al., 2008a). Foram reportados, para a YZ, valores de dureza ao redor de 12 GPa e módulo de elasticidade entre 220 e 240 GPa (Guazzato et al., 2004a). Tinschert et al. (2000) relataram um valor alto de módulo de Weibull para a YZ (18,4). Entretanto, outros estudos encontraram valores mais baixos de módulo de Weibull, variando entre 10 e 16 (Liu; Chen, 1991; Kosmac et al., 1999; Luthardt et al., 2002; Teixeira et al., 2007; Yilmaz et al., 2007).

Apesar da $Y Z$ apresentar um mecanismo de tenacificação que eleva suas propriedades mecânicas, este mesmo mecanismo pode resultar em um comportamento indesejável: a degradação das propriedades mecânicas em baixa temperatura (low temperature degradation- LTD) (Piconi; Maccauro, 1999; Denry; Kelly, 2008). Kobayashi et al. (1981) observaram que os cristais da YZ podem 
apresentar uma transformação lenta da fase tetragonal para monoclínica nos cristais de zircônia da superfície, em ambiente úmido e temperaturas relativamente baixas $\left(150-400^{\circ} \mathrm{C}\right)$. A transformação ocorre através de um processo de nucleação e crescimento dos cristais e é acompanhada pelo aumento de volume, provocando tensões e micro-trincas nos cristais vizinhos. Esse processo de degradação da superfície é exacerbado pela presença de água. O crescimento da zona de transformação resulta em aumento do número de micro-trincas, extrusão dos cristais e aumento da rugosidade superficial, o que leva à degradação da resistência. Qualquer fator que afete a estabilidade da zircônia tetragonal pode afetar esse processo de degradação(Denry; Kelly, 2008; Chevalier; Gremillard, 2009). Entre esses fatores estão o tamanho do cristal (Heuer et al., 1982; Cottom; Mayo, 1996), a quantidade de estabilizador (Hannink et al., 2000) e a presença de tensões residuais (Kosmac et al., 1999; Guazzato et al., 2005; Deville et al., 2006; Kim et al., 2010).

Cristais de $Y Z$ acima de um tamanho crítico são menos estáveis e mais susceptíveis à degradação, enquanto que cristais de tamanho menor $(<1 \mu \mathrm{m})$ apresentam menor degradação (Heuer et al., 1982). Entretanto, tamanhos muito reduzidos $(<0,2 \mu \mathrm{m})$ restringem o aumento da tenacidade por transformação levando a uma redução das propriedades mecânicas (Cottom; Mayo, 1996). O processo de sinterização interfere diretamente no tamanho dos cristais, sendo que altas temperaturas e longo tempo de sinterização resultam em maior tamanho de cristal (Denry; Kelly, 2008).

A diminuição na concentração de estabilizador pode resultar em menor estabilidade dos cristais tetragonais, gerando zonas de nucleação para transformação espontânea da fase tetragonal para monoclínica (Hannink et al., 2000; Denry; Kelly, 2008). Papanagiotou et al. (2006) observaram que o tratamento térmico da $\mathrm{YZ}$ em baixas temperaturas e umidade não afetou os valores de resistência à flexão, porém houve uma diminuição significativa da quantidade de estabilizador, o que pode aumentar a susceptibilidade do material à degradação em baixa temperatura.

Tensões residuais podem ser introduzidas durante o processamento das restaurações. Estudos investigaram o efeito da usinagem, alterações térmicas, e dos procedimentos de acabamento e polimento no comportamento mecânico da cerâmica $\mathrm{YZ}$ e encontraram resultados controversos. Os procedimentos de usinagem e acabamento podem induzir uma camada de tensões de compressão na 
superfície da cerâmica melhorando as propriedades mecânicas do material. No entanto, também podem produzir defeitos profundos que ultrapassam essa camada de compressão, aumentado a susceptibilidade à degradação em baixas temperaturas (Kosmac et al., 1999; Guazzato et al., 2005; Kim et al., 2010). O tratamento térmico da $\mathrm{YZ}$ com temperaturas entre 900 e $1000{ }^{\circ} \mathrm{C}$ pode induzir a transformação reversa da fase monoclínica para tetragonal. Por isso, sugere-se que a sinterização da camada de porcelana sobre a infra-estrutura da YZ possa provocar essa reversão de fase, resultando na liberação das tensões de compressão presentes na superfície cerâmica e, conseqüentemente, na diminuição da resistência à fratura. Oilo et al. (2008) relataram redução nos valores de resistência à flexão e microdureza da cerâmica $Y Z$ após tratamento térmico com temperaturas utilizadas no processo de sinterização e glaze da cerâmica de cobertura.

\subsubsection{In-Ceram Zircônia - IZ}

Em 1965, McLean e Hughes introduziram na Odontologia uma cerâmica reforçada com alumina. Observaram que a resistência da cerâmica reforçada com alumina era dependente da fração volumétrica do material cristalino incorporado à matriz vítrea, mas era limitada pela dificuldade de eliminar a porosidade durante 0 processo de sinterização (Mclean, 1967). A partir disso, houve um avanço na Odontologia em direção ao desenvolvimento de sistemas cerâmicos a base de alumina.

O sistema In-Ceram Alumina (ICA) foi introduzido em 1989, sendo composto por uma cerâmica à base de alumina infiltrada por vidro. Esse sistema é constituído por uma infra-estrutura de alumina parcialmente sinterizada, com alto grau de porosidade, a qual ganha resistência por meio da infiltração de um vidro a base de óxido de lantânio (Giordano et al., 1995; Della Bona et al., 2008). Além disso, tensões residuais de compressão, que irão melhorar a resistência, também são introduzidas devido às diferenças no coeficiente de expansão térmica da alumina e do vidro (Giordano et al., 1995). O ICA apresenta uma resistência à flexão entre 300600 MPa (Zeng et al., 1996; Tinschert et al., 2000; Chong et al., 2002; Guazzato et al., 2002; Rizkalla; Jones, 2004; Guazzato et al., 2004b; Della Bona et al., 2008) e 
tenacidade a fratura entre 3,2-4,4 MPa•m ${ }^{1 / 2}$ (Guazzato et al., 2002; Rizkalla; Jones, 2004; Guazzato et al., 2004b; Tinschert et al., 2007). Esse sistema é indicado como infra-estrutura em restaurações unitárias anteriores e posteriores e PPFs em dentes anteriores (Probster, 1996).

As propriedades mecânicas do ICA podem ser melhoradas adicionando-se óxido de zircônio ao material, resultando em uma cerâmica à base de alumina infiltrada por vidro e reforçada com zircônia (Chong et al., 2002; Guazzato et al., 2004a; Della Bona et al., 2007). A primeira marca comercial desse tipo de sistema foi o sistema In-Ceram Zircônia (IZ), no qual se adicionou, aproximadamente, 35\% de zircônia parcialmente estabilizada por óxido de cério (Della Bona et al., 2007). Este material é indicado para a confecção de coroas unitárias e PPFs posteriores (Tinschert et al., 2001). Para esse sistema, o fabricante recomenda que as dimensões mínimas necessárias de um conector para a construção de PPFs posteriores seja de $16 \mathrm{~mm}^{2}$ de secção transversal, considerando-se uma distância entre pilares de $10 \mathrm{~mm}$.

As restaurações de IZ podem ser confeccionadas pela técnica da barbotina (slip-cast) ou pelo sistema CAD-CAM utilizando blocos pré-fabricados (Apholt et al., 2001; Raigrodski, 2004; Guazzato et al., 2004a). Esses dois métodos diferem basicamente na fase inicial de confecção da infra-estrutura porosa de alumina e zircônia. A técnica da barbotina envolve a aplicação de uma suspensão de alumina e zircônia utilizando um molde de gesso especial. A água é absorvida por capilaridade pelo gesso fazendo com que as partículas fiquem condensadas em uma infraestrutura densa. Essa infra-estrutura é levada ao forno para sinterização parcial. Os blocos para CAD-CAM são fabricados por meio da prensagem a seco (dry-press) de uma mistura de partículas de óxido de alumínio e óxido de zircônio e subseqüente sinterização até que uma microestrutura porosa seja obtida. A fase de infiltração do vidro é igual em ambas as técnicas. Essa etapa envolve a aplicação de um vidro de silicato de alumínio e lantânio sobre a infra-estrutura porosa e infiltração a $1100^{\circ} \mathrm{C}$. Essa infiltração de vidro espontânea ocorre por capilaridade. A resistência desse material é dependente da união entre as partículas de alumina e zircônia e da completa infiltração do vidro na infra-estrutura porosa, eliminando porosidades e áreas susceptíveis à propagação de trincas (Mclaren; White, 1999; Apholt et al., 2001; Della Bona et al., 2008). A estrutura dos blocos pré-fabricados apresenta menor volume de poros e é mais homogênea do que a estrutura produzida com a 
técnica da barbotina, o que poderia resultar em propriedades mecânicas superiores (Mclaren; White, 1999; Apholt et al., 2001).

A cerâmica IZ é composta por aproximadamente $36 \%$ de alumina, 32\% de zircônia e $22 \%$ de vidro. Três tamanhos diferentes de cristais de alumina podem ser observados na IZ: cristais alongados com aproximadamente $10 \mu \mathrm{m}$ largura, cristais facetados com diâmetro entre 1 e $4 \mu \mathrm{m}$, e cristais esféricos com diâmetro menor do que $1 \mu \mathrm{m}$. Os cristais de zircônia apresentam-se em duas formas: cristais facetados com tamanho médio de $2 \mu \mathrm{m}$ e pequenos cristais esféricos com tamanho inferior a 1 $\mu \mathrm{m}$ (Guazzato et al., 2004a).

Os valores médios de módulo de elasticidade e dureza do sistema IZ são aproximadamente $240 \mathrm{GPa}$ e $11 \mathrm{GPa}$, respectivamente (Guazzato et al., 2002; Guazzato et al., 2004a). Foram encontrados valores médios de resistência à flexão para a IZ entre 440 e $620 \mathrm{MPa}$ e tenacidade entre 3,0 e 6,2 MPa.m ${ }^{1 / 2}$ (Seghi; Sorensen, 1995; Apholt et al., 2001; Chong et al., 2002; Guazzato et al., 2002; Tinschert et al., 2007; Yilmaz et al., 2007; Taskonak et al., 2008b; Bottino et al., 2009).

O mecanismo de tenacificação da IZ é uma combinação de mecanismos relacionados aos cristais de alumina e zircônia. Os cristais de alumina são responsáveis por deflexão de trincas. Esse mecanismo ocorre quando uma trinca desvia de sua trajetória devido à: a) presença de tensões residuais; b) segunda fase resistente à fratura (ex: fibras, partículas; e c) contornos de grãos. A reorientação do plano de propagação da trinca fora do plano principal faz com que a tensão na ponta dessa trinca perca intensidade e isso resulta em um aumento de tenacidade. Em outro mecanismo de tenacificação relacionado com os cristais de alumina, a trinca sofre um desvio de sua trajetória e a energia é dissipada como resultado do contato físico entre as duas superfícies da trinca em propagação, que pode resultar na extrusão de grãos (contact shielding) (Guazzato et al., 2004b). Os cristais de zircônia são responsáveis pelos mecanismos de transformação de fase e nucleação de micro-trincas, relatados anteriormente (Guazzato et al., 2004a) 


\subsubsection{Alumina policristalina - $A L$}

Cerâmicas com alto conteúdo de alumina têm sido utilizadas na confecção de implantes desde 1964, quando Sanhaus utilizou esse material para substituir dentes perdidos (Hulbert et al., 1987). Essa cerâmica apresenta uma combinação de boas propriedades mecânicas, biocompatibilidade e excelente resistência à corrosão (De Aza et al., 2002). Da mesma forma que as cerâmicas à base de zircônia, esse sistema é utilizado na confecção de próteses ortopédicas (ex: fêmur). A contração de sinterização da alumina é entre 15 e 20\%, o que dificultou a produção de restaurações puras de alumina com adequada adaptação utilizando a tecnologia do pó. Com a introdução do sistema CAD-CAM na Odontologia, além de restaurações à base de zircônia, também foi possível fabricar restaurações utilizando sistemas cerâmicos à base de alumina policristalina (Andersson; Oden, 1993).

Procera AllCeram foi o primeiro sistema cerâmico odontológico com alto conteúdo de alumina introduzido no mercado. Nesse sistema as restaurações são produzidas através da compactação de um pó de alumina em um troquel, utilizando a técnica de prensagem a seco. Posteriormente, o conjunto é levado a um forno e sinterizado a $1550^{\circ} \mathrm{C}$ durante 1 hora. Antes do processo de compactação, o modelo do preparo (troquel) é usinado pelo sistema CAD-CAM Procera e suas dimensões são aumentadas com o objetivo de compensar a contração de sinterização. $\mathrm{Na}$ análise microestrutural dessa cerâmica foi observado um tamanho médio de cristal de $4 \mu \mathrm{m}$ e não foram encontradas porosidades ou defeitos no limite entre a cerâmica de infra-estrutura e a porcelana. Esse material apresenta um valor médio de resistência à flexão em três pontos de $600 \mathrm{MPa}$ e densidade igual a $3,94 \mathrm{~g} / \mathrm{cm}^{3}$ (Andersson; Oden, 1993). Zeng et al. (1996) encontraram para esse sistema valores de módulo de Weibull entre 6 e 11, dependendo do método de ensaio utilizado.

Outro exemplo de alumina policristalina $(A L)$ é o material Vita In-Ceram $A L$. Essa cerâmica é composta por $100 \%$ de óxido de alumínio $\left(\mathrm{Al}_{2} \mathrm{O}_{3}\right)$, possui um tamanho médio de cristal de $2 \mu \mathrm{m}$ e densidade igual a $3,94 \mathrm{~g} / \mathrm{cm}^{3}$. Sua indicação inclui coroas unitárias (anteriores e posteriores) e PPFs anteriores de 3 elementos. Segundo informações do fabricante (Vita Zahnfabrik, Bad Sackingen, Alemanha), esta cerâmica apresenta valores médios de resistência à flexão ao redor de 500 $\mathrm{MPa}$, tenacidade à fratura igual a $3,5 \mathrm{MPa} \cdot \mathrm{m}^{1 / 2}$ e módulo de elasticidade de 380 
GPa. A cerâmica AL é apresentada comercialmente na forma de blocos présinterizados para uso em sistema CAD CAM. Da mesma forma que a cerâmica $Y Z$, a contração de sinterização é compensada durante a usinagem das restaurações.

\subsection{ESTRUTURAS EM CAMADAS}

As próteses totalmente cerâmicas podem ser confeccionadas de duas formas: (1) como uma restauração cerâmica monolítica ou (2) como uma estrutura em camadas, composta por uma cerâmica de infra-estrutura e uma cerâmica de recobrimento (porcelana). Os sistemas cerâmicos com alto conteúdo cristalino apresentam boas propriedades mecânicas, mas têm alta opacidade. Por isso, é necessário o recobrimento da infra-estrutura com uma porcelana, que apresenta melhores propriedades ópticas, para obter uma restauração com características de cor e translucidez semelhantes à estrutura dental (Della Bona; Kelly, 2008; Della Bona, 2009). Geralmente, os materiais de infra-estrutura e recobrimento são estudados separadamente, fornecendo informações importantes sobre o comportamento mecânico dos componentes individuais da restauração. No entanto, também é preciso ter conhecimento do comportamento desses materiais quando unidos em uma estrutura em camadas. Investigações da estrutura em camadas fornecem informações sobre a distribuição de tensões, modo e origem de fratura, união da interface e tensões térmicas, que não são obtidas quando os materiais são avaliados separadamente (Studart et al., 2007).

Zeng et al. (1998) observaram um comportamento diferente para as porcelanas avaliadas com uma configuração monolítica ou em camadas. Não foi encontrada diferença significativa nos valores de resistência à flexão entre duas porcelanas monolíticas. Entretanto, foi observada diferença estatística quando esses materiais foram avaliados na configuração de duas camadas, combinados com a infra-estrutura de alto conteúdo de alumina (Procera AllCeram). Esses resultados comprovam a necessidade da avaliação das propriedades dos materiais numa configuração de multicamadas.

A interface desempenha um papel importante no desempenho mecânico de estruturas cerâmicas em camadas. O comportamento de propagação de trincas é 
influenciado pela energia de fratura da interface e pela diferença entre o módulo de elasticidade dos materiais (Cazzato; Faber, 1997; Thompson, 2000). A diferença de coeficiente de expansão térmica entre os materiais pode produzir tensões residuais na interface que também interferem no modo de fratura dessas estruturas (Swain, 2009). Outros fatores que podem influenciar no comportamento das estruturas em camada são as propriedades mecânicas do material submetido à região de máxima concentração de tensões de tração durante o carregamento e a proporção entre os materiais (Kelly, 1995).

Em uma estrutura em camadas, com a porcelana em tração, a trinca se propaga diretamente através da interface quando a tenacidade da interface é maior do que a tenacidade do material de infra-estrutura, comportando-se como uma estrutura homogênea. Por outro lado, quando a tensão de fratura é maior do que a tenacidade da interface, a trinca sofre deflexão e se propaga lateralmente entre o material de infra-estrutura e a porcelana resultando em delaminação (Thompson, 2000). O modo de fratura depende da razão entre a tenacidade do material de infraestrutura e da interface e da razão entre as propriedades elásticas dos dois materiais que compõem a estrutura (parâmetro Dundards) (Cazzato; Faber, 1997). A diferença entre o módulo de elasticidade de duas camadas cerâmicas pode resultar numa transferência significativa de tensões de tração através da interface no material com maior módulo de elasticidade. Se esse material também apresenta maior resistência e módulo de Weibull, o risco de fratura da estrutura de duas camadas pode ser reduzido. Porém, se a camada cerâmica com menor módulo de elasticidade possui melhores propriedades mecânicas, o risco de fratura pode aumentar por causa da transferência de tensões de tração para a camada com maior distribuição de defeitos durante o carregamento (Anusavice; Tsai, 1997; Della Bona et al., 2003).

A avaliação dos corpos-de-prova com a camada de porcelana em compressão tem como objetivo simular o modo de fratura de coroas totalmente cerâmicas (White et al., 1994; Zeng et al., 1998). Os ensaios com a camada de porcelana na área de tração simulam a condição de fratura de PPFs, onde a máxima tensão de tração está no conector (Kelly et al., 1995; Guazzato et al., 2004c). Análise de elementos finitos (AEF) demonstrou que quando a porcelana está na região de tração durante o ensaio, existem duas áreas de concentração de tensões de tração, a interface e a superfície da porcelana. Já no caso da infra-estrutura em 
tração, as tensões são distribuídas uniformemente através do corpo-de-prova e a máxima tensão de tração está somente na superfície do material de infra-estrutura. Nos corpos-de-prova monolíticos, as tensões são uniformes através da estrutura e não dependem do módulo de elasticidade do material (Guazzato et al., 2005; Hsueh et al., 2008).

As investigações com estruturas em camadas indicam que o material na área de tração durante o ensaio, o material na área de compressão e sua interação apresentam um efeito significativo nos valores de resistência e modo de fratura (Guazzato et al., 2004c; White et al., 2005). White et al. (1994) observaram que mesmo variando a proporção entre as camadas e a razão entre o módulo de elasticidade dos materiais, o material na área de tração é um fator determinante na resistência à fratura de estruturas em camadas. Exceto nos casos em que um material com um módulo de elasticidade muito baixo está na área de compressão. Outros estudos também sugerem que o material em tração durante o ensaio determina a resistência à flexão e a confiabilidade dos corpos-de-prova em camadas (Della Bona et al., 2003; Guazzato et al., 2004c).

Quando o material de infra-estrutura é testado em tração, geralmente observam-se valores de resistência à fratura semelhantes aos obtidos pelos corposde-prova monolíticos da cerâmica de infra-estrutura (Zeng et al., 1998; Della Bona et al., 2003). Dependendo do sistema cerâmico, a estrutura de duas camadas pode obter valor inferior à estrutura monolítica de infra-estrutura, porém a resistência desses corpos-de-prova ainda é superior à estrutura monolítica de porcelana (Zeng et al., 1998). Por outro lado, quando a porcelana está em tração, o material de infraestrutura tem pouca influência nos valores de resistência à flexão das estruturas de duas camadas (Thompson, 2004). Studart et al. (2007) observaram que o crescimento subcrítico de trincas em condições semelhantes ao ambiente oral leva à fratura da cerâmica de recobrimento antes da ruptura do material de infra-estrutura. Além disso, encontraram valores de resistência característica e módulo de Weibull para as estruturas de duas camadas semelhantes aos valores obtidos para porcelanas.

A proporção entre material de infra-estrutura e porcelana também pode afetar as propriedades mecânicas e modo de fratura de estruturas em camadas. Thompson (2000) examinou a influência do método de ensaio e da proporção entre as camadas no modo de fratura de estruturas cerâmicas. Foram avaliados corpos- 
de-prova de duas camadas (ICA/porcelana) com a porcelana em tração. A proporção entre as camadas teve influência no modo de fratura. Houve maior ocorrência de falhas na interface (43\%) nos corpos-de-prova com uma proporção de infra-estrutura/porcelana de 2:1. Entretanto, para os corpos-de-prova com proporção $1: 2$, que simulavam a configuração de coroas protéticas, não foi observada falha na interface. Em relação às metodologias de ensaio, o grupo submetido à flexão biaxial apresentou maior quantidade de falhas na interface (22\%) do que os grupo submetidos a flexão em três e quatro pontos.

Em outro estudo, Thompson (2004) avaliou a influência da proporção entre as camadas no crescimento subcrítico de trincas e módulo de Weibull. Foram realizados ensaios de resistência à flexão biaxial com diferentes taxas de carregamento e com a camada de porcelana em tração. Os parâmetros de Weibull variaram com a proporção entre infra-estrutura e porcelana, para uma mesma taxa de carregamento. Além disso, demonstrou que uma maior espessura de infraestrutura reduziu o efeito do crescimento subcrítico de trincas.

White et al. (2005) observaram que os corpos-de-prova com o material de infra-estrutura em tração apresentaram valores de resistência à fratura dez vezes maior do que os corpos-de-prova com a porcelana em tração. Houve uma tendência de aumento na resistência a flexão com o aumento na espessura do material de infra-estrutura. Com base nesses resultados, os autores recomendam que a superfície inferior dos conectores de PPFs e outras áreas de alta concentração de tensões de tração não recebam recobrimento com porcelana. Além disso, é indicado que seja utilizada uma espessura grande de cerâmica de infra-estrutura nas restaurações.

Segundo Fleming et al. (2005), quando o material de infra-estrutura foi testado em tração, a resistência à fratura aumentou com o aumento da proporção entre infra-estrutura e porcelana. A resistência à fratura e o modo e origem da fratura em estruturas de duas camadas foi dependente da proporção entre os materiais e do módulo de elasticidade do material em tração. Por outro lado, em outro estudo de Fleming et al. (2006) a proporção entre os materiais não teve influência nos resultados de resistência à flexão quando uma espessura de infra-estrutura de $1 \mathrm{~mm}$ foi utilizada. Esse comportamento foi observado tanto para os grupos testados com a porcelana em tração como em compressão. Entretanto, o módulo de Weibull e 
modo de fratura foram influenciados pela proporção entre a cerâmica de infraestrutura e a porcelana e pelo material em tração durante o teste.

Em um estudo de Hsueh et al. (2008) utilizando análise de elementos finitos foi observada uma alteração da localização da máxima tensão de tração dependendo da proporção entre a espessura da infra-estrutura e da porcelana. Esses resultados foram confirmados pelo o teste in vitro, já que houve um aumento na probabilidade de falha na interface das estruturas a partir da configuração 1:2 para 1:1 e 2:1. Sugere-se que esse comportamento está relacionado com a mudança da máxima de tração da superfície da porcelana para a interface porcelana/infra-estrutura.

O comportamento mecânico de estruturas em camadas também é influenciado pela presença de tensões residuais induzidas pela diferença de coeficiente de expansão térmica (CTE) entre os materiais e pelo gradiente térmico produzido durante o resfriamento da estrutura. O processo de recobrimento das restaurações protéticas envolve um procedimento de sinterização em altas temperaturas $\left(750-900^{\circ} \mathrm{C}\right)$ e subseqüente resfriamento da peça. Foi observado que a compatibilidade entre o CET da porcelana e do material de infra-estrutura é crítica para evitar a formação de trincas após a queima. Quando a porcelana tem um CTE muito maior $(<10 \%)$ do que o da infra-estrutura, trincas podem ser geradas na superfície da porcelana como conseqüência das tensões de tração induzidas durante o resfriamento. Se ao contrário, o CTE do material de infra-estrutura é maior, pode ocorrer delaminação da porcelana. Geralmente, tanto nas restaurações metalo-cerâmicas como nas totalmente cerâmicas, o CTE da porcelana é um pouco menor do que o CTE do material de infra-estrutura, de forma que tensões de compressão são desenvolvidas na superfície da porcelana e tensões compensatórias de tração são geradas na superfície da infra-estrutura (Anusavice et al., 1989; Swain, 2009). Entretanto, nas restaurações totalmente cerâmicas a infraestrutura é rígida e não permite deformação plástica induzida pelas tensões de incompatibilidade térmica. Dessa maneira, o risco de tensões destrutivas na camada de recobrimento é maior do que nas restaurações metalo-cerâmicas (De Kler et al., 2007; Della Bona, 2009; Fischer et al., 2009).

Segundo estudos de Hsueh et al. (2008) e Swain (2009), em infra-estruturas de zircônia e alumina, quando o CTE da porcelana é menor do que da infraestrutura, tensões de compressão são desenvolvidas na interface, porém na 
superfície da porcelana existe uma leve tensão de tração. Esse comportamento pode ser negativo já que facilita a nucleação de trincas na superfície. Análise de elementos finitos demonstrou que as tensões térmicas são lineares ao longo da espessura de cada camada, mas são descontinuas na interface por causa da diferença de CTE e módulo de elasticidade entre os materiais. Swain (2009) observou que a magnitude das tensões residuais na porcelana são praticamente independentes do módulo de elasticidade do material de infra-estrutura, mas estão diretamente relacionadas com a incompatibilidade de CTE. Por outro lado, as tensões residuais geradas no material de infra-estrutura são proporcionais aos valores de módulo de elasticidade desses materiais.

Outra fonte de tensões residuais nas restaurações são os gradientes térmicos gerados nessas estruturas durante o resfriamento. Pode-se distinguir dois grupos de materiais que se comportam de maneira diferente quando resfriados rapidamente a partir da temperatura de sinterização ou glaze: (1) aqueles com porcelana unida à infra-estrutura de cerâmica policristalina, como alumina e zircônia, e (2) aqueles com a porcelana unida à uma cerâmica vítrea. Nas cerâmicas policristalinas, a infraestrutura se comporta de maneira elástica durante a variação de temperatura. Já no segundo caso, a fase vítrea presente no material de infra-estrutura e na porcelana é inicialmente exposta a uma temperatura superior a temperatura de transição vítrea $\left(T_{g}\right)$, resultando em uma dispersão das tensões geradas pelo gradiente térmico. Tensões irão se desenvolver apenas quando os materiais forem resfriados abaixo da $\mathrm{T}_{\mathrm{g}}$, sendo que essas tensões são de compressão na superfície e de tração na estrutura interna. Como conseqüência da presença dessas tensões residuais a resistência aparente do material é aumentada. Entretanto, as tensões de compressão estão confinadas em uma espessura muito pequena da superfície ( $16 \%$ da espessura total) e a maior parte do material é submetida a tensões de tração. Então, à medida que a trinca ultrapassa essa camada de compressão, pode se propagar espontaneamente na camada submetida à tração (Swain, 2009).

Nas estruturas em camadas, o gradiente de temperatura não é simétrico e a temperatura na interface é determinada pelo material com maior difusividade térmica. Assim, um material com baixa difusividade térmica resulta em uma maior diferença de temperatura entre as camadas e altas tensões residuais são produzidas na estrutura. Swain (2009) concluiu que estruturas compostas por uma camada espessa de porcelana e um material de infra-estrutura com baixa difusividade 
térmica, como a YZ e cerâmicas vítreas, são mais susceptíveis ao desenvolvimento de tensões de tração. A presença dessas tensões residuais pode resultar no desenvolvimento de trincas e lascamento da porcelana. As estruturas com infraestrutura de alumina apresentam menor magnitude de tensões residuais por causa da maior difusividade térmica da alumina e menor valor de CTE.

\subsection{PONTES PARCIAIS FIXAS - PPFS}

Os ensaios de resistência à flexão (biaxial, três ou quatro pontos) são freqüentemente utilizados para caracterizar as propriedades mecânicas dos materiais cerâmicos. Porém, os corpos-de-prova padronizados para esses testes não conseguem simular a situação clínica porque não levam em conta a influência da geometria da prótese na distribuição das tensões. Além disso, os procedimentos de desgaste e polimento realizados para a padronização desses corpos-de-prova nem sempre reproduzem os procedimentos utilizados na confecção das restaurações dentárias. Esses passos adicionais podem introduzir defeitos e produzir padrões de fratura que não correspondem à situação clínica (Oh; Anusavice, 2002; Pallis et al., 2004). Por isso, através da avaliação dos sistemas cerâmicos na forma de restaurações é possível prever de maneira mais exata o comportamento in vivo desses materiais.

A forma da PPF não é uniforme. Essa restauração apresenta uma combinação complexa de múltiplas convexidades e concavidades dependendo da geometria do dente substituído e de seu alinhamento na arcada dentária. A distribuição de tensões é afetada pela mudança de forma dos componentes protéticos. A influência da geometria na distribuição de tensões pode ser mais crítica em PPFs posteriores, onde a altura do conector é normalmente limitada pela coroa clínica curta dos molares e porque cargas mais altas são produzidas nessa região. Além disso, os técnicos dentários costumam criar ameias agudas na região de conector com o objetivo de melhorar a estética. Esses fatores podem produzir maior concentração de tensões resultando em falha das PPFs na região de conectores (Oh; Anusavice, 2002; Larsson et al., 2007). 
A literatura sugere que a resistência à fratura das PPFs está diretamente relacionada com o tamanho do conector (Fischer et al., 2003; Larsson et al., 2007; Wolfart et al., 2007). Quanto menor a área de secção transversal do conector maior a concentração de tensões, aumentando a probabilidade de fratura (Fischer et al., 2003). Entretanto, nem sempre é possível obter um conector com dimensões adequadas. Além do material de infra-estrutura, deve existir espaço na restauração para a porcelana, aumentando o diâmetro do conector para um total de 5 a $6 \mathrm{~mm}$. Essas dimensões são difíceis de serem obtidas clinicamente. Um conector muito grande pode resultar em invasão do espaço interproximal, o que prejudica a higiene oral do paciente e pode ocasionar problemas periodontais. Quando não é possível obter uma espessura suficiente de conector indica-se a utilização de outros tipos de sistemas, como o metalo-cerâmico, para a confecção das restaurações (Tinschert et al., 2001; Oh; Anusavice, 2002; Larsson et al., 2007).

Além do tamanho, a forma do conector também influencia a distribuição de tensões na PPF. Oh e Anusavice (2002) observaram que o raio de curvatura da ameia gengival do conector teve influência na resistência à fratura das PPFs. A carga de fratura aumentou $140 \%$ à medida que o raio aumentou de 0,25 para 0,90 $\mathrm{mm}$. Os resultados sugeriram que a ameia oclusal pode ser confeccionada com forma mais aguda, para favorecer a estética, desde que a ameia gengival apresente um raio maior de curvatura. Outro estudo reportou valores de carga de fratura de PPFs com infra-estruturas de $\mathrm{YZ}$ e de dissilicato de lítio e com forma de conector arredondada, $77 \%$ e $196 \%$ maiores do que os valores obtidos para as PPFs com forma aguda, respectivamente. Também concluíram que a resistência à fratura dos materiais cerâmicos de infra-estrutura é afetada pela forma do conector (Plengsombut et al., 2009).

A distribuição de tensões nas PPFs pode ser avaliada através da análise de elementos finitos. Estudos observaram que a região cervical dos conectores apresenta maior concentração de tensões de tração e que a magnitude das tensões varia conforme o material analisado (Kelly et al., 1995; Motta et al., 2008; Plengsombut et al., 2009). Esse padrão de tensões é observado quando o carregamento é realizado no centro do pôntico ou distribuído entre todos os elementos da prótese. Quando apenas os retentores são solicitados, a máxima tensão de tração é encontrada na ameia oclusal dos conectores (Motta et al., 2008). 
A análise da superfície de fratura de PPFs que falharam clinicamente encontrou resultados semelhantes aos observados utilizando AEF (Kelly et al., 1995; Taskonak et al., 2008a). Geralmente, a fratura de PPFs totalmente cerâmicas tem origem em defeitos presentes na área gengival do conector, ao redor dos quais ocorre uma concentração de tensões durante a mastigação (Kelly et al., 1995; Magne et al., 2002; Fischer et al., 2003; Studart et al., 2007). Kelly et al. (1995) realizaram análise fractográfica de PPFs fraturadas in vivo e in vitro e observaram que, em 70 a $78 \%$ de todas as amostras, a fratura se iniciou na interface entre a cerâmica de infra-estrutura e a porcelana na região cervical do conector. Taskonak et al. (2008a) também encontraram a origem de fratura de PPFs de YZ na área cervical do conector. Entretanto, o defeito inicial foi localizado na superfície externa da porcelana e não na interface. Nesse estudo, apenas uma PPF fraturou devido a uma falha com origem na margem do retentor posterior.

Os sistemas metalo-cerâmicos são considerados o padrão ouro para confecção de restaurações protéticas. Estudos in vitro com PPFs totalmente cerâmicas de $\mathrm{YZ}$ encontraram valores relativamente altos de carga de fratura, entre 2.237 e 3.480 N (Tinschert et al., 2001; Sundh et al., 2005; Wolfart et al., 2007). Esses valores são compatíveis com os encontrados para PPFs metalo-cerâmicas (2.800 a 3.500 N) (Chitmongkolsuk et al., 2002). Outro estudo também observou que os valores de carga de fratura de PPFs metalo-cerâmicas (1318 N) foram semelhantes àqueles encontrados para peças confeccionadas com o sistema $\mathrm{YZ}$ (1248 N) (Kilicarslan et al., 2004).

A literatura reporta para PPFs de três elementos de $Y Z$ uma média de valores de carga de fratura entre 981 e 3480 N (Tinschert et al., 2001; Sundh et al., 2005; Sundh; Sjogren, 2006; Att et al., 2007; Wolfart et al., 2007; Beuer et al., 2008) e para PPFs de quatro elementos valores entre 706 e $1262 \mathrm{~N}$ (Luthy et al., 2005; Kohorst et al., 2007). Já o sistema IZ apresenta valores um pouco menores, entre 841 e $1500 \mathrm{~N}$ para PPFs de três elementos e uma média de $470 \mathrm{~N}$ para PPFs de quatro elementos (Tinschert et al., 2001; Luthy et al., 2005; Beuer et al., 2008). Em geral, uma PPF de quatro elementos possui resistência quase duas vezes menor do que uma PPF de três elementos (Luthy et al., 2005).

As restaurações metalo-cerâmicas apresentam um bom prognóstico clínico. Karlsson (1986) relatou uma taxa de sucesso de 93\% para PPFs metalo-cerâmicas durante um período de observação de 10 anos. Outro estudo encontrou uma taxa de 
sucesso de $79 \%$ durante um período de 18 a 23 anos para as restaurações metalocerâmicas (Palmqvist; Swartz, 1993). Apesar do grande número de estudos clínicos com restaurações totalmente cerâmicas, os períodos de acompanhamento ainda são relativamente curtos (2 a 5 anos) (Suarez et al., 2004; Vult Von Steyern et al., 2005; Sailer et al., 2006; Sailer et al., 2007a; Crisp et al., 2008; Edelhoff et al., 2008; Molin; Karlsson, 2008; Ohlmann et al., 2008; Tinschert et al., 2008; Beuer et al., 2009; Cehreli et al., 2009). Para as PPFs totalmente cerâmicas, a probabilidade de falha está relacionada com as propriedades dos sistemas cerâmicos utilizados, a distância entre os pilares e a localização na arcada dentária (Raigrodski, 2004).

A taxa de fratura das infra-estruturas de $\mathrm{YZ}$ e IZ nesses estudos clínicos é baixa, sendo em média 2\% e 6\%, respectivamente (Suarez et al., 2004; Della Bona; Kelly, 2008). Entretanto, outros problemas são comumente relatados como a ocorrência de cárie secundária, perda de retenção da peça e lascamento da porcelana de recobrimento (Della Bona; Kelly, 2008). A presença de cárie secundária é um fator biológico que geralmente não está relacionado com o tipo de material utilizado nas restaurações protéticas (Della Bona; Kelly, 2008). O lascamento da porcelana é considerado atualmente um dos principais problemas relacionados ao uso de infra-estruturas de YZ (Fischer et al., 2008). Neste tipo de falha, a fratura se propaga na porcelana de recobrimento podendo ou não atingir a interface com a infra-estrutura cerâmica, provocando uma delaminação (Taskonak et al., 2008a). Embora os lascamentos pequenos possam ser reparados sem a necessidade de remoção da prótese, os grandes (envolvendo fratura de cúspides ou contatos interproximais), levam à necessidade de troca da restauração (Scherrer et al., 2007). Os estudos clínicos que avaliaram peças protéticas com infra-estrutura de YZ mostraram taxas de lascamento variando desde 0 até $50 \%$, dependendo do período de acompanhamento (Sailer et al., 2007a; Crisp et al., 2008; Edelhoff et al., 2008; Molin; Karlsson, 2008; Tinschert et al., 2008). Essas taxas de lascamento da porcelana são consideradas altas principalmente se comparadas àquelas obtidas para próteses metalo-cerâmicas, que apresentam índices clínicos de lascamento ao redor de 2\% (Pjetursson et al., 2007; Sailer et al., 2007b). 


\subsection{ENVELHECIMENTO MECÂNICO}

O carregamento cíclico, como o que ocorre durante a mastigação, contribui para o crescimento subcrítico de trincas (SCG) em materiais cerâmicos (Chevalier et al., 1999). Quando um material é submetido a um longo período de tensões repetitivas e em nível subcrítico ocorre o desenvolvimento de micro-trincas nas áreas de concentração de tensões ou próximas à superfície. Devido ao contínuo carregamento, essas trincas se unem, formando uma trinca maior que se propaga até que um último ciclo exceda a resistência do material, levando à falha catastrófica (Wiskott et al., 1995; Callister Jr, 2002). Em condições subcríticas, a distribuição de tamanho inicial dos defeitos muda em função do tempo, de acordo com o comportamento de crescimento subcrítico de trincas de cada material. Conseqüentemente, os padrões de fratura de um material que sofreu ciclagem mecânica são diferentes daquele que não foi previamente solicitado mecanicamente. Studart et al. (2007) observaram que no carregamento rápido, a fratura dos corposde-prova teve origem nas trincas naturais presentes na cerâmica de cobertura, as quais se propagaram através da interface. Já a fratura dos CP submetidos à ciclagem mecânica se originou de trincas presentes na camada externa da cerâmica de cobertura.

O efeito do carregamento cíclico no crescimento subcrítico de materiais cerâmicos pode ser determinado por meio de ensaios que simulem ao máximo as condições do ambiente oral. O meio oral possui vários fatores que podem levar à degradação das propriedades físicas e mecânicas das restaurações cerâmicas. A água presente na cavidade oral (saliva, agente cimentante, túbulos dentinários) contribui para os fenômenos de crescimento subcrítico de trincas (Wiederhorn, 1967) e degradação da YZ (Kobayashi et al., 1981). A resistência do material também pode ser degradada pelas variações térmicas causadas pelo consumo de alimentos e líquidos quentes e frios (Ritter et al., 1985). Tensões relacionadas com a mastigação e com diferenças na expansão térmica entre os vários componentes das restaurações também contribuem para a redução da resistência da cerâmica (Morena et al., 1986; Della Bona et al., 2003). Dessa forma, para o desenvolvimento de um ambiente oral artificial deve-se levar em consideração todos os fatores supracitados (Delong; Douglas, 1983). 
A força e a freqüência utilizadas na ciclagem mecânica in vitro devem ser similares às que ocorrem durante a mastigação. A duração das forças oclusais varia entre 0,21 e 0,35 s (Jemt et al., 1979), e a freqüência da mastigação varia de 0,6 a $2,3 \mathrm{~Hz}$ (Delong; Douglas, 1983). Existe grande contradição nos estudos quanto à magnitude das forças geradas durante a mastigação e isso se deve aos diferentes métodos de mensuração e regiões da boca avaliadas. A literatura relata uma força mastigatória média de $220 \mathrm{~N}$ para a região posterior (Proeschel; Morneburg, 2002) e valores de $1181 \mathrm{~N}$ no caso de hábito parafuncional (Hidaka et al., 1999). Limitando essas forças a uma área de contato de $7-8 \mathrm{~mm}^{2}$ (molar), obtemos uma pressão média de mastigação de 27-31 MPa (Lohbauer et al., 2008). Para apresentar relevância clínica, deve-se realizar os ensaios com o mínimo de $10^{6}$ ciclos, já que esse número corresponde a um tempo de uso da restauração de aproximadamente 1 ano (Wiskott et al., 1995; Rosentritt et al., 2006; Lohbauer et al., 2008).

Existem vários estudos avaliando a influência da ciclagem térmica e mecânica nas propriedades das cerâmicas, porém não existe uma padronização dos testes. São utilizadas diferentes máquinas de ciclagem, variações na freqüência, carga e número de ciclos, diferentes materiais para os pilares e para o antagonista. Rosentritt et al. (2006) avaliaram os diferentes parâmetros utilizados nos estudos de ciclagem e observaram influência significante nos resultados para diferentes forças de carregamento, distância de abertura bucal, material do antagonista e do pilar, e presença de periodonto artificial. Não houve diferença estatisticamente significante para o tipo de máquina de ciclagem, freqüência e presença de movimento lateral.

Um estudo avaliou a influência da simulação de regimes mastigatórios na cerâmica $Y Z$ e não observou diferença significativa nos valores de resistência entre os grupos submetidos à ciclagem mecânica e o grupo controle (sem ciclagem). Os autores sugeriram que as cargas e número de ciclos utilizados não foram suficientes para induzir o acúmulo de uma quantidade suficiente de danos para produzir uma redução significativa da resistência. Entretanto, ao aumentar o número de ciclos para $10^{6}$, com carga de $80 \mathrm{~N}$, houve redução do módulo de Weibull como resultado do acúmulo de micro-trincas (Curtis et al., 2006). Jung et al. (2000) relataram diminuição nos valores de resistência à fratura da cerâmica ICA após $10^{6}$ ciclos com aplicação de carga cíclica de 200N e 500N. Para a cerâmica YZ não houve alteração da resistência quando essas cargas foram utilizadas, entretanto quando a carga foi 
aumentada para $3.000 \mathrm{~N}$, houve queda da resistência após $10^{4}$ ciclos e fratura antes de se completarem $10^{6}$ ciclos.

Alguns estudos avaliaram a resistência à fratura de PPFs de três e quatro elementos à base de zircônia após ciclagem térmica e mecânica e não observaram alteração significante nos valores de resistência (Sundh et al., 2005; Kohorst et al., 2007; Wolfart et al., 2007; Beuer et al., 2008). Beuer et al. (2008) avaliaram a carga de fratura PPFs de três elementos confeccionadas com os sistemas ICA, IZ e YZ e também observaram que o efeito da fadiga não foi estatisticamente significante. Encontraram efeito significante do material de infra-estrutura. Para todos os grupos avaliados, os valores de carga de fratura encontrados foram aproximadamente 30 a $105 \%$ maiores do que $500 \mathrm{~N}$, que é considerado o valor mínimo de carga de fratura de PPF para que um material possa ser indicado para uso clínico na região posterior. Entretanto, foi observado que os valores mínimos de carga de fratura dos grupos ICA e IZ foram muito próximos a $500 \mathrm{~N}$. Por outro lado, carga de fratura mínima da $\mathrm{YZ}$ foi em média $40 \%$ maior do que $500 \mathrm{~N}$. Portanto, os autores recomendam o uso de infra-estruturas de YZ em PPFs posteriores ao invés das cerâmicas ICA e IZ.

Por outro lado, um estudo avaliou PPFs de três elementos de YZ e observou que os valores de carga de fratura após o procedimento de envelhecimento foram cerca de 8 a 19\% menores do que os valores obtidos pelo grupo controle. Entretanto, mesmo após o procedimento de envelhecimento, as PPFs apresentaram resultados superiores a $1000 \mathrm{~N}$ (Att et al., 2007). O limite para a fadiga cíclica aplicado às cerâmicas dentais é aproximadamente $50 \%$ da sua carga de fratura. Por isso, pode-se assumir que valores ao redor de $1000 \mathrm{~N}$ representam um prognóstico clínico favorável para PPFs totalmente cerâmicas (Tinschert et al., 2001).

Um estudo comparou a taxa de sucesso clínico de PPFs totalmente cerâmicas com os resultados obtidos em laboratório e encontrou correlação positiva. Observaram diminuição nos valores de carga de fratura das PPFs submetidas à ciclagem térmica e mecânica em relação ao grupo controle. Durante a ciclagem foi observado lascamento da porcelana e não houve falha no material de infra-estrutura. A taxa de sobrevivência calculada utilizando dados in vivo foi de $70 \%$ após 10 anos e foi semelhante aos resultados obtidos com a simulação in vitro (73\%) (Rosentritt et al., 2009). 


\subsection{FRACTOGRAFIA DE MATERIAIS CERÂMICOS}

Fractografia é a análise criteriosa das superfícies de fratura (Mecholsky, 1995a). Segundo Fréchette (1990), a ciência da fractografia é o estudo de fragmentos e sua interpretação em termos de propriedades dos materiais e condições que levam à fratura. A norma ASTM 1322 (2003) define fractografia como meios e métodos para caracterizar corpos-de-prova ou componentes fraturados. Essa análise envolve a avaliação da superfície de fratura que contém marcas resultantes da interação da trinca em propagação com a microestrutura do material e as áreas de tensão. O objetivo da fractografia é determinar as causas ou fatores que levaram a uma perda de função indesejada. Portanto, é um elemento fundamental para o planejamento e desenvolvimento de materiais (Della Bona et al., 2003; Quinn, 2007; Scherrer et al., 2008; Taskonak et al., 2008a).

Duas ferramentas importantes na análise de superfícies fraturadas são o estereomicroscópio e o microscópio eletrônico de varredura (MEV). O estreomicroscópio possibilita uma visão ampliada, natural e tridimensional da superfície de fratura. Além disso, retém toda informação de cor, rugosidade superficial e refletividade. O MEV possibilita visualizar a falha mais claramente porque tem boa profundidade de campo, alta resolução e instrumentos de análise química (Quinn, 2007; Scherrer et al., 2008). Outras ferramentas, como lupas, microscópio óptico e microscópio de força atômica podem ser utilizados como acessórios de suporte da análise fractográfica. Fontes de luz clara são recomendadas para facilitar a análise de cerâmicas escuras e o uso de grandes ampliações. Iluminação direcionada pode ser obtida com guias de fibra óptica que direcionam um feixe de luz intenso na superfície de fratura, em ângulo. lluminação vicinal ou com baixa angulação é muito efetiva para acentuar picos e depressões nas superfícies de fratura (Quinn, 2007).

O preparo de amostras cerâmicas começa com a limpeza da superfície de fratura utilizando acetona, etanol, ou metanol. Etanol é mais indicado porque a acetona e o metanol freqüentemente deixam uma película de resíduos na superfície. Um recobrimento de ouro ou carbono (grafite) pode ser realizado na superfície dos corpos-de-prova que têm pouca refletividade ou que são translúcidos (Mecholsky, 1995b; Quinn et al., 2005). Além disso, podem ser confeccionadas réplicas da 
superfície de fratura quando as amostras são grandes e de difícil posicionamento no microscópio ou quando não é possível remover a peça para análise no laboratório. As réplicas também podem servir de garantia caso o componente seja perdido ou danificado. Em alguns casos, a superfície de fratura é mais facilmente analisada na réplica do que no original (Quinn, 2007; Scherrer et al., 2007).

Nos materiais friáveis, como as cerâmicas, existem três regiões características envolvendo a origem de fratura (Figura 2.1). A primeira região é relativamente lisa (mirror), a segunda apresenta uma textura fibrosa e aspecto nebuloso (mist) e a terceira é mais heterogênea e com características mais pronunciadas na superfície (hackle). Essa última região leva à ramificação macroscópica da trinca (crack branching), ou seja, bifurcação da trinca principal (Mecholsky, 1995b). O mirror é a região onde a trinca se propaga a partir de um defeito na origem de fratura. A trinca acelera de uma velocidade próxima a zero até a velocidade terminal dentro da região de mirror. A velocidade terminal da trinca é limitada pela velocidade com a qual a energia elástica é transferida para a ponta da trinca. À medida que a trinca acelera a partir da origem, pequenas porções da ponta da trinca começam a se desviar do plano principal de fratura. Esse desvio momentâneo é limitado pelo custo energético de criar novas superfícies de fratura. Então, essas pequenas variações no plano da trinca logo retornam ao plano de propagação principal. À medida que a trinca se propaga, essas perturbações se tornam grandes o suficiente para serem observadas em nível microscópico, dando origem à região chamada mist. À medida que a trinca continua avançando, as perturbações locais aumentam e começam a oscilar e formam segmentos maiores. Dessa forma, são gerados pequenos degraus que correm em direção paralela à direção de propagação da trinca. Essas linhas são denominadas velocity hackles e apontam para a origem da fratura. Apesar desse processo de aumento da rugosidade de superfície ser descrito como gradual, existem dois pontos de transição: o limite mirror-mist e o limite mist-hackle (Fréchette, 1990; Quinn, 2007). Esses limites podem ou não ser simétricos em relação à origem da falha, dependendo de fatores como a distribuição de tensões e a forma da trinca (Mecholsky, 1995b). 


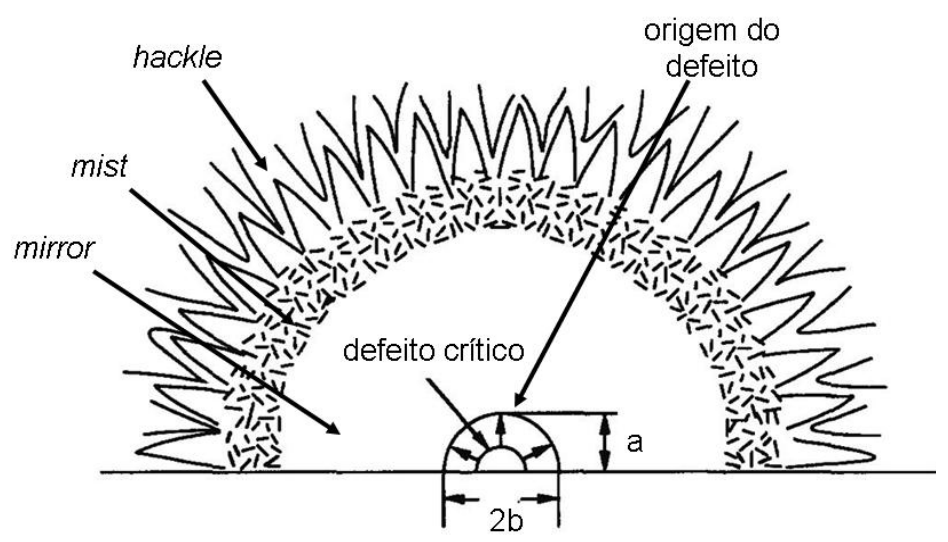

Figura 2.1 - Desenho esquemático da superfície de fratura. Pode-se observar as três regiões características que envolvem a origem de fratura: mirror, mist e hackle (Mecholsky, 1995b)

É possível localizar a origem e direção de propagação da trinca através da observação de marcas características da superfície de fratura (Mecholsky, 1995b). As marcas mais comuns são: (1) microstructural hackles; (2) wake hackles; (3) twist hackles; (4) Wallner lines; e (5) arrest lines. Microstructural hackles são linhas pronunciadas geralmente formadas por variações na microestrutura do material. Wake hackle é uma marca produzida quando uma trinca em propagação encontra uma singularidade elástica como uma inclusão ou um poro. A frente da trinca se separa $e$ as duas frentes passam o obstáculo, freqüentemente, em planos levemente diferentes, criando um degrau ou uma cauda entre elas. Essa cauda pode desaparecer rapidamente ou persistir por longas distâncias. Twist hackles podem ser geradas pela trinca inicial à medida que passa por cantos ou irregularidades geométricas, ou à medida que as condições de tensão mudam. Também podem ocorrer em espécimes que apresentaram, inicialmente, fortes gradientes térmicos ou de tensão. Wallner line é uma marca em semicírculo com contorno em forma de onda. Essas linhas são produzidas por uma excursão temporária da frente da trinca fora do plano principal de propagação em resposta a um desvio no eixo de tensão principal. A forma da linha depende da forma e velocidade da onda elástica e da ponta da trinca, bem como da direção em que a onda intercepta a trinca. Normalmente elas não apresentam exatamente a mesma forma que a frente da trinca, mas são curvadas na direção de propagação. Wallner lines primárias são formadas como resultado do encontro da trinca com uma irregularidade externa. Wallner lines secundárias ocorrem como resultado de irregularidades próprias da 
trinca, como as regiões de mist e hackle. É comum que tanto linhas primárias como secundárias estejam presentes na superfície de fratura. Por último, arrest lines são linhas agudas que correspondem à região em que a trinca hesita ou pára de propagar. A origem de fratura está sempre localizada no lado côncavo da primeira arrest line (Fréchette, 1990; Mecholsky, 1995b; Quinn, 2007).

Geralmente a resistência de materiais cerâmicos é verificada através de ensaios de flexão. Um sinal característico da fratura produzida por ensaios de flexão é a curva de compressão (compression curl). Em um espécime submetido à flexão existe um gradiente de tensões. À medida que a trinca se propaga da região submetida à tração em direção à região submetida à compressão, sua velocidade diminui e a trinca muda de direção. Em corpos-de-prova mais resistentes a trinca pode ramificar, criando uma curva dupla. A origem de fratura é oposta a curva de compressão (Quinn et al., 2005; Quinn, 2007).

Uma vez que a origem da fratura foi localizada, é possível realizar uma análise fractográfica quantitativa. Essa análise pode ser utilizada para identificar o tamanho da falha ou defeito inicial, o valor e natureza da tensão de fratura, a presença de tensões residuais ou crescimento subcrítico, e para o reconhecimento de defeitos locais de processamento que podem afetar o processo de fratura (Mecholsky, 1995b; Della Bona et al., 2003; Taskonak et al., 2008a). O tamanho da falha crítica inicial deve ser medido e, se possível, as distâncias até os limites mirrormist, mist-hackle e crack branching também devem ser mensuradas.

A mecânica da fratura pode ser utilizada para estimar o tamanho do defeito crítico, a resistência à fratura ou a tenacidade do material. Se dois desses fatores são conhecidos, o terceiro pode ser calculado segundo a equação de Griffith-Irwin (Griffith, 1920; Irwin, 1957; Mecholsky, 1995a) (Equação 2.1):

$$
K_{I C}=Y \sigma_{f} \sqrt{c}
$$

Equação 2.1

onde $K_{\mathrm{IC}}$ é a tenacidade à fratura $\left(\mathrm{MPa} \cdot \mathrm{m}^{1 / 2}\right)$, $\sigma_{\mathrm{f}}$ é a tensão de fratura (MPa), $\mathrm{Y}$ é o fator geométrico de intensidade de tensão (adimensional) e c é o tamanho do defeito crítico $(m)$. A maioria das falhas mecânicas possui forma semi-elíptica e sua dimensão pode ser caracterizada utilizando a medida da profundidade (a) e a metade da largura (b), como pode ser observado na figura 2.1. Dessa forma, o tamanho do defeito crítico é dado por (Equação 2.2):

$$
c=\sqrt{a b}
$$


No caso de falhas de canto, c corresponde à distância do canto ao limite da falha crítica na região de mirror.

Y é um parâmetro adimensional que leva em conta a localização e geometria do defeito inicial e as condições de carregamento, e também depende da razão a/b. $Y$ pode ser calculado utilizando a interpretação do trabalho de Irwin feita por Randall (Randall, 1966) (Equação 2.3):

$$
Y=\left(0,515 Q^{1 / 2}\right)^{-1}
$$

Equação 2.3

$Q$ varia de 1,00 , para falhas longas e rasas $(Y=1,94)$, até 2,46 , para falhas semi-circulares $(Y=1,24)$. Para falhas de canto, $Y$ pode ser aproximado pela equação 2.4:

$$
Y=1,12^{2} \frac{2}{\pi^{1 / 2}}
$$

Equação 2.4

onde $1,12^{2}$ representa a correção para falhas de superfície e $2 / \pi^{1 / 2}$ representa a correção para um defeito na forma circular. Portanto, para defeitos de canto, o valor de $Y$ é igual a 1,4 (Della Bona et al., 2004).

Além do tamanho do defeito crítico, o tamanho da região de mirror também pode ser utilizado para estimar a tensão de fratura. A relação entre o raio do mirror (R) e $\sigma_{f}$ é a seguinte (Equação 2.5):

$$
\sigma_{f} \sqrt{R}=A
$$

Equação 2.5

onde A é uma constante relacionada às propriedades do material e possui unidade de intensidade de tensão $\left(\mathrm{MPa} \cdot \mathrm{m}^{1 / 2}\right)$. $\mathrm{R}$ pode ser calculado até o limite mirror-mist ou mist-hackle. A microestrutura das cerâmicas policristalinas mascara a maioria dos detalhes da região de mirror. Além disso, nos materiais em geral não é possível reconhecer a região de mist. Portanto, recomenda-se que o valor de $\mathrm{R}$ seja calculado utilizando-se o limite mirror-hackle. Esse limite é a periferia onde pode ser identificada a presença de novas linhas de hackle e existe uma mudança de rugosidade em relação à região interna do mirror. Linhas de hackle prematuras e degraus isolados provenientes de irregularidades microestruturais devem ser ignorados (Mecholsky, 1995b; Quinn, 2007).

A razão entre o tamanho do mirror e o tamanho da falha crítica $(\mathrm{R} / \mathrm{c})$ pode ser utilizada para determinar a presença de crescimento subcrítico, a existência ou ausência de tensões residuais e estimar a dimensão fractal (Mecholsky, 1995b). O valor $\mathrm{R} / \mathrm{c}$ deve estar de acordo com os valores relatados na literatura ou obtidos em 
laboratório. Um valor discrepante pode indicar presença de tensões residuais localizadas ou globais, ou crescimento subcrítico. Se os valores R/c são muito maiores do que os valores tabulados, a superfície de fratura deve ser analisada para encontrar evidências de crescimento subcrítico (Mecholsky, 1995b; Quinn, 2007).

A forma do mirror sugere a natureza da tensão de fratura. Um campo de tensões de tração geralmente resulta em um mirror simétrico e uniforme, um campo de tensões produzido por um ensaio de flexão resulta em um mirror simétrico mas não-uniforme, e um campo de tensões produzido por um carregamento de torção produz twist hackles no limite do mirror. Se a forma do mirror é atípica, pode-se suspeitar da presença de tensões compressivas residuais (Mecholsky, 1995b). Quanto menor o tamanho do mirror, maior o valor de tensão na origem. Um tamanho de mirror pequeno está relacionado com uma estrutura resistente e um defeito pequeno. Ao contrário, um tamanho grande de mirror significa que a tensão de fratura foi baixa e indica um defeito grande. Em alguns casos a estrutura é tão fraca que o tamanho do mirror é maior do que a secção transversal do corpo-de-prova (Quinn, 2007).

O modo de propagação da trinca, inter ou transgranular, também influencia nas características da região de mirror. Transgranular é um modo de fratura em que a trinca se propaga através dos cristais e planos cristalinos, enquanto no modo intergranular a trinca se propaga através dos limites dos cristais. É mais difícil definir o tamanho do mirror quando a fratura é intergranular. O crescimento subcrítico de trincas geralmente ocorre de forma intergranular, já que limites de grãos são mais fracos e fases secundárias ou vítreas normalmente estão distribuídas nessas regiões. Em cerâmicas policristalinas pode ocorrer uma transição entre a propagação transgranular e intergranular (Mecholsky, 1995b; Quinn, 2007).

Nas pesquisas in vitro, a causa de fratura é conhecida. Portanto, o principal objetivo da análise fractográfica é identificar falhas e estudar as interações da trinca com a microestrutura. Também, é possível verificar se o teste foi realizado de forma adequada e se os dispositivos e corpos-de-prova estavam alinhados corretamente. Por outro lado, a análise da superfície de fratura de restaurações cerâmicas que falharam in vivo é um processo mais complicado. A maior parte dessas falhas ocorre em baixos níveis de tensão. Portanto, raramente é possível observar a região de mirror em uma fratura clínica. Além disso, o estado de tensões é transitório e nãouniforme, e as marcas características da fratura friável são freqüentemente 
mascaradas pela rugosidade de superfície. Restaurações acumulam danos de múltiplos eventos e em múltiplas regiões, dificultando a identificação do defeito crítico de fratura (Quinn, 2007).

Muitos fatores podem estar associados à formação e propagação de trincas em restaurações cerâmicas, incluindo: (1) forma da restauração; (2) nãohomogeneidade microestrutural; (3) tamanho e distribuição de falhas superficiais; (4) tensões residuais e gradientes de tensões induzidos pelo polimento ou processamento térmico; (5) as condições do ambiente oral em contato com a restauração; (6) características da interface entre a restauração e o cimento, e interface entre o material de infra-estrutura e o material de recobrimento; (7) espessura e variação da espessura na restauração; (8) módulo de elasticidade dos componentes da restauração; (9) magnitude e orientação das forças aplicadas (Thompson et al., 1994). A interação entre essas variáveis complica a interpretação do processo de fratura. Segundo Thompson et al. (1994), a distribuição das trincas em determinada região é um fator mais dominante na fratura de coroas cerâmicas do que a espessura. A geometria também é um parâmetro importante já que, se a distribuição dos defeitos na restauração é homogênea, a geometria irá determinar a origem da fratura. 


\section{PROPOSIÇÃO}

Os objetivos desse trabalho foram:

1. Determinar a resistência à flexão em três pontos e módulo de Weibull de três cerâmicas usadas para confecção de infra-estrutura de PPFs (YZ- zircônia tetragonal parcialmente estabilizada por óxido de ítrio; IZ- cerâmica a base de alumina infiltrada por vidro e reforçada com zircônia; AL- alumina policristalina) e duas porcelanas (VM7 e VM9), testando a hipótese de que o comportamento mecânico dos materiais de infra-estrutura é superior ao comportamento das porcelanas.

2. Determinar o coeficiente de susceptibilidade ao crescimento subcrítico de trinca $(n)$ das cerâmicas de infra-estrutura e das porcelanas. A hipótese a ser testada é a de que os materiais com alto conteúdo cristalino apresentam maior valor de $n$.

3. Determinar o tamanho de defeito crítico e a tenacidade à fratura $\left(K_{I C}\right)$ das cerâmicas de infra-estrutura e das porcelanas utilizando análise fractográfica quantitativa. A hipótese é a de que as porcelanas apresentam maior tamanho de defeito crítico e menor valor de $K_{l C}$ do que os materiais de infra-estrutura.

4. Avaliar o efeito da configuração (uma, duas ou três camadas) na resistência à flexão e modo de fratura dos corpos-de-prova, testando a hipótese de que o material em tração durante o ensaio de flexão controla o comportamento mecânico dessas estruturas.

5. Avaliar a influência do tamanho da área de secção transversal dos conectores na carga de fratura das PPFs. A hipótese a ser testada é de que um maior tamanho de conector produz maiores valores de carga de fratura.

6. Avaliar o efeito da ciclagem mecânica na carga de fratura de PPFs construídas com os diferentes materiais para infra-estrutura. A hipótese é a de que a ciclagem mecânica reduz a carga de fratura e esse efeito varia de acordo com o tipo de material de infra-estrutura.

7. Avaliar, usando $A E F$, a influência do material de infra-estrutura e do tamanho da área de secção transversal do conector na distribuição de tensões das 
PPFs, testando a hipótese de que a distribuição de tensões varia de acordo com o tipo de material de infra-estrutura e tamanho de conector.

8. Realizar análise fractográfica das PPFs fraturadas testando a hipótese de que o tipo de material cerâmico influencia o padrão de fratura das PPFs.

9. Relacionar o comportamento mecânico dos materiais cerâmicos testados na configuração de barra e de PPF. A hipótese a ser testada é de que o comportamento mecânico observado para os corpos-de-prova em forma de barra é semelhante ao observado para as PPFs. 


\section{MATERIAL E MÉTODOS}

Foram estudados três sistemas cerâmicos para infra-estrutura de PPFs (Vita In-Ceram YZ, Vita In-Ceram Zircônia e Vita In-Ceram AL) e duas porcelanas de recobrimento (Vita VM7 e Vita VM9). Os materiais utilizados estão descritos na tabela 4.1.

Tabela 4.1 - Descrição dos sistemas cerâmicos utilizados nesse estudo

\begin{tabular}{|c|c|c|c|}
\hline Legenda & Material $^{*}$ & Tipo de material & Indicação \\
\hline YZ & Vita In-Ceram YZ & $\begin{array}{l}\text { zircônia tetragonal parcialmente } \\
\text { estabilizada com óxido de ítrio }\end{array}$ & infra-estrutura \\
\hline $\mathbf{I Z}$ & Vita In-Ceram Zircônia & $\begin{array}{l}\text { cerâmica à base de alumina, } \\
\text { reforçada com zircônia e infiltrada } \\
\text { por vidro }\end{array}$ & infra-estrutura \\
\hline $\mathbf{A L}$ & Vita In-Ceram AL & alumina policristalina & infra-estrutura \\
\hline VM7 & Vita VM7 & porcelana feldspática & recobrimento \\
\hline VM9 & Vita VM9 & porcelana feldspática & recobrimento \\
\hline
\end{tabular}

Os materiais foram fabricados pela Vita Zahnfabrik, Bad Sackingen, Alemanha.

\subsection{CONFECÇÃO DOS CORPOS-DE-PROVA}

\subsubsection{Estruturas em forma de barra}

Três tipos de corpo-de-prova em forma de barra foram construídos, todos com dimensões de $2 \mathrm{~mm} \times 4 \mathrm{~mm} \times 16 \mathrm{~mm}$ :

(1) barra monolítica, composta somente de um material;

(2) barra de duas camadas, composta de uma camada de $1 \mathrm{~mm}$ de cerâmica de infra-estrutura e uma camada de $1 \mathrm{~mm}$ de porcelana;

(3) barra de três camadas, composta de $1 \mathrm{~mm}$ de cerâmica para infraestrutura recoberta por todos os lados com $0,5 \mathrm{~mm}$ de porcelana. 
4.1.1.1 Corpos-de-prova monolíticos (uma camada)

Barras de $Y Z$, IZ e AL foram obtidas através do corte de blocos cerâmicos pré-fabricados. Primeiramente, o pino metálico do bloco cerâmico foi descolado aquecendo-se o conjunto em uma chapa quente. O bloco cerâmico foi fixado com cera pegajosa em um tubo de PVC e posicionado no porta-amostras da cortadeira (Isomet 1000, Buehler, Lake Bluff, EUA). Os cortes foram realizados com um disco diamantado a 275 rpm sob intensa refrigeração (Figura 4.1, partes A e B).

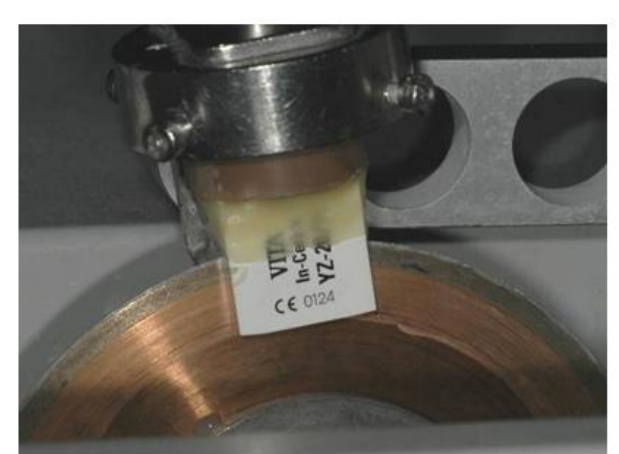

A

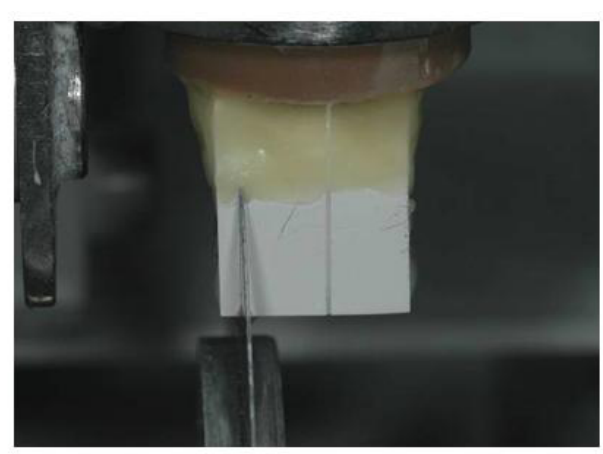

B

Figura 4.1 - Bloco de YZ fixado ao tubo de PVC com cera pegajosa e sendo seccionado na cortadeira. A) Vista lateral do primeiro corte sendo realizado. B) Segundo corte sendo realizado

Os corpos-de-prova de $\mathrm{YZ}$ e $\mathrm{AL}$ foram sinterizados no forno Zyrcomat (Vita Zahnfabrik, Alemanha) (Figura 4.2, partes A e B). O material IZ foi infiltrado com vidro. Uma mistura de pó de vidro (Zirconia Glass Powder, Vita Zahnfabrik, Alemanha) e água destilada foi aplicada sobre a superfície com $4 \mathrm{~mm}$ das barras de IZ (Figura 4.3, partes A e B). O forno Inceramat 3 (Vita Zahnfabrik, Alemanha) foi utilizado para o ciclo de infiltração do vidro sendo o excesso removido com pedras montadas em um motor elétrico. O procedimento de infiltração do vidro pode ser visto na figura 4.3. Os ciclos de sinterização da $Y Z$ e $A L$ e o ciclo de infiltração do vidro do IZ estão apresentados na tabela 4.2 . 


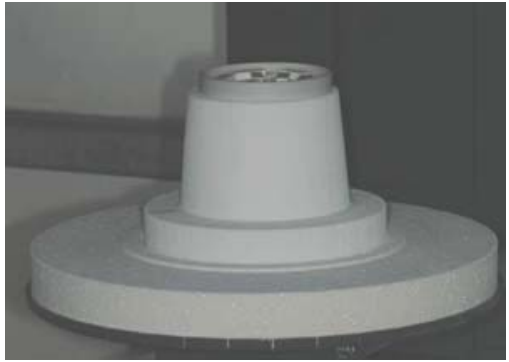

A

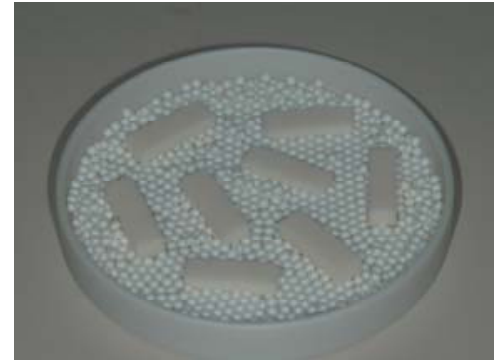

B

Figura 4.2 - A) Corpos-de-prova na bandeja sobre a base de refratário do forno Zyrcomat. B) Corpos-de-prova de AL sinterizados

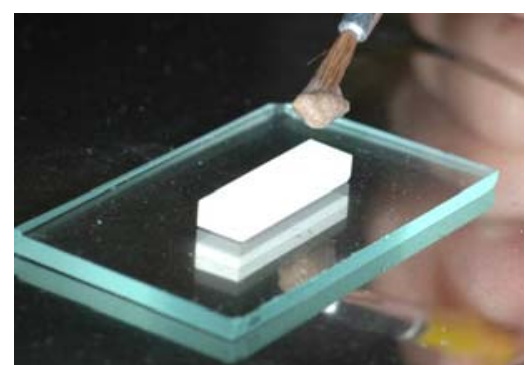

A

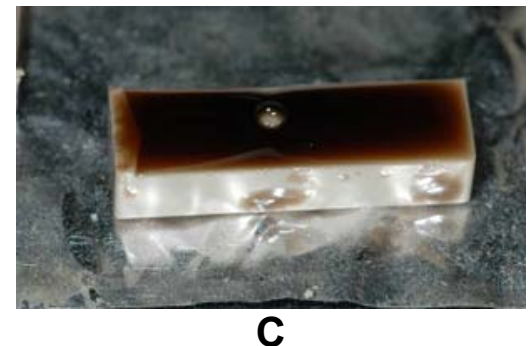

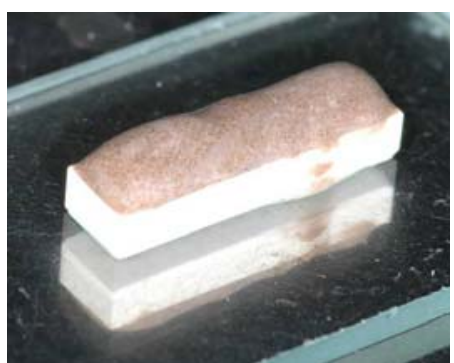

B

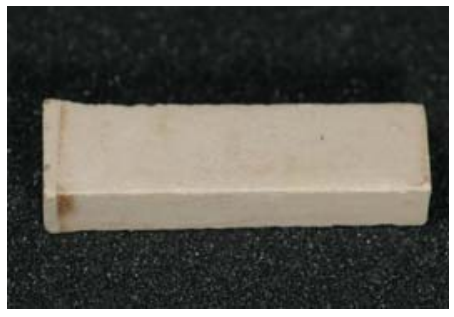

D

Figura 4.3 - A) Aplicação da pasta de vidro na barras de IZ. B) Pasta de vidro aplicada sobre a superfície do corpo-de-prova. C) Barra logo após o ciclo de infiltração do vidro. D) Barra após a remoção do excesso de vidro com pontas montadas

Tabela 4.2 - Ciclos de sinterização dos materiais YZ e AL e ciclo de infiltração de vidro do IZ

\begin{tabular}{lcc}
\hline & YZ e AL & IZ \\
\hline Temperatura $1\left({ }^{\circ} \mathbf{C}\right)$ & - & 200 \\
\hline Temperatura 2 $\left({ }^{\circ} \mathbf{C}\right)$ & 1530 & 1110 \\
\hline Tempo de queima na temperatura 1 (horas) & - & 0,5 \\
\hline Tempo de queima na temperatura 2 (horas) & 2 & 6 \\
\hline Taxa de aquecimento ( $\left.{ }^{\circ} \mathbf{C} / \mathbf{m i n}.\right)$ & 25 & - \\
\hline Tempo de resfriamento (horas) & 7,5 & $\sim 3$ \\
\hline
\end{tabular}

Corpos-de-prova de VM7 e VM9 foram fabricados a partir de uma mistura de pó de porcelana e água destilada. A mistura foi aplicada em uma matriz metálica e condensada com vibração manual. O excesso de água foi removido com papel absorvente e foi utilizada uma lâmina para dar acabamento superficial. A 
sinterização dos corpos-de-prova com o ciclo recomendado pelo fabricante (Tabela 4.3) foi realizada no forno Keramat I (Knebel, Porto Alegre, Brasil).

Tabela 4.3 - Ciclos de sinterização das porcelanas VM7 e VM9 e do Effect Bonder e ciclo de glaze

\begin{tabular}{lccc}
\hline & VM7 e VM9 & Effect Bonder & Glaze \\
\hline Tempo de secagem (min.) & 6 & 6 & - \\
\hline Vácuo (mmHg) & 29 & 29 & - \\
\hline Temperatura inicial $\left({ }^{\circ} \mathbf{C}\right)$ & 500 & 500 & 500 \\
\hline Temperatura máxima $\left({ }^{\circ} \mathbf{C}\right)$ & 910 & 980 & 900 \\
\hline Temperatura de desligamento do vácuo $\left({ }^{\circ} \mathbf{C}\right)$ & 910 & 980 & - \\
\hline Tempo de queima sem vácuo & 1 & 1 & 1 \\
\hline Taxa de aquecimento $\left({ }^{\circ} \mathbf{C} / \min .\right)$ & 55 & 80 & 80 \\
\hline Tempo de resfriamento $(\min )$. & 6 & 6 & 6 \\
\hline
\end{tabular}

Após a sinterização da $\mathrm{YZ}, \mathrm{AL}, \mathrm{VM} 7$ e VM9 e da infiltração de vidro na IZ, todos os corpos-de-prova foram submetidos a um procedimento de usinagem utilizando uma retificadora plana MSG-600 (Mitutoyo, São Paulo, SP, Brasil) com rebolos diamantados (Winter, Saint-Gobain Abrasivos LTDA, São Paulo, Brasil), tendo como base as especificações descritas na ASTM C 1421 (2001). O objetivo do processo de usinagem é obter barras com as dimensões desejadas e superfícies opostas paralelas entre si. Cada face foi usinada em 3 estágios, utilizando-se rebolos de granulação grossa, média e fina. O desbaste mínimo realizado em cada rebolo foi de 0,06 $\mathrm{mm}$ por face. O avanço vertical realizado a cada etapa foi de 0,01 $\mathrm{mm}$ para os rebolos grosso e médio, e de $0,002 \mathrm{~mm}$ para o rebolo fino. Esse cuidado tem como objetivo evitar a geração de defeitos nos corpos de prova e a criação de tensões residuais superficiais. Todo o processo de usinagem foi feito sob intensa refrigeração com uma solução de água deionizada e óleo solúvel. O desgaste foi realizado sempre paralelamente ao longo do maior eixo dos corpos de prova.

Posteriormente, todos os corpos-de-prova foram polidos utilizando a politriz semi-automática Ecomet 4 (Buehler, Lake Bluff, IL, EUA). Foi utilizada uma seqüência específica de polimento para cada material. Apenas a superfície do lado a ser solicitada em tração durante o ensaio de flexão foi polida e a lisura dos corposde-prova foi verificada em um microscópio óptico.

Os quatro cantos (união entre as superfícies ou lados maiores) dos corposde-prova foram chanfrados utilizando-se um dispositivo e lixa d'água (Figura 4.4, 
partes A e B). A largura do chanfro foi padronizada em 0,1 $\mathrm{mm}$ como preconiza a norma ISO 6872 (2008). A figura 4.5 mostra os corpos-de-prova monolíticos de YZ (parte A) e AL (parte B) em suas diferentes fases de preparação, desde o corte até o a chanframento dos cantos.

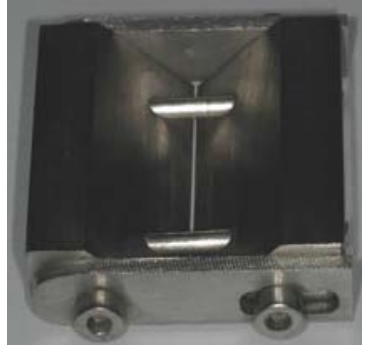

A

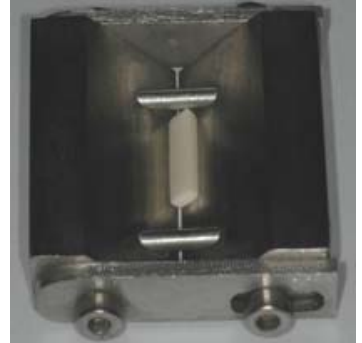

B

Figura 4.4 - A) Dispositivo para chanfrar os cantos das barras de cerâmica. B) Corpo-de-prova posicionado dentro do dispositivo para chanframento dos cantos

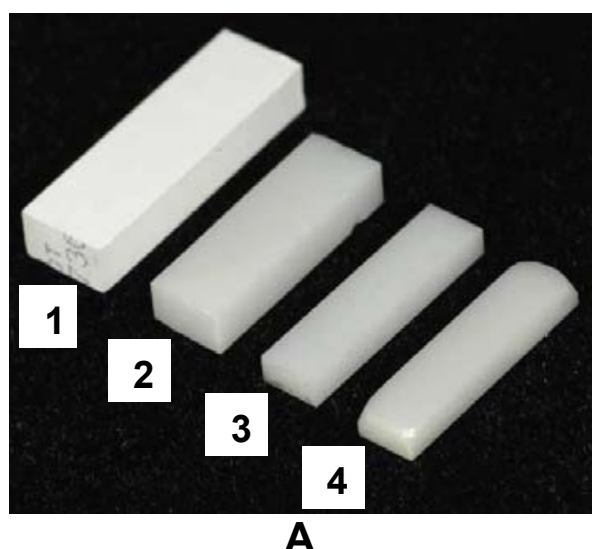

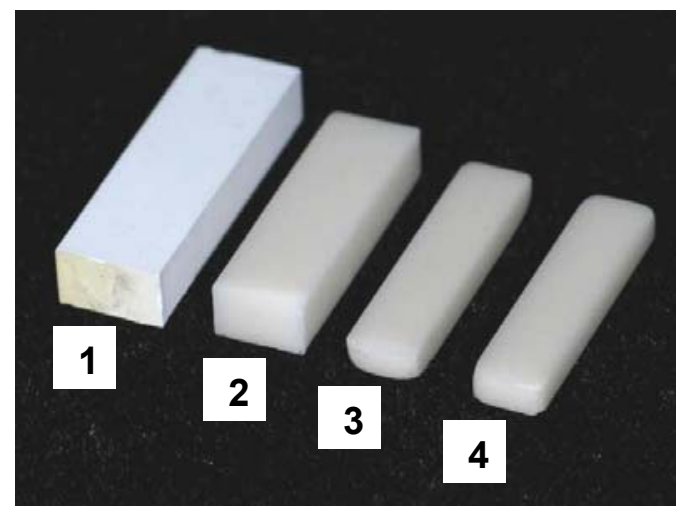

B

Figura 4.5 - Corpos-de-prova monolíticos de YZ (A) e AL (B): (1) antes da sinterização; (2) após sinterização; (3) após usinagem; (4) após polimento de uma das faces e chanframento dos cantos

\subsubsection{Corpos-de-prova de duas camadas}

As barras de material de infra-estrutura foram recobertas pela porcelana indicada pelo fabricante: porcelana VM7 para os materiais AL e IZ e porcelana VM9 para YZ. Foram fabricados 20 corpos-de-prova para cada grupo: YZ/VM9, IZ/VM7 e AL/VM7. 
Foram fabricadas barras de cerâmica de infra-estrutura com $1 \mathrm{~mm}$ de espessura seguindo os passos de corte, sinterização, infiltração de vidro (IZ) e usinagem descritos anteriormente para os corpos-de-prova monolíticos. Para a fabricação do corpo-de-prova de duas camadas, a barra de infra-estrutura foi posicionada em uma matriz de aço e uma das suas faces foi recoberta com uma mistura de pó de porcelana e água destilada. O corpo-de-prova com o recobrimento de porcelana foi removido da matriz e levado ao forno Keramat I para sinterização da porcelana. Para o grupo YZ, antes do recobrimento com porcelana, foi aplicado um agente de união indicado pelo fabricante (Effect Bonder, Vita Zahnfabrik, Alemanha). O agente foi aplicado com auxílio de um pincel em uma das faces da barra cerâmica, como pode ser observado da figura 4.6. A sinterização do agente de união foi realizada no forno Keramat I seguindo o ciclo recomendado pelo fabricante (Tabela 4.3).

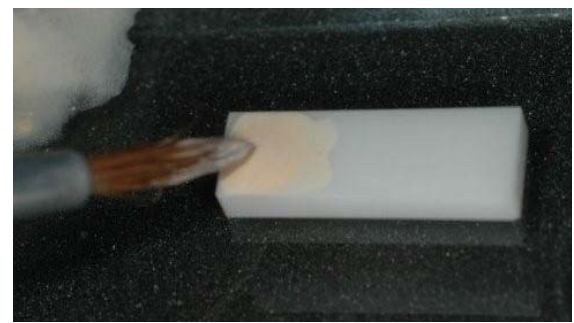

A

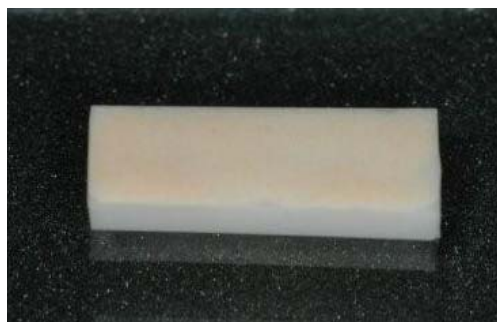

B

Figura 4.6 - A) Aplicação do agente de união (Effect Bonder) com auxílio de um pincel sobre a barra de YZ. B) barra de YZ com a camada de Effect Bonder

Após o recobrimento com porcelana, os corpos-de-prova foram usinados até as dimensões finais $(2 \mathrm{~mm} \times 4 \mathrm{~mm} \times 16 \mathrm{~mm}$ ) seguindo os passos descritos anteriormente. Para cada grupo, metade dos corpos-de-prova tiveram a superfície do material de infra-estrutura polida e a outra metade teve a superfície da porcelana polida $(n=10)$. Os processos de polimento e chanfro dos quatro cantos foram realizados seguindo os mesmos procedimentos descritos para os corpos-de-prova monolíticos. A figura 4.7 apresenta a imagem das barras de duas camadas após o procedimento de usinagem. 


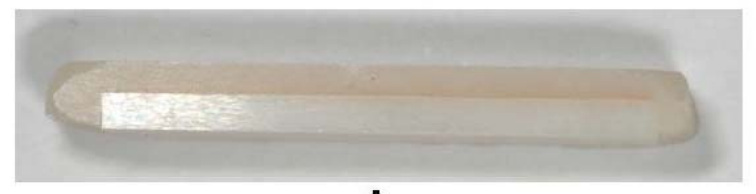

A

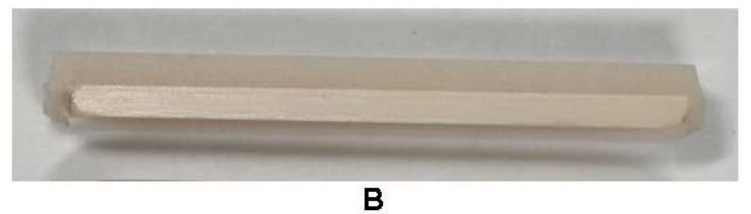

B

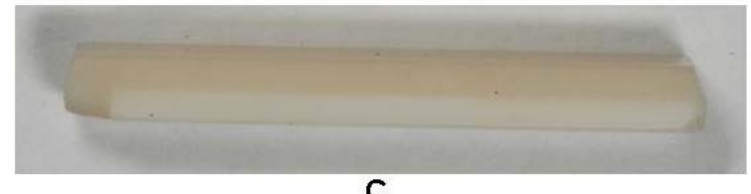

C

Figura 4.7 - Corpos-de-prova de duas camadas após usinagem. A) YZ sob a VM9. B) IZ sob a VM7. C) AL sob a VM7

\subsubsection{Corpos-de-prova de três camadas}

Para a produção de corpos-de-prova de três camadas, foram usinadas barras de infra-estrutura com dimensões de $1 \mathrm{~mm} \times 3 \mathrm{~mm} \times 15 \mathrm{~mm}$. Inicialmente, uma camada de porcelana foi aplicada na base da matriz metálica (Figura 4.8, partes A e B). A infra-estrutura foi centralizada sobre essa camada de porcelana (Figura 4.8, parte C). A espessura de porcelana foi controlada ajustando-se a altura do êmbolo metálico que compõe o fundo da matriz metálica (Figura 4.8, parte D). Uma segunda camada de porcelana foi aplicada sobre a infra-estrutura (Figura 4.8, parte E). Os excessos foram removidos com uma lâmina e o corpo-de-prova final foi extraído da matriz (Figura 4.8, partes F, G e H). Parte da porcelana de uma das pontas da barra foi removida de modo a expor a infra-estrutura (Figura 4.8, parte I). Esse procedimento foi realizado para controlar a quantidade de desgaste da porcelana e o paralelismo entre os materiais durante a usinagem. 


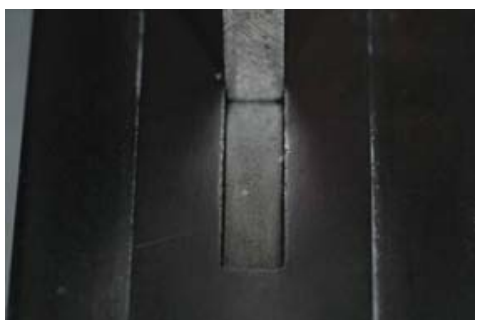

A

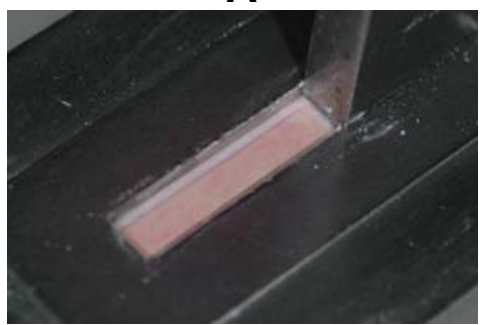

D

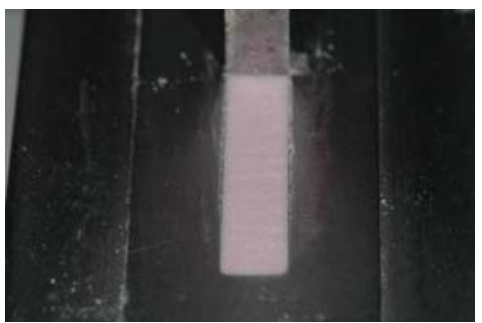

G

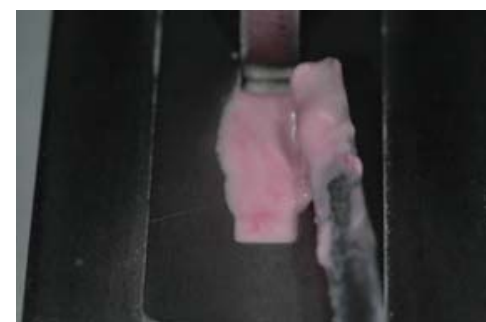

B

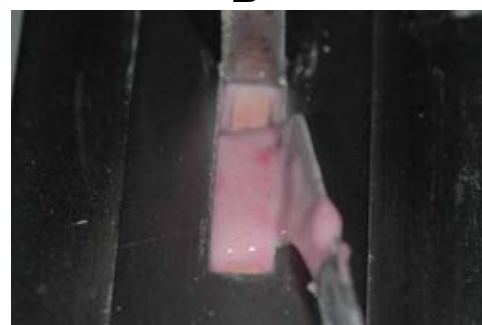

E

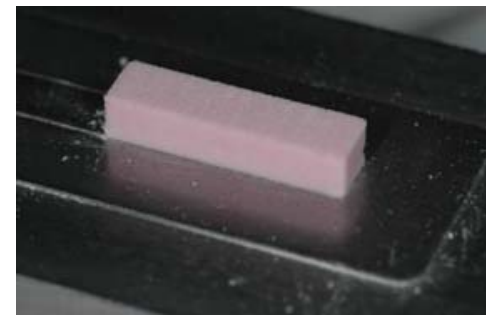

H

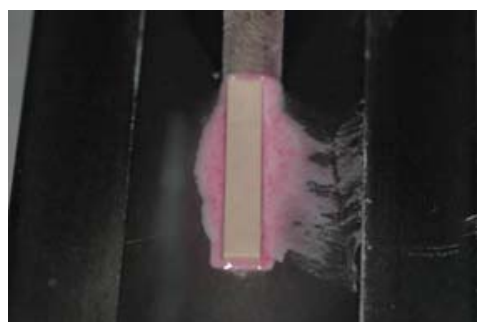

C

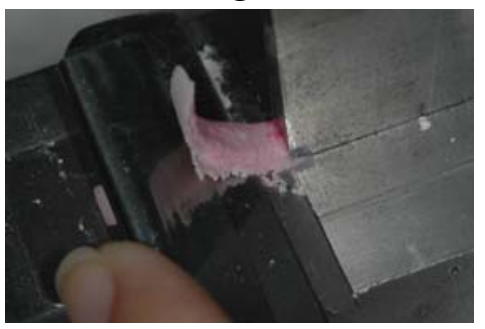

$\mathbf{F}$

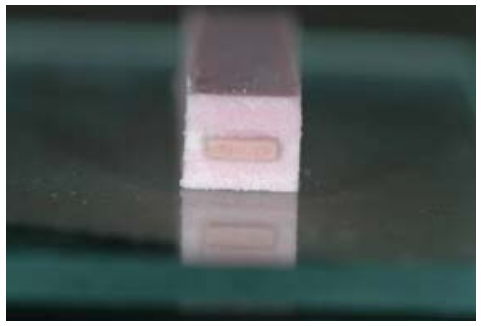

I

Figura 4.8 - Passos de confecção do corpo-de-prova de três camadas. A) Matriz metálica. B) Primeira camada de porcelana sendo aplicada. C) Inserção da barra de infra-estrutura na camada de porcelana. D) Base da matriz ajustada para receber a segunda camada de porcelana. E) Aplicação da segunda camada de porcelana. F) Remoção do excesso de porcelana com uma lâmina. G) Corpo-de-prova após remoção do excesso de porcelana. H) Corpo-de-prova extraído da matriz. I) Vista da extremidade do corpo-deprova onde a porcelana foi removida para visualização da infra-estrutura

Os corpos-de-prova foram levados ao forno Keramat I para realizar o ciclo de sinterização da porcelana. A figura 4.9 mostra o corpo-de-prova após a sinterização. As barras foram usinadas até as dimensões finais, garantindo uma espessura uniforme de $0,5 \mathrm{~mm}$ de porcelana ao redor das quatro faces principais (maiores) da infra-estrutura. Após a usinagem, a extremidade com infra-estrutura exposta foi totalmente recoberta com porcelana. Os procedimentos de polimento e chanframento dos cantos foram realizados seguindo os passos descritos para as barras monolíticas. 


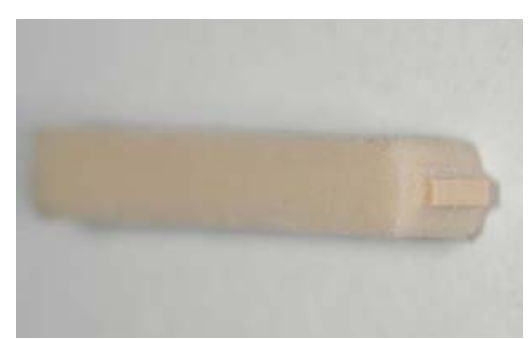

A

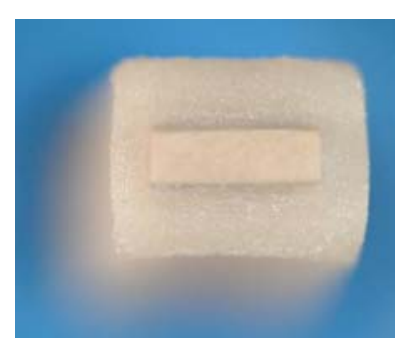

B

Figura 4.9 - Corpo-de-prova de três camadas após sinterização da porcelana. A) Vista lateral. B) Detalhe da extremidade com infra-estrutura exposta

Com o objetivo de facilitar a interpretação dos resultados, as estruturas em forma de barra foram classificadas levando em consideração o número de camadas (uma, duas ou três camadas) e a configuração do ensaio de flexão (porcelana em tração ou infra-estrutura em tração). Essa classificação pode ser vista na tabela 4.4.

Tabela 4.4 - Classificação das estruturas em forma de barra com relação ao número de camadas (uma, duas ou três) e à configuração do ensaio de flexão (porcelana em tração ou infraestrutura em tração)

\begin{tabular}{|c|c|c|c|c|}
\hline \multirow{2}{*}{ Material } & \multirow{2}{*}{$\begin{array}{c}\text { Uma } \\
\text { camada }\end{array}$} & \multicolumn{2}{|c|}{$\begin{array}{c}\text { Duas camadas } \\
\end{array}$} & \multirow{2}{*}{$\begin{array}{c}\text { Três } \\
\text { camadas }\end{array}$} \\
\hline & & Porcelana em tração & Infra-estrutura em tração & \\
\hline $\mathbf{Y Z}$ & $\mathrm{YZ}$ & YZ-PT & YZ-IT & YZ-TRI \\
\hline IZ & IZ & IZ-PT & IZ-IT & IZ-TRI \\
\hline $\mathbf{A L}$ & $\mathrm{AL}$ & AL-PT & AL-IT & AL-TRI \\
\hline VM7 & VM7 & - & - & - \\
\hline VM9 & VM9 & - & - & - \\
\hline
\end{tabular}

\subsubsection{Estruturas em forma de PPF}

Foram construídos dois modelos de aço inoxidável simulando dentes com preparos protéticos, como pode ser observado na figura 4.10 . O preparo possui 4,5 $\mathrm{mm}$ de altura, angulação de $6^{\circ}$ e um término em chanfro de $120^{\circ}$, como proposto no estudo de Sundh et al. (2005) (Figura 4.10, parte C). A distância de $16 \mathrm{~mm}$ entre o centro dos dois pilares corresponde à distância entre um segundo pré-molar e um segundo molar inferior (span $=10 \mathrm{~mm}$ ) (Figura 4.10, parte A). Foi construído um bloco de resina acrílica (JET, Classico, São Paulo, SP, Brasil) para simular a gengiva que fica logo abaixo do pôntico da PPF (Figura 4.10, parte B). Antes de começar o 
escaneamento da peça, foi confeccionada uma infra-estrutura de resina acrílica para que se pudesse avaliar o eixo de inserção da PPF e verificar a presença de retenções ou defeitos no modelo de aço inox. O modelo foi considerado adequado.

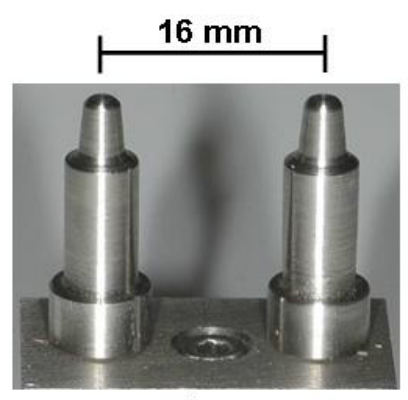

A

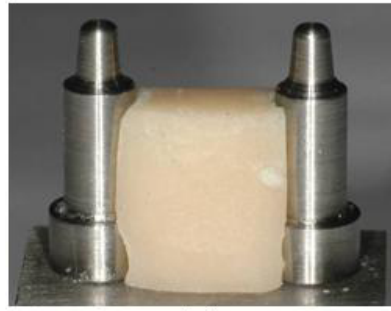

B

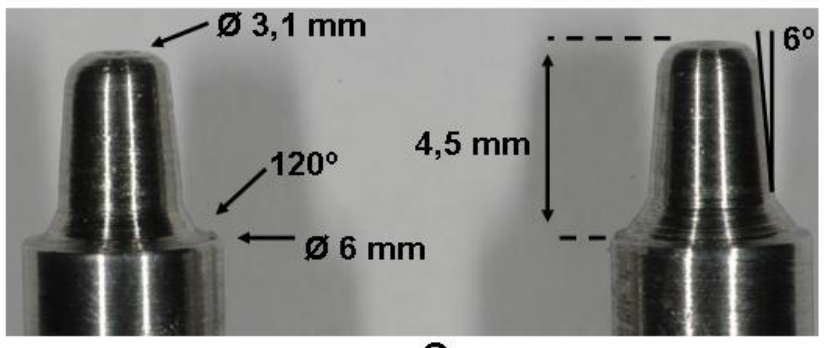

C

Figura 4.10 - A) Modelo em aço inox simulando dentes com preparos protéticos para receber coroas totalmente cerâmicas com término em chanfro como proposto por Sundh et al. (2005). B) Bloco de resina acrílica posicionado no modelo para simular a gengiva que fica abaixo do pôntico. C) Dimensões dos pilares protéticos: altura de 4,5 $\mathrm{mm}$, preparo com inclinação de $6^{\circ}$, término em chanfro de $120^{\circ}, 3,1 \mathrm{~mm}$ de diâmetro na área oclusal e $6 \mathrm{~mm}$ de diâmetro na área cervical

O modelo de aço inoxidável foi moldado com silicone de adição (Aquasil ${ }^{\mathrm{TM}}$ Soft Putty, pasta pesada, e Aquasil ${ }^{\mathrm{TM}}$ Low Viscosity, pasta leve, Dentsply, Petrópolis, RJ, Brasil) utilizando-se a técnica da dupla moldagem (Figura 4.11).

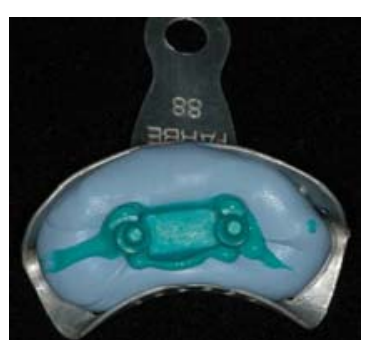

A

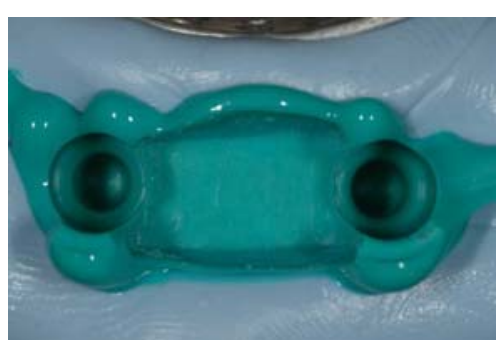

B

Figura 4.11 - Molde dos preparos obtido com silicone de adição. A) Vista geral. B) Detalhe 
O modelo de gesso (Figura 4.12) foi confeccionado utilizando-se um gesso tipo IV especial para CAD/CAM (CAM-base, Dentona AG, Dortmund, Alemanha). Esse gesso possui propriedades ópticas que oferecem contraste suficiente para 0 escaneamento a laser, dispensando a utilização de agentes de contraste sobre o modelo. O modelo de gesso foi recortado nas dimensões compatíveis com o suporte para escaneamento do CEREC inLab (Sirona Dental Systems, Charlote, NC, EUA).

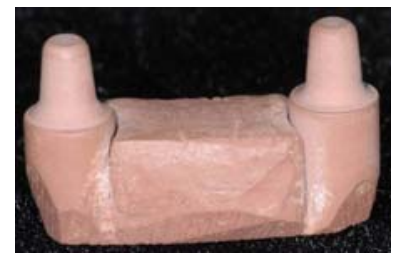

A

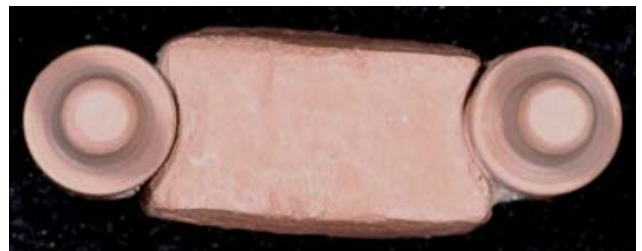

B

Figura 4.12 - Modelo de gesso especial reproduzindo os preparos feitos em aço inoxidável. A) Vista lateral. B) Vista oclusal

O modelo final foi preso com cera pegajosa a um suporte e levado ao equipamento CEREC inLab para o escaneamento dos preparos. Antes do escaneamento ser iniciado, foram determinados os dentes da arcada que receberiam a PPF utilizando o programa InLab 3D versão 2.90 (Sirona Dental Systems, Charlote, NC, EUA). Os elementos 35 e 37 foram selecionados como pilares e o elemento 36 como pôntico. Na técnica para confecção de PPFs, o modelo é escaneado por um feixe de laser em três ângulos diferentes: $+45^{\circ}, 0^{\circ}$ (vista oclusal), e $-45^{\circ}$. Com base nessas três imagens, o programa monta uma imagem tridimensional do modelo de gesso sobre a qual a infra-estrutura da PPF é construída (Figura 4.13).

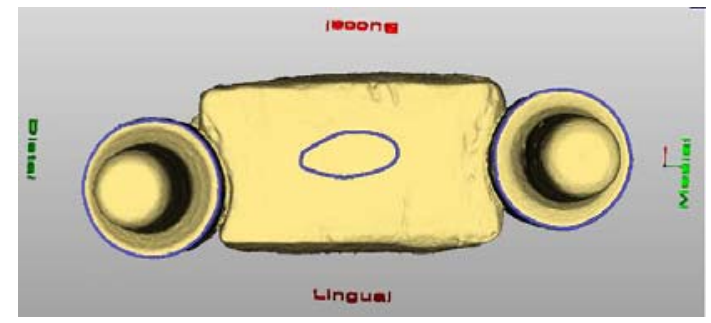

A

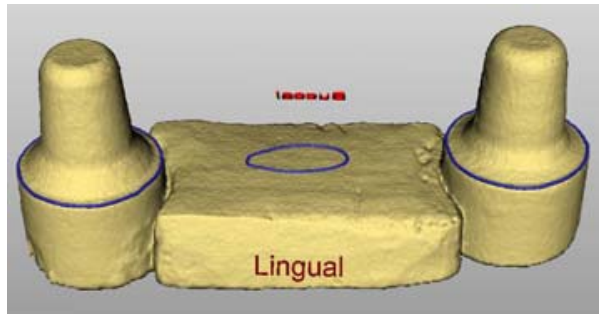

B

Figura 4.13 - Imagem tridimensional do modelo de gesso sobre a qual a PPF foi construída. Vista oclusal $(A)$ e vista lingual $(B)$ do modelo com os términos dos preparos e a base do pôntico delimitados (linhas azuis) 
O material de infra-estrutura foi selecionado e os términos dos pilares e da base do pôntico foram delimitados. Ao final, o programa cria o desenho da infraestrutura (Figura 4.14), seguindo os parâmetros específicos de cada sistema cerâmico.

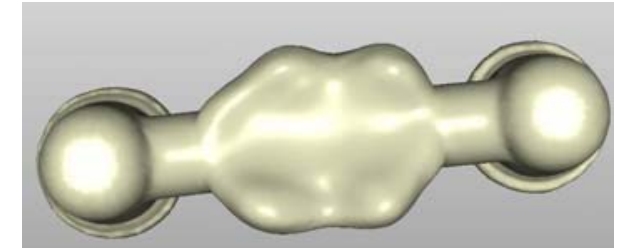

A

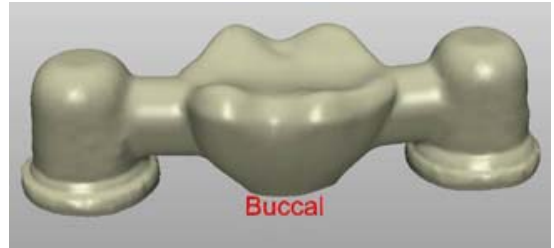

B

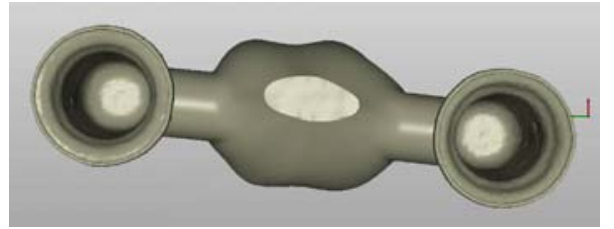

C

Figura 4.14 - Desenho final de uma PPF de YZ com conector de $9 \mathrm{~mm}^{2}$. A) Vista oclusal. B) Vista vestibular. C) Vista interna

O desenho final da infra-estrutura da PPF foi enviado para o CEREC inLab para que a usinagem do bloco de cerâmica pré-sinterizado fosse realizada. A figura 4.15 mostra um bloco de $Y Z$ dentro do CEREC inLab imediatamente antes da usinagem ser realizada (parte A) e logo após esse procedimento (partes B e C).

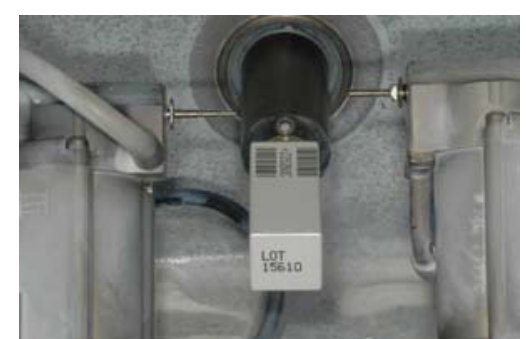

A

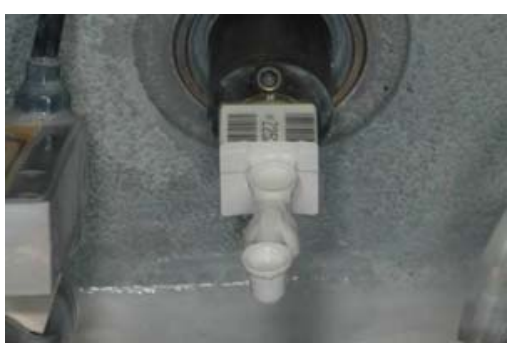

B

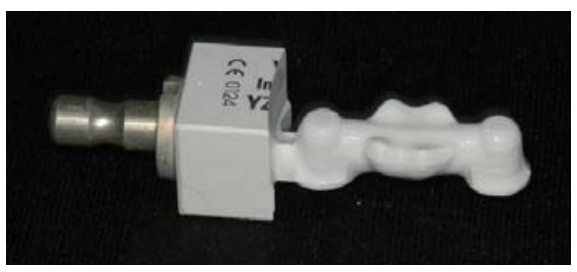

C

Figura 4.15 - A) Bloco de YZ posicionado no CEREC inLab. B) PPF logo após a usinagem. C) PPF usinada e antes de ser separada do bloco cerâmico 
A usinagem é realizada pela máquina com duas pontas diamantadas e sob intensa refrigeração. Após esse processo, as infra-estruturas foram destacadas do bloco com a ajuda de uma ponta diamantada montada em uma caneta de alta rotação com intensa refrigeração.

As infra-estruturas de $Y Z$ e $A L$ foram sinterizadas no forno Zyrcomat. As infra-estruturas de IZ foram infiltradas com vidro utilizando o forno Inceramat 3. A superfície externa das infra-estruturas de IZ foi jateada com óxido de alumínio para remover o excesso de vidro. Os passos de confecção de uma infra-estrutura de IZ estão representados na figura 4.16. A figura 4.17 apresenta as infra-estruturas com conector de $16 \mathrm{~mm}^{2}$ dos três sistemas cerâmicos estudados.

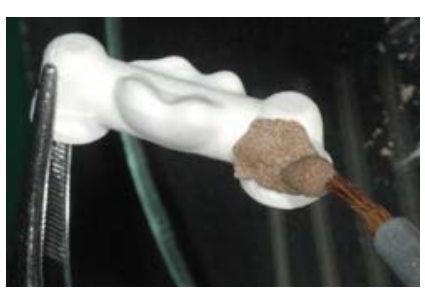

A

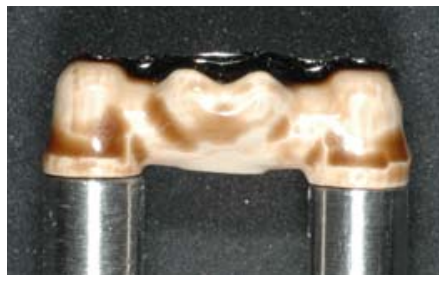

B

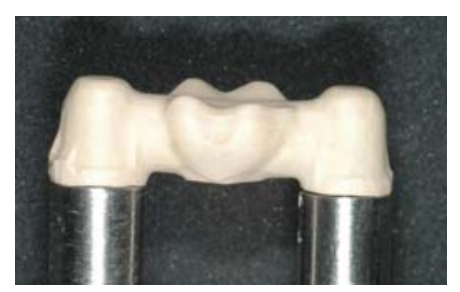

C

Figura 4.16 - Processo de infiltração do vidro nas PPFs de IZ. A) Aplicação da pasta de vidro com pincel. B) Vista lateral da PPF logo após ciclo de infiltração do vidro. C) PPF após remoção dos excessos de vidro

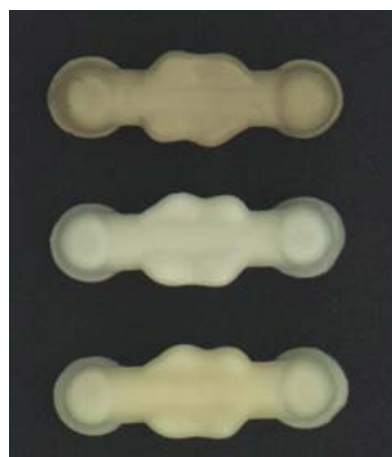

A

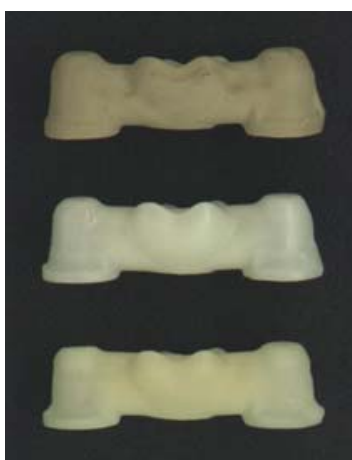

B

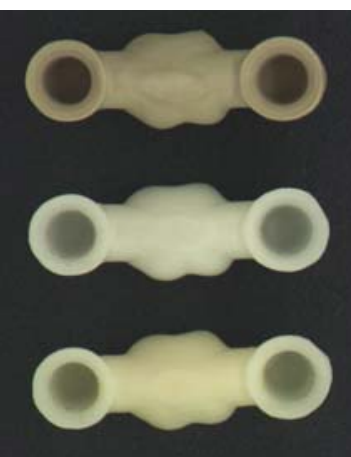

C

Figura 4.17 - Infra-estruturas com conector de $16 \mathrm{~mm}^{2}$ dos sistemas IZ (acima), YZ (centro) e AL (abaixo). A) Vista oclusal. B) Vista vestibular. C) Vista cervical

Depois que o processo de confecção das infra-estruturas das PPFs foi finalizado, iniciou-se o processo de aplicação da camada de porcelana. Foi utilizada a porcelana VM9 para as infra-estruturas de YZ e a VM7 para as infra-estruturas de $A L$ e de IZ. O pó da porcelana foi misturado com água destilada e a pasta resultante 
foi aplicada de forma uniforme com um pincel ao redor de toda a infra-estrutura. Em seguida, as PPFs foram levadas ao forno Keramat I para a realização do ciclo de sinterização da porcelana. Foram realizadas três aplicações de porcelana para obter a espessura desejada. Antes do recobrimento com porcelana, o agente de união (Effect Bonder, Vita) foi aplicado na superfície externa das infra-estruturas de YZ e sinterizado. Foi utilizada uma borracha de acabamento montada em motor elétrico para desgastar a porcelana até atingir uma espessura de, aproximadamente, 1,2 $\mathrm{mm}$ na região dos pilares e pôntico, e de, aproximadamente, 0,6 mm nos conectores. O controle da espessura foi realizado com um paquímetro em seis diferentes pontos como proposto na metodologia de Sundh et al. (2005) (Figura 4.18). Por último, as PPFs foram submetidas a um ciclo de glaze no forno Keramat I, seguindo as recomendações do fabricante (Tabela 4.3, página 59).

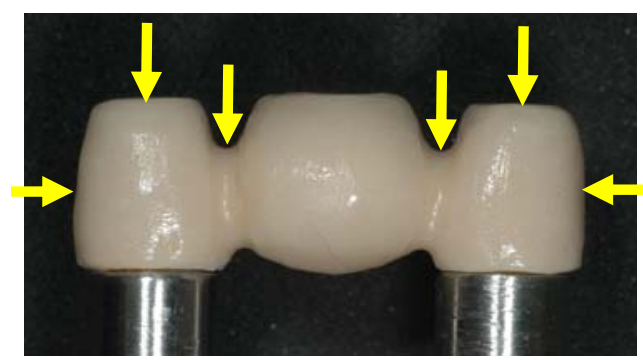

Figura 4.18 - Imagem de uma PPF mostrando os pontos de controle da espessura da camada de porcelana (flechas em amarelo)

O procedimento de limpeza das PPFs foi realizado por meio da imersão das peças em banho sônico com água destilada. As PPFs foram cimentadas sobre os pilares metálicos com cimento de fosfato de zinco (SS White, Rio de Janeiro, RJ, Brasil), seguindo as instruções do fabricante. Com o objetivo de garantir o adequado assentamento das peças sobre os preparos, uma carga de $15 \mathrm{~N}$ foi aplicada uniformemente sobre a superfície oclusal da PPF por 10 minutos, utilizando um dispositivo de cimentação.

Foram confeccionadas 20 PPFs de cada material com área de secção transversal dos conectores de $16,0 \mathrm{~mm}^{2}$. Essa dimensão de conector foi escolhida com base nas recomendações do fabricante para PPFs de IZ com uma distância entre pilares de 16,0 mm. Adicionalmente, somente para o material $Y Z$, foram construídas 10 PPFs com área de secção transversal dos conectores de $9,0 \mathrm{~mm}^{2}$. 
Este grupo foi adicionado ao trabalho para determinar o efeito da área de secção transversal do conector na carga de fratura das PPFs de YZ. A dimensão de 9,0 $\mathrm{mm}^{2}$ foi escolhida pois é a dimensão recomendada pelo fabricante para PPFs de $\mathrm{YZ}$ com uma distância entre os pilares de $16,0 \mathrm{~mm}$. Sendo assim, foram construídas 70 PPFs neste trabalho.

\subsection{MÉTODOS ANALÍTICOS PARA A CARACTERIZAÇÃO DOS MATERIAIS}

\subsubsection{Densidade}

Foi utilizado o princípio de Arquimedes para determinar a densidade aparente dos corpos-de-prova seguindo a ASTM B962 (2008). As massas dos corpos-de-prova secos e imersos em um béquer com água destilada foram medidas em uma balança analítica (H35AR, Mettler, Zurique, Suíça). Foram utilizados 10 corpos-de-prova monolíticos de cada material para determinar a densidade. A equação 4.1 foi utilizada para o cálculo da densidade $(\rho)$ :

$$
\rho=\frac{m_{\text {ar }}}{m_{\text {ar }}-m_{\text {água }}} \cdot \rho_{\text {água }}
$$

onde $m_{a r}$ e $m_{\text {água }}$ são as massas do corpo-de-prova medidas no ar e imerso em água, respectivamente, e págua é a densidade da água na temperatura em que as medidas foram realizadas (essa temperatura foi aferida com um termômetro).

\subsubsection{Constantes elásticas}

O módulo de elasticidade (E) e o coeficiente de Poisson (v) foram determinados pelo método do pulso-eco ultra-sônico (Della Bona et al., 2008; Rosa et al., 2009). Esse método se baseia na velocidade de propagação da onda no material. Para determinar as constantes elásticas é necessário obter o tempo de vôo 
do pulso e a espessura do corpo-de-prova. Um aparelho emissor-receptor de pulso ultra-sônico (pulser-receiver, 5900 PR, Panametrics, Waltham, MA, EUA) de 200 $\mathrm{MHz}$ foi utilizado com o auxílio de dois transdutores de onda, um longitudinal (V208RM, Panametrics, Waltham, MA, EUA) e outro transversal (V222-BB-RM, Panametrics, Waltham, MA, EUA), ambos de $20 \mathrm{MHz}$. Foi utilizado um acoplante (Couplant SWC, Panametrics) entre a amostra e o transdutor para realizar as medições e o tempo de vôo do pulso ultra-sônico foi determinado em um osciloscópio (TDS 1002, Tektronix, Beaverton, OR, EUA). A espessura dos corposde-prova $(n=10)$ foi medida com um micrômetro digital (156-101, Mitutoyo, Japão). As velocidades longitudinal e transversal do pulso ultra-sônico foram determinadas pelas equações 4.2 e 4.3 :

$$
\begin{gathered}
V_{T}=\frac{2 b}{t_{T}} \\
V_{L}=\frac{2 b}{t_{L}}
\end{gathered}
$$

Equação 4.2

Equação 4.3

onde $\mathrm{V}$ é a velocidade, b é a espessura da amostra e t é o tempo de vôo do pulso ultra-sônico. Os subscritos $T$ e $L$ referem-se às ondas transversal e longitudinal, respectivamente.

O módulo de elasticidade, E, e o coeficiente de Poisson, $v$, foram calculados seguindo as equações propostas na norma ASTM E 494-95 (2001) (Equações $4.4 \mathrm{e}$ 4.5):

$$
\begin{gathered}
E=\rho \cdot\left(\frac{3 \cdot V_{T}{ }^{2} \cdot V_{L}{ }^{2}-4 . V_{T}{ }^{4}}{V_{L}{ }^{2}-V_{T}{ }^{2}}\right) \\
v=0,5 \cdot \frac{V_{L}{ }^{2}-2 \cdot V_{T}{ }^{2}}{V_{L}{ }^{2}-V_{T}{ }^{2}}
\end{gathered}
$$

Equação 4.4

Equação 4.5

onde $\rho$ é a densidade.

\subsubsection{Análise microestrutural}

A superfície polida dos corpos-de-prova dos materiais $Y Z$ e AL foi submetida a um tratamento térmico para facilitar a análise microestrutural, pois evidencia os 
limites entre os cristais. $O$ tratamento foi realizado em um forno elétrico (FD44, Yamato) com uma temperatura de $1470^{\circ} \mathrm{C}$ durante 30 minutos. As porcelanas VM7 e VM9 também foram submetidas a um tratamento de superfície. Nesses casos, a superfície polida foi condicionada com ácido hidrofluorídrico a $2 \%$ por 15 segundos (Gonzaga, 2007). Os corpos-de-prova foram analisados no microscópio eletrônico de varredura (MEV) acoplado com um espectrômetro por dispersão de energia (EDS). A análise química (EDS) foi realizada com baixo aumento (300x), para análise de uma região geral dos materiais, e com maiores aumentos, para análise de cada fase presente nos materiais (Gonzaga, 2007).

Imagens da superfície dos corpos-de-prova foram obtidas no MEV. Um programa para tratamento de imagens (Photoshop 7.0, Adobe, USA) foi utilizado para delimitar manualmente os cristais e as fases. As imagens replicadas foram levadas a um programa analisador de imagem (Image J, EUA) para determinar o tamanho e a fração volumétrica dos cristais. Os valores de tamanhos de cristais utilizados neste trabalho equivalem ao diâmetro de Feret, ou seja, a maior distância entre dois pontos quaisquer ao longo do perímetro analisado (Kaye, 1998).

\subsection{ENSAIOS MECÂNICOS}

\subsubsection{Análise de Weibull e comportamento de crescimento subcrítico de trincas}

Os parâmetros de crescimento subcrítico de trincas foram determinados por meio do ensaio de fadiga dinâmica utilizando cinco taxas de tensão constantes: $10^{-2}$, $10^{-1}, 10^{0}, 10^{1}$ e $10^{2} \mathrm{MPa} / \mathrm{s}$. Dez corpos-de-prova de cada grupo foram testados para cada taxa de tensão (Pinto et al., 2008; Rosa et al., 2009). Com exceção da taxa de $1 \mathrm{MPa} / \mathrm{s}$, em que 30 barras foram ensaiadas para realizar a análise estatística de Weibull (Weibull, 1939; Ritter, 1995a). Os ensaios mecânicos foram realizados de acordo com a norma ISO 6872 (2008). A resistência a flexão em três pontos $\left(\sigma_{f}\right)$ foi determinada utilizando uma máquina de ensaios universal (Sintech 5G, MTS, São Paulo, Brasil) e um programa de controle de velocidade de carregamento para 
manter as taxas de tensão constantes (TestWorks 4 Advanced Rate Control Option, MTS). O dispositivo de flexão em três pontos pode ser observado na figura 4.19.

Durante os ensaios, o dispositivo de flexão foi colocado dentro de um recipiente e imerso em saliva artificial com sistema de aquecimento para manter a temperatura constante de $37^{\circ} \mathrm{C}$. A saliva artificial foi produzida com a seguinte composição (Ten Cate; Duijsters, 1982): $100 \mathrm{~mL}$ de $\mathrm{KH}_{2} \mathrm{PO}_{4}(2,5 \mathrm{mM}) ; 100 \mathrm{~mL}$ de $\mathrm{Na}_{2} \mathrm{HPO}_{4}(2,4 \mathrm{mM}) ; 100 \mathrm{~mL}$ de $\mathrm{KHCO}_{3}(1,50 \mathrm{mM}) ; 100 \mathrm{~mL}$ de $\mathrm{NaCl}(1,0 \mathrm{mM}) ; 100$ $\mathrm{mL}$ de $\mathrm{MgCl}_{2}(0,15 \mathrm{mM}) ; 100 \mathrm{~mL}$ de $\mathrm{CaCl}_{2}(1,5 \mathrm{mM}) ;$ e $6 \mathrm{~mL}$ de Ácido Cítrico $(0,002$ $\mathrm{mM})$.

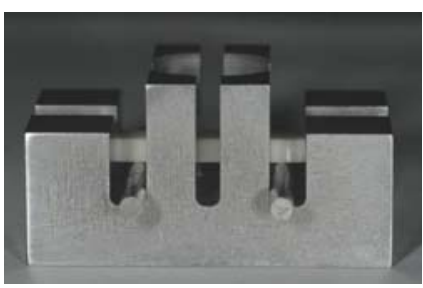

A

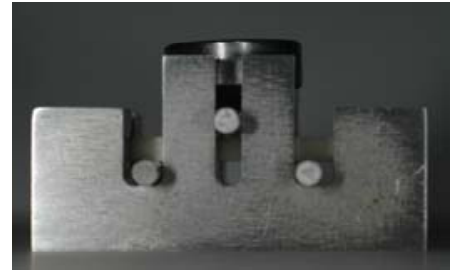

B

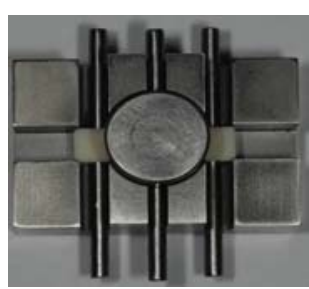

C

Figura 4.19 - Dispositivo para ensaio de resistência à flexão em três pontos. A) Vista lateral do corpo-de-prova posicionado sobre os dois suportes cilíndricos de apoio. Vista lateral (B) e superior (C) do corpo-de-prova dentro do dispositivo pronto para o ensaio

Os valores de resistência a flexão $\left(\sigma_{f}\right)$ para as barras monolíticas foram determinados de acordo com a equação 4.6.

$$
\sigma_{f}=\frac{3 P l}{2 w b^{2}}
$$

onde $\mathrm{P}$ é a carga de fratura $(\mathrm{N})$, I é a distância entre os apoios (12 mm), w é a largura do corpo-de-prova ( $\mathrm{mm})$, e b é a sua espessura $(\mathrm{mm})$.

Segundo a ASTM C 1368 (2001), uma pré-carga de até $80 \%$ da carga de fratura não tem muita influência nos resultados do ensaio de fadiga dinâmica, pois o crescimento significativo da trinca só ocorre em cargas próximas à da fratura. Com base nessa norma, optou-se por utilizar uma pré-carga de aproximadamente $50 \%$ do valor de carga de fratura dos corpos-de-prova durante os ensaios com a taxa de carregamento de $0,01 \mathrm{MPa} / \mathrm{s}$. Esse procedimento foi realizado com o objetivo de diminuir o tempo dos ensaios. O valor de pré-carga foi calculado baseando-se em uma análise de regressão feita a partir dos resultados obtidos nas outras taxas de carregamento (Gonzaga, 2007). 
Os parâmetros $n$ (coeficiente de crescimento subcrítico) e $\sigma_{\text {fo }}$ (parâmetro escalar) e desvio padrão foram calculados de acordo com as equações apresentadas na ASTM C 1368 (2001b), onde $\sigma$ é a taxa de tensão (MPa/s) (Equação 4.7):

$$
\log \sigma_{f}=\left(\frac{1}{n+1}\right) \log \sigma \cdot \log \sigma_{f 0}
$$

As curvas de tempo de vida (life-time curves) dos materiais foram construídas de acordo com a correlação entre o logaritmo da tensão de fratura e o logaritmo do tempo até a fratura dos corpos-de-prova ensaiados no teste de fadiga dinâmica (Fairhurst et al., 1993; Gonzaga, 2007).

O módulo de Weibull $(\mathrm{m})$ e a resistência característica $\left(\sigma_{0}\right)$ foram determinados analisando os dados de resistência à fratura para a taxa de tensão de $1 \mathrm{MPa} / \mathrm{s}$ de acordo com a distribuição de Weibull de dois parâmetros (Equação 4.8):

$$
P_{f}=1-\exp \left[-\left(\frac{\sigma_{f}}{\sigma_{0}}\right)^{m}\right]
$$

onde $P_{f}$ é a probabilidade de fratura.

A probabilidade de fratura em função da tensão de fratura $\left(P_{f((\sigma i)}\right)$ foi calculada de acordo com a equação 4.9:

$$
P_{f(\sigma i)}=\frac{(i-0,5)}{N}
$$

onde $\mathrm{N}$ é o número de corpos-de-prova ensaiados e i é o número de ordem da tensão de fratura (classificada em ordem crescente).

A análise de Weibull foi realizada com auxílio do programa de estatística Weibull++ (Reliasoft, Tucson, EUA). Os parâmetros $m$ e $\sigma_{0}$ foram estimados pelo método de probabilidade máxima (maximum likelihood). O limite superior e inferior dos intervalos de confiança de $95 \%$ de $\mathrm{m}$ e $\sigma_{0}$ foram calculados com o método da razão de verossimilhança (likelihood ratio).

Com base nos resultados obtidos através do ensaio de fadiga dinâmica e da análise estatística de Weibull, foram construídos diagramas tensão-probabilidadetempo (SPT- stress-probability-time) para os cinco materiais cerâmicos (Gonzaga, 2007). 


\subsubsection{Resistência à flexão em função da configuração do corpo-de-prova}

Os ensaios de resistência à flexão em três pontos dos corpos-de-prova de duas e três camadas foram realizado a $1 \mathrm{MPa} / \mathrm{s}$ como descrito para os corpos-deprova monolíticos. Para cada combinação de material (YZNMM9, IZ/VM7 e AL/VM7) três condições experimentais foram testadas $(n=10)$ :

a) Barra com duas camadas, com porcelana voltada para o lado de tração.

b) Barra com duas camadas, com cerâmica de infra-estrutura voltada para o lado de tração.

c) Barra com três camadas (porcelana - infra-estrutura - porcelana).

Para os corpos-de-prova de duas camadas, os valores de resistência $\left(\sigma_{f}\right)$ foram calculados de acordo com a equação 4.10 (Young; Budynas, 2002; Della Bona et al., 2003):

$$
\sigma_{f}=\frac{6 M}{w t_{t}^{2} K}\left(2+\frac{t_{c}}{t_{t}}+\frac{E_{t} t_{t}}{E_{c} t_{c}}\right)
$$

Equação 4.10

onde $\mathrm{M}$ e K são dados pelas equações 4.11 e 4.12 :

$$
\begin{array}{cc}
M=\frac{P L}{4} & \text { Equação 4.11 } \\
K=4+6 \frac{t_{c}}{t_{t}}+4\left(\frac{t_{c}}{t_{t}}\right)^{2}+\frac{E_{c}}{E_{t}}\left(\frac{t_{c}}{t_{t}}\right)^{3}+\frac{E_{t} t_{t}}{E_{c} t_{c}} & \text { Equação 4.12 }
\end{array}
$$

Substituindo-se $\mathrm{M}$ e $\mathrm{K}$ na equação 4.10 é obtida a seguinte equação final para o cálculo da resistência de corpos-de-prova de duas camadas (Equação 4.13):

$$
\sigma_{f}=\frac{3 E_{t} L P\left(E_{c} t_{c}{ }^{2}+2 E_{c} t_{c} t_{t}+E_{t} t_{t}{ }^{2}\right)}{2 w\left(E_{c}{ }^{2} t_{c}{ }^{4}+4 E_{c} E_{t} t_{c}{ }^{3} t_{t}+6 E_{c} E_{t} t_{c}{ }^{2} t_{t}{ }^{2}+4 E_{c} E_{t} t_{c} t_{t}^{3}+E_{t}{ }^{2} t_{t}^{4}\right)} \quad \text { Equação } 4.13
$$

onde, $P$ é a carga $(N), L$ é a distância entre os apoios inferiores (12 mm), $E_{t}$ é o módulo de elasticidade do material solicitado em tração (GPa), $t_{t}$ é a espessura do material solicitado em tração $(\mathrm{mm}), E_{c}$ é o módulo de elasticidade do material em compressão (GPa), $t_{c}$ é a espessura do material em compressão (mm) e w é largura do corpo-de-prova $(\mathrm{mm})$. As espessuras dos materiais em tração e compressão foram medidas em microscópio óptico. 
Para os corpos-de-prova de três camadas, os valores de resistência $\left(\sigma_{f}\right)$ foram calculados utilizando-se a equação 4.14 (Young; Budynas, 2002; Della Bona et al., 2003).

$$
\sigma_{f}=\frac{M Y}{I}
$$

onde $\mathrm{M}$ é o momento de força, $\mathrm{Y}$ é a distância a partir do eixo neutro até a fibra mais externa da estrutura e I é o momento de inércia da secção transversal que passa pelo centróide. Essas variáveis são substituídas pelas equações 4.15, 4.16, 4.17:

$$
\begin{aligned}
& M=\frac{P L}{4} \\
& Y=\frac{\left[\left(\frac{t_{t}^{2}}{2}\right)+\frac{E_{f}}{E_{t}}\left[\left(\frac{t_{f}{ }^{2}}{2}\right)+t_{t} t_{f}\right]+\frac{E_{c}}{E_{t}}\left[\left(\frac{t_{c}^{2}}{2}\right)+t_{c} t_{f}+t_{c} t_{t}\right]\right]}{\left[t_{t}+\left(\frac{E_{f}}{E_{t}}\right) t_{f}+\left(\frac{E_{c}}{E_{t}}\right) t_{c}\right]} \\
& I=\left\{\left[\left(\frac{1}{12}\right)\left(\frac{E_{c}}{E_{t}}\right) w t_{c}^{3}\right]+\left[\left(\frac{E_{c}}{E_{t}}\right) w t_{c}\left[t_{t}+t_{f}+\left(\frac{t_{c}}{2}\right)-Y\right]^{2}\right]+\left[\left(\frac{1}{12}\right)\left(\frac{E_{f}}{E_{t}}\right) w t_{f}^{3}\right]+\right. \\
& \left.\left[\left(\frac{E_{f}}{E_{t}}\right) w t_{f}\left[t_{t}+\left(\frac{t_{f}}{2}\right)-Y\right]^{2}\right]+\left[\left(\frac{1}{12}\right) w t_{t}^{3}\right]+\left[w t_{t}\left[\left(\frac{t_{t}}{2}\right)-Y\right]^{2}\right]\right\}
\end{aligned}
$$

\subsubsection{Carga de fratura das PPFs em função da ciclagem mecânica e da área de seção transversal do conector.}

A carga de fratura das PPFs com conector de $16 \mathrm{~mm}^{2}$ foi determinada em duas condições: 
a) controle (sem ciclagem) $(n=10)$;

b) após envelhecimento com ciclagem mecânica $(n=8)$.

As PPFs submetidas à ciclagem mecânica foram envelhecidas em um simulador de ciclos mastigatórios. O simulador utilizado é composto por 10 cilindros pneumáticos alinhados e montados sobre um chassi de aço e ligados a uma rede de ar (Figura 4.20, parte A). A pressão do ar, a velocidade de impulsão dos cilindros e sua freqüência são controladas por uma caixa de comando, que ao acionar o sistema, move os pistões localizados na parte interna desses cilindros, comprimindo os corpos-de-prova com força controlada. A força é dependente da pressão utilizada. O envelhecimento mecânico foi realizado com uma freqüência de $2 \mathrm{~Hz}$, carga de $140 \mathrm{~N}$ por $10^{6}$ ciclos em água destilada a $37^{\circ} \mathrm{C}$. A carga foi aplicada no centro do pôntico com uma esfera de aço de $6 \mathrm{~mm}$ de diâmetro, como pode ser observado na figura 4.20 , parte $B$.

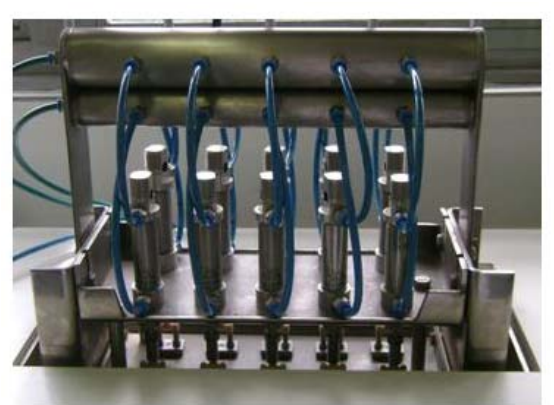

A

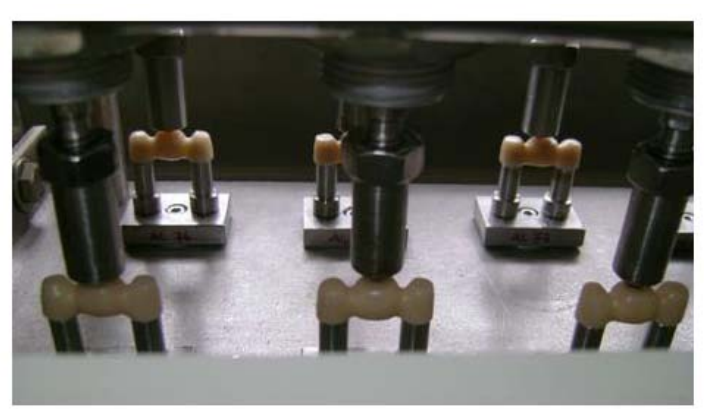

B

Figura 4.20 - Vista geral da máquina de ciclagem. B) PPFs posicionadas sob os pistões esféricos

Os ensaios de carga de fratura foram realizados em uma máquina de ensaios universal (Sintech 5G, MTS, São Paulo, Brasil) com a carga sendo aplicada no centro do pôntico por meio da mesma esfera de aço e velocidade de 0,5 $\mathrm{mm} / \mathrm{min}$ até a fratura (Figura 4.21). As PPFs foram testadas em água destilada a $37^{\circ} \mathrm{C}$.

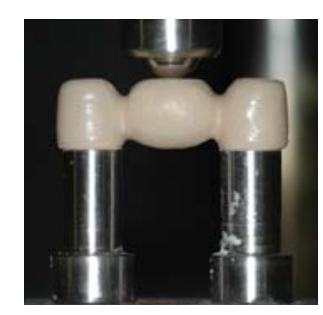

Figura 4.21 - PPF pronta para ensaio de carga de fratura 
As 10 PPFs de $Y Z$ com conector de $9,0 \mathrm{~mm}^{2}$ foram testadas até a fratura sem passar pelo processo de ciclagem mecânica.

As PPFs foram classificadas levando em consideração o tamanho de conector ( $9 \mathrm{~mm}^{2}$ ou $\left.16 \mathrm{~mm}^{2}\right)$ e a condição experimental (com ou sem ciclagem). A classificação se encontra na tabela 4.5.

Tabela 4.5 - Classificação das PPFs com relação ao tamanho de conector $\left(9 \mathrm{~mm}^{2}\right.$ ou $\left.16 \mathrm{~mm}^{2}\right)$ e a condição experimental (com ou sem ciclagem)

\begin{tabular}{ccccc}
\hline \multirow{2}{*}{ Conector } & $\begin{array}{l}\text { Ciclagem } \\
\text { mecânica }\end{array}$ & \multicolumn{3}{c}{ Material de infra-estrutura } \\
\cline { 2 - 5 } & - & $\mathrm{YZ}$ & $\mathrm{IZ}$ & $\mathrm{AL}$ \\
\hline $\mathbf{9} \mathbf{m m}^{2}$ & $\mathrm{Sem}$ & $\mathrm{YZ9}$ & - & - \\
\hline \multirow{2}{*}{$16 \mathbf{m m}^{2}$} & $\mathrm{YZ16}$ & $\mathrm{IZ16}$ & $\mathrm{AL} 16$ \\
\cline { 2 - 5 } & Com & $\mathrm{YZ16-CM}$ & $\mathrm{IZ16}-\mathrm{CM}$ & $\mathrm{AL} 16-\mathrm{CM}$ \\
\hline
\end{tabular}

\subsection{ANÁLISE FRACTOGRÁFICA}

O preparo dos corpos-de-prova para análise fractográfica começou com a limpeza da superfície de fratura. Os corpos-de-prova foram levados ao ultra-som por 15 minutos em uma solução de água e sabão e por mais 15 minutos em etanol. Análise qualitativa e quantitativa da superfície de fratura dos corpos-de-prova foi realizada seguindo os princípios da fractografia descritos anteriormente (Mecholsky, 1995b; American Society for Testing and Materials, 2003; Quinn, 2007).

\subsubsection{Estruturas em forma de barra}

A superfície de fratura de todos os corpos-de-prova foi analisada a olho nu e posteriormente no estereomicroscópio (Olympus SZ61, Olympus, Japão). Foram observadas marcas características da superfície para determinar a origem de fratura. A identificação da origem da fratura foi confirmada analisando-se a superfície de fratura da outra metade da barra. Foi utilizada fonte de luz externa direcionada lateralmente ao corpo-de-prova para facilitar a visualização dos relevos de 
superfície. Uma amostragem de cada grupo $(n=5)$ foi analisada no MEV (Stereoscan 440, LEO Electron Microscopy Ltd, Cambridge, Inglaterra). Foram obtidas imagens da superfície de fratura e o tamanho do defeito crítico (c) foi mensurado utilizando o programa Image J. A tenacidade à fratura $\left(\mathrm{K}_{\mathrm{IC}}\right)$ dos materiais cerâmicos foi estimada utilizando os valores de $\mathrm{c}$ e os valores de resistência à flexão $\left(\sigma_{f}\right)$ das estruturas monolíticas através da aplicação dos princípios da mecânica da fratura. A equação 2.1 (página 50) foi utilizada para esse cálculo.

\subsubsection{Estruturas em forma de PPFs}

Primeiramente foi analisado a olho nu o padrão macroscópico de fratura das PPFs. A PPF fraturada foi removida dos pilares metálicos e levada ao estereomicroscópio (Leica MZ 125, Leica Microsystems, Alemanha) para investigar a origem de fratura. Todas as PPFs foram analisadas em MEV para observar com maior precisão as características da superfície de fratura. $O$ valor de c foi obtido utilizando imagens de MEV e o programa Image J. Os valores de tenacidade à fratura dos materiais $\left(\mathrm{K}_{\mathrm{IC}}\right)$ e os valores de $\mathrm{c}$ das PPFs foram utilizados para estimar a tensão de fratura $(\sigma)$ das PPFs (Equação 2.1, página 50 ).

\subsection{ANÁLISE DE ELEMENTOS FINITOS (AEF)}

Os modelos dos preparos protéticos e as PPFs com conector de $9 \mathrm{~mm}^{2}$ e 16 $\mathrm{mm}^{2}$ foram escaneadas utilizando o equipamento do micro-tomografia computadorizada SkyScan 1172 (Skyscan, Aartselaar, Bélgica). Os parâmetros de escaneamento utilizados foram: voltagem de $100 \mathrm{kV}$, corrente de $100 \mu \mathrm{A}$, tempo de exposição de 2950 ms por quadro de imagem, filtro de $\mathrm{Al}+\mathrm{Cu}$, e tamanho de pixel de $17 \mu \mathrm{m}$. As imagens obtidas foram convertidas em arquivo do tipo bmp utilizando o programa NRecon (Skyscan, Aartselaar, Bélgica). 
Cortes tomográficos das estruturas foram gerados a cada $34 \mu \mathrm{m} e$ processados utilizando um programa de controle de imagens (Mimics 13.0, Materialise, Bélgica). Os objetos tridimensionais foram criados a partir de diferentes máscaras obtidas através da manipulação dos valores de cinza (Figura 4.22).

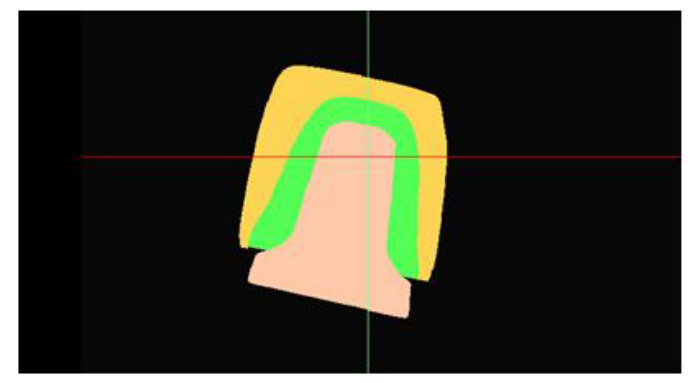

A

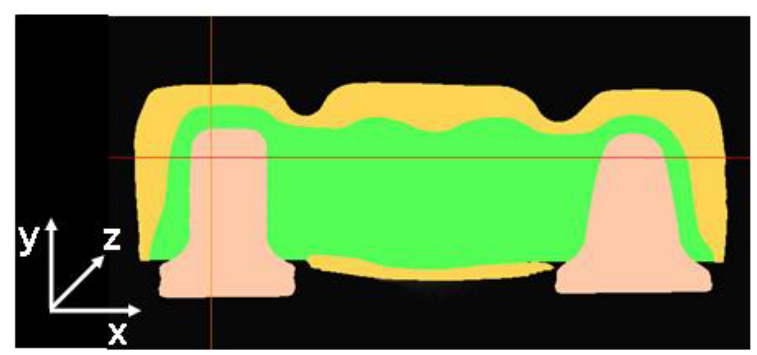

C

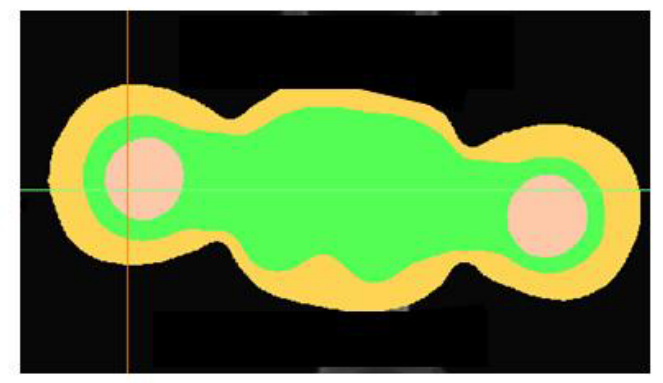

B

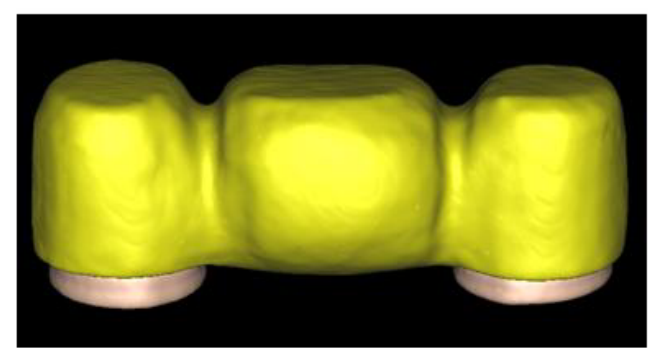

D

Figura 4.22 - Máscaras construídas a partir de cortes tomográficos. A) Vista sagital. B) Vista coronal. C) Vista axial. D) Modelo tridimensional da PPF. As máscaras de cores rosa, verde e amarelo correspondem aos pilares, infra-estrutura e camada de porcelana, respectivamente

Os objetos foram transferidos em pares para o programa Mimics Remesh. Nessa fase, as partes foram acopladas utilizando a ferramenta non-manifold assembly e recalculadas (remesh) como um objeto único. Esse procedimento garante a compatibilidade entre as superfícies e nós coincidentes entre as diferentes partes. Foi utilizado um valor de erro geométrico de 0,05 no procedimento de remesh. Foram gerados diferentes níveis de refinamento das malhas através do controle do tamanho dos elementos. O objeto foi separado em suas partes originais após o procedimento de remesh e foram geradas malhas volumétricas. Essas malhas foram importadas para o programa de análise de elementos finitos (ABACUS V6.8, Simulia, US). Foram construídos quatro modelos com diferentes níveis de refinamento para realizar o teste de convergência de malha. Foi selecionado o 
modelo com melhor combinação de precisão e custo computacional (Holmes et al., 1997).

O modelo final foi composto por elementos tetraédricos e por três camadas, seguindo a mesma configuração do teste in vitro: (1) pilares metálicos, (2) infraestrutura de cerâmica e (3) camada de porcelana (Figura 4.23).

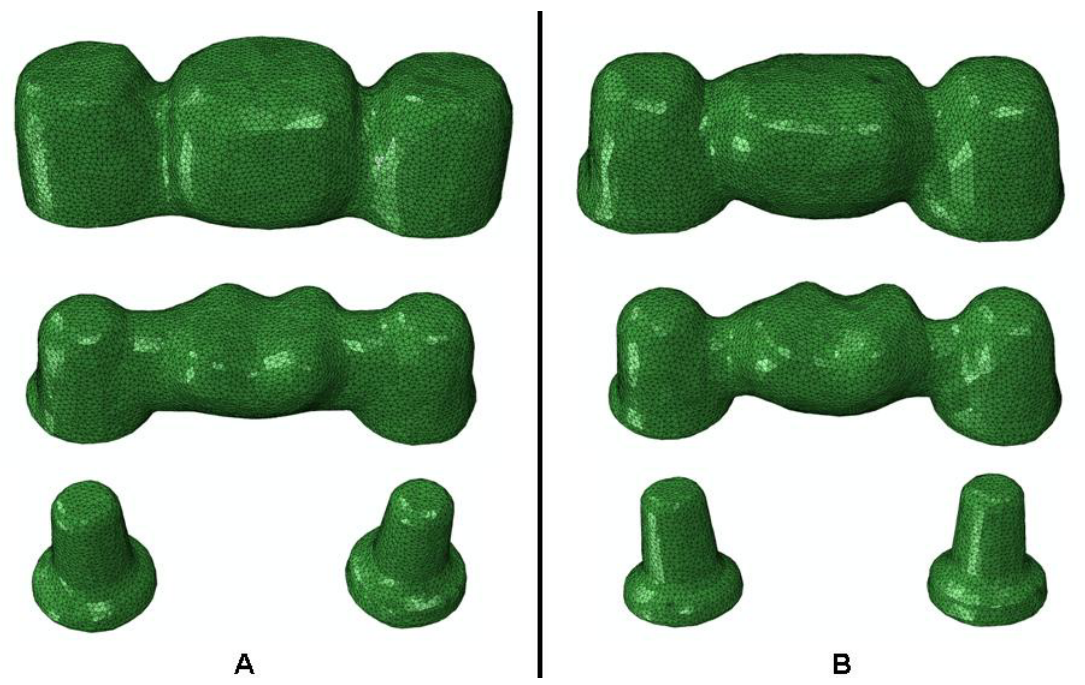

Figura 4.23 - Camadas do modelo final das PPFs com conector de $16 \mathrm{~mm}^{2}$ (A) e de $9 \mathrm{~mm}^{2}$ (B): pilares (abaixo), infra-estrutura (centro) e camada de porcelana (acima)

Foram criadas duas interfaces, entre os pilares e a infra-estrutura e entre a infra-estrutura e a camada de porcelana (Figura 4.24). A interface entre as malhas foi considerada perfeita.

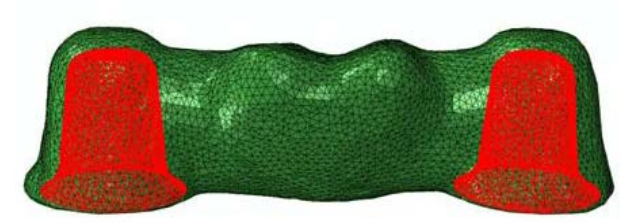

A

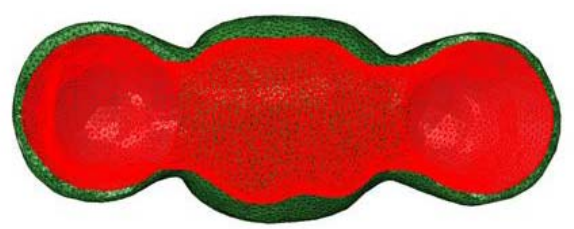

B

Figura 4.24 - A) Interface entre os pilares e a infra-estrutura. B) Interface entre a infra-estrutura e a camada de porcelana

A base da superfície inferior dos pilares foi fixada em todas as direções do espaço, não sendo permitido movimento de rotação ou translação. Foi realizado um carregamento de compressão, perpendicular ao longo eixo da restauração, no 
centro da superfície oclusal do pôntico. Foi utilizada uma carga de 200 N, distribuída em 20 nós localizados em uma área circular de $3 \mathrm{~mm}$ de diâmetro. Essa condição de carregamento simula o ensaio de carga de fratura na qual as PPFs foram submetidas in vitro. As condições de fixação e carregamento estão representadas na figura 4.25 .

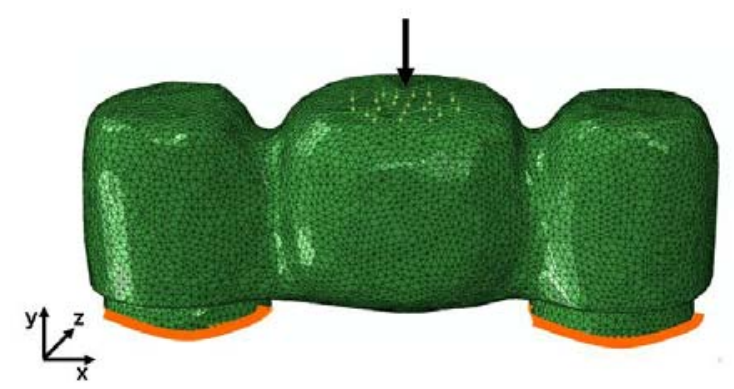

Figura 4.25 - Imagem de uma PPF com conector de $16 \mathrm{~mm}^{2}$ representando as condições de fixação e carregamento. A flecha indica a região e direção de carregamento e as faixas em laranja representam as regiões de fixação

Os valores de módulo de elasticidade $(E)$ e coeficiente de Poisson ( $v$ ) utilizados na simulação estão descritos na tabela 4.6. As propriedades elásticas dos materiais de infra-estrutura e recobrimento foram baseadas em dados obtidos nesse trabalho e concordam com os dados reportados pelo fabricante. As propriedades do pilar (aço inoxidável) foram obtidas da literatura (Rekow et al., 2006). Os materiais foram considerados isotrópicos, homogêneos e com comportamento elástico linear.

Tabela 4.6 - Valores de módulo de elasticidade (E) e coeficiente de Poisson (v) utilizados na AEF

\begin{tabular}{ccccccc}
\hline & \multicolumn{7}{c}{ Materiais } \\
\cline { 2 - 7 } & $\mathbf{Y Z}$ & $\mathbf{I Z}$ & $\mathbf{A L}$ & $\mathbf{V M 7}$ & $\mathbf{V M 9}$ & Aço Inoxidável \\
\hline $\mathbf{E}$ (GPa) & 209 & 247 & 390 & 67 & 67 & 190 \\
\hline $\boldsymbol{V}$ & 0,32 & 0,26 & 0,24 & 0,23 & 0,21 & 0,27 \\
\hline
\end{tabular}

A análise dos resultados foi feita com base no local e nos valores de tensão máxima principal. A infra-estrutura e a camada de porcelana foram analisadas separadamente para facilitar a comparação entre os grupos experimentais. 


\subsection{ANÁLISE ESTATÍSTICA}

Os resultados das propriedades mecânicas das estruturas em forma de barra e das PPFs foram analisados com o teste estatístico de Kruskal-Wallis (teste não paramétrico). Foi utilizado o teste de Tukey com um nível de significância de 5\% para comparação entre os grupos. Apenas quando o valor de $\mathrm{n}$ foi diferente entre os grupos experimentais a comparação entre os dados foi realizada com outro teste estatístico, o método de Dunn. A análise estatística não paramétrica foi utilizada porque os dados não passaram nos testes de normalidade e homocedasticidade. $\mathrm{Na}$ análise não paramétrica, a comparação entre os grupos é realizada com o valor da mediana.

Foi utilizada análise de variância e teste de Tukey para os resultados de densidade $(\rho)$, módulo de elasticidade $(E)$, coeficiente de Poisson $(v)$, tenacidade à fratura $\left(\mathrm{K}_{\mathrm{IC}}\right)$ e tamanho de defeito crítico (c).

As análises paramétricas e não-paramétricas foram realizadas com o auxílio do programa estatístico SigmaStat (Aspire Software International, Ashburn, VA, EUA). 


\section{RESULTADOS}

\subsection{CARACTERIZAÇÃO E ANÁLISE MICROESTRUTURAL}

\subsubsection{Microestrutura dos materiais de infra-estrutura}

A figura 5.1 apresenta a microestrutura dos materiais $\mathrm{YZ}$ e AL. A análise de espectroscopia por dispersão de energia (EDS) identificou apenas os elementos $\mathrm{O}$ e Zr para a cerâmica $Y Z$ e os elementos $\mathrm{O}$ e Al para a cerâmica AL. Por meio da análise em microscópio eletrônico de varredura (MEV) foi possível observar que a cerâmica YZ é constituída por cristais de zircônia com tamanho médio de 0,7 $\mu \mathrm{m}$ (Figura 5.1, parte A e Tabela 5.1). O material AL é constituído por cristais de alumina com um tamanho médio de 2,3 $\mu$ m (Figura 5.1, parte B e Tabela 5.1). Na figura 5.1 também é possível notar que o condicionamento térmico das cerâmicas $\mathrm{YZ}$ e $\mathrm{AL}$ revelou os contornos dos cristais de zircônia e alumina.

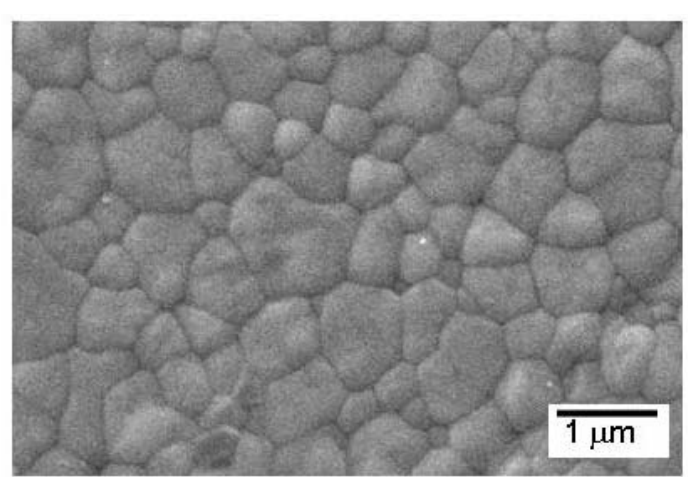

A

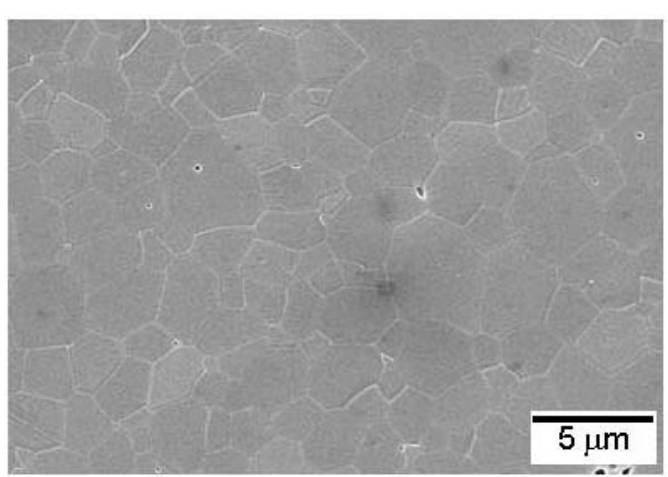

B

Figura 5.1 - Imagens de MEV das superfícies dos materiais de infra-estrutura. A) YZ. B) AL 
Tabela 5.1 - Tipo, fração volumétrica $(\%)$ e tamanho médio $(\mu \mathrm{m})$ de cristal das cerâmicas estudadas. Valores apresentados pela média \pm desvio-padrão

\begin{tabular}{|c|c|c|c|c|c|}
\hline & & & eriais & & \\
\hline & YZ & IZ & $A L$ & VM7 & VM9 \\
\hline Cristal & zircônia & alumina e zircônia & alumina & - & leucita \\
\hline $\begin{array}{l}\text { Fração de } \\
\text { volume (\%) }\end{array}$ & - & $\begin{array}{l}\text { alumina: } 46,0 \pm 3,3 \\
\text { zircônia:20,2 } 22,1\end{array}$ & - & - & $4,6 \pm 1,9$ \\
\hline $\begin{array}{c}\text { Tamanho } \\
\text { médio }(\mu \mathrm{m})\end{array}$ & $0,7 \pm 0,1$ & $\begin{array}{l}\text { alumina:2,5 } 2 \pm 0,3 \\
\text { zircônia: } 1,3 \pm 0,6\end{array}$ & $2,3 \pm 0,1$ & - & $1,4 \pm 0,2$ \\
\hline
\end{tabular}

O compósito IZ é constituído por dois tipos de cristais (alumina e zircônia) e uma fase amorfa (vidro a base de óxido de lantânio). Por isso foram obtidos três espectros de EDS para a IZ, correspondendo aos cristais de alumina, cristais de zircônia e a fase vítrea. Para os cristais de alumina foram encontrados os mesmos elementos observados no material $A L(O$ e $\mathrm{Al}$ ). Nos cristais de zircônia foram identificados os elementos $\mathrm{Zr}$, O e Ce, já que nesse material a zircônia é estabilizada por óxido de cério (Della Bona et al., 2007). Na fase vítrea, amorfa, foram identificados os elementos $\mathrm{C}, \mathrm{O}, \mathrm{La}, \mathrm{Al}, \mathrm{Si}$ e $\mathrm{Ca}$. Na imagem da figura 5.2 pode-se observar que essa cerâmica é constituída por cristais de alumina (partículas escuras) com tamanho médio de 2,5 $\mu \mathrm{m}$ e cristais de zircônia (partículas claras) com tamanho um pouco menor, ao redor de 1,3 $\mu \mathrm{m}$, dispersos em uma matriz vítrea a base de óxido de lantânio (matriz cinza) (Tabela 5.1). Não foi necessário nenhum tipo de condicionamento para evidenciar as fases da IZ na análise de MEV. As frações volumétricas de alumina e zircônia encontradas nesse material foram de $46,0 \%$ e $20,2 \%$, respectivamente (Tabela 5.1 ).

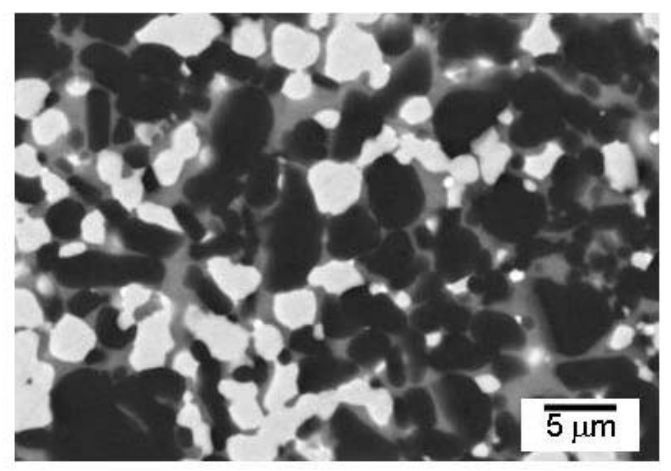

Figura 5.2 - Imagem de MEV da superfície do material IZ: as partículas mais claras correspondem aos cristais de zircônia, as partículas escuras aos cristais de alumina e a matriz cinza corresponde ao vidro de silicato de lantânio 


\subsubsection{Microestrutura dos materiais de recobrimento (porcelanas)}

A microestrutura das porcelanas VM7 e VM9 pode ser vista na figura 5.3. A porcelana VM7 não apresenta partículas de segunda fase, apenas uma fase vítrea, amorfa. O condicionamento ácido revelou regiões com diferenças de relevo que podem corresponder a vidros com diferentes composições (Figura 5.3, parte A). A porcelana VM9 mostrou uma matriz vítrea com partículas de leucita. Na figura 5.3, parte $B$, pode-se observar partículas de leucita com tamanho médio de 1,4 $\mu \mathrm{m}$ (Tabela 5.1) distribuídas em uma matriz vítrea, formando aglomerados que apresentaram algumas trincas ao seu redor. A fração volumétrica de leucita encontrada na VM9 foi de 4,6\% (Tabela 5.1). A análise de EDS identificou os mesmos elementos no vidro das duas porcelanas (VM7 e VM9). As partículas de leucita (VM9) mostraram os seguintes elementos: Si, Al, K, Na, Ca e O.

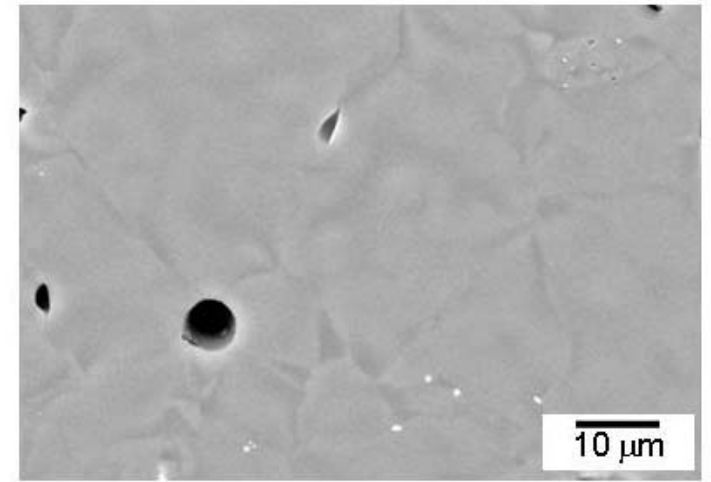

A

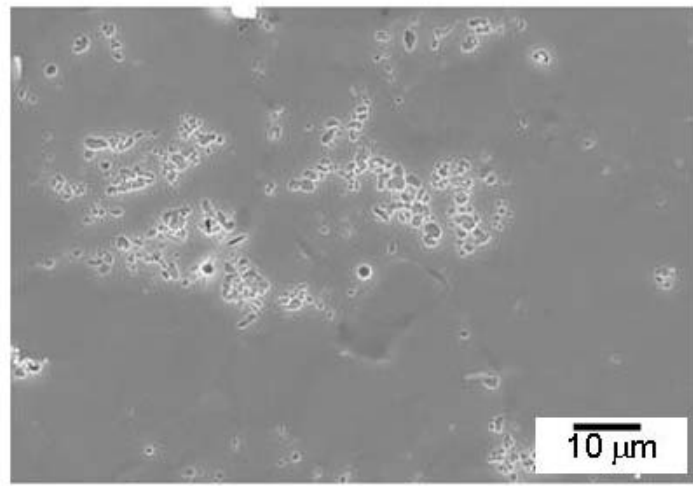

B

Figura 5.3 - Imagens de MEV das superfícies dos materiais de recobrimento. A) Porcelana VM7. B) Porcelana VM9

\subsubsection{Densidade e propriedades elásticas}

Os valores médios de densidade $(\rho)$, módulo de elasticidade $(E)$ e coeficiente de Poisson ( $v$ ) para os cinco materiais estudados se encontram na tabela 5.2. Foram observadas diferenças significantes entre os valores de densidade $(\rho)$ dos materiais. 
A cerâmica $Y Z$ apresentou o maior valor de $\rho$ e foi seguida pelos materiais $I Z, A L$, VM9 e VM7 em ordem decrescente. Os valores de densidade aparente dos materiais $\mathrm{YZ}$ e $\mathrm{AL}$ obtidos no presente trabalho foram comparados com os valores de densidade teórica, que são $6,10 \mathrm{~g} / \mathrm{cm}^{3}$ para $Y Z$ e $3,99 \mathrm{~g} / \mathrm{cm}^{3}$ para $A L$. Através dessa comparação pode-se observar que para ambos os materiais a densidade aparente foi $99 \%$ da densidade teórica, demonstrando o baixo grau de porosidade dessas cerâmicas.

Tabela 5.2 - Valores médios de densidade $(\rho)$, módulo de elasticidade $(E)$ e coeficiente de Poisson $(v)$ e desvio padrão para os cinco materiais estudados, além dos grupamentos estatísticos $(n=10)$

\begin{tabular}{cccccc}
\hline & $\mathbf{5}$ & Materiais \\
\cline { 2 - 6 } & $\mathbf{Y Z}$ & $\mathbf{Z}$ & $\mathbf{A L}$ & $\mathbf{V M 7}$ & $\mathbf{V M 9}$ \\
\hline$\rho\left(\mathbf{g} / \mathbf{c m}^{\mathbf{3}}\right)$ & $6,06 \pm 0,01 \mathrm{a}$ & $4,30 \pm 0,05 \mathrm{~b}$ & $3,95 \pm 0,01 \mathrm{c}$ & $2,34 \pm 0,08 \mathrm{e}$ & $2,44 \pm 0,03 \mathrm{~d}$ \\
\hline $\boldsymbol{E}(\mathbf{G P a})$ & $209,3 \pm 2,1 \mathrm{c}$ & $246,7 \pm 2,4 \mathrm{~b}$ & $390,4 \pm 8,3 \mathrm{a}$ & $66,7 \pm 5,5 \mathrm{~d}$ & $66,5 \pm 0,7 \mathrm{~d}$ \\
\hline $\mathrm{v}$ & $0,32 \pm 0,01 \mathrm{a}$ & $0,26 \pm 0,01 \mathrm{~b}$ & $0,24 \pm 0,01 \mathrm{bc}$ & $0,23 \pm 0,02 \mathrm{c}$ & $0,21 \pm 0,01 \mathrm{~d}$ \\
\hline \multicolumn{5}{c}{ Valores seguidos da mesma letra na linha são estatisticamente semelhantes $(\mathrm{p} \geq 0,05)}$.
\end{tabular}

Foi encontrada diferença estatística entre os valores de módulo de elasticidade $(E)$ dos materiais estudados, com exceção das duas porcelanas (VM7 e VM9) que apresentaram valores semelhantes. A cerâmica AL obteve o maior valor médio de $\mathrm{E}$ e os materiais $\mathrm{IZ}$ e $\mathrm{YZ}$ apresentaram valores intermediários. As porcelanas VM7 e VM9 apresentaram os menores valores de E, aproximadamente 3 a 6 vezes menores do que os valores obtidos para os materiais de infra-estrutura.

A cerâmica $Y Z$ apresentou o maior valor médio de coeficiente de Poisson (v), seguida pelos materiais IZ e AL. O menor valor de $v$ foi obtidos pela VM9. 


\subsection{ENSAIOS MECÂNICOS E ANÁLISE FRACTOGRÁFICA DAS ESTRUTURAS EM FORMA DE BARRA}

\subsubsection{Ensaio de resistência à flexão em três pontos dos corpos-de-prova monolíticos e análise de Weibull}

Os valores médios, desvio padrão (DP), coeficiente de variação (CV), mediana e valores mínimos e máximos de resistência à flexão $\left(\sigma_{f}\right)$ dos corpos-deprova monolíticos estão apresentados na tabela 5.3. Foram encontradas diferenças significativas entre os valores das medianas de $\sigma_{f}$ dos grupos estudados $(p<0.001)$. O grupo YZ obteve a maior mediana de $\sigma_{\mathrm{f}}$. Não foi observada diferença estatística entre os grupos $A L$ e IZ, que apresentaram valores de mediana intermediários. Os menores valores de mediana de $\sigma_{f}$ foram encontrados para as porcelanas (VM7 e VM9). É possível observar que o material $Y Z$ apresentou mediana de $\sigma_{f}$ aproximadamente duas vezes maior do que os valores de mediana dos materiais $\mathrm{AL}$ e IZ, e doze vezes maior do que os valores de mediana de $\sigma_{f}$ das porcelanas. A distribuição dos valores e as medianas de $\sigma_{f}$ dos grupos estudados podem ser observadas na figura 5.4 (boxplot).

Tabela 5.3 - Valores médios, desvio padrão (DP), coeficiente de variação (CV), mediana e valores mínimos e máximos de resistência à flexão $\left(\sigma_{f}\right)$ dos grupos experimentais (MPa), além do grupamento estatístico $(n=30)$

\begin{tabular}{ccccccc}
\hline Grupos & Média & DP & CV (\%) & Mediana $^{*}$ & Mínimo & Máximo \\
\hline YZ & 869,0 & 92,3 & 11 & 860,7 a & 724,6 & 1065,0 \\
\hline IZ & 408,6 & 32,5 & 8 & $411,5 \mathrm{~b}$ & 353,1 & 475,0 \\
\hline AL & 462,8 & 59,0 & 13 & $474,0 \mathrm{~b}$ & 419,9 & 567,5 \\
\hline VM7 & 69,6 & 12,0 & 17 & $69,8 \mathrm{c}$ & 46,6 & 98,6 \\
\hline VM9 & 64,7 & 8,9 & 14 & $65,5 \mathrm{c}$ & 46,5 & 82,0 \\
\hline
\end{tabular}

* Valores seguidos da mesma letra na coluna não apresentam diferença estatística $(p \geq 0,05)$. 


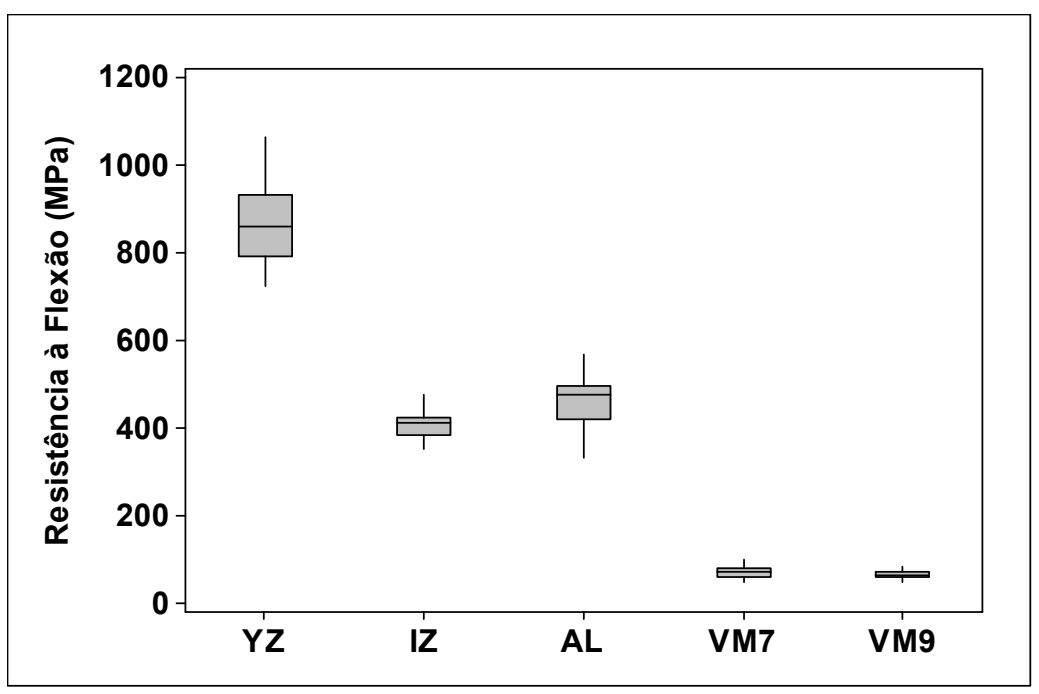

Figura 5.4 - Boxplot com os dados de resistência à flexão em três pontos $\left(\sigma_{f}\right)$ dos cinco grupos experimentais

A tabela 5.4 e a figura 5.5 mostram os resultados obtidos a partir da análise de Weibull dos dados de $\sigma_{f}$ dos corpos-de-prova monolíticos de cada um dos materiais estudados. Dois parâmetros foram obtidos: a resistência característica $\left(\sigma_{0}\right)$ e o módulo de Weibull $(m)$. Os valores de resistência à flexão para uma probabilidade de fratura de $5 \%$ também foram estimados através da análise de Weibull $\left(\sigma_{5} \%\right)$. As mesmas diferenças estatísticas observadas para os valores de $\sigma_{f}$ foram observadas para os valores de $\sigma_{0}$. Com exceção dos grupos $I Z$ e $A L$, que apresentaram diferença significante entre si para $\sigma_{0}$.

Tabela 5.4 - Valores dos parâmetros de Weibull, $\sigma_{0}$ (resistência característica) e m (módulo de Weibull), com seus respectivos intervalos de confiança de $95 \%$ e os valores de resistência para uma probabilidade de fratura de $5 \%\left(\sigma_{5 \%}\right)$, além dos grupamentos estatísticos $(n=30)$

\begin{tabular}{cccccc}
\hline & \multicolumn{5}{c}{ Grupos } \\
\cline { 2 - 6 } & $\mathbf{Y Z}$ & $\mathbf{I}$ & $\mathbf{A L}$ & $\mathbf{V M 7}$ & VM9 \\
\hline $\begin{array}{c}\boldsymbol{\sigma}_{\mathbf{0}} \\
(\mathbf{M P a})\end{array}$ & $\begin{array}{c}910,8 \mathrm{a} \\
(874,4-946,9)\end{array}$ & $\begin{array}{c}423,5 \mathrm{c} \\
(411,2-435,6)\end{array}$ & $\begin{array}{c}487,8 \mathrm{~b} \\
(467,4-508,1)\end{array}$ & $\begin{array}{c}74,7 \mathrm{~d} \\
(69,9-79,5)\end{array}$ & $\begin{array}{c}68,5 \mathrm{~d} \\
(65,2-71,7)\end{array}$ \\
\hline $\begin{array}{c}\boldsymbol{\sigma}_{5 \%} \\
(\mathbf{M P a})\end{array}$ & 673,2 & 340,4 & 355,0 & 45,9 & 47,8 \\
\hline $\mathbf{m}$ & $9,8 \mathrm{a}, \mathrm{b}$ & $15,6 \mathrm{a}$ & $9,4 \mathrm{a}, \mathrm{b}$ & $6,1 \mathrm{~b}$ & $8,2 \mathrm{a}, \mathrm{b}$ \\
& $(7,4-12,5)$ & $(10,2-17,4)$ & $(6,9-12,1)$ & $(4,6-7,8)$ & $(6,2-10,6)$ \\
\hline
\end{tabular}

Valores seguidos da mesma letra, na linha, não apresentam diferença estatística $(p \geq 0,05)$. 


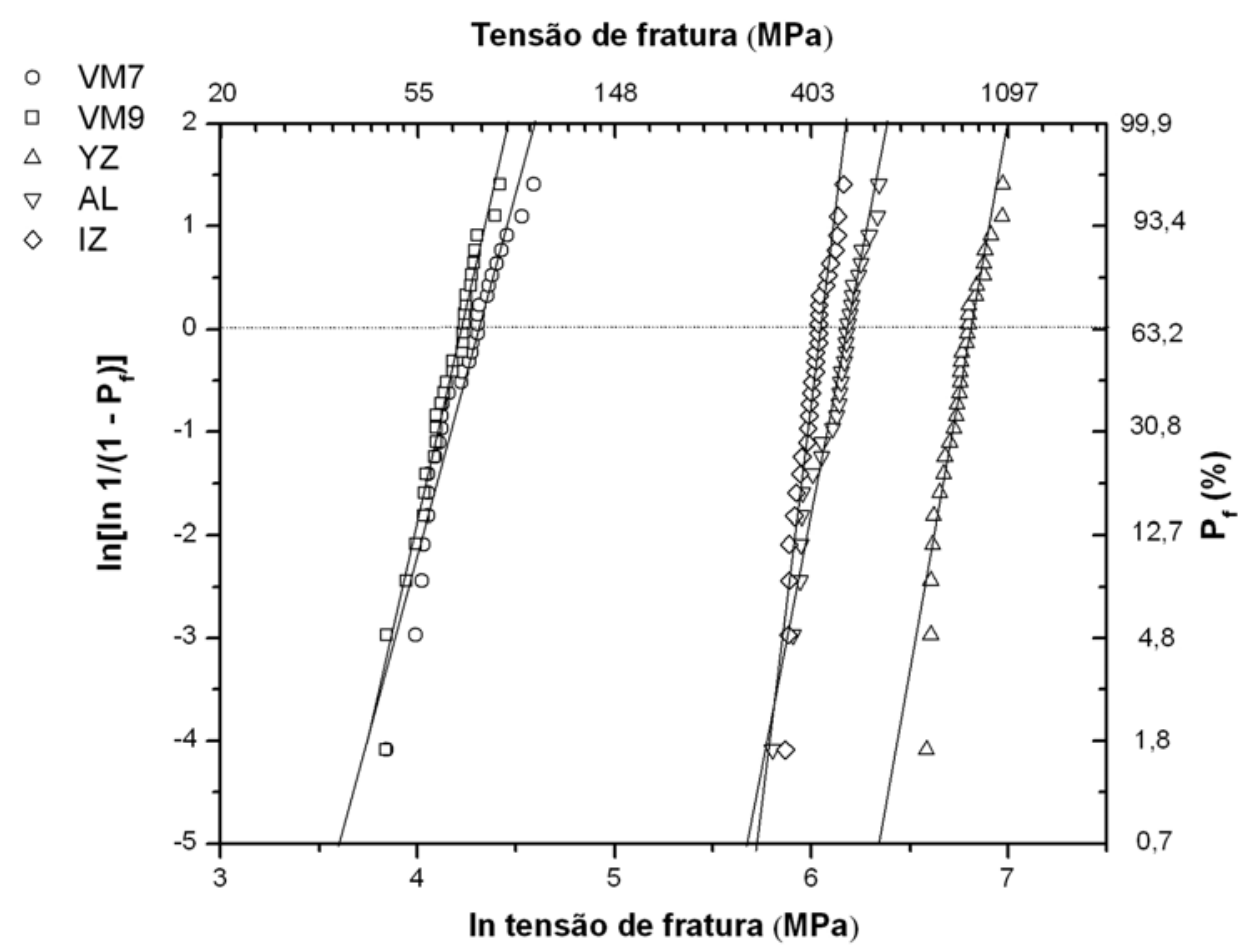

Figura 5.5 - Gráfico de Weibull mostrando os resultados de $\sigma_{f}$ para a taxa de carregamento de 1 $\mathrm{MPa} / \mathrm{s}$

Com relação ao módulo de Weibull, foi encontrada diferença estatística apenas entre os valores de $\mathrm{m}$ dos materiais $\mathrm{IZ}$ e VM7. Os valores de $\sigma_{0}$ e $\mathrm{m}$ são considerados estatisticamente diferentes quando os valores do intervalo de confiança dos grupos avaliados não se sobrepõem (Figura 5.6). Para cada material, a posição e a inclinação da curva no gráfico da figura 5.5 são determinadas pelo valor de $\sigma_{0}$ e $\mathrm{m}$, respectivamente. Materiais com menor valor de $\mathrm{m}$ apresentaram uma curva mais inclinada em relação aos grupos com maior valor de $\mathrm{m}$. As curvas dos materiais que apresentaram maiores valores de $\sigma_{0}$, como $\circ \mathrm{YZ}$, localizam-se mais à direita do que as curvas das porcelanas, que apresentaram valores mais baixos de $\sigma_{0}$. 


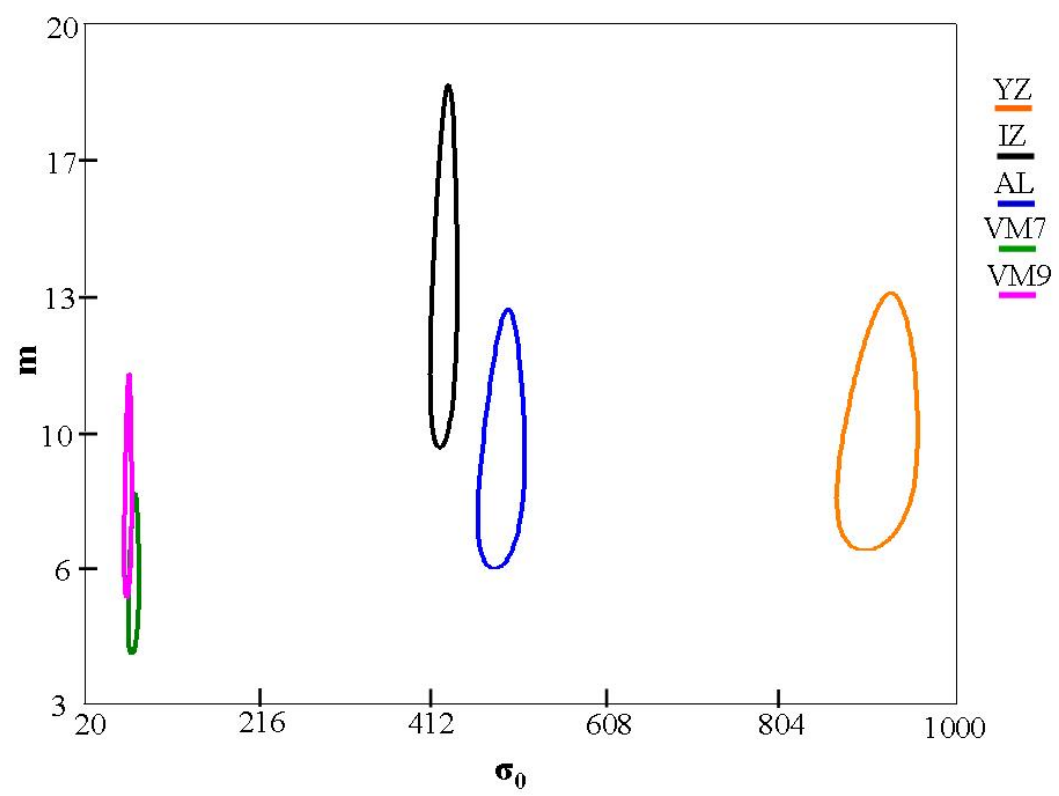

Figura 5.6 - Intervalos de confiança de $95 \%$ para os parâmetros $\sigma_{0}$ e m dos grupos experimentais

\subsubsection{Determinação do coeficiente de susceptibilidade ao crescimento sub- crítico da trinca $(n)$}

Os resultados referentes aos ensaios de fadiga dinâmica estão apresentados nas tabelas 5.5 e 5.6 e na figura 5.7. Na tabela 5.5 são apresentados os valores médios de resistência de cada material (tensão de fratura) em função da taxa de carregamento durante o ensaio. Existe uma tendência geral de diminuição do valor médio de resistência com a diminuição da velocidade de carregamento. Entretanto, dependendo do material e das taxas de carregamento consideradas, nem sempre a diminuição da taxa resultou em queda no valor de resistência. Como por exemplo, para o grupo $\mathrm{YZ}$, houve um aumento de $6 \%$ no valor de resistência quando a velocidade foi diminuída de 1 para 0,1 MPa/s. Um comportamento semelhante foi observado para o material AL quando diminui-se a taxa de 100 para $10 \mathrm{MPa} / \mathrm{s}$. 
Tabela 5.5 - Médias de tensão de fratura (MPa) em função da taxa de tensão com respectivos valores de desvio-padrão para os materiais estudados $(n=10)$

\begin{tabular}{|c|c|c|}
\hline Materiais & Taxa de tensão (MPa/s) & Tensão de fratura (MPa) \\
\hline \multirow{5}{*}{$Y Z$} & 100 & $938,0 \pm 148,3$ \\
\hline & 10 & $933,3 \pm 141,1$ \\
\hline & 1 & $869,0 \pm 92,3$ \\
\hline & 0,1 & $923,8 \pm 88,4$ \\
\hline & 0,01 & $820,1 \pm 176,9$ \\
\hline \multirow{5}{*}{$\mathbf{I Z}$} & 100 & $443,1 \pm 27,7$ \\
\hline & 10 & $422,0 \pm 28,6$ \\
\hline & 1 & $408,6 \pm 32,5$ \\
\hline & 0,1 & $409,6 \pm 21,3$ \\
\hline & 0,01 & $365,7 \pm 29,4$ \\
\hline \multirow{5}{*}{$A L$} & 100 & $474,7 \pm 55,7$ \\
\hline & 10 & $512,1 \pm 58,0$ \\
\hline & 1 & $462,8 \pm 59,0$ \\
\hline & 0,1 & $463,3 \pm 25,0$ \\
\hline & 0,01 & $440,3 \pm 58,4$ \\
\hline \multirow{5}{*}{ VM7 } & 100 & $68,5 \pm 12,0$ \\
\hline & 10 & $68,8 \pm 10,0$ \\
\hline & 1 & $69,4 \pm 12,2$ \\
\hline & 0,1 & $68,5 \pm 12,0$ \\
\hline & 0,01 & $50,0 \pm 4,8$ \\
\hline \multirow{5}{*}{ VM9 } & 100 & $63,5 \pm 5,4$ \\
\hline & 10 & $62,0 \pm 10,8$ \\
\hline & 1 & $64,7 \pm 8,9$ \\
\hline & 0,1 & $59,0 \pm 5,6$ \\
\hline & 0,01 & $50,2 \pm 5,4$ \\
\hline
\end{tabular}

Os gráficos da figura 5.7 mostram as curvas de regressão construídas sobre os dados de resistência em função da taxa de carregamento. Embora os gráficos apresentem-se em escalas diferentes, a inclinação de todas as curvas mostra a tendência de diminuição da resistência com o decréscimo da taxa de carregamento. Quanto maior a inclinação, maior é o valor do expoente da equação da curva e conseqüentemente maior é a susceptibilidade do material ao crescimento subcrítico. Nota-se que o material VM7 apresentou o maior expoente $(0,0268)$ e a $Y Z$ apresentou o menor $(0,0130)$. 

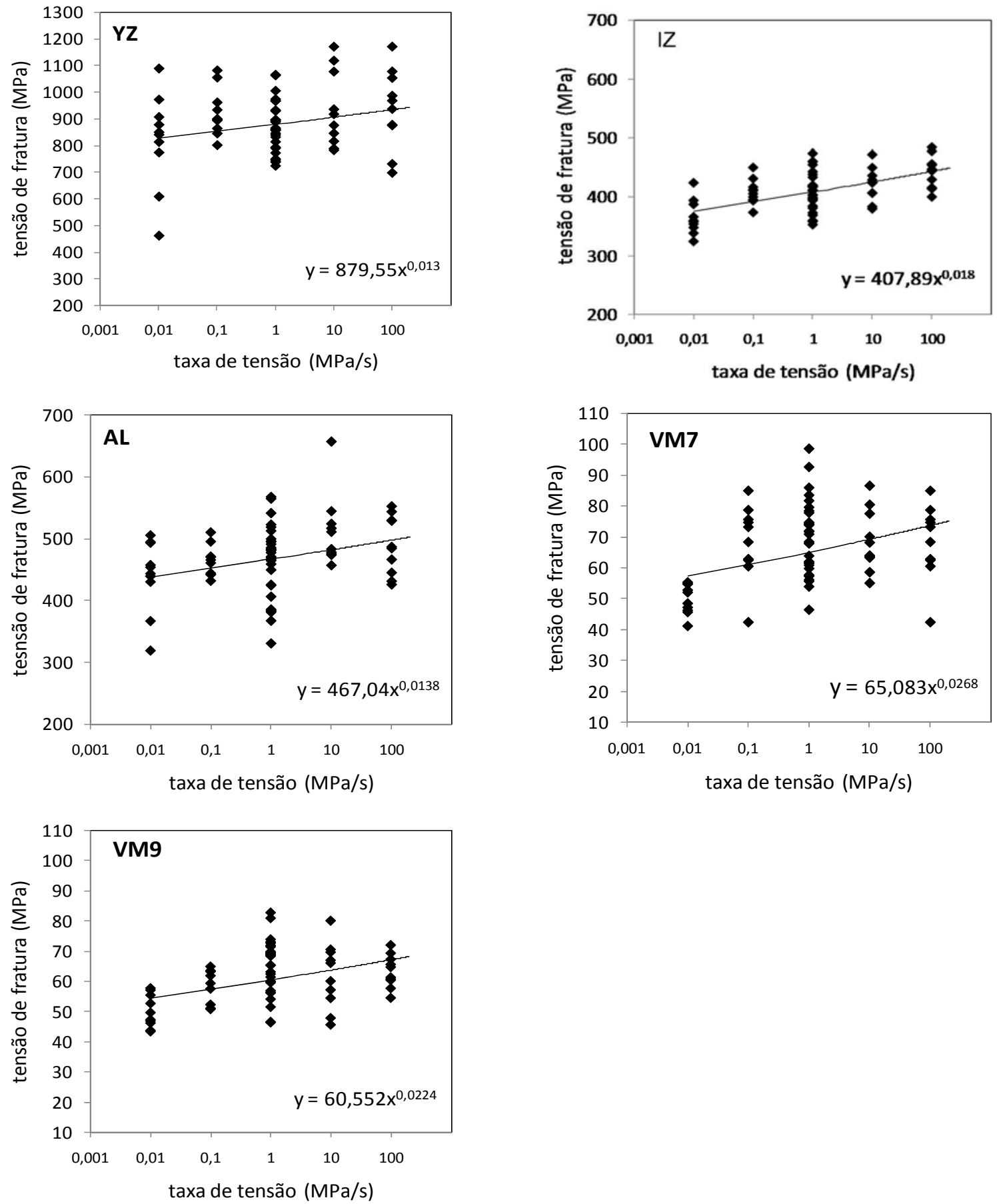

Figura 5.7 - Resultados de fadiga dinâmica, correlacionando os valores de tensão de fratura e a taxa de carregamento para os cinco materiais estudados

A tabela 5.6 mostra os parâmetros de crescimento subcrítico dos materiais estudados. Os materiais $\mathrm{YZ}$ e $\mathrm{AL}$ apresentaram os maiores valores de $n$ (76 e 72, respectivamente), os quais foram aproximadamente duas vezes maiores do que os valores obtidos pelas porcelanas (ao redor de 40). O material IZ apresentou um valor de $n$ intermediário (54). O parâmetro escalar $\sigma_{\mathrm{fo}}$ é considerado um indicativo da 
resistência dos materiais em momentos iniciais da sua utilização, portanto, seus valores (Tabela 5.6) são muito semelhantes aos de resistência média dos materiais (Tabela 5.3). Nota-se que o maior valor de $\sigma_{\mathrm{f} 0}$ foi obtido pelo $Y Z$, seguido em ordem decrescente por AL, IZ, VM7 e VM9.

Tabela 5.6 - Parâmetros de crescimento subcrítico obtidos no ensaio de fadiga dinâmica: $n$ e $\sigma_{\text {fo }}$, com seus respectivos valores de desvio-padrão

\begin{tabular}{cccccc}
\hline & \multicolumn{5}{c}{ Materiais } \\
\cline { 2 - 6 } & $\mathbf{Y Z}$ & $\mathbf{I Z}$ & $\mathbf{A L}$ & $\mathbf{V M 7}$ & VM9 \\
\hline $\boldsymbol{n}$ & $76 \pm 38$ & $54 \pm 10$ & $72 \pm 27$ & $36 \pm 11$ & $44 \pm 12$ \\
\hline $\boldsymbol{\sigma}_{\mathrm{f} 0}(\mathbf{M P a})$ & $879,5 \pm 0,02$ & $407,9 \pm 0,01$ & $467,0 \pm 0,01$ & $65,08 \pm 0,02$ & $60,55 \pm 0,02$ \\
\hline
\end{tabular}

A figura 5.8 apresenta as curvas de tempo de vida (lifetime curves) obtidas para os cinco materiais estudados através da correlação entre o logaritmo do tempo de fratura e logaritmo da tensão de fratura. A tabela 5.7 mostra os valores de resistência necessários para a fratura em tempos de 1 dia $\left(\sigma_{1 \mathrm{~d}}\right), 1$ ano $\left(\sigma_{1 \mathrm{a}}\right)$ e 10 anos $\left(\sigma_{10 a}\right)$ para os cinco materiais estudados. Nota-se que a diferença entre os tempos de 1 dia e 10 anos reflete diretamente o valor de $n$ de cada material. Sendo assim, essa diferença é menor para materiais com maiores valores de $n$. A degradação da resistência dos materiais YZ e AL após 10 anos foi significativamente menor em comparação com a observada para as porcelanas. Em termos percentuais, as porcelanas têm sua resistência degradada duas vezes mais após esse período de tempo. O compósito IZ sofre uma degradação intermediária, com sua resistência decaindo $13 \%$ após 10 anos. 


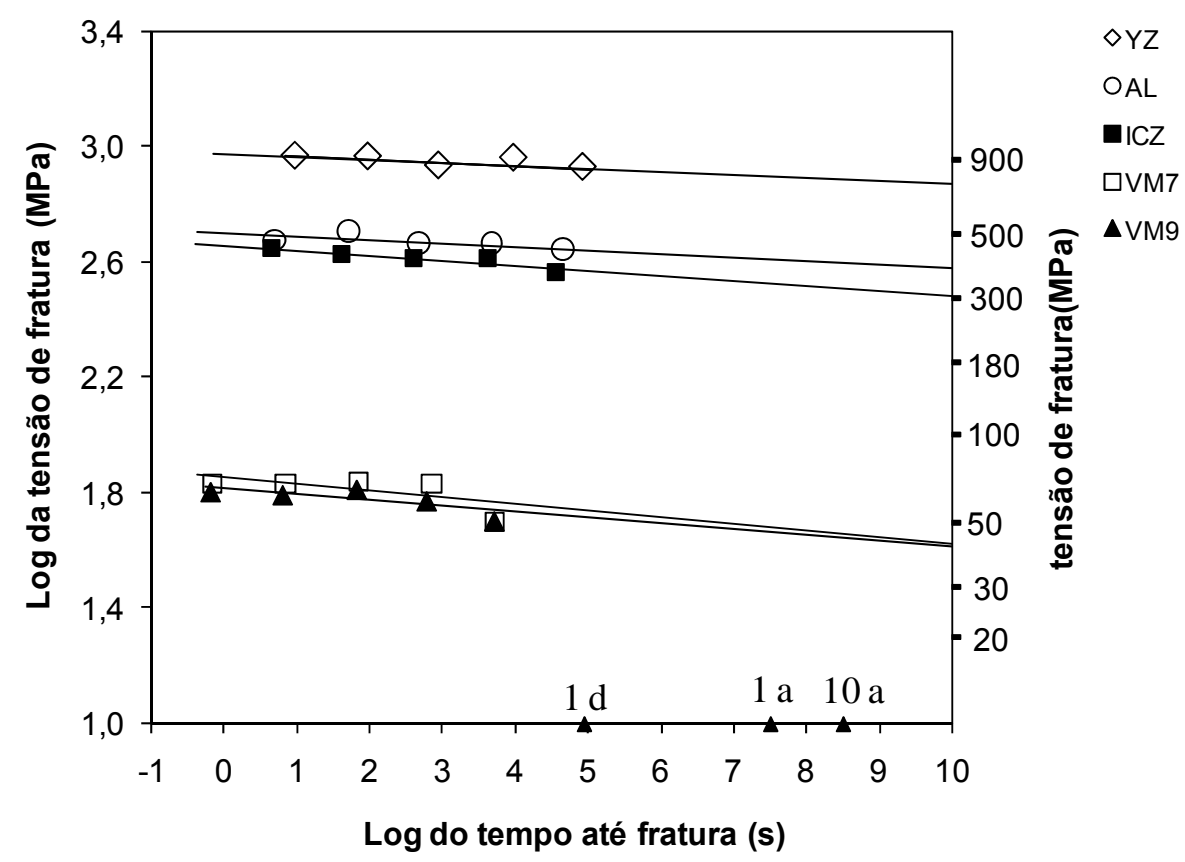

Figura 5.8 - Curvas de tempo de vida (lifetime curve) obtidas para os cinco materiais estudados, através da correlação entre log do tempo de fratura e log da tensão de fratura. No eixo $x$ foram colocadas marcações indicando os tempo de 1 dia (1d), 1 ano (1a) e 10 anos (10a)

Tabela 5.7 - Valores de tensão de ruptura, em MPa, necessários para fratura dos cinco materiais em tempos de vida de 1 dia $\left(\sigma_{1 \mathrm{~d}}\right), 1$ ano $\left(\sigma_{1 \mathrm{a}}\right)$ e 10 anos $\left(\sigma_{10 \mathrm{a}}\right)$ e diferença, em \%, entre os valores de $\sigma_{1 \mathrm{~d}}$ e $\sigma_{10 \mathrm{a}}$. Valores obtidos a partir das curvas de regressão da figura 5.8

\begin{tabular}{cccccc}
\hline & \multicolumn{5}{c}{ Materiais } \\
\cline { 2 - 6 } & $\mathbf{Y Z}$ & $\mathbf{I Z}$ & $\mathbf{A L}$ & VM7 & VM9 \\
\hline $\boldsymbol{\sigma}_{1 \mathrm{~d}}$ & 839 & 371 & 438 & 55 & 52 \\
\hline $\boldsymbol{\sigma}_{1 \mathrm{a}}$ & 790 & 335 & 408 & 48 & 46 \\
\hline $\boldsymbol{\sigma}_{10 \mathrm{a}}$ & 771 & 321 & 397 & 46 & 44 \\
\hline $\begin{array}{c}\text { Diferença entre } \\
\boldsymbol{\sigma}_{1 \mathrm{~d}} \mathbf{e} \boldsymbol{\sigma}_{\text {10a }}(\%)\end{array}$ & 8 & 13 & 9 & 17 & 15 \\
\hline
\end{tabular}

Os diagramas SPT (stress-probability-time) construídos com os resultados de Weibull e SCG dos cinco materiais estudados estão representados na figura 5.9. A inclinação da curva no gráfico está relacionada com o valor de $\mathrm{m}$. No diagrama SPT assume-se que o valor de $m$ não se altera com o tempo, portanto a inclinação das curvas é igual nos três gráficos. Essas curvas mudam de posição para os tempos de $1 \mathrm{dia}, 1$ ano e 10 anos conforme a susceptibilidade ao crescimento subcrítico de cada material (valor de $n$ ). Pode-se observar que as curvas dos materiais $Y Z$ e AL se deslocam na mesma proporção, já que possuem valor de $n$ semelhante. A curva do 
material IZ se afasta da curva do material $A L$ com o tempo por causa de sua maior susceptibilidade ao crescimento subcrítico.
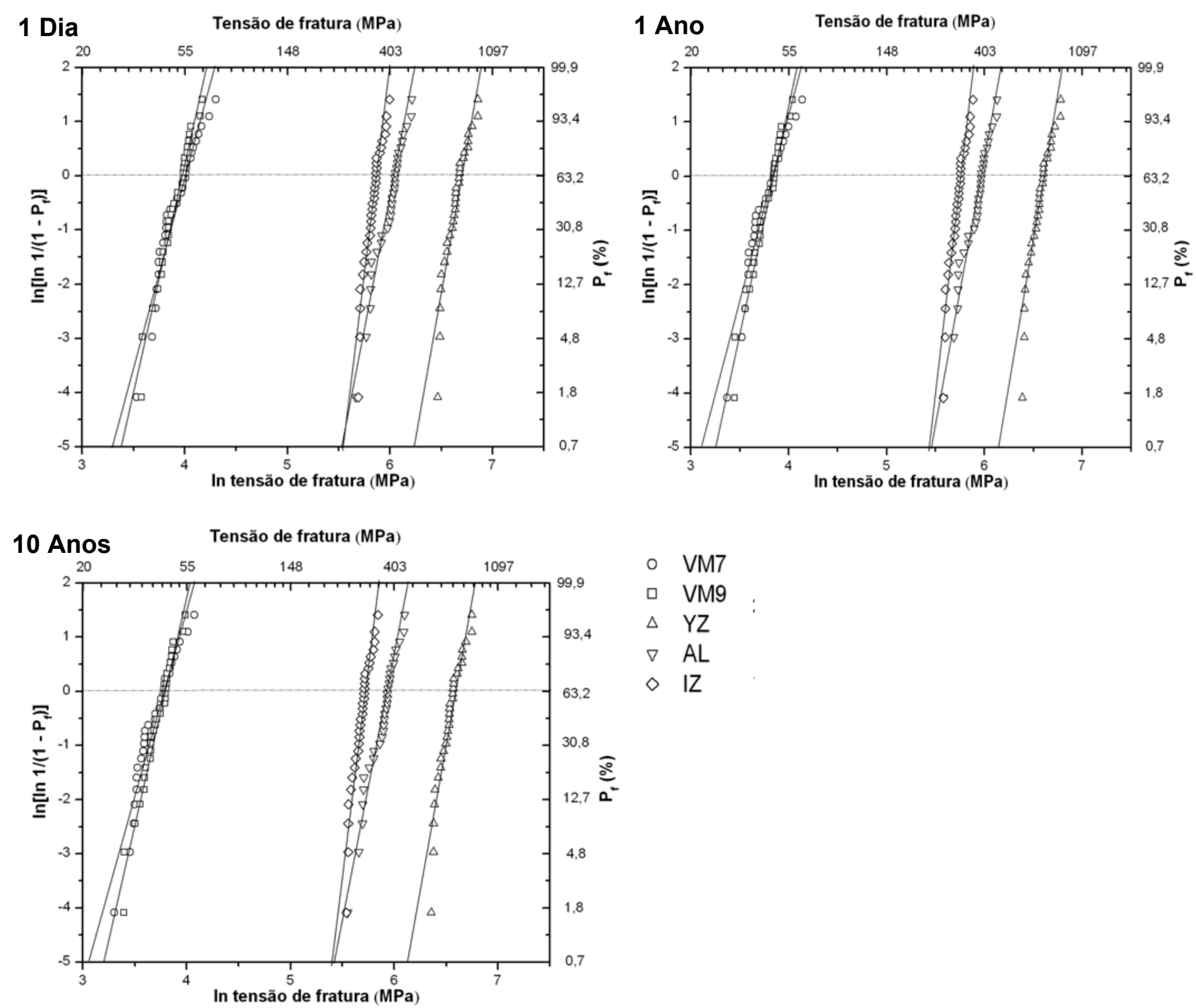

Figura 5.9-Gráficos SPT para os tempos de 1 dia, 1 ano e 10 anos

A tabela 5.8 apresenta os valores de tensão necessários para fratura dos materiais em tempos de vida de 1 dia $\left(\sigma_{1 \mathrm{~d}}\right), 1$ ano $\left(\sigma_{1 \mathrm{a}}\right)$ e 10 anos $\left(\sigma_{10 \mathrm{a}}\right)$ para uma probabilidade de falha de $5 \%$. Esses dados foram obtidos utilizando os diagramas SPT. Os valores da tabela 5.8 são semelhantes aos valores apresentados na tabela 5.7. Entretanto, os diagramas SPT permitem a estimativa da tensão de fratura para diferentes probabilidades de falha, já que levam em consideração não apenas o valor médio de tensão de fratura mas também o módulo de Weibull. 
Tabela 5.8 - Valores de tensão necessários para fratura dos cinco materiais em tempos de vida de 1 dia $\left(\sigma_{1 \mathrm{~d}}\right), 1$ ano $\left(\sigma_{1 \mathrm{a}}\right)$ e 10 anos $\left(\sigma_{10 \mathrm{a}}\right)$ para uma probabilidade de falha de $5 \%$, obtidos através dos diagramas SPT $(\mathrm{MPa})$

\begin{tabular}{cccccl}
\hline & \multicolumn{5}{c}{ Materiais } \\
\cline { 2 - 6 } & YZ & IZ & AL & VM7 & VM9 \\
\hline$\sigma_{1 \mathrm{~d}}$ & 845 & 368 & 452 & 60 & 57 \\
\hline $\boldsymbol{\sigma}_{1 \mathrm{a}}$ & 782 & 330 & 416 & 50 & 50 \\
\hline $\boldsymbol{\sigma}_{10 \mathrm{a}}$ & 759 & 316 & 403 & 47 & 47 \\
\hline
\end{tabular}

\subsubsection{Análise fractográfica qualitativa e quantitativa dos corpos-de-prova monolíticos}

Os corpos-de-prova monolíticos apresentaram um padrão semelhante de fratura entre si. $O$ defeito teve origem na superfície da barra submetida à tensões de tração durante o ensaio e se propagou através do material formando uma curva (compression curl) no lado de compressão. Esse comportamento é típico de corposde-prova testados em flexão (Quinn, 2007). A figura 5.10 apresenta as imagens de estereomicroscópio da superfície de fratura dos materiais de infra-estrutura (YZ, IZ e $\mathrm{AL}$ ). É possível observar nessas imagens marcas características como as hackle lines $(\mathrm{HL})$, que apontam para a origem da fratura, e a compression curl (CC), no lado oposto ao defeito (flecha).

A rugosidade de superfície dos corpos-de-prova de infra-estrutura possibilitou a localização da origem de fratura utilizando o estereomicroscópio. Entretanto, os corpos-de-prova de porcelana (VM7 e VM9) apresentaram uma superfície de fratura pouco rugosa, o que dificultou a identificação das marcas características que indicam a localização do defeito. Portanto, para esses corpos-de-prova, a origem de fratura foi localizada utilizando o MEV (Figura 5.12).

Em todos os corpos-de-prova dos grupos $Y Z, I Z$ e $A L$ o defeito inicial foi localizado na superfície da face solicitada em tração. Nenhum defeito teve origem nos cantos ou no interior da barra. Porém para os grupos VM7 e VM9 foram identificadas falhas de canto. Foi observado que durante o procedimento de chanfro dos cantos, as porcelanas sofreram maior desgaste do que os materiais de infraestrutura, por apresentarem dureza menor. Em alguns casos, o desgaste em 
excesso da porcelana acabou produzindo outro ângulo concentrador de tensões, o que explica a presença de falhas de canto nesses dois grupos (VM7 e VM9).

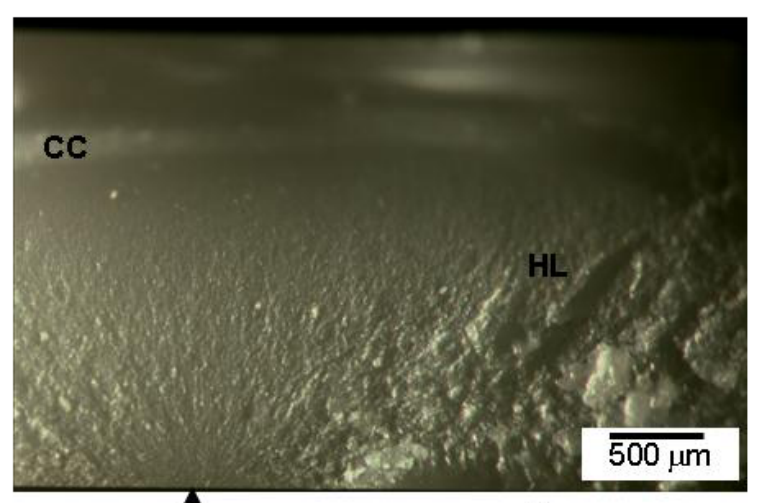

A

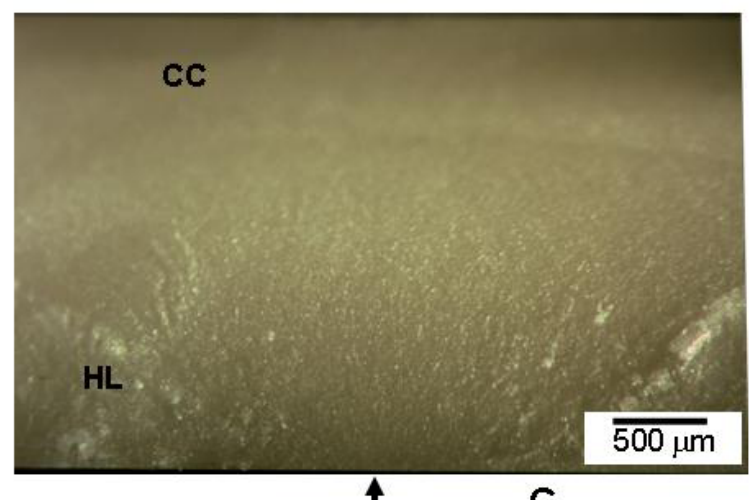

Figura 5.10 - Imagem de esteremicroscópio da superfície de fratura dos materiais de infraestrutura. A) YZ. B) IZ. C) AL. Pode-se observar a presença de marcas características como compression curl (CC) e hackle lines ( $\mathrm{HL})$. As flechas apontam para a origem de defeito

Pode-se observar na figura 5.11 as imagens de MEV da superfície de fratura dos materiais de infra-estrutura. As mesmas características de fratura observadas na análise de estereomicroscópio podem ser visualizadas nessas imagens, como as hackle lines e compression curl. Porém, as micrografias obtidas no MEV permitem a observação de um maior número de detalhes fractográficos. Para o material $Y Z$ foi possível localizar uma área menos rugosa ao redor do defeito crítico, correspondendo a zona de mirror (Figura 5.11, partes A e B). Entretanto, nos materiais $I Z$ e $A L$ essa região foi mascarada pela microestrutura rugosa dessas cerâmicas (Figura 5.11, partes C, D, E e F). 


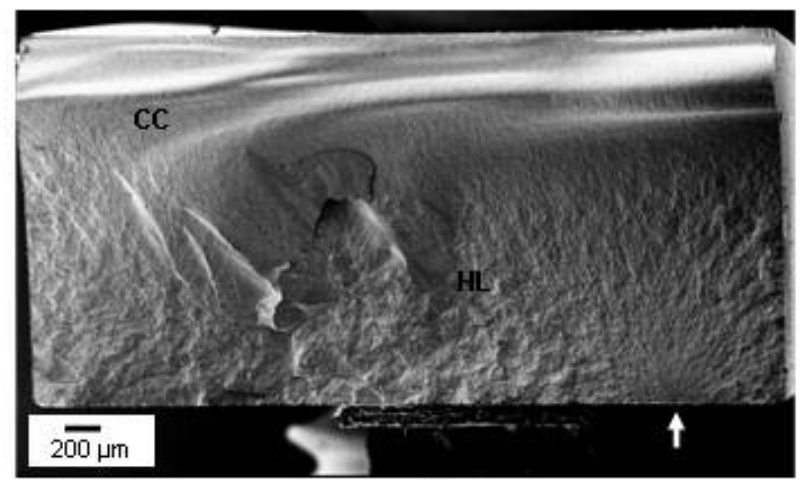

A

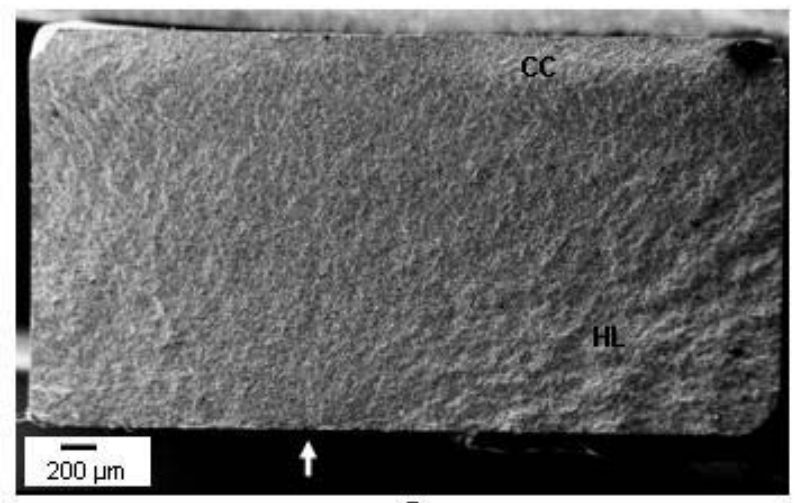

C

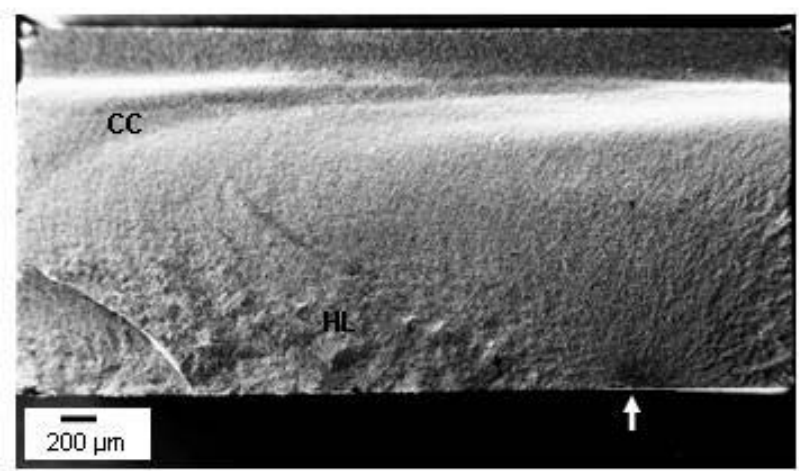

E

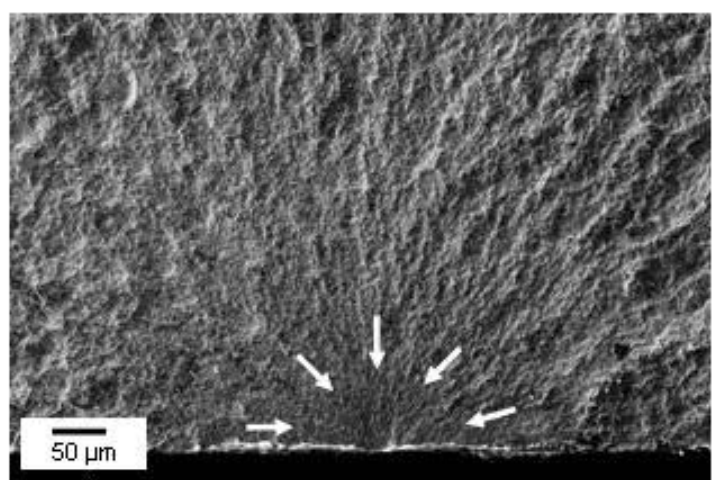

B

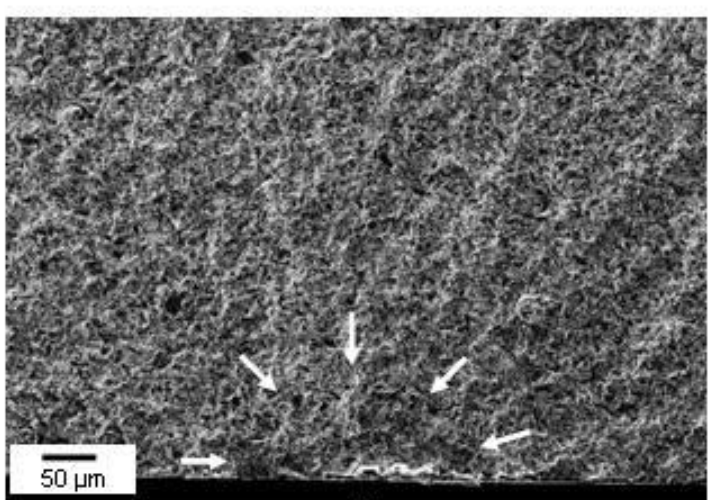

$\mathrm{D}$

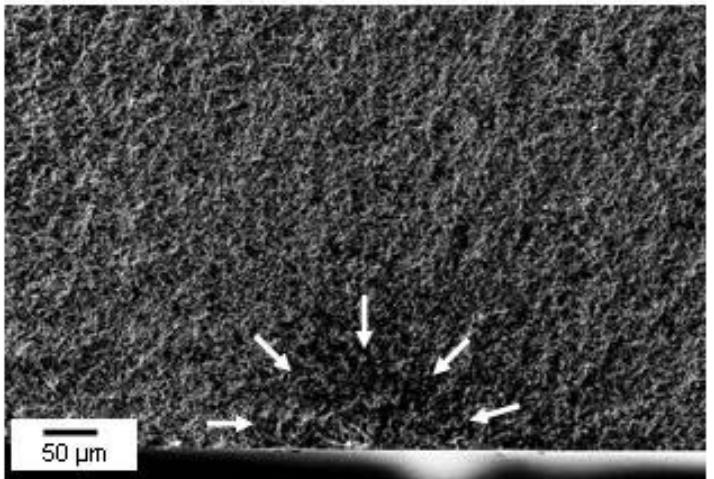

$\mathbf{F}$

Figura 5.11 - Imagens de MEV da superfície de fratura dos materiais de infra-estrutura. A e B) YZ. $C$ e D) IZ. E e F) AL. Pode-se observar a presença de marcas características como compression curl (CC) e hackle lines (HL). As flechas indicam o defeito crítico

As imagens de MEV para as porcelanas VM7 e VM9 estão apresentadas na figura 5.12. Por causa da alta porosidade desses materiais, é possível identificar um grande número de wake hackles apontando para a origem do defeito. Também pode-se observar a presença de Wallner lines na superfície de fratura das porcelanas. 


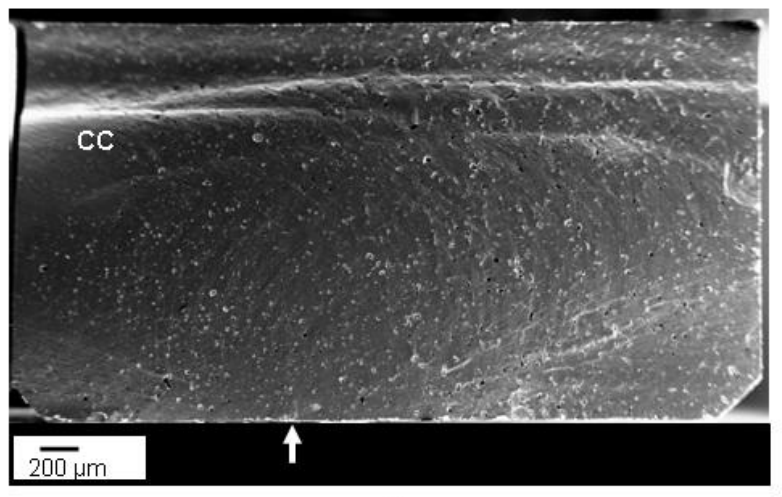

A

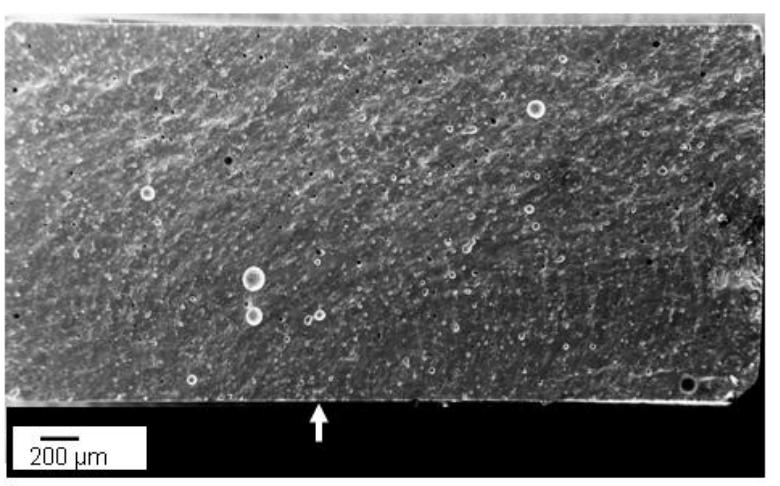

C

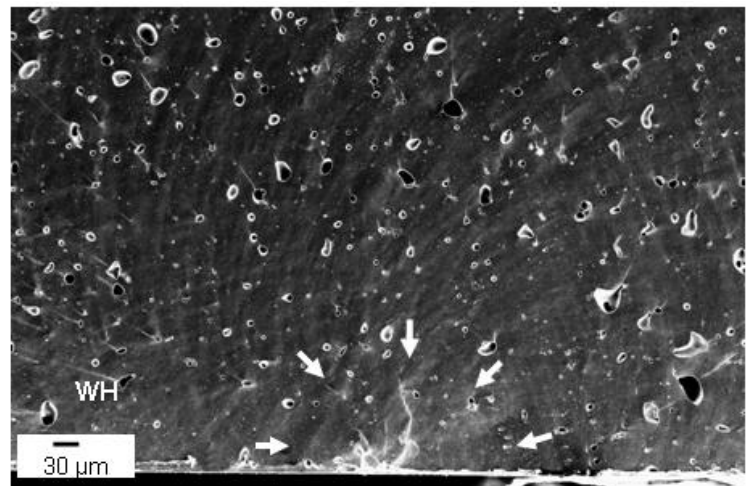

B

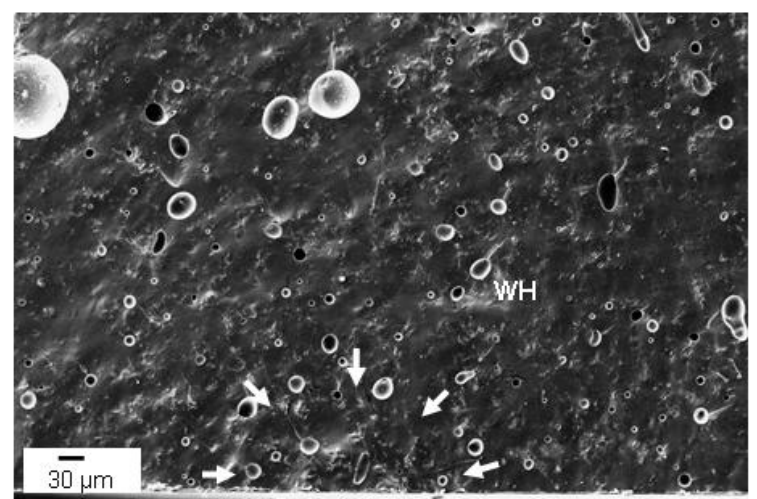

D

Figura 5.12 - Imagens de MEV da superfície de fratura das porcelanas. A e B) VM7. C e D) VM9;. Pode-se observar marcas características como compression curl (CC) e wake hackles (WH). As flechas indicam o defeito crítico

Os valores médios de tamanho de defeito crítico (c) e tenacidade à fratura $\left(\mathrm{K}_{\mathrm{Ic}}\right)$ para os grupos experimentais se encontram na tabela 5.9. Não houve diferença no tamanho de defeito crítico (c) entre as duas porcelanas. Entretanto, o valor de c das porcelanas foi significativamente maior do que o valor de $\mathrm{c}$ dos materiais de infra-estrutura. Também não foi observada diferença estatística entre os valores de c dos três materiais de infra-estrutura. A cerâmica $\mathrm{YZ}$ apresentou o maior valor de $\mathrm{K}_{\mathrm{Ic}}$. Os materiais $\mathrm{IZ}$ e $\mathrm{AL}$ obtiveram valores intermediários de $\mathrm{K}_{\mathrm{Ic}}$ e estatisticamente semelhantes. As porcelanas apresentaram os menores valor de $\mathrm{K}_{\mathrm{Ic}}$.

Tabela 5.9 - Valores médios de tamanho crítico de defeito $(\mathrm{c})$, tenacidade à fratura $\left(\mathrm{K}_{\mathrm{Ic}}\right)$ e desvio padrão para os materiais estudados, além dos grupamentos estatísticos $(n=25)$

\begin{tabular}{cccccc}
\hline & \multicolumn{5}{c}{ Materiais } \\
\cline { 2 - 6 } & $\mathbf{Y Z}$ & $\mathbf{I Z}$ & $\mathbf{A L}$ & $\mathbf{V M 7}$ & $\mathbf{V M 9}$ \\
\hline $\mathbf{c}(\mu \mathrm{m})$ & $34 \pm 9 \mathrm{~b}$ & $48 \pm 10 \mathrm{~b}$ & $40 \pm 8 \mathrm{~b}$ & $75 \pm 16 \mathrm{a}$ & $86 \pm 25 \mathrm{a}$ \\
\hline $\mathbf{K}_{\mathbf{I c}}\left(\mathbf{M P a}_{\mathbf{m}} \mathbf{m}^{1 / 2}\right)$ & $6,5 \pm 0,3 \mathrm{a}$ & $3,6 \pm 0,2 \mathrm{~b}$ & $3,6 \pm 0,2 \mathrm{~b}$ & $0,7 \pm 0,1 \mathrm{c}$ & $0,7 \pm 0,1 \mathrm{c}$ \\
\hline
\end{tabular}

Valores seguidos da mesma letra na linha não apresentam diferença estatística $(p \geq 0,05)$. 
A figura 5.13 apresenta o tamanho do defeito crítico (c) para cada taxa de tensão para os materiais estudados. Pode-se observar que houve uma tendência ao aumento do tamanho do defeito com a diminuição da taxa de tensão.
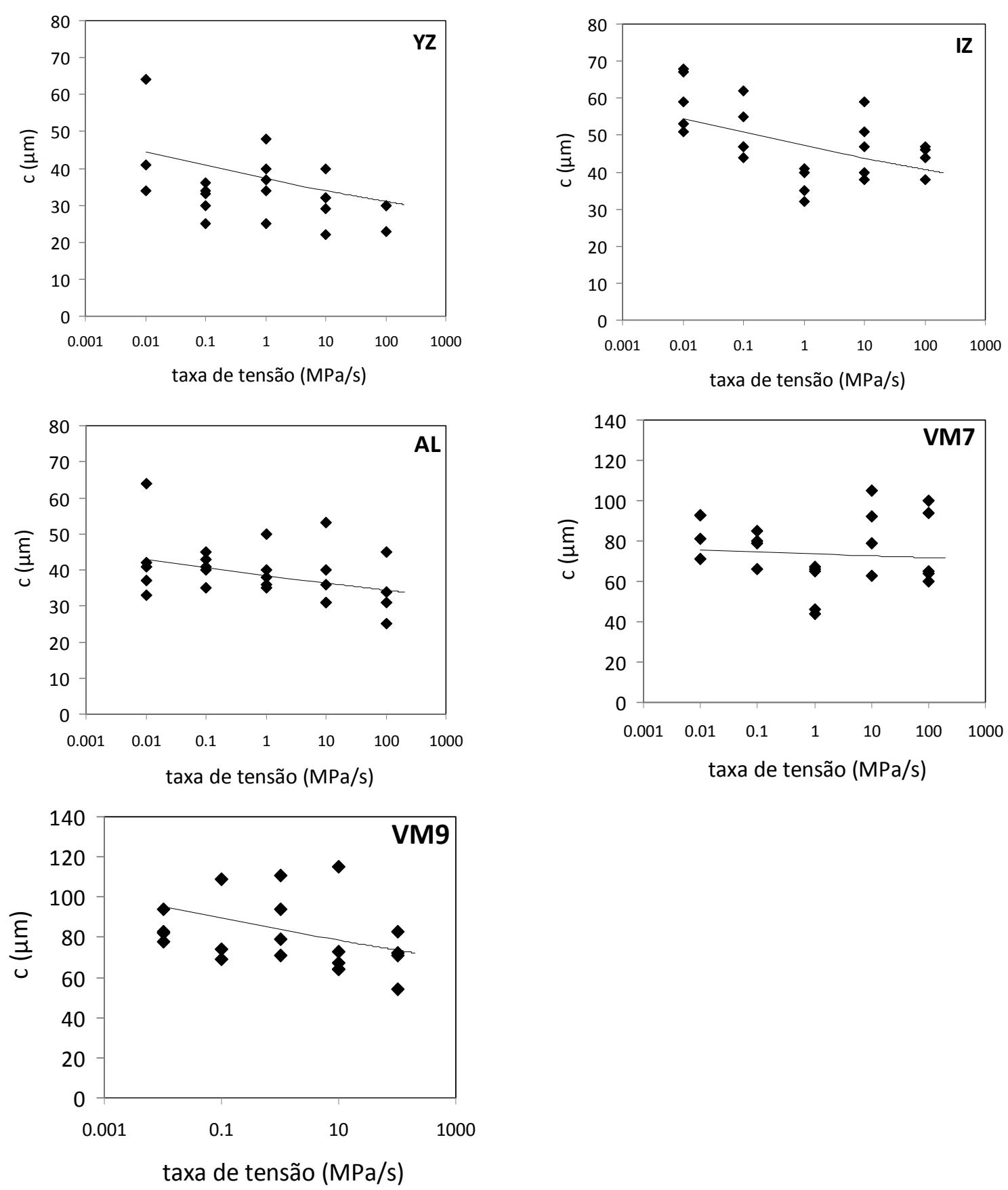

Figura 5.13 - Gráficos mostrando o tamanho de defeito crítico $(\mu \mathrm{m})$ em função das taxas de tensão $(\mathrm{MPa} / \mathrm{s})$ para cada grupo experimental $(n=5)$ 


\subsubsection{Efeito da configuração na resistência à flexão em três pontos e modo de fratura dos corpos-de-prova em forma de barra}

A tabela 5.10 mostra a comparação entre os valores de resistência a flexão $\left(\sigma_{f}\right)$ dos corpos-de-prova em forma de barra em função do material e da configuração (uma, duas ou três camadas). Nesta tabela, os resultados de resistência referentes aos corpos-de-prova monolíticos são os mesmos já apresentados na tabela 5.3 (mediana). Os grupos YZ e YZ-IT apresentaram medianas de $\sigma_{f}$ estatisticamente semelhantes entre si e maiores do que os demais grupos estudados. Não houve diferença nos valores de $\sigma_{f}$ entre os grupos IZ e IZ-IT e entre os grupos AL e AL-IT. Os valores das medianas de $\sigma_{f}$ dos grupos YZ-PT, IZPT, IZ-TRI, AL-PT e AL-TRI foram estatisticamente semelhantes aos valores obtidos pelos grupos VM7 e VM9.

Tabela 5.10 - Valores de resistência à flexão em três pontos $\left(\sigma_{f}\right)$ para os corpos-de-prova em forma de barra em função do material e da configuração da estrutura. Valores dispostos em mediana $(\mathrm{MPa}) \pm$ desvio padrão, e grupamento estatístico $(n=10)$

\begin{tabular}{ccccc}
\hline \multirow{2}{*}{ Materiais } & \multirow{2}{*}{ Uma camada } & \multicolumn{2}{c}{ Duas camadas } & \multirow{2}{*}{ Três camadas } \\
\cline { 3 - 4 } & & PT & IT & \\
\hline YZ & $860,7 \pm 92,3 \mathrm{a}$ & $57,6 \pm 7,6 \mathrm{e}$ & $765,6 \pm 128,7 \mathrm{a}$ & $82,9 \pm 9,9 \mathrm{~d}$ \\
\hline $\mathbf{I Z}$ & $411,5 \pm 32,5 \mathrm{c}$ & $61,3 \pm 9,1 \mathrm{e}$ & $411,6 \pm 21,6 \mathrm{bc}$ & $63,5 \pm 11,8 \mathrm{e}$ \\
\hline $\mathbf{A L}$ & $474,0 \pm 59,0 \mathrm{~b}$ & $65,8 \pm 15,8 \mathrm{e}$ & $413,7 \pm 87,6 \mathrm{bc}$ & $63,0 \pm 7,3 \mathrm{e}$ \\
\hline VM7 & $69,8 \pm 12,0 \mathrm{e}$ & & & \\
\hline VM9 & $65,5 \pm 8,9 \mathrm{e}$ & & & \\
\hline
\end{tabular}

Valores seguidos da mesma letra são estatisticamente semelhantes $(p \geq 0,05)$.

O padrão de fratura das estruturas em camadas foi classificado em dois tipos: fratura total e fratura parcial (falha de apenas uma das camadas). O tipo de fratura observado para cada grupo experimental pode ser visto na tabela 5.11. 
Tabela 5.11 - Tipo de fratura dos corpos-de-prova em camadas em função do material e configuração da estrutura

\begin{tabular}{|c|c|c|c|c|c|c|}
\hline \multirow{3}{*}{ Materiais } & \multicolumn{4}{|c|}{ Duas camadas } & \multirow{2}{*}{\multicolumn{2}{|c|}{$\begin{array}{c}\text { Três camadas } \\
\text { TRI }\end{array}$}} \\
\hline & \multicolumn{2}{|c|}{ PT } & \multicolumn{2}{|c|}{ IT } & & \\
\hline & Total & Parcial & Total & Parcial & Total & Parcial \\
\hline YZ & 0 & 10 & 3 & 7 & 2 & 8 \\
\hline IZ & 0 & 10 & 10 & 0 & 5 & 5 \\
\hline $\mathrm{AL}$ & 0 & 10 & 10 & 0 & 10 & 0 \\
\hline
\end{tabular}

Todos os corpos-de-prova de duas camadas testados com a porcelana em tração apresentaram fratura parcial, como pode ser observado na tabela 5.11 e na figura 5.14.

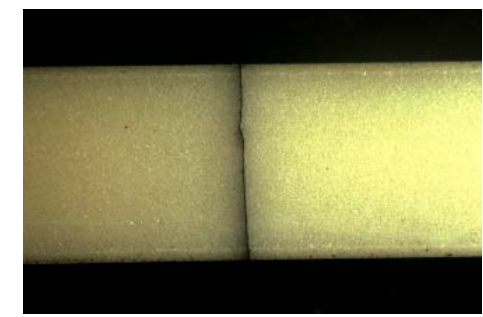

A

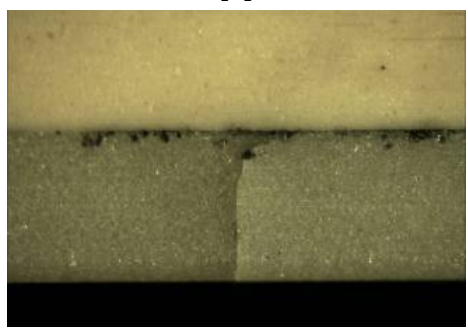

C

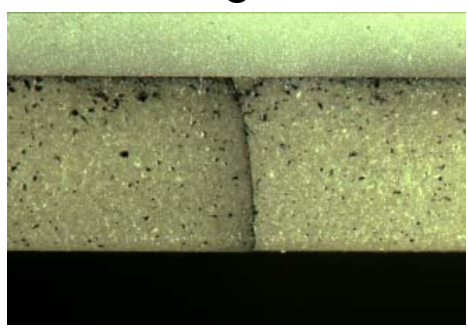

E

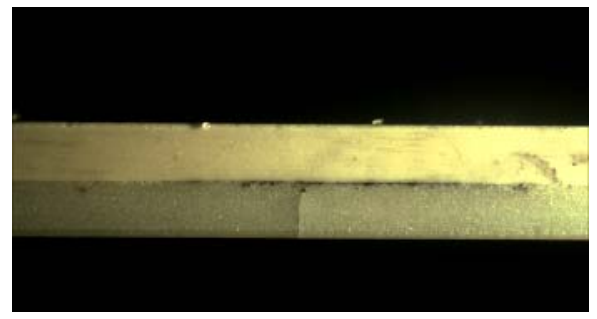

B

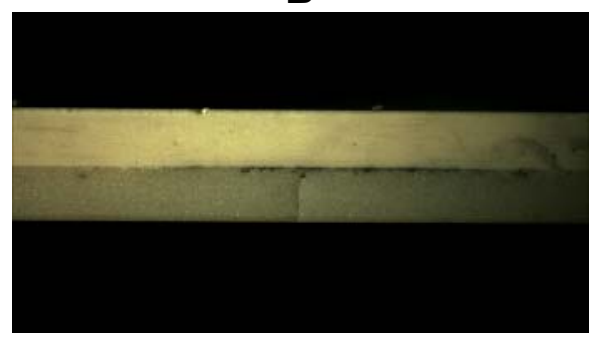

D

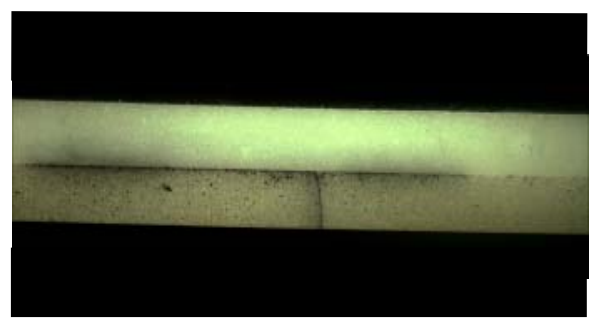

$\mathbf{F}$

Figura 5.14 - Corpos-de-prova de duas camadas após fratura em ensaio de flexão em três pontos com a porcelana em tração (PT). A e B) YZ-PT. C e D) IZ-PT. E e F) AL-PT. As trincas foram coradas com tinta preta para facilitar visualização. Nas imagens o material de infra-estrutura está sobre a camada de porcelana

A fratura teve início na camada de porcelana (em tração) e se propagou até a atingir a cerâmica de infra-estrutura. Imediatamente antes de atingir a infra-estrutura, 
a trinca sofreu uma deflexão ou bifurcação (Figura 5.14, partes B, C, D, E e F), provavelmente por encontrar neste ponto tensões de compressão e um aumento significativo e repentino do módulo de elasticidade. Nota-se que o mesmo modo de fratura ocorreu independentemente do material de infra-estrutura utilizado. O ensaio de resistência foi interrompido neste ponto e a carga obtida foi aplicada à equação 4.13 para o cálculo da resistência à fratura.

Os corpos-de-prova de duas camadas ensaiados com a infra-estrutura em tração dos grupos IZ e AL apresentaram apenas fratura total (Tabela 5.11). Já o grupo YZ-IT apresentou os dois tipo de fratura, total e parcial. A figura 5.15 mostra a superfície de fratura de corpos-de-prova dos grupos YZ-IT, IZ-IT e AL-IT que fraturaram como um corpo único. Nesses casos, a fratura iniciou na camada de infraestrutura em tração e se propagou sem desvios até a porcelana.

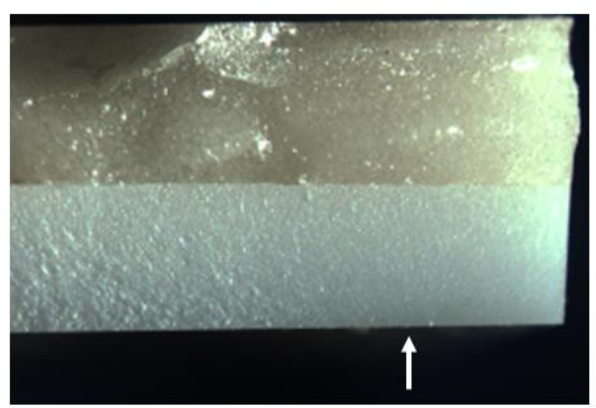

A

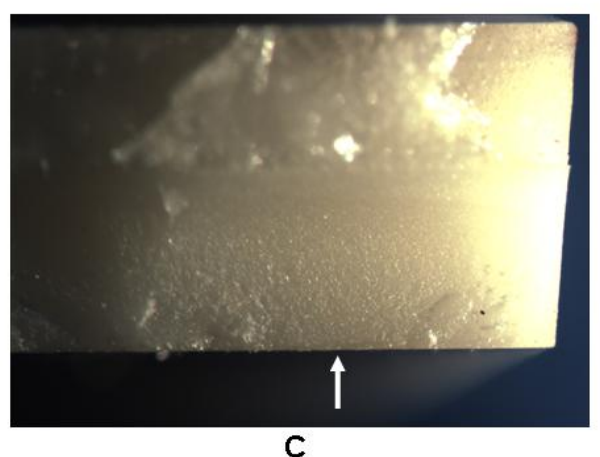

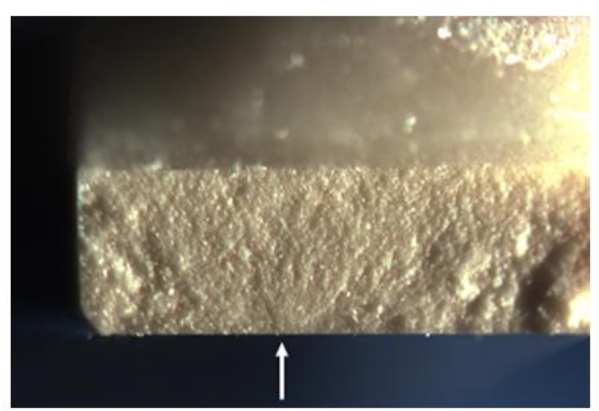

B

Figura 5.15 - Corpos-de-prova de duas camadas após fratura em ensaio de flexão de três pontos com material de infra-estrutura em tração. A) YZ-IT. B) IZ-IT. C) AL-IT. As flechas apontam para a origem do defeito crítico

Através da análise fractográfica dos corpos-de-prova foi possível observar que a origem do defeito crítico foi localizada na superfície da camada de infraestrutura (Figura 5.15 e Figura 5.16). Não foram encontradas falhas de canto ou internas. Análise de MEV evidenciou também a presença de cone cracks na 
superfície da porcelana em contato com o suporte de aplicação da carga (Figura $5.16)$.

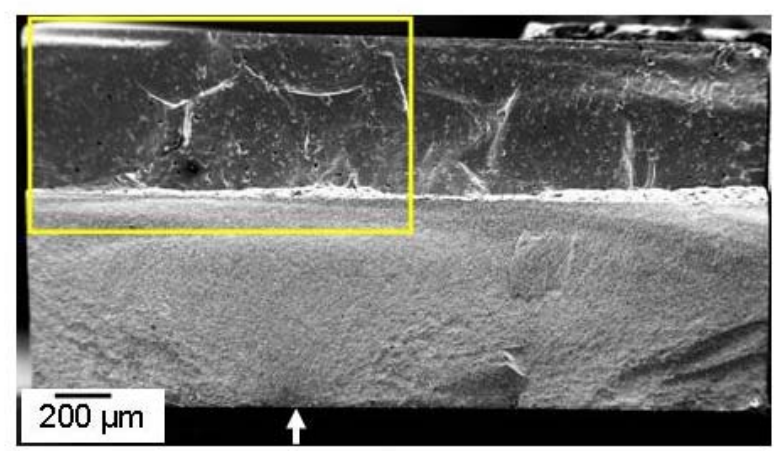

A

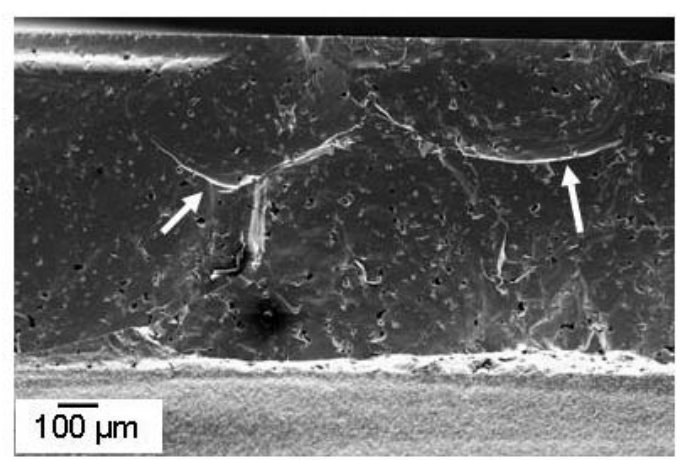

B

Figura 5.16 - Imagem de MEV da superfície de fratura de um corpo-de-prova do grupo IZ-IT. A) Imagem geral da superfície de fratura com a flecha apontando para a origem de defeito. B) Vista ampliada da interface entre a porcelana e a infra-estrutura (ampliação do quadro marcado na imagem A), as flechas evidenciam a presença de cone cracks na camada de porcelana submetida às tensões de compressão

A figura 5.17 mostra o padrão de falha dos corpos-de-prova do grupo YZ-IT que sofreram fratura parcial. Nessas estruturas, a porcelana que estava em compressão fraturou antes de ocorrer a falha da cerâmica de infra-estrutura. $\mathrm{Na}$ maioria dos casos houve também delaminação da camada de porcelana.

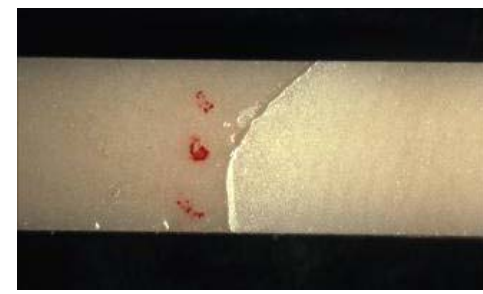

A

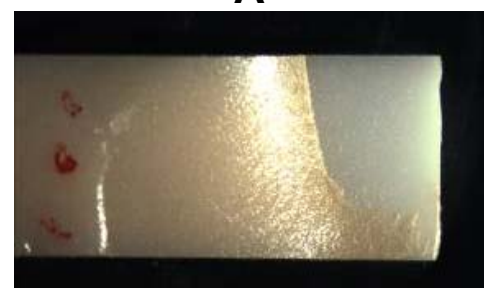

C

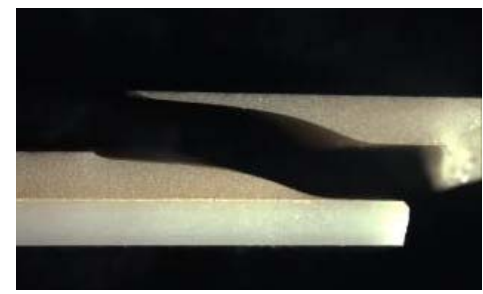

B

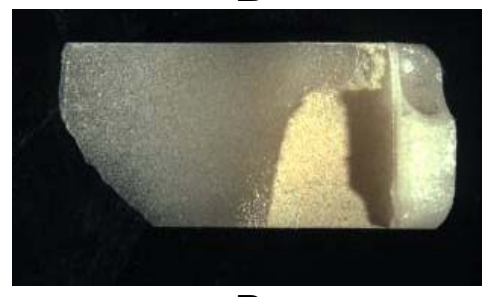

D

Figura 5.17 - Imagem do padrão de fratura parcial de um corpo-de-prova do grupo YZ-IT. A) Vista da camada de porcelana com os pedaços fraturados reposicionados. B) Vista lateral do corpo-de-prova fraturado com os pedaços sendo reposicionados. C) Vista da superfície de fratura da porcelana com parte da infra-estrutura exposta. D) Pedaço de porcelana que delaminou após a fratura 
Os corpos-de-prova de três camadas também apresentaram os dois tipos de fratura (parcial e total), como pode ser visto na figura 5.18. Oito corpos-de-prova do grupo YZ-TRI e cinco do grupo IZ-TRI tiveram somente a camada de porcelana que estava em tração fraturada (Tabela 5.11 e Figura 5.18, partes A e B), de forma semelhante à observada para as estruturas de duas camadas com porcelana em tração (Figura 5.14). Nesses casos a trinca iniciou na porcelana que estava em tração e se propagou em direção ao lado de compressão sofrendo uma acentuada deflexão ao atingir a região central da barra (Figura 5.18, partes A e B).

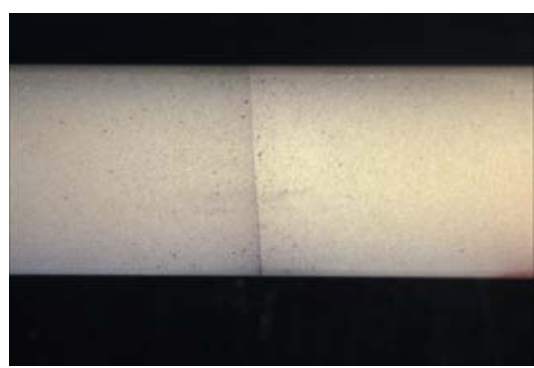

A

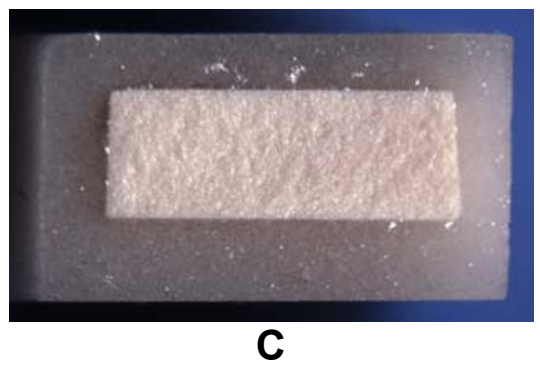

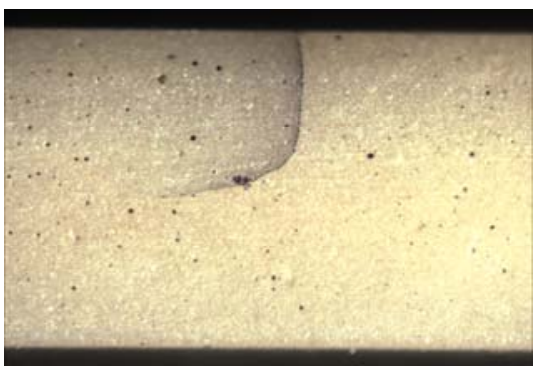

B

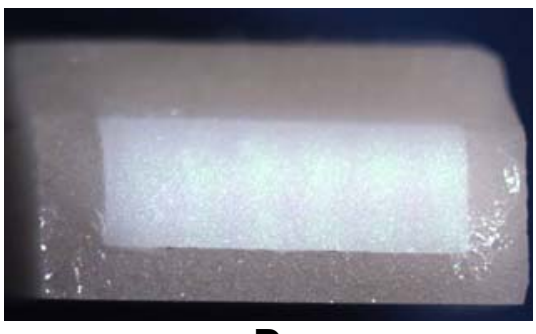

D

Figura 5.18 - Corpos-de-prova de três camadas após fratura em ensaio de flexão em três pontos. Vista superior (A) e vista lateral (B) de um corpo-de-prova do grupo YZ-TRI com fratura parcial. Superfície de fratura de corpo-de-prova dos grupos IZ-TRI (C) e ALTRI (D) que fraturaram como um corpo-único (fratura total)

Todos os corpos-de-prova do grupo AL-TRI fraturaram como um corpo único (fratura total), com a origem da fratura localizada na camada da porcelana submetida às tensões de tração (Figura 5.18 , parte $D$ ). A superfície dos corpos-deprova de três camadas que apresentaram fratura total foi analisada utilizando MEV (Figura 5.19). A origem do defeito crítico foi localizada na superfície da camada de porcelana em tração durante o ensaio (Figura 5.19, parte B). Não foi possível localizar outro defeito na camada de infra-estrutura e o plano de fratura foi único para as três camadas, indicando que a trinca se propagou de maneira catastrófica 
através da estrutura. Em alguns corpos-de-prova também foram identificados cone cracks na superfície da porcelana submetida às tensões de compressão.

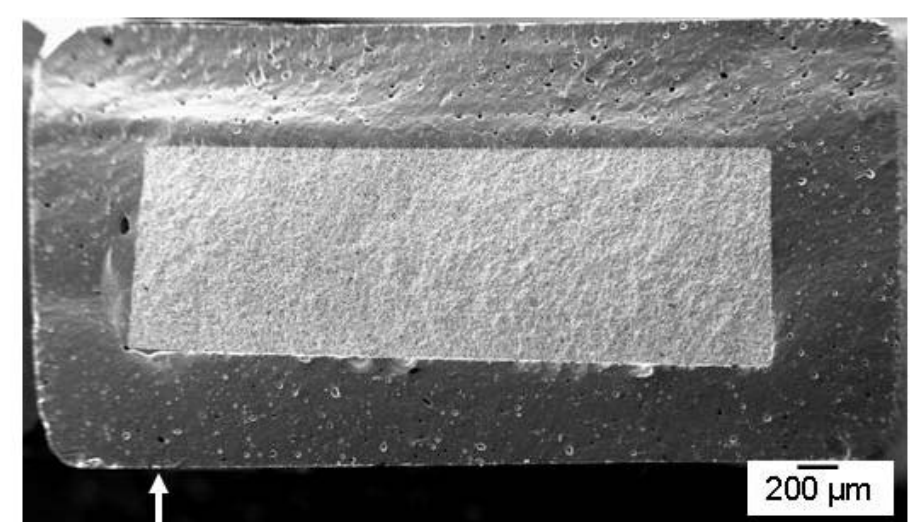

A

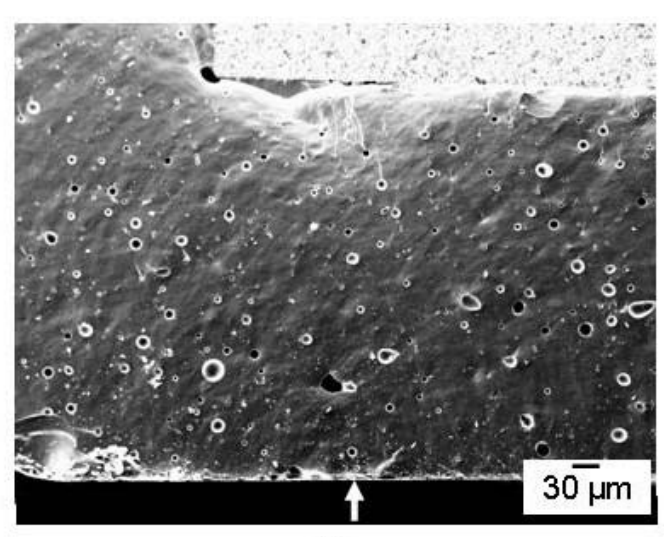

B

Figura 5.19 - Imagem de MEV da superfície de fratura de um corpo-de-prova do grupo IZ-TRI. A) Vista geral da superfície de fratura. B) Vista ampliada camada de porcelana evidenciando a origem do defeito. A flecha aponta para a origem do defeito crítico

\subsection{CARGA DE FRATURA E ANÁLISE FRACTOGRÁFICA DE PPFS TOTALMENTE CERÂMICAS}

\subsubsection{Influência do tipo de material e tamanho de conector}

Os valores de média, desvio padrão (DP), coeficiente de variação (CV), mediana e valores mínimo e máximo da carga de fratura $(\mathrm{N})$ para os grupos estudados se encontram na tabela 5.12 e na figura 5.20 (boxplot). O grupo YZ16 apresentou a maior mediana de carga de fratura. Não houve diferença entre os resultados de carga de fratura obtidos para os grupos YZ9, IZ16 e AL16. 
Tabela 5.12 - Valores de média, desvio padrão (DP), coeficiente de variação (CV), mediana, valores mínimos e máximos da carga de fratura $(\mathrm{N})$ para os grupos experimentais, e o grupamento estatístico* $(n=10)$

\begin{tabular}{ccccccc}
\hline Grupos & Média & DP & CV & Mediana* $^{*}$ & Mínimo & Máximo \\
\hline YZ9 & 2205 & 186 & 8 & $2211 \mathrm{~b}$ & 1864 & 2478 \\
\hline YZ16 & 4526 & 406 & 9 & $4540 \mathrm{a}$ & 3931 & 5202 \\
\hline IZ16 & 2309 & 134 & 6 & $2340 \mathrm{~b}$ & 2015 & 2469 \\
\hline AL16 & 1973 & 238 & 12 & $1994 \mathrm{~b}$ & 1622 & 2322 \\
\hline
\end{tabular}

*Valores seguidos da mesma letra na coluna são estatisticamente semelhantes $(p \geq 0,05)$.

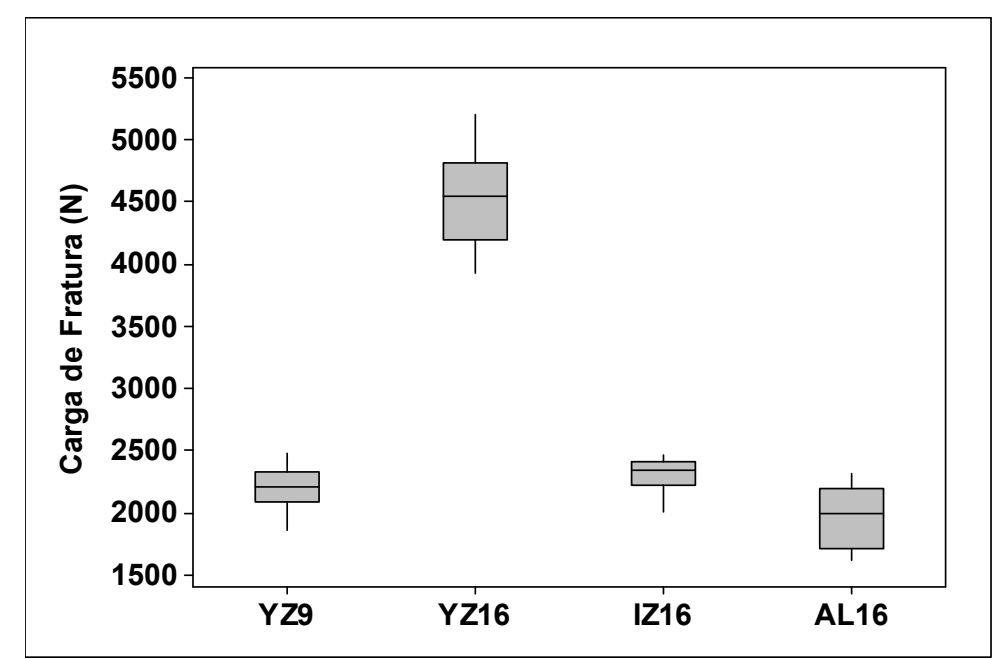

Figura 5.20 - Boxplot com os dados de carga de fratura $(\mathrm{N})$ dos quatro grupos experimentais

\subsubsection{Influência do envelhecimento mecânico}

Não foi observada influência da ciclagem mecânica nos valores de carga de fratura dos grupos avaliados. Para cada material de infra-estrutura, as medianas de carga de fratura obtidas pelo grupo controle e pelo grupo submetido à ciclagem mecânica foram estatisticamente semelhantes. A tabela 5.13 apresenta os valores de média, desvio padrão (DP), coeficiente de variação (CV), mediana e valores mínimo e máximo da carga de fratura $(\mathrm{N})$ para os grupos experimentais. Apesar da semelhança estatística, pode-se observar na tabela 5.13 e na figura 5.21 que houve um aumento (praticamente o dobro) nos valores de desvio padrão e coeficiente de variação para os grupos YZ16-CM e IZ16-CM em relação aos grupos controles (YZ16 e IZ16). 
Tabela 5.13 - Valores de média, desvio padrão (DP), coeficiente de variação (CV), mediana, valores mínimos e máximos da carga de fratura $(\mathrm{N})$ para os grupos controle e submetidos à ciclagem mecânica (CM), e o grupamento estatístico*. O valor de $\mathrm{n}$ para os grupos ciclados foi igual a 8

\begin{tabular}{ccccccc}
\hline Grupos & Média & DP & CV & Mediana* $^{*}$ & Mínimo & Máximo \\
\hline YZ16 & 4526 & 406 & 9 & $4540 \mathrm{a}$ & 3931 & 5202 \\
\hline YZ16-CM & 3944 & 719 & 18 & $3916 \mathrm{a}$ & 3074 & 4839 \\
\hline IZ16 & 2309 & 134 & 6 & $2340 \mathrm{~b}$ & 2015 & 2469 \\
\hline IZ16-CM & 2195 & 265 & 12 & $2196 \mathrm{~b}$ & 1835 & 2599 \\
\hline AL16 & 1973 & 238 & 12 & $1994 \mathrm{~b}$ & 1622 & 2322 \\
\hline AL16-CM & 2036 & 257 & 13 & $1977 \mathrm{~b}$ & 1724 & 2355 \\
\hline
\end{tabular}

*Valores seguidos da mesma letra na coluna são estatisticamente semelhantes $(p \geq 0,05)$.

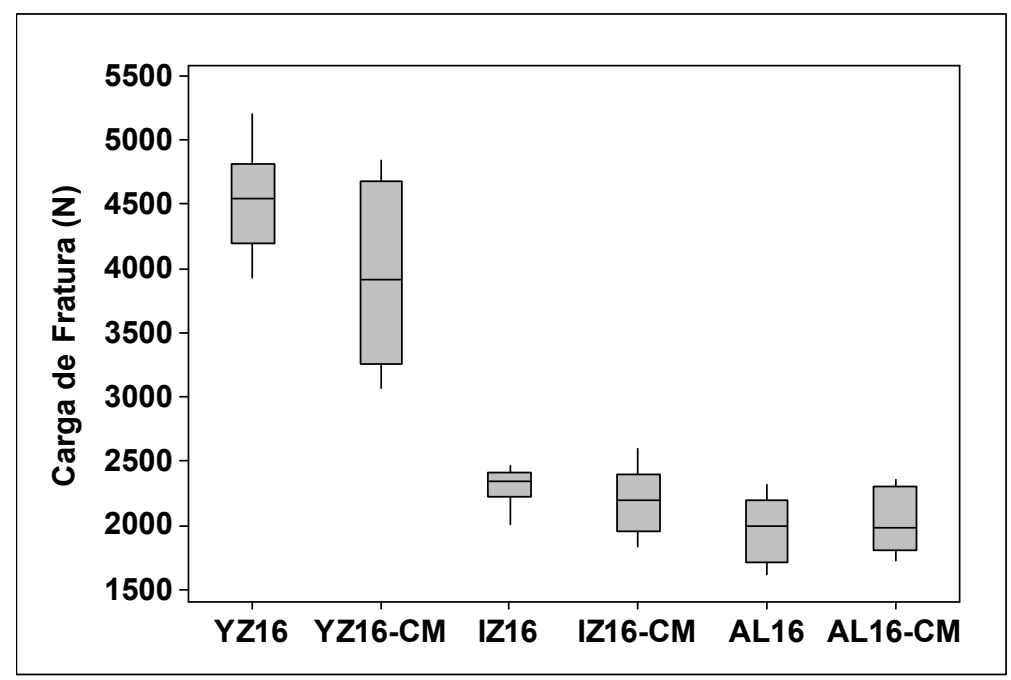

Figura 5.21 - Boxplot com os dados de carga de fratura (N) das PPFs dos grupos controle e submetidos à ciclagem mecânica (CM) para os três materiais de infra-estrutura

\subsubsection{Análise fractográfica}

A análise macroscópica das PPFs após o ensaio mecânico revelou que a fratura teve início na região cervical do conector ou pôntico e se propagou de forma oblíqua em direção à superfície oclusal. Em apenas 6 PPFs a fratura teve origem em um dos retentores, na margem adjacente ao conector. Portanto, o padrão de fratura macroscópica foi classificado em três tipos: (1) fratura do conector; (2) fratura do pôntico e (3) fratura do retentor (Figura 5.22). A presença ou não de delaminação da camada de porcelana durante a fratura também foi registrada. A tabela 5.14 mostra, para os grupos experimentais, a quantidade de cada tipo de fratura macroscópica e 
o número de PPFs que apresentaram delaminação da porcelana. O grupo YZ9 apresentou o maior número de fraturas de conector. Todas as fraturas do grupo IZ16 foram localizadas no pôntico. Os grupos YZ9, IZ16, AL16 e AL16-CM não apresentaram fratura do retentor. Os grupos AL16 e AL16-CM apresentaram o menor número de PPFs com delaminação da porcelana durante a fratura.

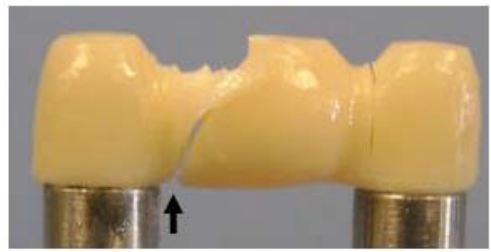

A

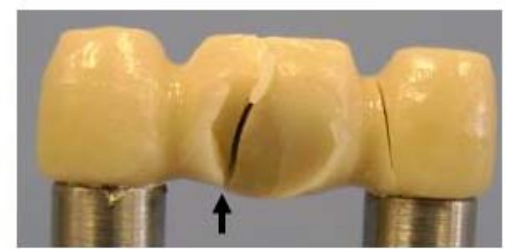

B

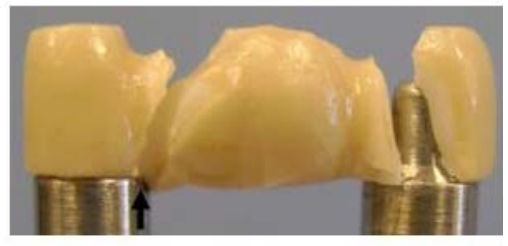

C

Figura 5.22 - Padrão de fratura macroscópica das PPFs, classificado de acordo com a origem da fratura. A) Fratura do conector. B) Fratura do pôntico. C) Fratura do retentor. As flechas apontam para o local de início da fratura

Tabela 5.14 - Número de PPFs com padrão de fratura iniciando no conector, no pôntico e nos retentores, para cada grupo experimental, além do número de delaminações. $O$ valor de n para os grupos controle e ciclado (CM) foi 10 e 8, respectivamente

\begin{tabular}{cccccccc}
\hline & \multicolumn{1}{c}{ Grupos } \\
\cline { 2 - 9 } & YZ9 & YZ16 & YZ16-CM & IZ16 & IZ16-CM & AL16 & AL16-CM \\
\hline Conector & 7 & 0 & 0 & 0 & 2 & 5 & 2 \\
\hline Pôntico & 3 & 7 & 6 & 10 & 5 & 5 & 6 \\
\hline Retentor & 0 & 3 & 2 & 0 & 1 & 0 & 0 \\
\hline Delaminação & 7 & 7 & 6 & 6 & 4 & 3 & 1 \\
\hline
\end{tabular}

Análise da superfície de fratura utilizando estereomicroscópio e MEV revelou diferentes origens de fratura. Na região cervical do pôntico e dos conectores, a origem da trinca foi localizada na superfície externa da porcelana ou na interface entre a porcelana e a cerâmica de infra-estrutura. Nos retentores, a trinca teve origem no material de infra-estrutura, na superfície interna da margem adjacente ao conector (Figura 5.23). 


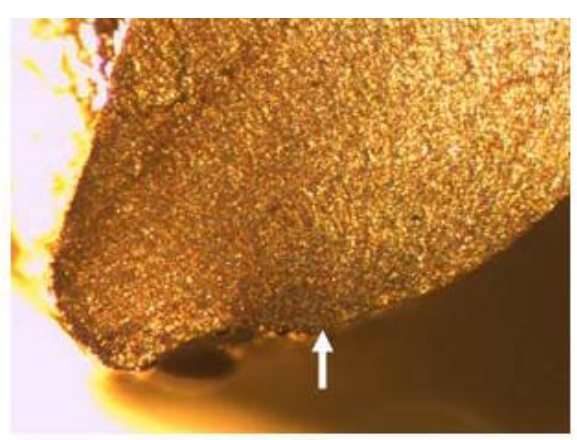

A

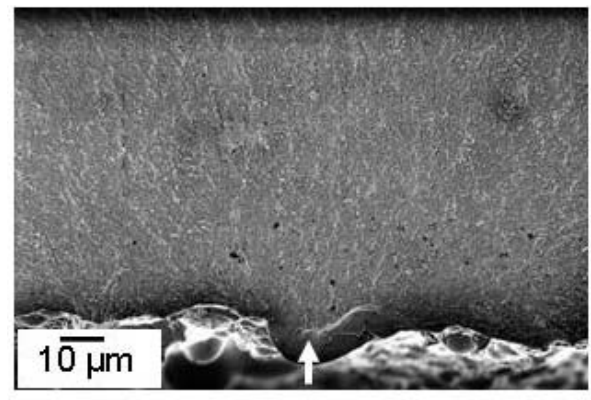

C

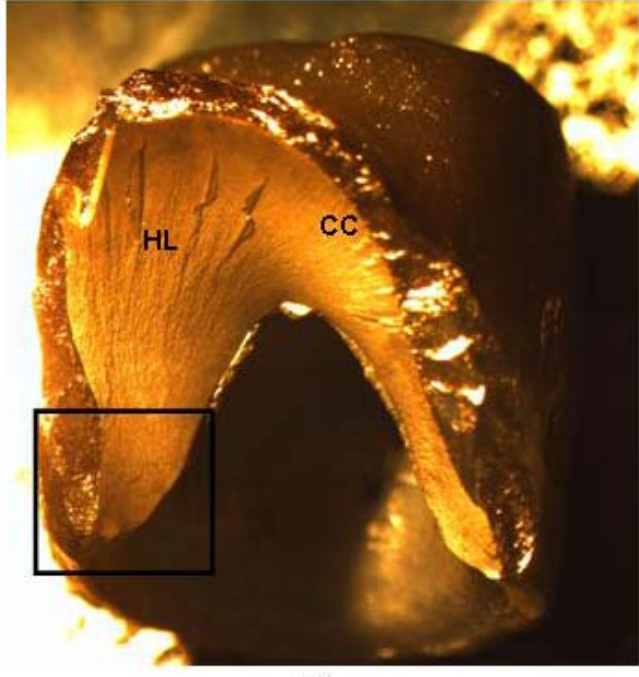

B

Figura 5.23 - Imagens da superfície de fratura de uma PPF do grupo YZ16 com fratura do retentor e origem do defeito na superfície interna da margem adjacente ao conector. A) Imagem de estereomicroscópio ampliada no local da origem do defeito. B) Imagem de estereomicroscópio da superfície de fratura do retentor. C) Imagem de MEV do defeito crítico. Pode-se observar marcas características como compression curl (CC) e hackles lines (HL). As flechas indicam a origem do defeito

A tabela 5.15 apresenta a origem de fratura para cada grupo avaliado. Para todos os grupos experimentais, foi possível encontrar até 8 corpos-de-prova com falhas com origem na superfície da porcelana do pôntico ou do conector. Os grupos IZ16, AL16 e AL16-CM apresentaram falha com origem na interface, sendo que o material $A L$ apresentou o maior número de falhas desse tipo. Não foi possível localizar a origem em algumas PPFs porque a superfície de fratura estava muito danificada.

Tabela 5.15 - Número de PPFs com origem de fratura na superfície da porcelana, na interface, na superfície interna da margem do conector e número de fraturas não identificadas para cada grupo estudado. $\mathrm{O}$ valor de $\mathrm{n}$ para os grupos controle e ciclado $(\mathrm{CM})$ foi 10 e 8 , respectivamente

\begin{tabular}{cccccccc}
\hline & \multicolumn{7}{c}{ Grupos } \\
\cline { 2 - 8 } & YZ9 & YZ16 & YZ16-CM & IZ16 & IZ16-CM & AL16 & AL16-CM \\
\hline Superfície & 8 & 6 & 6 & 6 & 4 & 4 & 0 \\
Interface & 0 & 0 & 0 & 2 & 0 & 6 & 6 \\
Margem & 0 & 3 & 2 & 0 & 1 & 0 & 0 \\
Não identificada & 2 & 1 & 0 & 2 & 3 & 0 & 2 \\
\hline
\end{tabular}


Nas PPFs com origem de fratura na superfície da porcelana foram encontrados dois defeitos críticos, um localizado na camada de porcelana e outro no material de infra-estrutura (Figura 5.24). Geralmente, o plano de fratura da porcelana foi diferente do plano de fratura da cerâmica de infra-estrutura. Esse comportamento foi evidenciado pela presença de delaminação da porcelana.

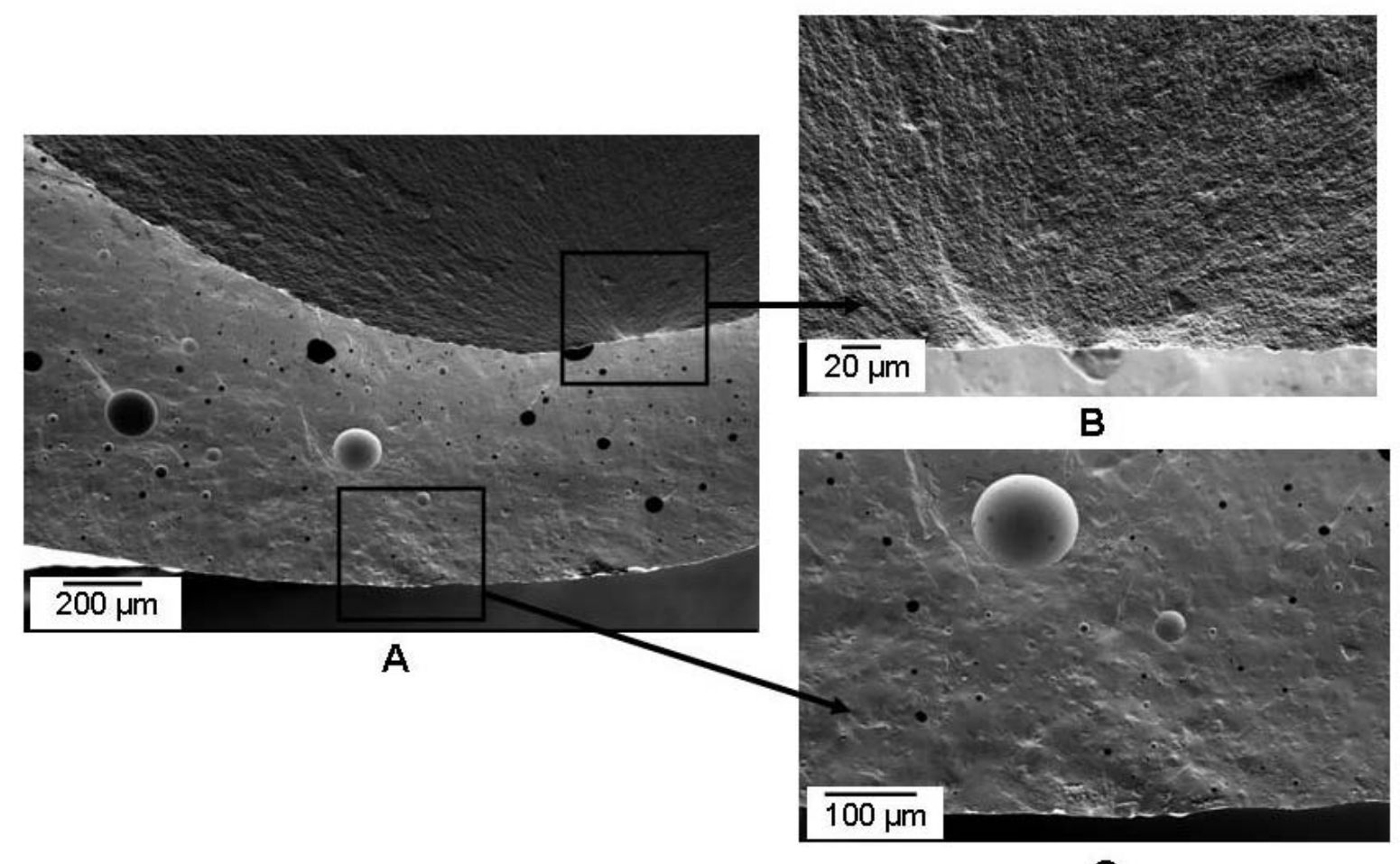

C

Figura 5.24 - Imagens de MEV da superfície de fratura de uma PPF do grupo YZ16 com fratura do pôntico e origem do defeito na superfície externa da porcelana. A) Imagem da região cervical do pôntico mostrando a camada de porcelana e a cerâmica de infraestrutura, os dois defeitos estão evidenciados nas caixas pretas. B) Defeito crítico na infra-estrutura. C) Defeito crítico na porcelana

Na superfície de fratura das PPFs com falha de interface foi encontrado apenas um defeito crítico, localizado na cerâmica de infra-estrutura. A camada de porcelana e o material de infra-estrutura apresentaram mesmo plano de fratura. Não foi observada delaminação da camada de porcelana nessas PPFs. Esse tipo de fratura pode ser observado na figura 5.25. 


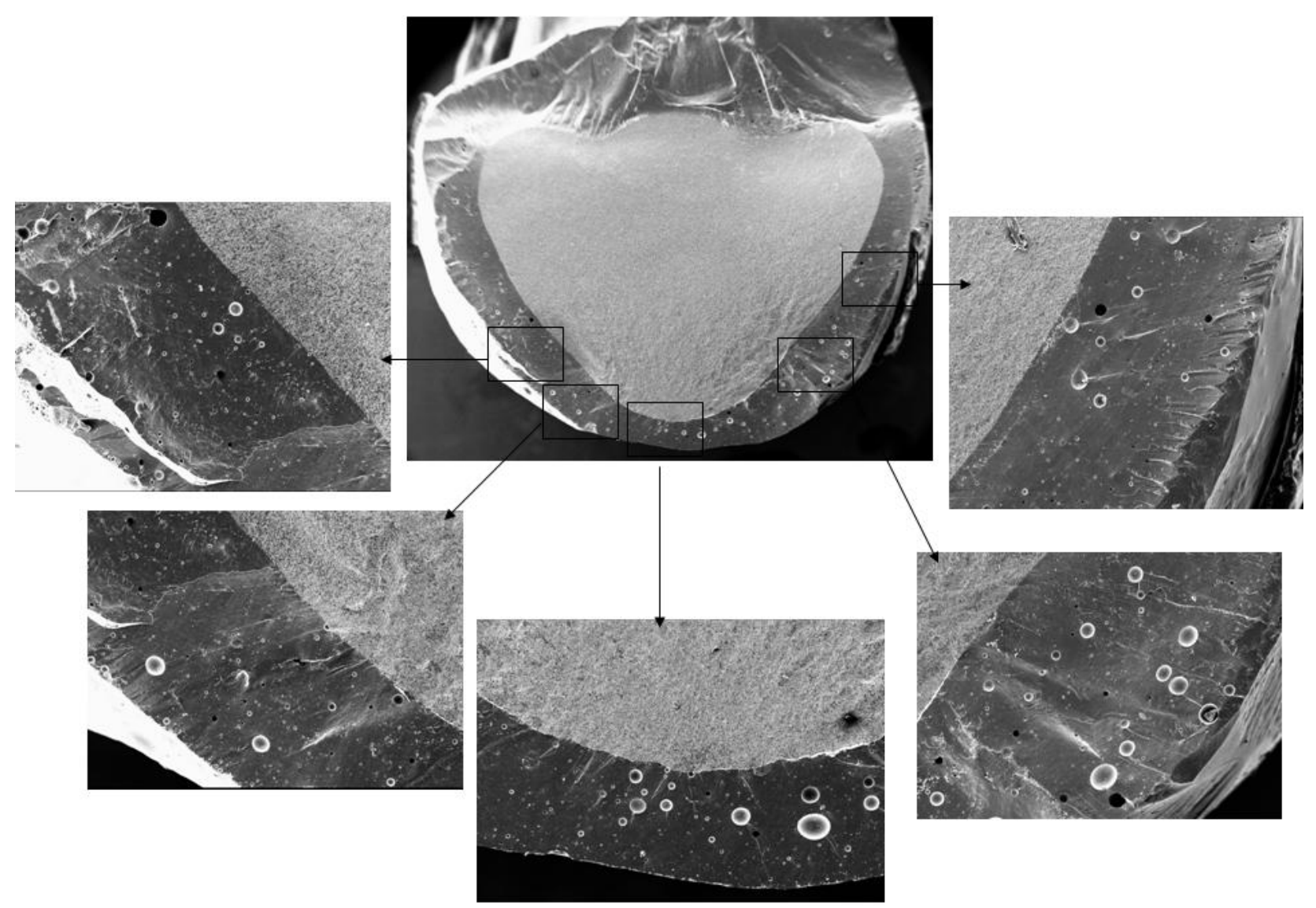

Figura 5.25 - Imagens de MEV mapeando a superfície de fratura de uma PPF do grupo AL16 com fratura do pôntico e origem do defeito na interface. Pode-se perceber nas imagens ampliadas da superfície de fratura que as wake hackles apontam para a interface

A tabela 5.16 apresenta os valores médios de tamanho de defeito crítico (c) e de tensão de fratura $\left(\sigma_{f}\right)$ das infra-estruturas das PPF. $O$ valor de $\sigma_{f}$ foi estimado utilizando os princípios da fractografia quantitativa (Equação 2.1, página 50) e com o valor de tenacidade à fratura $\left(\mathrm{K}_{\mathrm{IC}}\right)$ obtido para as barras monolíticas (Tabela 5.9, página 100). Foi utilizado um valor de $Y$ igual a 1,24. Pode-se observar que o tamanho de defeito crítico foi semelhante entre os grupos experimentais. Os valores de tensão de fratura $\left(\sigma_{f}\right)$ do grupo controle e submetido à ciclagem mecânica foram muito próximos, para cada material de infra-estrutura. A tensão de fratura foi semelhante para o grupo YZ9 e YZ16. A figura 5.26 apresenta a imagem da superfície de fratura de uma PPF de IZ e outra de AL, evidenciando o defeito crítico que foi mensurado para realizar a estimativa da resistência à fratura da infraestrutura. Não foi realizada a estimativa de resistência da porcelana porque na maioria dos casos essa camada estava muito danificada e não era possível medir o tamanho do defeito crítico. 
Tabela 5.16 Valores médios de tamanho do defeito crítico (c) e tensão de fratura $\left(\sigma_{f}\right)$ das infraestruturas dos grupos experimentais. $O$ valor de $n$ para os grupos controle e ciclado (CM) foi igual a 8 e 5 , respectivamente. Os valores estão dispostos em média \pm desvio padrão

\begin{tabular}{cccccccc}
\hline & \multicolumn{7}{c}{ Grupos } \\
\cline { 2 - 8 } & YZ9 & YZ16 & YZ16-CM & IZ16 & IZ16-CM & AL16 & AL16-CM \\
\hline $\mathbf{c ~}(\mu \mathrm{m})$ & $32 \pm 6$ & $25 \pm 5$ & $31 \pm 4$ & $38 \pm 6$ & $34 \pm 5$ & $38 \pm 5$ & $37 \pm 6$ \\
\hline$\sigma_{\mathbf{f}}$ & $939,1 \pm$ & $1072,6 \pm$ & $945,4 \pm$ & $473,0 \pm$ & $498,9 \pm 38$ & $461,1 \pm$ & $475,5 \pm$ \\
$(\mathbf{M P a})$ & 81,7 & 115,1 & 49,2 & 41,0 & & 26,9 & 37,3 \\
\hline
\end{tabular}

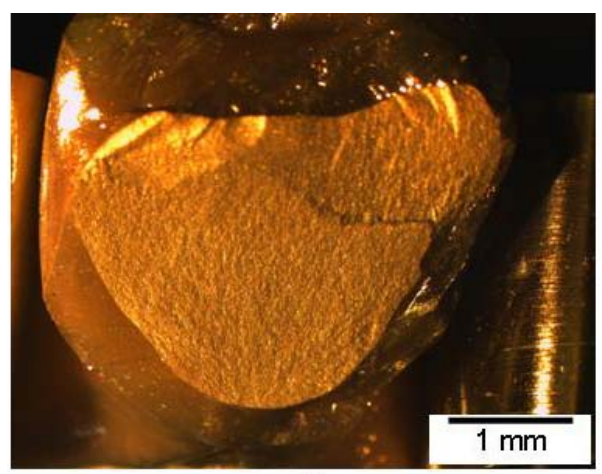

A

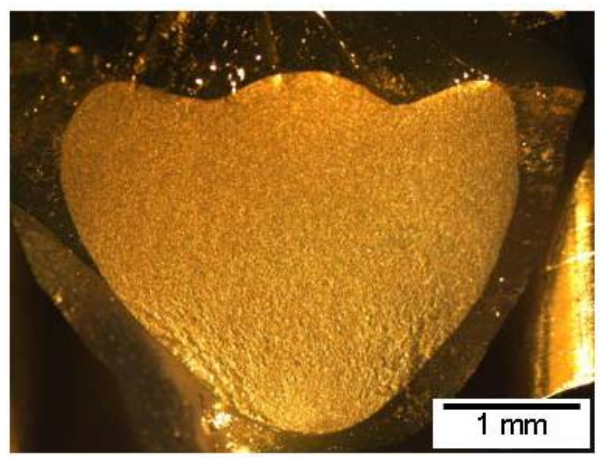

C

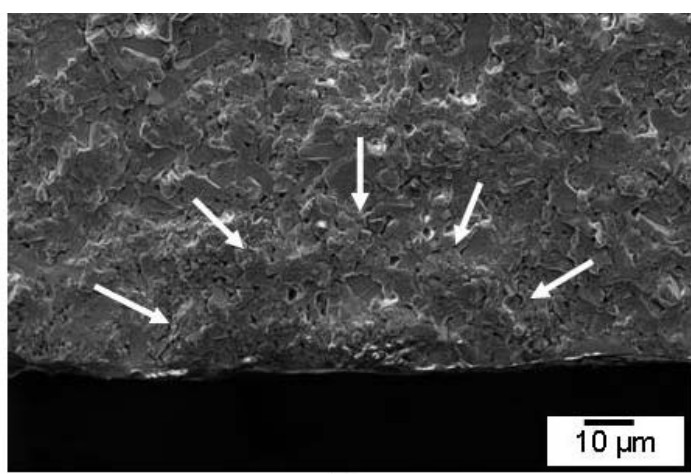

B

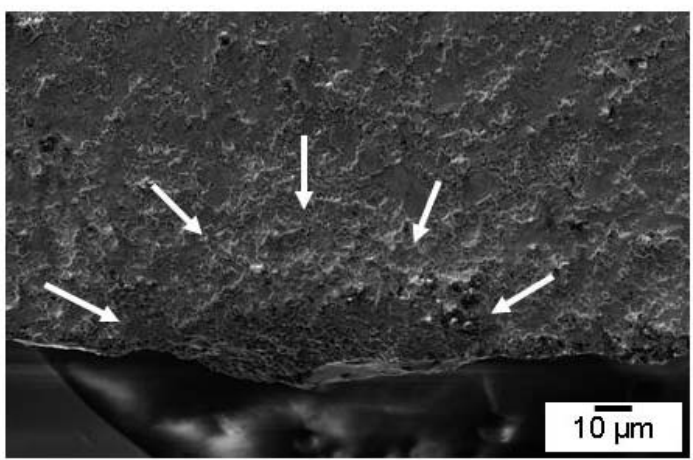

D

Figura 5.26 - Imagens de estereomicroscópio da superfície de fratura de uma PPF do grupo IZ16 (A) e do grupo AL16 (C). Imagens de MEV do defeito crítico para a infra-estrutura do grupo IZ16 (B) e AL16 (D)

\subsection{ANÁLISE DE ELEMENTOS FINITOS (AEF)}

Foi observada uma boa convergência de resultados para os quatro modelos avaliados. O modelo final utilizado na análise apresentou um número total de 127.191 elementos. Esse modelo foi selecionado pois obteve melhor precisão de resultados sem prolongar de maneira significativa o tempo necessário para a análise. 
Em todos os modelos avaliados o pico de tensão máxima de tração foi encontrado na infra-estrutura. As imagens da análise apresentam escala de tensão semelhante para facilitar a comparação entre os grupos. As regiões com cores quentes representam tensões de tração e as regiões com cores frias tensões de compressão.

Considerando apenas as infra-estruturas dos grupos YZ9 e YZ16, pode-se observar que o padrão geral de distribuição de tensões foi semelhante. Na figura 5.27 é possível observar, para ambos os modelos, maior concentração de tensões de tração na região cervical do pôntico e nas regiões gengival e lateral dos conectores. Nessa imagem também é evidenciada uma maior concentração de tensões de tração na oclusal dos conectores de $9 \mathrm{~mm}^{2}$ do que nos conectores de 16 $\mathrm{mm}^{2}$.

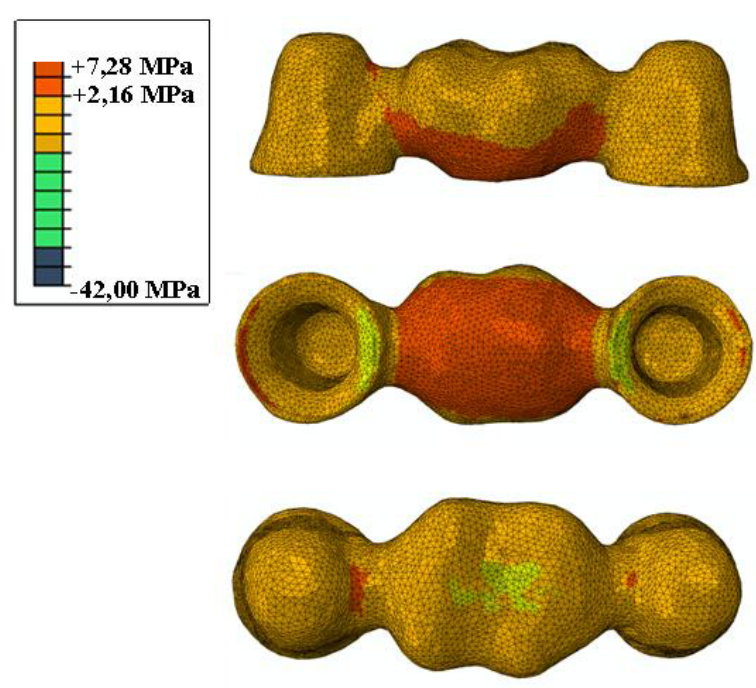

A

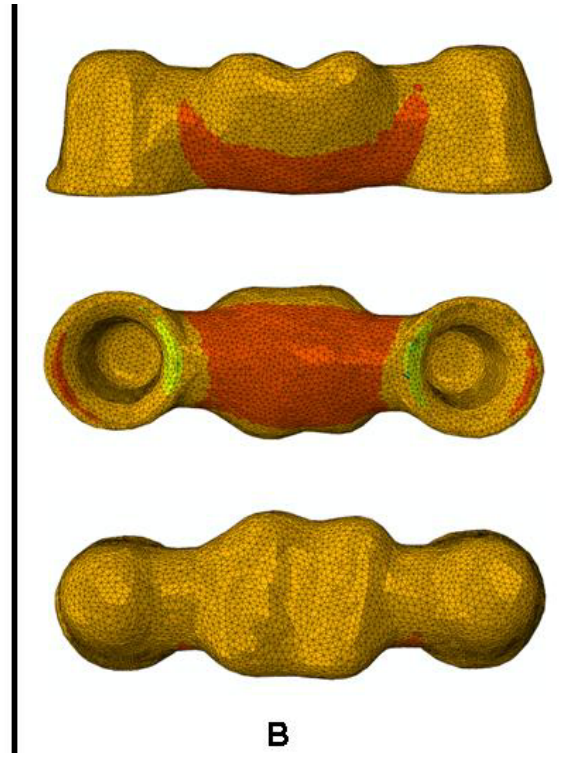

B

Figura 5.27 - Imagem lateral, cervical e oclusal das infra-estruturas dos grupos YZ9 (A) e YZ16 (B)

Quando a escala é modificada para evidenciar melhor as faixas de tensões nota-se que na infra-estrutura de $16 \mathrm{~mm}^{2}$ a distribuição de tensões de tração é mais uniforme e localiza-se logo abaixo do pôntico. Já na infra-estrutura de $9 \mathrm{~mm}^{2}$ as tensões máximas de tração são concentradas em regiões menores e mais próximas dos conectores (Figura 5.28). Além disso, na figura 5.28 também é possível observar que a infra-estrutura de $16 \mathrm{~mm}^{2}$ possui maior concentração de tensões de tração nos retentores do que a de $9 \mathrm{~mm}^{2}$. 


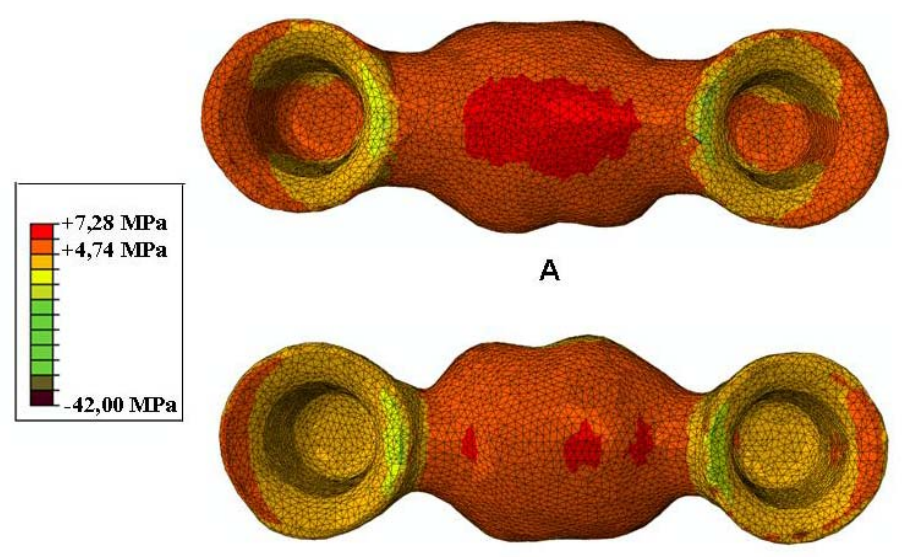

B

Figura 5.28 - Faixas de tensões na região cervical das infra-estruturas de $16 \mathrm{~mm}^{2}$ (A) e $9 \mathrm{~mm}^{2}$ (B)

Para os grupos YZ9 e YZ16, o mesmo comportamento observado nas infraestruturas foi encontrado na camada de porcelana, com maior concentração de tensões de tração nas regiões de pôntico e conectores (Figura 5.29). Nas PPFs de $16 \mathrm{~mm}^{2}$ as tensões de tração foram mais concentradas na região cervical do pôntico e nas PPFs de $9 \mathrm{~mm}^{2}$ na região cervical dos conectores.

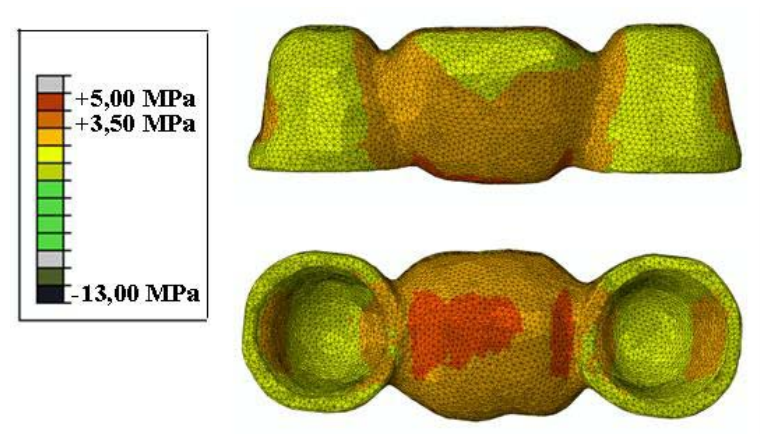

A

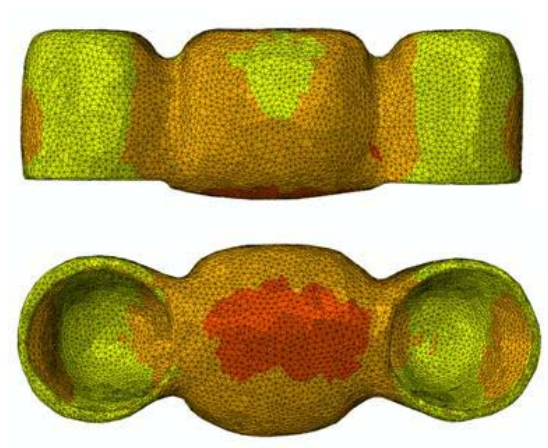

B

Figura 5.29 - Imagem lateral e cervical da camada de porcelana do grupo YZ9 (A) e YZ16 (B)

Quando as infra-estruturas com mesmo tamanho de conector $\left(16 \mathrm{~mm}^{2}\right)$ e diferentes sistemas cerâmicos foram comparadas observaram-se padrões de tensão semelhantes (Figura 5.30). A figura 5.30 apresenta as faixas de tensões para as infra-estruturas dos grupos IZ16 e AL16. O modelo YZ16 já foi apresentado na figura 5.27. Pode-se observar que para a cerâmica $A L$ foi encontrada uma pequena diferença, sendo que houve uma maior concentração de tensões na região cervical do pôntico em relação aos outros sistemas (Figura 5.30, parte B). 


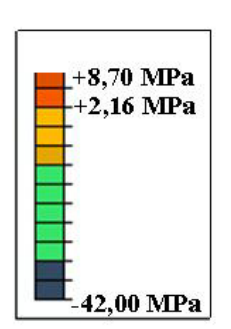

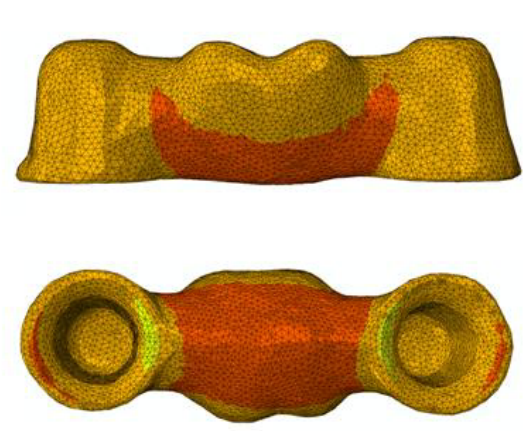

A

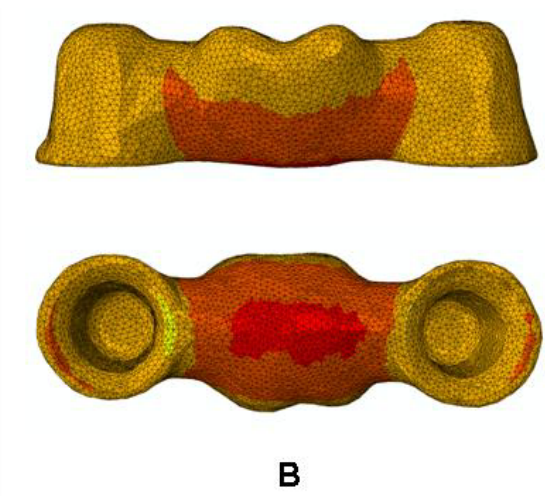

Figura 5.30 - Imagem lateral e cervical das infra-estruturas com conector de $16 \mathrm{~mm}^{2}$ para os sistemas IZ (A) e AL (B)

Considerando a camada de porcelana dos grupos YZ16, IZ16 e AL16, foi observado um aumento da concentração de tensões de tração na região cervical do pôntico e conectores com a diminuição do módulo de elasticidade do material de infra-estrutura (Figura 5.31). O mesmo comportamento foi observado nos retentores.

Nos modelos de infra-estrutura, para todos os grupos avaliados, foi observada concentração de tensões de tração na margem do retentor oposta ao conector. Na margem adjacente ao conector foram encontradas tensões de compressão.
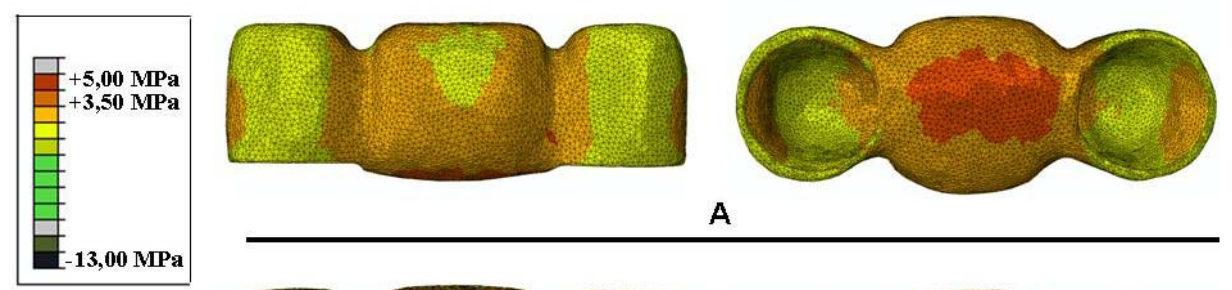

A
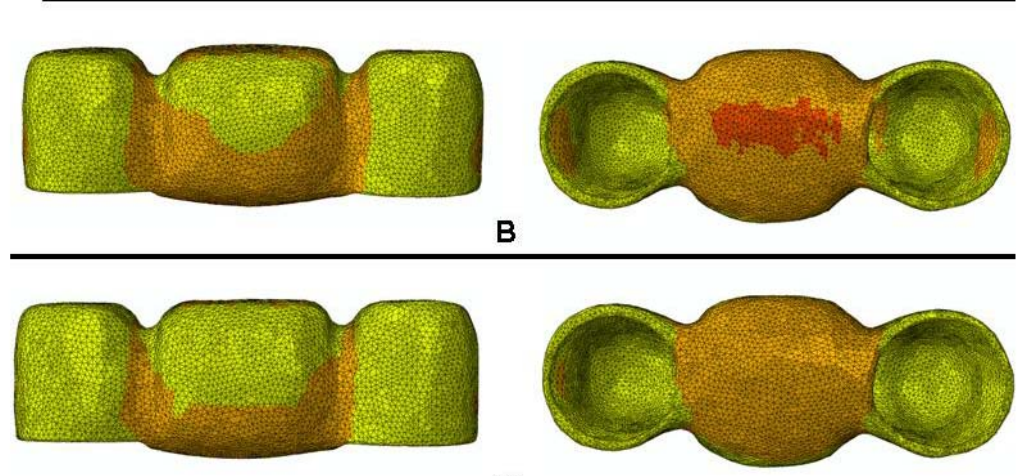

C

Figura 5.31 - Imagem lateral e cervical da camada de porcelana dos grupos YZ16 (A), IZ16 (B) e AL16 (C) 
Os valores de tensão de tração máxima principal da infra-estrutura e da camada de porcelana dos modelos avaliados estão na tabela 5.17. Em todos os modelos, o pico máximo da tensão máxima principal foi localizado na região cervical do pôntico, próximo a um dos conectores. Não foi observada grande diferença entre os valores de tensão de tração para os grupos estudados, tanto na infra-estrutura como na camada de porcelana. Para o grupo AL foi observado um valor um pouco maior de tensão máxima principal na infra-estrutura e menor na camada de porcelana em comparação aos demais modelos avaliados. O modelo YZ9 apresentou valores de tensão um pouco maiores do que o YZ16.

Tabela 5.17 - Valor da tensão de tração máxima principal para os modelos avaliados (MPa)

\begin{tabular}{ccccc}
\hline & \multicolumn{5}{c}{ Grupos } \\
\cline { 2 - 5 } & YZ9 & YZ16 & AL16 & IZ16 \\
\hline Infra-estrutura & 7,28 & 6,65 & 8,70 & 7,06 \\
\hline Porcelana & 3,82 & 2,66 & 1,90 & 2,46 \\
\hline
\end{tabular}




\section{DISCUSSÃO}

\subsection{RESISTÊNCIA À FLEXÃO DE CORPOS-DE-PROVA MONOLÍTICOS}

A cerâmica $Y Z$ apresentou os maiores valores de $\sigma_{f}$ entre os grupos estudados. Os resultados obtidos para esse sistema estão de acordo com valores reportados na literatura (Guazzato et al., 2004a) e pelo fabricante (900 MPa). Guazzato et al. (2004a) avaliaram os sistemas YZ e IZ (blocos pré-fabricados) e observaram valores de resistência à flexão em três pontos muito próximos aos encontrados no presente estudo, $840 \mathrm{MPa}$ e $476 \mathrm{MPa}$, respectivamente. Por outro lado, Oilo et al. (2008) encontraram valores um pouco mais altos de $\sigma_{f}$ para a cerâmica YZ, ao redor de $1500 \mathrm{MPa}$. A variação dos valores encontrados na literatura para as propriedades mecânicas da $Y Z$ pode estar relacionada com as diferenças na quantidade do óxido estabilizante, tamanho e orientação de cristal e método de processamento utilizado, e da influência desses fatores na porosidade e metaestabilidade dos cristais tetragonais (Denry; Kelly, 2008; Della Bona, 2009). No presente estudo, após a sinterização, as barras foram submetidas a um procedimento de usinagem com o objetivo de se obter espessura adequada e produzir faces lisas e paralelas entre si. Para a $\mathrm{YZ}$, esse procedimento de desgaste pode resultar em corpos-de-prova com valores de resistência superiores, por causa da camada de tensões de compressão induzidas na superfície pela transformação da fase tetragonal para monoclínica. No entanto, dependendo da severidade e temperatura da usinagem e da porcentagem de transformação de fase induzida, esse procedimento pode ser deletério para a resistência do material (Kosmac et al., 1999; Luthardt et al., 2002; Guazzato et al., 2005; Kim et al., 2010). Como o procedimento de usinagem realizado no presente estudo seguiu as recomendações da ASTM-C-1421 (2001), que visa minimizar a geração de defeitos e tensões residuais nos corpos de prova, sugere-se que não houve uma degradação das propriedades da YZ. Entretanto, seria necessária uma avaliação do conteúdo de cristais monoclínicos da superfície para se obter informações mais precisas sobre os efeitos desse procedimento nos corpos-de-prova de $Y Z$. 
Para os sistemas a base de zircônia (YZ e IZ), alguns autores observaram valores de resistência à flexão mais elevados do que os valores encontrados no presente estudo (Kosmac et al., 1999; Guazzato et al., 2002; Yilmaz et al., 2007). No entanto, o método de ensaio utilizado nesses trabalhos foi flexão biaxial. A distribuição de tensões é diferente nos vários métodos de ensaios de flexão. No ensaio de flexão biaxial, o volume de material submetido às tensões de tração é usualmente menor do que no ensaio de flexão em três pontos. Considerando que os valores de resistência aumentam à medida que o volume sujeito às tensões de tração diminui, pode-se esperar resultados um pouco maiores quando o ensaio de flexão biaxial é utilizado (Della Bona, 2009). Além disso, o ensaio de flexão biaxial é menos sensível aos defeitos nas bordas e às imperfeições de superfície do que os ensaios de flexão em três e quatro pontos (Zeng et al., 1996).

Com relação ao sistema $I Z$, outro fator que pode afetar os valores de resistência é o método de fabricação dos corpos-de-prova (técnica da barbotina ou blocos pré-fabricados) (Yilmaz et al., 2007). Entretanto, não existe um consenso na literatura a respeito da influência da técnica de confecção dos corpos-de-prova no comportamento mecânico da IZ. Guazzato et al. (2004a) observaram que os valores de resistência à flexão para o material $I Z$ foram maiores quando foi utilizada a técnica da barbotina em comparação com os blocos pré-fabricados. Porém, encontraram valores de tenacidade à fratura semelhantes para as duas técnicas de confecção de corpos-de-prova. Segundo os autores, esse resultado foi conseqüência da porosidade e não do processamento dos materiais. A distribuição deficiente das partículas de alumina e zircônia e a baixa solubilidade entre as fases cristalinas e a matriz vítrea resultaram em maior volume de poros no sistema IZ. Além disso, uma temperatura baixa de sinterização, utilizada com o objetivo de evitar contração do material e garantir maior precisão na confecção das restaurações, não favorece a coalescência e distribuição uniforme dos cristais (Della Bona et al., 2007). Outro estudo avaliou a resistência à flexão de um compósito semelhante ao IZ (In-Ceram Alumina) e não encontrou diferença significativa entre as duas técnicas de confecção de corpos-de-prova. Entretanto, os valores de desvio padrão dos grupos confeccionados pela técnica da barbotina foram 50\% e 100\% maiores do que o valor do grupo usinado. Além disso, foi possível observar a presença de macro-porosidades na superfície de fratura dos corpos-de-prova 
produzidos pela técnica da barbotina, sugerindo que a fabricação industrial de blocos cerâmicos produz uma estrutura mais homogênea (Apholt et al., 2001).

No presente estudo os corpos-de-prova foram confeccionados utilizando blocos pré-sinterizados para CAD-CAM e não a técnica da barbotina. Algumas investigações reportam para a IZ resultados de flexão em três pontos superiores aos obtidos no presente estudo (500-600 MPa), utilizando a técnica da barbotina (Seghi; Sorensen, 1995; Chong et al., 2002; Guazzato et al., 2004a). Por outro lado, Bottino et al. (2009) também utilizaram essa técnica de confecção de corpos-de-prova e encontraram valores de $\sigma_{f}$ muito próximos aos observados para o grupo IZ (440 MPa). Um estudo observou valores altos de resistência à flexão em três pontos para corpos-de-prova do sistema IZ confeccionados a partir de blocos pré-fabricados (Apholt et al., 2001). Entretanto, nessa investigação os corpos-de-prova foram obtidos através da usinagem dos blocos pelo sistema CAD-CAM. No presente estudo, as barras foram obtidas através do corte dos blocos em uma cortadeira com disco de diamante. A metodologia de confecção dos corpos-de-prova tem influência na população dos defeitos e, conseqüentemente, nas propriedades mecânicas dos materiais. Portanto, além da técnica de confecção, outros fatores relacionados à metodologia de obtenção dos corpos-de-prova devem ser levados em consideração quando os resultados de diferentes estudos são comparados.

$O$ material $A L$ foi introduzido recentemente no mercado por isso não foram encontrados estudos comparativos. O valor médio de resistência à flexão reportado pelo fabricante para a $A L$ foi maior do que o valor observado no presente estudo. Além disso, um estudo com outro sistema cerâmico de alumina policristalina (Procera AllCeram) também observou valores de resistência à flexão em três pontos significativamente mais altos (600 MPa) (Andersson; Oden, 1993). No entanto, é importante ressaltar que os valores de $\sigma_{f}$ obtidos pelo grupo AL foram semelhantes aos obtidos pelo grupo IZ.

Com relação às porcelanas, uma investigação relatou um valor médio de resistência à flexão em três pontos para VM7 (63,5 $\mathrm{MPa}$ ) muito próximo ao valor encontrado no presente estudo (Bottino et al., 2009). Por outro lado, Fischer et al. (2008) observaram valores mais altos de resistência para porcelanas utilizadas no recobrimento de infra-estruturas de $\mathrm{YZ}$, variando entre 77,8 MPa e 106,6 MPa. A diferença entre os resultados encontrados na literatura está relacionada com a dificuldade de padronização dos corpos-de-prova de porcelana devido à 
sensibilidade da técnica de fabricação. A proporção pó-líquido tem influência na confiabilidade dos resultados de resistência à fratura (Fleming et al., 1999; Fleming et al., 2000). Fleming et al. (2000) observaram que para um proporção pó-líquido ótima de porcelana $(0.91 \mathrm{~g}$ de pó e $0,33 \mathrm{ml}$ de líquido) a porosidade aparente é menor do que para as outras proporções avaliadas, resultando em menor variabilidade dos resultados. Os autores sugerem que, para porcelanas, a comparação entre valores de resistência só pode ser realizada se os corpos-deprova são produzidos de maneira a garantir a reprodutibilidade dos resultados. A temperatura e tempo de sinterização da porcelana também têm influência na porosidade (Cheung; Darvell, 2002). Em geral, menor porosidade é obtida quando a sinterização da porcelana é realizada em alta temperatura e curto período de tempo. É possível identificar as condições ótimas de sinterização através do mapeamento do comportamento de cada material em diferentes combinações de temperatura e tempo (Cheung; Darvell, 2002). Os poros têm efeito deletério na resistência à fratura dos materiais porque podem atuar como concentradores de tensões e também porque reduzem a área de secção transversal sobre a qual a carga é aplicada. Além das porcelanas, o sistema IZ também pode ter suas propriedades mecânicas comprometidas pelo volume de poros, caso a distribuição das partículas de alumina e zircônia seja deficiente ou existir uma baixa solubilidade entre as fases cristalinas e a matriz vítrea (Guazzato et al., 2004a).

Através da análise fractográfica dos corpos-de-prova monolíticos foi possível observar que o tamanho de defeito crítico foi semelhante entre os materiais de infraestrutura (34 a $48 \mu \mathrm{m}$ ) e entre as porcelanas (75 a $86 \mu \mathrm{m})$. Esse resultado reflete a influência da metodologia de confecção dos corpos-de-prova e da microestrutura na distribuição dos defeitos. Apesar dos procedimentos de usinagem e polimento da superfície serem semelhantes para todos os materiais, os passos iniciais de confecção dos corpos-de-prova foram diferentes para os materiais de infra-estrutura (corte de blocos pré-fabricados) e para as porcelanas (suspensão pó-líquido). A fabricação industrial de blocos cerâmicos pode garantir uma microestrutura mais uniforme e menor tamanho e fração volumétrica de poros (Apholt et al., 2001). Por outro lado, a técnica de confecção da porcelana é sensível a vários fatores, como mencionado no parágrafo acima, e sua microestrutura apresenta maior tamanho e fração volumétrica de poros, produzindo maiores defeitos de superfície (Fleming et al., 1999; Fleming et al., 2000). 
Segundo a norma ISO 6872 (2008), um material cerâmico pode ser indicado como infra-estrutura de PPF envolvendo a restauração de molares se apresentar um valor de resistência à flexão $\left(\sigma_{f}\right)$ de no mínimo $500 \mathrm{MPa}$. Se esse valor for superior a $800 \mathrm{MPa}$, o material também pode ser indicado como infra-estrutura de PPFs de quatro ou mais elementos, como é o caso da $Y Z$, que apresentou valor médio de $\sigma_{f}$ igual a $869 \mathrm{MPa}$ no presente estudo. No entanto, o sistema IZ é indicado pelo fabricante para a confecção de PPFs posteriores, mas apresentou valor médio de $\sigma_{f}$ inferior a $500 \mathrm{MPa}$. Os resultados obtidos pela IZ foram semelhantes aos encontrados para o sistema $A L$, que é indicado como infra-estrutura de PPFs apenas na região anterior (sem substituição de molares). Para as duas porcelanas estudadas, a média de $\sigma_{f}$ foi superior a $50 \mathrm{MPa}$, que é considerado o valor mínimo de resistência para que o material possa ser utilizado no recobrimento de infraestruturas de metal ou cerâmica.

\subsection{CONFIABILIDADE DOS SISTEMAS CERÂMICOS}

Os valores de $m$ das cerâmicas de infra-estrutura variaram entre 9 e 16 e das porcelanas entre 6 e 8 , porém não houve diferença estatística entre os grupos. Apenas foi observada diferença significativa entre os valores de $m$ dos grupos $\mathrm{IZ} \mathrm{e}$ VM7, sendo que a porcelana VM7 apresentou o menor valor de $\mathrm{m}$, como pode ser observado pela maior inclinação da curva desse material no gráfico da figura 5.5 (página 90) Valores de $\mathrm{m}$ muito próximos indicam uma dispersão de dados semelhante para os grupos avaliados. Portanto, estima-se que a confiabilidade desses sistemas cerâmicos também seja semelhante.

Os valores de módulo de Weibull dos materiais de infra-estrutura obtidos no presente estudo estão na mesma faixa de valores encontrados na literatura, entre 9 e 18 para cerâmicas a base de zircônia e alumina (Zeng et al., 1996; Kosmac et al., 1999; Tinschert et al., 2000, 2007; Chong et al., 2002; Luthardt et al., 2002; Teixeira et al., 2007; Yilmaz et al., 2007). Tinchert et al. (2007) encontraram um valor de $\mathrm{m}$ para IZ $(13,9)$ muito próximo ao observado no presente estudo, utilizando blocos pré-sinterizados para CAD-CAM. É importante ressaltar que os valores de módulo de 
Weibull estão relacionados com o volume solicitado durante 0 ensaio, 0 processamento dos corpos-de-prova, o acabamento de superfície e o ambiente em que os ensaios são realizados (Della Bona, 2009). Portanto, a comparação entre valores de diferentes estudos deve ser feita com cautela, já que essas variações experimentais influenciam o tamanho e a distribuição dos defeitos nos corpos-deprova.

Os valores de $\mathrm{m}$ e $\sigma_{0}$ observados para o material VM7 foram 6,1 e 74,7 MPa, respectivamente. Esses resultados foram muito próximos aos encontrados no trabalho de Gonzaga et al. ( $m=5,0$ e $\sigma_{0}=76,7 \mathrm{MPa}$ ), embora esse estudo tenha utilizado o método de flexão biaxial. Cattel et al. (1997) avaliaram a resistência à flexão em três pontos de materiais cerâmicos e encontraram valores de $\mathrm{m}$ ao redor de 5 para uma porcelana vítrea. Valores de $\mathrm{m}$ um pouco mais altos, entre 7 e 14, são reportados para porcelanas vítreas reforçadas com cristais de leucita, como a VM9 (Fairhurst et al., 1993; Cattell et al., 1997; Teixeira et al., 2007; Rosa et al., 2009). No presente estudo, o valor de m para a VM9 $(8,2)$ foi um pouco maior do que a VM7 $(6,1)$. Porém, houve intersecção entre os valores de intervalo de confiança dos dois grupos, indicando semelhança estatística (Figura 5.6, página 91).

A resistência à fratura com uma probabilidade de falha de $63,5 \%$ é descrita pelo valor de $\sigma_{0}$. Entretanto, para a aplicação odontológica, parece mais relevante o obter valor de resistência com uma probabilidade de falha de 1 ou $5 \%\left(\sigma_{5 \%}\right)$. Os valores de $\sigma_{5 \%}$ para os materiais estudados foram obtidos através da análise de Weibull e estão apresentados na tabela 5.4 (página 89). O grupo YZ apresentou um valor relativamente alto de $\sigma_{5 \%}$ (673 MPa) em comparação com os demais materiais, refletindo suas propriedades mecânicas superiores. Os grupos IZ e AL apresentaram diferença estatística para os valores de $\sigma_{0}$. Entretanto, quando uma probabilidade de falha de $5 \%$ foi avaliada, os valores de resistência desses dois materiais foram semelhantes, refletindo a maior variabilidade de resultados do grupo AL. Para aplicação clínica, quando materiais com valores de resistência à fratura muito próximos são considerados, como no caso da IZ e $A L$, deve-se optar pelo sistema com maior valor de $\mathrm{m}$, garantindo um prognóstico mais confiável. Porém, se um material apresentar valor médio de resistência à fratura muito superior, como a $Y Z$, o valor de $\sigma_{5 \%}$ tende a ser alto mesmo se existir uma maior variabilidade, o que justifica a sua aplicação. Os valores de $\sigma_{5 \%}$ obtidos pelas porcelanas foram inferiores 
a $50 \mathrm{MPa}$. Esses resultados estão relacionados com os baixos valores de resistência à fratura e módulo de Weibull encontrados para esses dois materiais (VM7 e VM9).

\subsection{COMPORTAMENTO DE CRESCIMENTO SUBCRÍTICO DE TRINCAS - SCG}

No ensaio de fadiga dinâmica, foi observada uma diminuição nos valores médios de resistência à flexão com a diminuição na taxa de carregamento (Tabela 5.5, página 92 e Figura 5.7, página 93). Esse comportamento está relacionado com o fato de que o defeito iniciador da fratura tem mais tempo para crescer e se propagar nas menores taxas de carregamento (Fairhurst et al., 1993). No entanto, pode-se observar na tabela 5.5 (página 92), que para materiais com baixa susceptibilidade ao crescimento subcrítico, como o $\mathrm{YZ}$ e o $\mathrm{AL}$, nem sempre houve diminuição dos valores de resistência em taxas baixas de carregamento.

Foi observada uma tendência ao aumento do tamanho do defeito crítico com a diminuição da taxa de tensão, o que sugere a presença de crescimento subcrítico de trincas nas taxas de carregamento mais lentas. Taskonak et al. (2008b) relataram um comportamento semelhante ao observado no presente estudo e encontraram maior tamanho de defeito crítico quando o ensaio foi realizado em água do que em óleo (condição inerte), comprovando a influência da umidade no crescimento subcrítico. No presente estudo não foi avaliada a resistência inerte dos corpos-deprova. O comportamento de SCG dos materiais foi observado em meio úmido apenas variando as taxas de carregamento.

Os valores de $n$ para as cerâmicas estudadas indicam que esses materiais se comportam de maneira diferente em relação ao efeito que a exposição a um meio úmido, sob tensão, tem no crescimento subcrítico de trincas e na degradação das propriedades mecânicas. Os altos valores de $n$ obtidos pelos materiais $\mathrm{YZ}$ e $\mathrm{AL}$ mostram que a microestrutura das cerâmicas policristalinas resulta em uma barreira muito mais eficiente ao crescimento lento de trincas em meio úmido do que as porcelanas e os compósitos. Teixeira et al. (2007) também observaram maiores valores de $n$ para cerâmicas policristalinas de alumina $(43,6)$ e de $\mathrm{YZ}(56,8)$ do que para porcelanas (28). Observaram menor degradação da resistência com o tempo 
para a YZ. Foi estimada uma redução de 50\%, 36\% e 29\% nos valores de resistência à flexão após 10 anos para a porcelana, alumina, e YZ, respectivamente.

$\mathrm{Na}$ literatura, o comportamento de propagação de trincas da $Y Z$ foi investigado em condições de carregamento estático e cíclico. Foi observada influência da temperatura, tensão e ambiente na velocidade de propagação de trincas, sugerindo que o mecanismo de corrosão sob tensão é o principal responsável pelo crescimento subcrítico de trincas no regime de carregamento estático. No carregamento cíclico, a taxa de propagação de trincas está relacionada não só com a corrosão sob tensão, mas também com o processo de fadiga cíclica, que envolve a degradação dos mecanismos de aumento de tenacidade por transformação e de crack bridging. Os resultados também demonstram que o aumento no fator de intensidade de estresse $\left(\mathrm{K}_{\mathrm{l}}\right)$ leva a um aumento na quantidade de conteúdo monoclínico e na intensidade das tensões de bloqueio de trincas resultantes da transformação de fase (Chevalier et al., 1999).

Outro estudo demonstrou que o comportamento de crescimento subcrítico de trincas pode ser diferente no interior e na superfície da cerâmica $Y Z$. A transformação de fase tetragonal para monoclínica induz uma camada compressiva nas proximidades da superfície que pode modificar o crescimento subcrítico das trincas. Como conseqüência, um valor de tenacidade de $6 \mathrm{MPa}^{1 / 2} \mathrm{~m}^{1 / 2}$ foi encontrado para o interior do material, enquanto a superfície alcançou um valor de tenacidade aparente de $18 \mathrm{MPa} \cdot \mathrm{m}^{1 / 2}$. O valor de tenacidade obtido na superfície é resultado da superposição das tensões produzidas pelas trincas e as tensões de compressão induzidas pela zona de transformação de fase. O crescimento subcrítico na superfície é caracterizado por um alto valor de $n(\sim 100)$. O valor de $n$ para os defeitos internos foi baixo, ao redor de 26 (Chevalier et al., 1995).

Um estudo investigou o comportamento de SCG das cerâmicas policristalinas de alumina e $\mathrm{YZ}$. Apesar da $\mathrm{YZ}$ apresentar um valor maior de tenacidade $\left(\mathrm{K}_{\mathrm{Ic}}\right)$ do que a alumina, os valores de $\mathrm{K}_{10}$ (stress intensity threshold), desses dois materiais foram próximos. Isso significa que a magnitude da tensão na ponta da trinca necessária para que se inicie o crescimento do defeito é semelhante nessas cerâmicas. A alumina apresenta alta resistência à corrosão, ou seja, baixa susceptibilidade ao crescimento subcrítico. Por outro lado, a zircônia pode ter a energia de fratura reduzida na presença de um ambiente úmido (De Aza et al., 2002). Um comportamento semelhante foi observado no presente estudo, em que o 
grupo AL apresentou um valor de $n$ tão alto quanto o obtido pela $Y Z$ apesar de suas propriedades mecânicas serem inferiores.

Os valores intermediários de $n$ para a IZ podem estar relacionados ao fato da microestrutura ser uma composição de cristais de alumina e zircônia em uma matriz vítrea. Apesar dos cristais agirem impedindo a propagação de trincas, a fase amorfa (vidro a base de óxido de lantânio) localizada nos contornos dos cristais é mais susceptível ao ataque corrosivo pelas moléculas de água. Portanto, o valor de $n$ é menor do que aquele obtido para cerâmicas policristalinas ( $Y Z$ e $A L$ ), porém maior do que o observado para as porcelanas. Zhu et al. (2003) encontraram, para um sistema similar ao $I Z$, valores de $n$ do vidro de infiltração e do compósito muito próximos, confirmando a influência significativa da fase vítrea no comportamento de SCG. Outro estudo observou uma diminuição do valor de $n$ quando uma pequena quantidade de vidro (5\%) foi adicionada a uma alumina policristalina (Barinov et al., 1998).

Tinschert et al. (2007) observaram um valor de $n$ relativamente baixo para a $I Z$, ao redor de 21,9 e também atribuíram esse resultado a alta susceptibilidade ao crescimento subcrítico de trincas da fase vítrea. Era esperado que a alta proporção de cristais de alumina na estrutura cerâmica e a presença do mecanismo de tenacificação por transformação dos cristais de zircônia dificultassem a propagação de trincas no material. No entanto, a longo prazo, esses mecanismos de reforço não foram muito eficientes. Para a $Y Z$, observaram uma grande queda nos valores de resistência na presença de um ambiente úmido. Sugere-se que a fase tetragonal é desestabilizada em um ambiente úmido pelas reações de hidrólise entre a água e o óxido de ítrio. Com o tempo, quando a concentração de ítrio cai abaixo de um determinado nível, ocorreria a transformação espontânea da fase tetragonal para monoclínica. Além disso, podem ocorrer reações entre as moléculas de água e as ligações $\mathrm{O}-\mathrm{Zr}$, contribuindo para a degradação da estrutura cristalina.

Um estudo avaliou o comportamento de crescimento subcrítico dos sistemas In-Ceram Alumina e IZ submetidos à fadiga cíclica. Demonstraram que um ambiente úmido combinado com carregamento cíclico resulta na propagação da trinca em níveis de tensão aproximadamente $50 \%$ menores do que os valores de resistência inerte dos materiais, evidenciando a grande susceptibilidade dos sistemas cerâmicos ao SCG. Os autores também atribuíram os baixos valores de $n$ encontrados para esses dois compósitos (valores de $n$ entre 20 e 30) à presença da fase vítrea. 
Observaram que o ambiente úmido aumentou significativamente a susceptibilidade ao crescimento subcrítico do material IZ em comparação ao material In-Ceram Alumina. Entretanto, em condições semelhantes de carregamento, um maior tempo de vida é estimado para o IZ por causa de sua maior resistência à flexão (Salazar Marocho et al., 2010).

No caso das porcelanas, os valores de $n$ relativamente baixos estão relacionados ao fato de sua microestrutura ser composta principalmente por uma matriz vítrea. A literatura apresenta valores de $n$ variando de 15 a 41 para porcelanas (Morena et al., 1986; Fairhurst et al., 1993; Pinto et al., 2008; Gonzaga et al., 2009; Rosa et al., 2009). Esses valores são semelhantes aos valores obtidos para vidros de silicato (15 a 19), que estão entre os materiais cerâmicos mais susceptíveis ao SCG (Ritter, 1978; Gupta; Jubb, 1981). No caso das porcelanas reforçadas com leucita, como a VM9, essa similaridade indica que a matriz vítrea possui mais influência no comportamento mecânico desses materiais do que a presença de fase cristalina (Morena et al., 1986). Esses resultados estão de acordo com um estudo de Cesar et al. (2008) que não encontraram, para as porcelanas estudadas, influência do conteúdo de leucita na resistência ao crescimento subcrítico de trincas.

O ideal é que os parâmetros $n$ e $\sigma_{\mathrm{f} 0}$ tenham valores elevados, indicando um material com alta resistência mecânica e baixa susceptibilidade ao crescimento subcrítico de trincas (Fairhurst et al., 1993). Portanto, o presente estudo mostrou que o material com melhor desempenho foi a cerâmica $Y Z$, que apresentou os maiores valores de $n$ e $\sigma_{\mathrm{f} 0}, 76$ e 879,5 MPa, respectivamente. Apesar do alto valor de $n$ encontrado para o material $\mathrm{AL}$, o valor de $\sigma_{\mathrm{fo}}$ foi menor do que o observado para a YZ. As porcelanas possuem um desempenho mecânico inferior, já que apresentaram os menores valores para os dois parâmetros estudados, $n$ e $\sigma_{\mathrm{f} 0}$.

\subsection{ESTIMATIVA DO TEMPO DE VIDA PARA OS MATERIAIS CERÂMICOS}

O coeficiente $n$ dos materiais está diretamente relacionado à inclinação das curvas de tempo de vida (Figura 5.8, página 95). Quanto maior o valor de $n$, menor a inclinação da curva e conseqüentemente menor é a degradação da resistência do 
material em função do tempo. Dessa forma, é possível notar que o material com melhor desempenho em termos de resistência ao crescimento subcrítico é o $\mathrm{YZ}$. Além de sua resistência ser a mais alta no tempo de 1 dia, a inclinação da sua curva no gráfico é a menor de todas indicando pouca degradação da resistência após 10 anos. A diferença entre os valores de resistência dos materiais $A L$ e IZ aumenta com o decorrer do tempo (1 dia até 10 anos) (Tabela 5.7, página 95). Esse comportamento é resultado da maior susceptibilidade ao crescimento subcrítico de trincas do IZ. As duas porcelanas apresentam comportamentos muito semelhantes na figura 5.8 (página 95). Embora exista uma pequena diferença entre os valores de resistência desses materiais após 1 dia, a maior inclinação da curva da VM7 resulta numa semelhança entre os valores de resistência dessas porcelanas após 10 anos.

$\mathrm{Na}$ tabela 5.7 (página 95), pode-se comparar os valores de $\sigma_{10}$, que representam a tensão de fratura dos materiais após dez anos. Considerando-se que a tensão média aplicada na região de molares pode variar de 27 a $31 \mathrm{MPa}$ em condições de oclusão normal (Lohbauer et al., 2008), nota-se que após 10 anos, a resistência das duas porcelanas estará muito próxima desses valores, aumentando assim o risco de fratura da restauração. Por outro lado, os materiais $Y Z, A L$ e IZ apresentam valores de resistência prevista após 10 anos de 10 a 25 vezes maiores do que os valores de tensão média na região de molares, demonstrando que a degradação da resistência ocorrida nesses materiais não é crítica como nas porcelanas.

Os dados obtidos com o ensaio de fadiga dinâmica também podem ser associados à análise de Weibull para construção dos diagramas SPT. O diagrama SPT é outra ferramenta utilizada para se estimar o tempo de vida de um material cerâmico em função da tensão a que ele é submetido. Porém, além do tempo de vida e da tensão, o diagrama SPT permite avaliar diferentes probabilidades de falha. Foram calculadas as tensões de fratura dos materiais após 1 dia, 1 ano e 10 anos para uma probabilidade de falha de 5\% (Tabela 5.8, página 97) e os valores encontrados foram muito próximos aos observados na tabela 5.7 (página 95).

Uma limitação dessas estimativas de vida é que elas consideram uma aplicação de tensão constante durante o tempo. Entretanto, considerando um período de 10 anos, um indivíduo permanece em oclusão apenas 1 a $4 \%$ desse tempo, o que equivale a um período de aplicação de tensão constante entre 38 e 152 dias (Gonzaga, 2007). Foram construídos gráficos SPT para esses tempos com 
o objetivo de se estimar a probabilidade de falha dos materiais para um período de uso clínico de 10 anos. Essa análise foi realizada levando em consideração a faixa de tensões mastigatórias (27 a $31 \mathrm{MPa}$ ). A probabilidade de falha para os materiais de infra-estrutura foi de $0 \%$. Para as porcelanas, a probabilidade de falha também foi pequena, entre 2 e 5\% para a VM7 e entre 1 e $3 \%$ para VM9, indicando um bom prognóstico clínico para esses materiais cerâmicos.

A extrapolação desses resultados para a prática clínica deve ser feita com muito cuidado, pois na cavidade oral os materiais irão fraturar assim que o tamanho crítico do defeito para uma determinada tensão for alcançado em qualquer período de tempo, dependendo das condições de tensão a que a restauração for submetida. Como as tensões desenvolvidas no ambiente bucal são complexas, torna-se difícil saber ao certo a condição de tensão a que o material foi submetido (Gonzaga, 2007). Além disso, essas tensões são intermitentes e pode ocorrer fechamento (crack healing) ou arredondamento (blunting) da ponta da trinca durante os períodos sem carregamento, alterando o comportamento de SCG (Fairhurst et al., 1993). Por outro lado, os parâmetros obtidos podem ser muito úteis na comparação entre diferentes materiais.

\subsection{TENACIDADE À FRATURA DOS MATERIAIS CERÂMICOS}

O valor de tenacidade à fratura da $\mathrm{YZ}\left(6,5 \mathrm{MPa} \cdot \mathrm{m}^{1 / 2}\right)$ foi mais alto do que os valores obtidos pelos demais materiais avaliados. A literatura também reporta altos valores de tenacidade à fratura para a YZ, entre 4,4 e 9,4 MPa•m ${ }^{1 / 2}($ Liu; Chen, 1991; Luthardt et al., 2002; Guazzato et al., 2004a; Tinschert et al., 2007; Yilmaz et al., 2007). No presente estudo, os materiais AL e IZ apresentaram valores de tenacidade semelhantes $\left(3,6 \mathrm{MPa} \cdot \mathrm{m}^{1 / 2}\right)$. Esses resultados estão de acordo com os valores obtidos pelo fabricante para o sistema AL. Entretanto, estudos demonstraram uma grande variação em relação aos resultados de tenacidade para a IZ, entre 3,0 e 6,2 MPa•m ${ }^{1 / 2}$ (Guazzato et al., 2002; Guazzato et al., 2004a; Tinschert et al., 2007; Yilmaz et al., 2007; Taskonak et al., 2008b). Os diferentes valores de tenacidade encontrados na literatura podem estar relacionados com as metodologias de ensaio utilizadas, entre elas estão os testes: a) fratura por 
indentação (identation fracture -IF), b) identation strength (IS), c) surface crack in flexure (SCF).

No método de IF, trincas radiais são geradas na superfície do corpo-de-prova com uma indentação de dureza Vickers. $O$ valor de tenacidade à fratura é obtido através da medida do tamanho da trinca de indentação. Uma desvantagem desse método é o alto coeficiente de variação (30-40\%), relacionado à heterogeneidade da microestrutura das cerâmicas e às dificuldades em se fazer a medida correta do comprimento da trinca (Anstis et al., 1981). Além disso, a presença de SCG também pode influenciar os resultados (Rosentiel; Porter, 1989).

O teste IS envolve a introdução de um defeito por meio de indentação de dureza Vickers ou Knoop e fratura em um ensaio de flexão. $O$ cálculo de $K_{\mathrm{lc}}$ é realizado utilizando-se as dimensões do corpo-de-prova, a carga de fratura, a dureza, o módulo de elasticidade e a carga de indentação (Chantikul et al., 1981). Entretanto, as tensões residuais induzidas pela indentação somam-se às tensões aplicadas à cerâmica, resultando em valores de resistência e tenacidade à fratura menores (Scherrer et al., 1999).

Pode-se obter uma boa estimativa da tenacidade à fratura utilizando análise fractográfica de corpos-de-prova de cerâmica (Scherrer et al., 1999). O teste SCF é realizado de maneira semelhante ao teste IS, em que um defeito é introduzido por meio de indentação de dureza Vickers e o corpo-de-prova é ensaiado em flexão. Entretanto, no teste SCF, a zona de tensão residual da indentação é removida antes do ensaio mecânico e as dimensões do defeito na superfície de fratura são mensuradas por meio de análise fractográfica (Petrovic et al., 1976a). A tenacidade é estimada com os valores de carga de fratura e tamanho do defeito crítico (c) (Scherrer et al., 1999). Essa metodologia é semelhante à utilizada no presente estudo. A principal diferença é que no presente estudo o defeito crítico teve origem em falhas naturais do material, não em uma falha controlada. Ambas as metodologias são baseadas em um sólido conhecimento de fractografia e da mecânica de fratura e a tenacidade à fratura é calculada levando-se em conta o tamanho do defeito medido em um nível microestrutural (Petrovic et al., 1976b).

A precisão da estimativa da tenacidade depende da facilidade de medição do defeito, que está relacionada com a microestrutura de material e a experiência e interpretação do examinador (Scherrer et al., 1999). No presente trabalho, materiais com diferentes microestruturas foram analisados e as medidas foram realizadas por 
um único observador. O coeficiente de variação dos valores de tenacidade para os materiais de infra-estrutura foi baixo, entre 4 a $6 \%$. Esse resultado é semelhante ao coeficiente de variação reportado na literatura e indica que os valores de tenacidade foram consistentes e reprodutíveis (Quinn et al., 1994; Scherrer et al., 1999). Para as porcelanas, esse coeficiente foi um pouco mais alto, entre 18 e $21 \%$, refletindo uma maior dificuldade de determinação do tamanho de defeito crítico relacionada com a microestrutura desses materiais. Um fator que favorece essa metodologia é que a precisão na determinação do tamanho do defeito crítico tem pequena influência nos valores de tenacidade à fratura. Um erro relativo de $10 \%$ no tamanho da trinca é reduzido a uma alteraçao de $5 \%$ ou menos na tenacidade calculada. A tenacidade à fratura é mais sensível à precisão na medida da tensão de fratura (Scherrer et al., 1999).

Com relação às porcelanas, a literatura reporta um tendência à aumento da tenacidade à fratura com o aumento do conteúdo de leucita. Estudos observaram que a trinca sofre deflexão ao encontrar um cristal de leucita e a alteração na direção de propagação resulta em diminuição no fator de intensidade de tensão na ponta da trinca. O desvio da trinca ocorre por ação de campos de tensão de tração e compressão que são induzidos na interface entre a matriz vítrea e a leucita durante o resfriamento do material por causa da diferença de CTE entre as duas fases (Cesar et al., 2005; Yoshimura et al., 2005). Entretanto, esse comportamento não foi observado no presente estudo, em que a porcelana vítrea (VM7) e a porcelana reforçada com leucita (VM9) apresentaram valor semelhante de $\mathrm{K}_{\mathrm{lc}}\left(0,7 \mathrm{MPa} \cdot \mathrm{m}^{1 / 2}\right)$. Esse resultado pode estar relacionado com a baixa fração volumétrica de leucita encontrada na porcelana VM9, aproximadamente 4,6\%. Cesar et al. (2005) reportaram aumento significativo nos valores de tenacidade à fratura para porcelanas com conteúdo de leucita superior a $15 \%$. O material com conteúdo de leucita semelhante ao encontrado no presente estudo, ao redor de $6 \%$, apresentou valor de tenacidade semelhante às porcelanas vítreas (entre 0,7 e 0,8 MPa•m ${ }^{1 / 2}$ ).

No presente estudo, a tenacidade foi estimada utilizando os dados de resistência à flexão em três pontos e tamanho de defeito crítico dos corpos-de-prova monolíticos testados com diferentes taxas de tensão. Os valores de tenacidade foram semelhantes em todas as taxas de tensão indicando que a tenacidade à fratura é uma propriedade intrínseca do material que não depende das variáveis experimentais (Della Bona, 2009). Esses resultados estão de acordo com um estudo 
de Taskonak et al. (2008b) que avaliaram a tenacidade à fratura de materiais cerâmicos (IZ e porcelana) com a mesma metodologia utilizada no presente estudo. Para a porcelana, os autores compararam os valores de tenacidade obtidos através da mensuração de falhas naturais e de falhas controladas (indentação Vickers) e encontraram resultados semelhantes, validando a metodologia utilizada no presente estudo. Relataram para a porcelana um valor médio de tenacidade à fratura (ao redor de $0,65 \mathrm{MPa} \cdot \mathrm{m}^{1 / 2}$ ) semelhantes ao obtido para a VM7 e a VM9. Por outro lado, encontraram um valor médio de $\mathrm{K}_{\mathrm{Ic}}$ significativamente maior para a $\mathrm{IZ}$, aproximadamente $5,0 \mathrm{MPa} \cdot \mathrm{m}^{1 / 2}$ e foram identificadas falhas internas e de canto para a IZ, que não foram observadas no presente estudo, indicando diferentes populações de defeitos para um mesmo material.

\subsection{EFEITO DA CONFIGURAÇÃO DO CORPO-DE-PROVA NA RESISTÊNCIA À FLEXÃO}

Foram encontrados valores de $\sigma_{f}$ maiores para os corpos-de-prova em duas camadas com a infra-estrutura em tração do que com a porcelana em tração. Esse comportamento indica que o material em tração durante o ensaio de flexão controla a resistência e o modo de fratura das estruturas em camadas. Isso está de acordo com resultados encontrados na literatura utilizando testes mecânicos e AEF (White et al., 1994; Della Bona et al., 2003; Guazzato et al., 2004c; White et al., 2005).

Para cada material de infra-estrutura, os valores de $\sigma_{f}$ dos corpos-de-prova monolíticos foram semelhantes aos valores obtidos pelos corpos-de-prova de duas camadas com a infra-estrutura em tração. Em ambas configurações, a máxima tensão de tração durante o ensaio está localizada na superfície inferior do corpo-deprova (Hsueh et al., 2006). O modo de fratura também foi semelhante para esses grupos, sendo que a trinca teve origem na superfície do material de infra-estrutura e se propagou de maneira catastrófica através do corpo-de-prova. Apenas para o grupo YZ-IT foi encontrado em $70 \%$ dos corpos-de-prova outro modo de fratura. Nesses casos a camada de porcelana que estava em compressão fraturou antes de ocorrer a fratura da camada de infra-estrutura. Durante o carregamento foram 
produzidos cone cracks na camada de porcelana em contato com o suporte de aplicação da carga. À medida que a carga foi aumentando, a trinca se propagou em direção à interface e sofreu deflexão, resultando em delaminação da porcelana. Isso indica que resistência à compressão da porcelana foi menor do que a resistência à tração da YZ. Também foram encontrados cone cracks na camada de porcelana dos grupos IZ-IT e AL-IT, porém a fratura do material de infra-estrutura ocorreu antes que essas trincas se propagassem até a interface. Portanto, não ocorreu delaminação desses corpos-de-prova. Resultados semelhantes foram descritos por Guazzato et al. (2004c), sendo que a porcelana foi destruída antes da fratura da YZ em $80 \%$ dos corpos-de-prova avaliados.

Alguns estudos também observaram que o material de infra-estrutura tem influência significativa nos valores de resistência à flexão e no modo de fratura das estruturas em camadas quando está em tração durante o ensaio (Zeng et al., 1998; Della Bona et al., 2003). Della Bona et al. (2003) investigaram a resistência à flexão em quatro pontos e o modo de fratura de corpos-de-prova monolíticos e de duas e três camadas. As estruturas de três camadas foram compostas por cerâmica de infra-estrutura $(0,8 \mathrm{~mm})$, porcelana $(0,3 \mathrm{~mm})$ e glaze $(0,1 \mathrm{~mm})$, e as estruturas de duas camadas foram compostas apenas por infra-estrutura $(1,1 \mathrm{~mm})$ e glaze $(0,1$ $\mathrm{mm}$ ). Todos os corpos-de-prova foram ensaiados com a camada de infra-estrutura em tração. Observaram que o glaze não teve influência nos valores de resistência à flexão e módulo de Weibull. As estruturas de duas e três camadas apresentaram valor de resistência à flexão semelhante aos corpos-de-prova monolíticos. Nesse estudo, a confiabilidade das estruturas cerâmicas recobertas com porcelana foi relacionada primeiramente com a confiabilidade da cerâmica de infra-estrutura.

Outro estudo também avaliou a resistência à flexão de corpos-de-prova monolíticos e estruturas de duas camadas com a cerâmica de infra-estrutura em tração (Zeng et al., 1998). Para um sistema com alto conteúdo de alumina (Procera), os valores de resistência à flexão dos corpos-de-prova monolíticos foram semelhantes aos valores obtidos para as estruturas de duas camadas (espessura da infra-estrutura $=1 \mathrm{~mm}$ ), indicando que a influência da porcelana na resistência à fratura foi insignificante. Ao contrário, no sistema In-Ceram Alumina, os valores médios de resistência obtidos pelos corpos-de-prova de duas camadas foram inferiores aos valores encontrados para os corpos-de-prova monolíticos de infraestrutura. Apesar dessa diferença, os resultados encontrados para as estruturas em 
camadas ainda foram superiores aos observados para o grupo monolítico de porcelana. Segundo os autores, as diferenças encontradas para esses dois sistemas de infra-estrutura estão relacionadas com a composição e compatibilidade entre os materiais e com as características da interface.

A diferença entre a espessura do material de infra-estrutura na configuração monolítica $(2 \mathrm{~mm})$ e em camadas $(1 \mathrm{~mm})$ não teve influência nos resultados de resistência à flexão. Isso pode ser explicado pelo fato de que a área submetida às tensões de tração no ensaio de flexão em três pontos se limita à região inferior do corpo-de-prova, localizada entre os suportes cilíndricos de apoio e logo abaixo do suporte de aplicação da carga. Portanto, para ambas as configurações de corpo-deprova, a área solicitada é a mesma e está confinada na cerâmica de infra-estrutura. Análise fractográfica comprovou esse comportamento, sendo que a origem da falha para esses grupos foi localizada na superfície inferior do corpo-de-prova. Os materiais localizados na região superior do corpo-de-prova durante o teste (cerâmica de infra-estrutura no grupo monolítico e porcelana no grupo de duas camadas) estão submetidos às tensões de compressão.

Com exceção do grupo YZ-TRI, não houve diferença nos resultados de resistência à flexão entre os corpos-de-prova monolíticos de porcelana, as estruturas de duas camadas com a porcelana em tração e as estruturas de três camadas. Esses resultados demonstram que a porcelana controlou o comportamento mecânico dessas estruturas em camadas. A presença de um material de infraestrutura com melhores propriedades mecânicas não aumentou a resistência a flexão e não impediu a fratura da porcelana que estava em tração no momento do ensaio nesses grupos.

Nos corpos-de-prova de duas camadas com a porcelana em tração a trinca teve origem na superfície da porcelana, se propagou em direção à camada de infraestrutura e sofreu uma deflexão ou bifurcação na região próxima a interface. Esse comportamento resultou em fratura parcial da estrutura e, em alguns casos, em delaminação da camada porcelana. A deflexão na interface pode ser resultado da grande diferença nos valores de tenacidade e de módulo de elasticidade entre os materiais de infra-estrutura e de recobrimento (Thompson, 2000). Nesses casos a tensão necessária para fratura do material de infra-estrutura foi maior do que a tenacidade da interface. Além disso, foi demonstrado em AEF que quando a porcelana está em tração durante o ensaio, a interface também é um local de 
concentração de tensões de tração (Guazzato et al., 2004c; Hsueh et al., 2008). Outro fator a ser considerado é a presença de tensões residuais na interface induzidas durante o processamento como, por exemplo, as tensões produzidas durante a queima da porcelana (Hsueh et al., 2008).

É importante ressaltar que quando os corpos-de-prova foram testados com a porcelana em tração o ensaio foi suspenso após a falha da camada de porcelana. Não houve fratura da camada de infra-estrutura. O que também explica a semelhança entre esses valores de resistência e os valores obtidos pelos corpos-deprova monolíticos de porcelana.

Studart et al. (2007) também observaram que nas estruturas constituídas por um material de infra-estrutura com alto valor de tenacidade, como as cerâmicas $\mathrm{YZ}$ e $I Z$, a trinca se propaga na camada de recobrimento e sofre deflexão na interface. Os autores observaram que a fratura dos corpos-de-prova teve origem em defeitos naturais da camada de porcelana levando à fratura da cerâmica de recobrimento antes da ruptura do material de infra-estrutura. Portanto, as falhas iniciais na cerâmica de recobrimento não provocam falha completa da restauração cerâmica, mas expõem à infra-estrutura à umidade da cavidade oral.

Para os grupos YZ-TRI e IZ-TRI $80 \%$ e $50 \%$ dos corpos-de-prova, respectivamente, apresentaram fratura parcial, semelhante à observada nas estruturas de duas camadas com porcelana em tração. Entretanto, todos os corposde-prova do grupo AL-TRI fraturaram como um corpo único (fratura total). Apesar da porcelana estar localizada na área de tração tanto nas estruturas de duas camadas como na de três, existe uma diferença entre a proporção dos materiais nessas duas configurações. Pode-se dizer que existe uma proporção de 1:1 (porcelana: infraestrutura) na estrutura de duas camadas e de 1:2 na estrutura de três camadas. Um estudo observou que a máxima tensão de tração é transferida da superfície para a interface com o aumento da proporção entre a porcelana e a infra-estrutura (1:2) (Hsueh et al., 2008). Portanto, a distribuição de tensões é diferente nesses dois tipos de corpo-de-prova (duas e três camadas), refletido diretamente no seu padrão de fratura. 


\subsection{PRÓTESES PARCIAIS FIXAS}

\subsubsection{Efeito do tipo de material de infra-estrutura e do tamanho de secção transversal na carga de fratura das PPFs}

Considerando o tipo de material de infra-estrutura, a mesma ordem de valores de resistência foi observada para as barras monolíticas e para as PPFs, sendo que o sistema $Y Z$ apresentou o melhor desempenho. Alguns estudos também observaram valores de carga de fratura superiores para PPFs confeccionadas com infra-estrutura de YZ em comparação a outros sistemas cerâmicos (Tinschert et al., 2001; Luthy et al., 2005; Wolfart et al., 2007; Beuer et al., 2008). Tinschert et al. (2001) avaliaram a carga de fratura de PPFs totalmente cerâmicas e encontraram melhores resultados quando a $Y Z$ foi utilizada como material de infra-estrutura. Neste estudo, o sistema IZ e uma cerâmica à base de dissilicato de lítio (IPS Empress II) obtiveram valores de carga de fratura intermediários. Os menores valores de carga de fratura (abaixo de $1000 \mathrm{~N}$ ) foram encontrados para a In-Ceram Alumina e uma cerâmica vítrea à base de leucita (IPS Empress). Outro estudo com PPFs de quatro elementos mostrou um valor médio de carga de fratura para infraestruturas de $Y Z 1,5$ vezes maior ( $706 \mathrm{~N}$ ) do que o valor obtido pelas infra-estruturas de IZ (470 N) e 2,7 vezes maior do que as infra-estruturas à base de dissilicato de lítio $(260 \mathrm{~N})$. Segundo esse estudo, a probabilidade de fratura das PPFs de dissilicato de lítio, IZ e YZ, quando submetidas a uma carga de $500 \mathrm{~N}$, é $100 \%$, 53\% e $5 \%$, respectivamente (Luthy et al., 2005).

Os valores médios de carga de fratura do grupo YZ16 foram superiores aos do grupo YZ9, indicando que o tamanho de conector tem influência no desempenho mecânico das PPFs. Esses resultados estão de acordo com a literatura, que reporta um aumento da resistência à fratura das PPFs com o aumento do tamanho e do raio de curvatura do conector (Oh; Anusavice, 2002; Larsson et al., 2007; Plengsombut et al., 2009). Quando o tamanho do conector é aumentado, as tensões são distribuídas em uma área maior. Além disso, existe uma alteração da geometria da PPF, sendo que o ângulo das ameias também é maior, diminuindo a concentração de tensões nessa área. Esses fatores influenciam diretamente nos valores de resistência à 
fratura. A carga de fratura de PPFs totalmente cerâmicas com diferentes tamanhos de conector foi avaliada após ciclagem térmica e mecânica com carga entre $30 \mathrm{~N} \mathrm{e}$ $300 \mathrm{~N}$ durante $10^{4}$ ciclos e freqüência de $1 \mathrm{~Hz}$. Os valores de carga de fratura foram diretamente proporcionais ao tamanho do conector. Exceto para os grupos com diâmetro de conector igual a 2,0 mm e 2,5 mm em que todas as fraturas ocorreram durante a ciclagem mecânica (Larsson et al., 2007).

Entretanto, Wolfart et al. (2007) observaram uma influência do tamanho do conector para infra-estruturas à base de dissilicato de lítio mas não para infraestruturas de $Y Z$. Esses resultados foram observados porque o lascamento da porcelana foi considerado um tipo de fratura. Portanto, para PPFs construídas com um material com alto valor de tenacidade como a $Y Z$, ocorre fratura da porcelana antes da infra-estrutura, ou seja, a porcelana controla o mecanismo de falha. Nesses casos, o tamanho do conector não afeta de maneira significativa o modo de falha. No presente estudo, foi evidenciada a influência do tamanho do conector porque a carga de fratura registrada corresponde à fratura total da PPF, não ao lascamento, apesar disso ter ocorrido em PPFs de todos os grupos.

Os estudos clínicos relatam uma maior taxa de lascamento da porcelana de recobrimento das PPFs em comparação à taxa de fratura da infra-estrutura (Della Bona; Kelly, 2008), concordando parcialmente com os resultados do presente estudo. Porém, é possível realizar o reparo dos pequenos lascamentos sem a necessidade de remoção da prótese (Scherrer et al., 2007). Portanto, esse tipo de fratura pode ser caracterizado como uma falha parcial da restauração. A falha de infra-estrutura é mais crítica, pois resulta na remoção e substituição da PPF. O ideal seria obter, no ensaio laboratorial, o valor de carga de fratura das duas camadas que compõem a PPF, infra-estrutura e porcelana. No entanto, não foi possível detectar esses dois picos de carga de fratura através da metodologia de ensaio utilizada no presente estudo.

Não houve diferença nos valores médios de carga de fratura entre as PPFs de $Y Z$ com conector de $9 \mathrm{~mm}^{2}(\mathrm{YZ})$ e as PPFs com conector de $16 \mathrm{~mm}^{2}$ confeccionadas com os outros materiais de infra-estrutura (IZ16 e AL16). Esses resultados estão de acordo com as indicações do fabricante, que levando em consideração as propriedades mecânicas dos sistemas cerâmicos, recomenda para PPFs posteriores (distância entre os pilares de $10 \mathrm{~mm}$ ) um conector maior $\left(16 \mathrm{~mm}^{2}\right.$ ) para infra-estruturas de $I Z$ do que para infra-estruturas de $Y Z\left(9 \mathrm{~mm}^{2}\right)$. A cerâmica 
AL só é recomendada para confecção de PPFs anteriores, porém obteve valores de carga de fratura semelhantes à cerâmica IZ. Levando em conta as dificuldades clínicas da confecção de PPFs com conector muito grande, o sistema YZ seria mais apropriado para esse tipo de restauração, já que é possível obter as mesmas propriedades mecânicas dos outros sistemas cerâmicos utilizando um tamanho de conector menor.

Studart et al. (2007) avaliaram o comportamento de crescimento subcrítico de trincas de estruturas em camadas com o objetivo de estabelecer um protocolo seguro de confecção de PPFs totalmente cerâmicas. Foi estimado um diâmetro mínimo de conector para reduzir as tensões na superfície da camada de porcelana. Para porcelana feldspática combinada com infra-estrutura de $Y Z$ ou IZ, a probabilidade de falha da camada de porcelana é pequena para PPFs de três elementos quando utilizado um diâmetro de conector igual ou maior do que $4 \mathrm{~mm}$. Segundo os autores, a confecção de PPFs com um diâmetro maior do que o valor mínimo recomendado pode garantir que o risco de fratura da porcelana por SCG seja menor do que 5\% dentro de um período de 20 anos. No caso de PPFs com mais de três elementos, a dimensão de conector preconizada (6 a $7 \mathrm{~mm}$ de diâmetro) é maior do que o tamanho clinicamente aceitável. Portanto, para PPFs muito extensas é provável que ocorra falha da porcelana em um período inferior a 20 anos.

\subsubsection{Efeito da ciclagem mecânica na carga de fratura das PPFs}

Não foi observada influência da ciclagem mecânica na carga de fratura das PPFs avaliadas. Entretanto, foi observado um aumento no coeficiente de variação dos grupos YZ16-CM e IZ16-CM com relação aos grupos controles. Esse resultado sugere a possibilidade de degradação da resistência em algumas PPFs. Considerando que os materiais cerâmicos são muito sensíveis ao tamanho e distribuição dos defeitos, existe uma grande variação nos dados de fadiga e envelhecimento cíclico. Portanto, um maior número de corpos-de-prova aumentaria o poder da análise estatística e seria possível evidenciar com maior precisão o efeito da ciclagem mecânica na carga de fratura das PPFs. 
O procedimento de ciclagem mecânica foi realizado com o objetivo de simular as condições que as PPFs são submetidas in vivo. Foi utilizada uma freqüência de 2 $\mathrm{Hz}$ e carga de $140 \mathrm{~N}$ para reproduzir a freqüência e carga produzidas durante a mastigação (Delong; Douglas, 1983; Hidaka et al., 1999; Proeschel; Morneburg, 2002). O envelhecimento foi realizado em ambiente úmido (água destilada), porém não foi realizada ciclagem térmica. O tempo de ciclagem foi correspondente a 1 ano de uso clínico $\left(10^{6}\right.$ ciclos). A correlação entre número de ciclos e tempo de uso clínico foi feita com base em um cálculo que estima uma média de 2700 ciclos mastigatórios por dia. Esse cálculo leva em conta três períodos de mastigação de 15 min por dia com uma freqüência de $1 \mathrm{~Hz}$. Isso resulta em um total de $10^{6}$ ciclos por ano (Wiskott et al., 1995; Lohbauer et al., 2008). Portanto, sugere-se um bom prognóstico clínico desses sistemas cerâmicos após um período de 1 ano, já que não houve degradação das propriedades mecânicas das PPFs durante o envelhecimento.

Apesar das diferenças de metodologia, os estudos investigando PPFs em IZ e YZ não observaram influência do envelhecimento térmico e mecânico nos resultados de carga de fratura (Sundh et al., 2005; Kohorst et al., 2007; Wolfart et al., 2007; Beuer et al., 2008).

Sundh et al. (2005) avaliaram a influência do tratamento térmico e do envelhecimento mecânico na carga de fratura de PPFs de YZ. As PPFs foram submetidas a 90 carregamentos/min, entre 0 e $50 \mathrm{~N}$, por $10^{5}$ ciclos. Após a ciclagem os corpos-de-prova foram carregados até a fratura com uma velocidade de 0,5 $\mathrm{mm} / \mathrm{min}$. A ciclagem mecânica não afetou significativamente os valores de carga de fratura. O tratamento térmico e o recobrimento com porcelana reduziram a resistência da $Y Z$.

Um estudo comparou a carga de fratura de PPFs de quatro elementos de YZ produzidas utilizando blocos cerâmicos pré e densamente sinterizados. As PPFs foram submetidas a ciclagem térmica durante $10^{4}$ ciclos entre $5^{\circ} \mathrm{C}$ e $50^{\circ} \mathrm{C}$ e ciclagem mecânica com carga de $100 \mathrm{~N}$ utilizando uma freqüência de $2,5 \mathrm{~Hz}$ por $10^{6}$ ciclos. Após o procedimento de envelhecimento, as PPFs foram carregadas até a fratura utilizando uma esfera de tungstênio posicionada no centro do pôntico. As PPFs produzidas com blocos densamente sinterizados obtiveram os maiores valores de carga de fratura. Observaram que a ciclagem não alterou significativamente os 
valores de resistência à fratura dos sistemas cerâmicos estudados (Kohorst et al., 2007).

Wolfart et al. (2007) não observaram influência da fadiga cíclica na carga de fratura de PPFs confeccionadas com o sistema YZ. Três condições experimentais foram avaliadas: (1) controle, (2) ciclagem mecânica com carga de $250 \mathrm{~N}$ e freqüência igual a $1,5 \mathrm{~Hz}$ até a fratura da PPF ou até $1,2 \times 10^{6}$ ciclos; (3) ciclagem mecânica com carga entre 50 e $600 \mathrm{~N}$ e freqüência de $0,5 \mathrm{~Hz}$ até a fratura ou $10^{4}$ ciclos; a YZ foi testada adicionalmente com carga entre 50 e 1500 N. O material YZ apresentou o maior valor de carga de fratura (aproximadamente $3000 \mathrm{~N}$ ) e sobreviveu a um maior número de ciclos do que a cerâmica à base de dissilicato de lítio.

A resistência a fratura de PPFs totalmente cerâmicas confeccionadas com os sistemas In-Ceram Alumina, IZ e YZ foi avaliada em um estudo de Beuer et al. (2008). Foram produzidas PPFs de três elementos com secção transversal dos conectores de $12 \mathrm{~mm}^{2}$. Previamente ao ensaio, dez PPFs de cada grupo foram submetidas a $10^{4}$ ciclos térmicos $\left(5^{\circ} \mathrm{C}-55^{\circ} \mathrm{C}\right)$ durante $1,2 \times 10^{6}$ ciclos de carregamento mecânico com carga de $50 \mathrm{~N}$ e freqüência igual a $2,5 \mathrm{~Hz}$. Os resultados demonstraram efeito significante do material de infra-estrutura, sendo que a YZ apresentou o maior valor de carga de fratura. Ao contrário, o efeito da fadiga não foi estatisticamente significante.

Por outro lado, um estudo encontrou influência da ciclagem térmica e mecânica na carga de fratura de PPFs de três elementos confeccionadas com infraestruturas de diferentes sistemas de YZ. Foi realizada ciclagem térmica e mecânica utilizando um simulador de mastigação com uma carga de $49 \mathrm{~N}$ e freqüência igual a $1,6 \mathrm{~Hz}$ durante $1,2 \times 10^{6}$ ciclos. Não foi observado lascamento das PPFs durante o processo de envelhecimento. Houve uma redução de 8 a 19\% nos valores de carga de fratura após a ciclagem mecânica. Além disso, não foi observada diferença estatística entre os diferentes sistemas cerâmicos antes do envelhecimento mecânico. Porém, após a ciclagem, o sistema Procera apresentou menor valor de carga de fratura do que o sistema DCS (Att et al., 2007).

Rosentritt et al. (2009) avaliaram a carga de fratura de PPFs de YZ e observaram diferença significativa nos resultados obtidos pelo grupo controle e os grupos ciclados. A simulação de mastigação foi realizada com a carga aplicada por um dente molar no centro do pôntico utilizando diferentes protocolos de 
envelhecimento: (1) carga de $50 \mathrm{~N}$ durante $1,2 \times 10^{5}$ ciclos, (2) carga de $50 \mathrm{~N}$ durante 3,6 $610^{6}$, (3) carga de $100 \mathrm{~N}$ durante $3,6 \times 10^{6}$. Foram observadas falhas da camada de porcelana durante a ciclagem, sendo que a taxa de sobrevivência das PPFs foi de $70 \%$ para o protocolo 1 e $30 \%$ para os protocolos 2 e 3 . As PPFs foram testadas até a fratura após o procedimento de envelhecimento, sendo que a falha da porcelana foi considerada um modo de fratura. Foram relatadas apenas duas falhas de infra-estrutura.

Um estudo avaliou a confiabilidade e modo de fratura de PPFs metalocerâmicas e a base de $Y Z$ submetidas à fadiga acelerada progressiva. Com base na distribuição de falhas encontradas nos testes de fadiga foram calculadas curvas de probabilidade de Weibull utilizando como parâmetro uma carga de $300 \mathrm{~N}$. Não observaram diferença na confiabilidade dos sistemas para 50.000 ciclos a $300 \mathrm{~N}$. Entretanto, observaram redução significativa da confiabilidade das PPFs de YZ com relação às PPFs metalo-cerâmicas quando o número de ciclos aumentou para 100.000 (Bonfante, 2009).

Considerando os valores médios de força mastigatória reportados na literatura para a região anterior $(150 \mathrm{~N})$ e posterior $(220 \mathrm{~N})$, alguns estudos preconizam um valor mínimo de carga de fratura ao redor de $300 \mathrm{~N}$ e $500 \mathrm{~N}$ para que um sistema cerâmico seja indicado para a confecção de PPFs anteriores e posteriores, respectivamente (Proeschel; Morneburg, 2002; Beuer et al., 2008). Os valores de carga de fratura encontrados no presente estudo foram 4 a 9 vezes maiores do que o limite de 500 N. Portanto, dentro das limitações dessa investigação, sugere-se que esses sistemas podem ser indicados para aplicação clínica na região posterior.

Uma limitação desse experimento está relacionada com o material e a mobilidade dos pilares utilizados para o ensaio mecânico. Foi observado que o aumento do módulo de elasticidade do material utilizado nos pilares de coroas e PPFs totalmente cerâmicas resulta em um aumento nos valores de resistência à fratura (Scherrer; De Rijk, 1993; Rosentritt et al., 2006). Os pilares utilizados no presente estudo foram confeccionados com aço inoxidável com módulo de elasticidade 15 vezes maior do que a dentina (16 GPa) (Rekow et al., 2006). Esse material foi selecionado levando em consideração os altos valores de carga de fratura das PPFs. Um material com módulo de elasticidade menor poderia não suportar as condições de carregamento do ensaio mecânico. Att et al. (2007) 
utilizaram dentes como pilares e observaram casos de fratura dos dentes durante 0 teste das PPFs. A falta de mobilidade dos pilares também pode resultar em valores de carga de fratura mais altos (Rosentritt et al., 2006). Alguns estudos simulam a mobilidade do ligamento periodontal envolvendo a porção correspondente à raiz dos pilares com um material polimérico (Att et al., 2007; Beuer et al., 2008). Porém, no presente estudo, os pilares foram rígidos. Portanto, os valores de carga de fratura obtidos no laboratório podem estar superestimados e devem ser extrapolados com cuidado para a situação clínica.

\subsubsection{Efeito do tipo de material de infra-estrutura e do tamanho de secção transversal na distribuição de tensões das PPFs}

Investigações clínicas e de AEF sugerem que a região de maior concentração de tensões de tração nas PPFs está localizada na cervical dos conectores (Kelly et al., 1995; Fischer et al., 2003; Motta et al., 2008). Entretanto, no presente estudo, AEF demonstrou maior concentração de tensões de tração na região cervical do pôntico e não dos conectores. Esse resultado pode ser explicado pelo tipo de carregamento utilizado e pela falta de mobilidade dos pilares. A AEF teve como objetivo simular o ensaio in vitro para visualizar a distribuição de tensões durante o carregamento e interpretar o comportamento de fratura das PPFs. Por isso, da mesma forma que o ensaio laboratorial, na AEF os pilares foram mantidos fixos e o carregamento foi realizado no centro do pôntico.

Quando uma carga é aplicada centralmente em uma barra, suportada por dois apoios, ocorre distribuição de tensões não-uniforme. A máxima tensão de tração ocorre na região inferior da barra, entre os apoios e logo abaixo do local de aplicação da carga. Por outro lado, quando a carga é aplicada uniformemente em toda a barra, a máxima tensão de tração ainda será localizada na região central mas apresenta menor magnitude (Kelly et al., 1995; Motta et al., 2008). Pelas observações de AEF do presente estudo, a PPF teve um comportamento similar a um corpo-de-prova em forma de barra suportado por dois apoios (pilares) e submetido a um carregamento localizado (região central do pôntico). Portanto, a 
máxima tensão de tração foi localizada logo abaixo da região de carregamento, ou seja, na região cervical do pôntico

O comportamento de PPFs de três elementos submetidas a diferentes condições de carregamento foi estudado por Motta et al. (2008). Foi simulada uma carga de $100 \mathrm{~N}$ aplicada: (1) em todas as faces oclusais (carregamento fisiológico), (2) apenas nos retentores, e (3) apenas no pôntico. Observaram alteração significativa na distribuição e valores de tensão para os diferentes modos de carregamento. No carregamento fisiológico as tensões máximas de tração foram localizadas na ameia dos conectores e na região cervical do pôntico. Quando apenas os retentores foram solicitados, a máxima de tração foi encontrada na ameia oclusal de ambos conectores. Para o carregamento concentrado no pôntico, a distribuição de tensões foi similar aos modelos submetidos ao carregamento fisiológico. Porém, os valores da máxima principal foram maiores e as tensões de tração também se estenderam até a região dos retentores. Esses resultados validam o tipo de carregamento utilizado no presente estudo (localizado), já que nesse método a distribuição de tensões produzida é semelhante ao carregamento fisiológico.

No presente estudo, não foi permitido movimento de rotação ou translação dos pilares nos modelos de AEF. Essa ausência de mobilidade dos pilares explica a maior concentração de tensões de tração na cervical do pôntico e não nos conectores, como seria esperado. Um estudo observou que quando os pilares são rígidos a maior concentração de tensão de tração é localizada na infra-estrutura, na região cervical e central do pôntico, logo abaixo da região de aplicação da carga (Kelly et al., 1995). Esse comportamento é semelhante ao observado no presente estudo. Entretanto, quando foi permitido movimento dos pilares a máxima tensão de tração ocorreu na região de conector, na interface entre infra-estrutura e porcelana (Kelly et al., 1995).

O tamanho do conector não influenciou de maneira significativa a distribuição de tensões e os valores de máxima principal dos modelos de YZ. Esse comportamento também pode ser explicado pela falta de mobilidade dos pilares, que resulta em uma maior concentração de tensões de tração no pôntico. Não é possível verificar a influência do tamanho dos conectores na distribuição de tensões já que essa região é menos solicitada. Além disso, o tamanho do pôntico é igual nos dois modelos, o que justifica a semelhança nos valores de tensão máxima principal 
encontrados. Diferenças muito pequenas foram observadas entre esses dois modelos, como a presença de tensões de tração em regiões mais próximas aos conectores na PPF de $9 \mathrm{~mm}^{2}$ e a maior concentração de tensões nos retentores para as PPFs de $16 \mathrm{~mm}^{2}$.

A semelhança na distribuição de tensões e nos valores de pico da tensão máxima principal dos três sistemas cerâmicos estudados está relacionada as propriedades elásticas desses materiais. As cerâmicas $Y Z$ e IZ apresentam valores muito próximos de módulo de elasticidade resultando em padrões semelhantes de distribuição de tensões. A AL apresenta um módulo de elasticidade mais elevado, o que refletiu em algumas diferenças em relação aos outros sistemas. A PPF de AL obteve o maior valor de tensão de tração na infra-estrutura e o menor valor na porcelana. Esse comportamento é explicado pelo fato de que um material com maior módulo de elasticidade produz menor deformação e resulta em menor transferência de tensões para a camada de porcelana (De Jager et al., 2006). Isso também pode ser evidenciado pelo fato de que a concentração de tensões de tração na camada de porcelana aumentou com a diminuição do módulo de elasticidade do material de infra-estrutura.

Fischer et al. (2003) avaliaram com AEF a distribuição de tensões em PPFs totalmente cerâmicas com diferentes materiais de infra-estrutura e tamanho de conector. Da mesma forma que o presente estudo, os autores observaram uma distribuição de tensões semelhante para os quatro materiais de infra-estrutura estudados. Naquele estudo foi permitida rotação do modelo no eixo y (paralelo ao longo eixo dos pilares) para simular o movimento fisiológico dos dentes. Dessa forma, o pico de tensão máxima principal de tração foi localizado na área cervical dos conectores e foi possível observar aumento da concentração de tensões de tração com a diminuição do tamanho dos conectores. A diminuição do tamanho do conector de $14 \mathrm{~mm}^{2}$ para $8,75 \mathrm{~mm}^{2}$ resultou em menor tempo de vida e maior probabilidade de fratura na análise de Weibull.

Foram feitas algumas simplificações do modelo de AEF em relação ao experimento laboratorial: (1) os materiais foram considerados homogêneos, isotrópicos e com comportamento elástico linear; (2) a influência da camada de cimento foi negligenciada; e (3) não foi considerada a influência das tensões residuais provenientes da incompatibilidade térmica desses materiais. Considerando que nos modelos de PPF os maiores valores de tensão de tração geralmente estão 
localizados na região de pôntico e conectores, sugere-se que a presença da camada de cimento não influenciaria de maneira significativa os resultados. Essa hipótese é confirmada pelo fato de que estudos com e sem camada de cimento encontraram distribuição semelhante de tensões para PPFs (Fischer et al., 2003; Motta et al., 2008). Além dos fatores já mencionados, essa simulação não levou em consideração os defeitos presentes nos materiais e nas interfaces. Portanto, não se pode fazer uma previsão do desempenho clínico com base nos valores de tensão máxima principal encontrados na AEF, apenas examinar a distribuição de tensões, dentro das limitações mencionadas. Não obstante, os padrões de distribuição e os valores relativos dos picos de tensão podem ser utilizados para auxiliar na comparação entre diferentes geometrias ou materiais (Motta et al., 2008).

\subsubsection{Padrão de fratura das PPFs em função do tipo de material de infra- estrutura, tamanho de conector e ciclagem mecânica}

O padrão macroscópico de fratura foi semelhante para todos os grupos. Em geral, a fratura iniciou na região cervical do conector ou pôntico e se propagou de forma oblíqua em direção à superfície oclusal, próximo a região de carregamento. Esse padrão de fratura está de acordo com os resultados de AEF. Na simulação matemática, houve maior concentração de tensões de tração na região cervical do pôntico das PPFs de $16 \mathrm{~mm}^{2}$. Já para as PPFs de $9 \mathrm{~mm}^{2}$, as tensões de tração foram localizadas mais próximas aos conectores. Esse comportamento também foi observado no ensaio in vitro, em que $70 \%$ das PPFs de $16 \mathrm{~mm}^{2}$ apresentaram fratura com origem na região de pôntico e $70 \%$ das PPFs de $9 \mathrm{~mm}^{2}$ apresentaram fratura com origem no conector.

Em uma pequena porcentagem das PPFs (9\%) a fratura teve início na superfície interna da margem do retentor, no material de infra-estrutura. Esse padrão de fratura foi observado principalmente para os grupos com infra-estrutura de

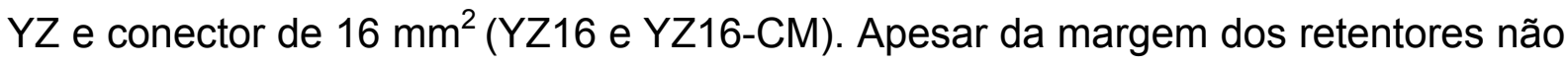
estar localizada na área mais crítica de tensões da PPF, ela apresenta uma espessura relativamente pequena em comparação aos conectores e pôntico, além de uma forma mais aguda. Portanto, essa área também se torna susceptível à 
fratura, principalmente quando é utilizada uma secção transversal grande $\left(16 \mathrm{~mm}^{2}\right) \mathrm{e}$ um material com altos valores de resistência, como a YZ. Da mesma forma, a AEF demonstrou, para a PPF com conectores de $16 \mathrm{~mm}^{2}$, maior concentração de tensões nos retentores quando a $Y Z$ foi utilizada em relação aos demais sistemas de infra-estrutura.

Em, aproximadamente, $60 \%$ das fraturas de conector e pôntico, a origem do defeito foi localizada na superfície externa da camada de porcelana, na região cervical. Nesses casos, a trinca se propagou da superfície em direção à interface e sofreu deflexão ao encontrar o material de infra-estrutura. Quando a magnitude da tensão excedeu o valor de $\mathrm{K}_{\mathrm{IC}}$ dos materiais de infra-estrutura a trinca reiniciou e se propagou resultando em fratura catastrófica da PPF. Nesses casos, foram identificados dois defeitos críticos, um na superfície da porcelana e outro na superfície da cerâmica de infra-estrutura. O comportamento de deflexão da trinca também foi evidenciado pela diferença entre os planos da superfície de fratura da porcelana e da infra-estrutura. Esse padrão de fratura pode estar relacionado com a grande diferença de valores de tenacidade entre as cerâmicas de infra-estrutura e as porcelanas ou com uma união interfacial deficiente entre os materiais (Taskonak et al., 2008a).

Taskonak et al. (2008a) observaram um comportamento semelhante de propagação de trincas para PPFs de quarto elementos de $Y Z$ que falharam clinicamente. Na maioria dos casos, a origem de fratura foi localizada na superfície da porcelana, na área gengival dos conectores. A trinca se propagou em direção à cerâmica de infra-estrutura e sofreu deflexão na interface. Um segundo defeito crítico, que controlou a fratura final das PPFs, foi observado na infra-estrutura de zircônia. Além disso, também foi observado um caso de fratura com origem na margem do retentor posterior.

Para os grupos de AL (AL16 e AL16-CM) foi observada fratura com origem na interface entre a porcelana e a cerâmica de infra-estrutura em 60 a $75 \%$ dos casos. $O$ defeito crítico foi localizado na superfície da infra-estrutura e a trinca se propagou através da estrutura sem sofrer deflexão na interface, a fratura ocorreu em um só plano. No presente estudo, o material AL apresentou o maior valor de módulo de elasticidade (390 GPa), aproximadamente seis vezes maior do que o valor da porcelana VM7 (67 GPa). Essa grande diferença entre as propriedades elásticas dos dois materiais pode induzir maior magnitude de tensões na interface. AEF também 
demonstrou, para a PPF de AL, maior concentração de tensões na infra-estrutura e menor concentração na camada de porcelana, em comparação com os outros sistemas (YZ e IZ). Além disso, a interface é um local de defeitos únicos, limite de fases e tensões de incompatibilidade térmica. Um estudo com PPFs de ICA que falharam in vitro e in vivo também encontrou na maioria dos casos ( $70 \%)$ origem de fratura na interface (Kelly et al., 1995).

Os padrões de fratura do grupo YZ16 com ou sem ciclagem foram semelhantes. Para os dois grupos, $60 \%$ das fraturas teve origem na superfície externa da porcelana, na área cervical do pôntico, e 20-30\% teve origem na superfície interna da margem do retentor, na cerâmica de infra-estrutura. Os grupos AL16 e AL16-CM também apresentaram padrão de fratura semelhante. A ciclagem mecânica influenciou apenas o padrão de fratura do sistema $I Z$, sendo que o grupo IZ-CM apresentou dois tipos de falha (fratura de retentor e de conector) que não foram encontrados para o grupo controle (IZ16)

O fato de que o tamanho do defeito crítico da infra-estrutura foi semelhante para todos os sistemas cerâmicos leva a algumas conclusões. Primeiro, indica influência significativa da metodologia de confecção na distribuição dos defeitos, já que foi utilizado o mesmo método para todas as infra-estruturas (usinagem em CADCAM). Além disso, a origem das falhas foi de superfície e não interna, justificando a maior influência do método de confecção do que da microestrutura do material na população de defeitos que originaram a fratura. Segundo, esses resultados comprovam que o ranqueamento observado para os valores de resistência à fratura dos materiais de infra-estruturas foi diretamente relacionado com os valores de tenacidade à fratura de cada cerâmica, já que a distribuição dos defeitos foi semelhante entre os grupos. Por último, comparando o tamanho de defeito dos grupos controle e dos grupos submetidos à ciclagem mecânica, sugere-se que o envelhecimento mecânico não foi capaz de provocar crescimento subcrítico de trincas no material de infra-estrutura. Esses resultados estão de acordo com os valores de carga de fratura, que foram semelhantes entre o grupo controle e o grupo ciclado (CM), para cada material de infra-estrutura.

Os valores estimados de tensão de fratura para as infra-estruturas de $Y Z, I Z$ e $\mathrm{AL}$ foram aproximadamente 950, 480 e $460 \mathrm{MPa}$, respectivamente. Esses resultados são muito próximos às médias de resistência à flexão em três pontos obtidas pelos corpos-de-prova monolíticos, sendo que a $\mathrm{YZ}$ apresentou um valor 
médio de $\sigma_{f}$ igual a $869 \mathrm{MPa}$, a IZ igual a $409 \mathrm{MPa}$ e a AL igual a $462 \mathrm{MPa}$. Essa boa relação entre os valores obtidos pelas infra-estruturas e pelas barras sugere que a distribuição de tensões é semelhante nesses dois ensaios, elevando a relevância dos ensaios de resistência por flexão (recomendados pela ISO 6872-2008). Esse raciocínio é qualificado pela análise fractográfica que demonstrou que os tamanhos dos defeitos críticos dos corpos-de-prova em forma de barra e das PPFs foram semelhantes para os materiais de infra-estrutura (Tabela 5.9 e Tabela 5.16). Lembra-se que essa análise fractográfica é sensível à experiência do examinador e dificultada pela microestrutura do material, condições da superfície de fratura e equipamentos analíticos disponíveis (Quinn, 2007; Della Bona, 2009).

Foram observados valores de tamanho de defeito crítico ao redor de $133 \mu \mathrm{m}$ e resistência à fratura entre 379 e 501 MPa para infra-estruturas de PPFs de YZ que falharam clinicamente (Taskonak et al., 2008a). O tamanho de defeito clínico é maior do que o encontrado no ensaio in vitro, o que sugere presença de crescimento subcrítico e justifica os menores valores de tensão de fratura. $O$ tamanho de defeito na camada de porcelana também foi estimado nesse estudo e variou entre 200 e $300 \mu \mathrm{m}$, resultando em valores de resistência à fratura ao redor de $30 \mathrm{MPa}$. Esse resultado indica que a falha da camada de porcelana ocorreu bem antes da falha da infra-estrutura.

Segundo Kelly (1999), as altas tensões produzidas durante o teste in vitro em comparação com as tensões observadas durante a mastigação são uma limitação dos ensaios laboratoriais. Ao contrário da fratura clínica, uma quantidade muito grande de energia é absorvida e liberada durante os testes in vitro. Isso pode produzir um comportamento de fratura diferente do comportamento observado in vivo. Entretanto, no presente estudo, apesar dos altos valores de tensão de fratura, foi observada uma boa relação entre o padrão de fratura observado para as PPFs in vitro e o padrão reportado na literatura para as PPFs in vivo (Kelly et al., 1995; Taskonak et al., 2008a). Apesar dos valores de resistência mais elevados, o ranqueamento desses valores é similar in vitro e in vivo (Della Bona; Kelly, 2008). Além disso, também foi encontrada uma boa relação entre o padrão de distribuição de tensões encontrado na AEF e as características de fratura das PPFs avaliadas. Portanto, sugere-se que as informações obtidas através do teste in vitro com estruturas em forma de PPF, qualificadas pela análise fractográfica e pela AEF 
podem ser utilizadas para prever o comportamento clínico dos sistemas cerâmicos estudados.

\subsection{RELAÇÃO ENTRE OS ENSAIOS COM CORPO-DE-PROVA EM FORMA DE BARRA E DE PPF}

O método utilizado na confecção dos corpos-de-prova em forma de barra para teste de resistência à flexão é um pouco diferente do método utilizado na confecção das PPFs. As barras foram submetidas a um procedimento de usinagem e polimento que não foi realizado para as PPFs. Esses procedimentos podem determinar o tamanho e distribuição dos defeitos extrínsecos (Kelly, 1995). Por outro lado, a infra-estrutura da PPF foi submetida a ciclos térmicos de sinterização da porcelana que não foram realizados nos corpos-de-prova monolíticos. Não obstante, a análise fractográfica demonstrou que o tamanho do defeito crítico do material de infra-estrutura foi semelhante para os corpos-de-prova em forma de barra (grupo monolítico) e os de PPF. Isso indica que os defeitos induzidos na superfície durante a confecção das barras foi semelhante aos defeitos induzidos pela usinagem em CAD-CAM das infra-estruturas de PPF. Além disso, os valores de tensão de fratura do material de infra-estrutura foram semelhantes para os dois tipos de corpos-deprova, sugerindo que o processo de sinterização da camada de porcelana não teve influência nas propriedades mecânicas dessas cerâmicas.

Outra limitação do ensaio de flexão é o fato de que o tipo de carregamento utilizado favorece a concentração de tensões na superfície, sendo menos sensível aos defeitos volumétricos (Kelly, 1995). Como os corpos-de-prova em forma de PPF também apresentaram a origem da fratura na superfície e não no interior do material de infra-estrutura, sugere-se que a distribuição de tensões foi semelhante para os dois tipos de corpos-de-prova. Além disso, ocorreu a distribuição de tensões prevista, ou seja, tensões de compressão na região superior dos corpos-de-prova e tensões de tração na superfície inferior, com maior concentração na área diretamente abaixo do ponto de aplicação da carga. Esse comportamento pode ser evidenciado pela AEF. 
Portanto, sugere-se que o ensaio de flexão em três pontos de corpos-deprova monolíticos realizado no presente estudo fornece informações confiáveis sobre o comportamento dos sistemas cerâmico de infra-estrutura utilizados na confecção de PPFs. Entretanto, não foi avaliado o tamanho de defeito crítico e tensão de fratura da camada de porcelana das PPFs. Por isso, não é possível correlacionar o comportamento dos corpos-de-prova em forma de barra e os de PPF para as porcelanas.

Foi observada uma aparente contradição em relação aos valores mínimos de resistência à flexão e a carga de fratura para recomendação de um material como infra-estrutura de PPFs na região posterior. Apesar dos valores médios de carga de fratura dos grupos IZ16 e AL16 terem sido superiores ao limite sugerido na literatura $(500 \mathrm{~N})$, os valores de resistência à flexão obtidos por esses materiais (IZ e $A L)$ foram inferiores ao limite preconizado pela norma ISO 6872 (2008) (500 MPa). Assim, essas cerâmicas (IZ e $A L)$ não podem ser recomendadas para PPFs na região posterior.

Corpos-de-prova de duas e três camadas com a porcelana em tração foram avaliados com o objetivo de simular o tipo de fratura observada nos conectores e pôntico. Nas estruturas de duas camadas, foi possível observar falha da porcelana antes da fratura total do corpo-de-prova e deflexão da trinca na interface. Através de análise fractográfica da superfície de fratura das PPFs também foi possível identificar deflexão da trinca na interface entre a porcelana e o material de infraestrutura. Para a maior parte das PPFs, foram encontrados dois defeitos críticos, um na porcelana e outro na infra-estrutura, sugerindo que a fratura da PPF ocorreu em duas etapas, iniciando na superfície externa (porcelana).

Entretanto, foi observado um modo de fratura para algumas PPFs que não foi encontrado nas estruturas em camadas, a falha com origem na interface. Uma dificuldade da extrapolação dos resultados obtidos com as estruturas em camadas para situação clínica é a proporção entre as camadas. A proporção entre a espessura do conector ou pôntico e a espessura da porcelana é muito maior do que a proporção entre as camadas dos corpos-de-prova em forma de barra. Essa diferença interfere diretamente na distribuição de tensões e modo de fratura dos corpos-de-prova. Isso também pode explicar a dificuldade na correlação entre o comportamento observado para as estruturas de três camadas e para as PPFs. 
Os resultados obtidos com as estruturas em camadas demonstraram que 0 material em tração durante o ensaio controlou os valores de resistência à fratura. Dessa forma, a cerâmica de infra-estrutura não melhorou a resistência da porcelana, já que o valor de $\sigma_{f}$ encontrado para as estruturas em camadas com a porcelana em tração foi semelhante ao observado para as barras monolíticas de porcelana. Nas PPFs, não foi possível verificar esse comportamento porque não foi estimada a tensão de fratura da camada de porcelana. 


\section{CONCLUSÕES}

1. Os valores de resistência à flexão em três pontos obtidos pelos materiais de infra-estrutura foram superiores aos valores obtidos pelas porcelanas, sendo que a $\mathrm{YZ}$ apresentou o maior valor médio de resistência à flexão. Os valores de módulo de Weibull foram semelhantes para os materiais estudados, com exceção dos grupos IZ e VM7, que apresentaram diferença estatística significante. Dessa forma, a hipótese experimental 1 foi parcialmente confirmada.

2. Os materiais cerâmicos com maior conteúdo cristalino ( $Y Z$ e $A L)$ apresentaram os maiores valores de $n$, seguidos pelo compósito $I Z$ e pelas porcelanas. Portanto, a hipótese experimental 2 foi confirmada.

3. As porcelanas apresentam maior tamanho de defeito crítico e menor valor de $\mathrm{K}_{\mathrm{IC}}$ do que os materiais de infra-estrutura, confirmando a hipótese experimental 3.

4. Independente do tipo de material, aquele submetido à tensão de tração durante o ensaio de flexão por três pontos determinou os valores de resistência à flexão dos corpos-de-prova. O modo de fratura variou com a configuração do corpode-prova (uma, duas ou três camadas) e com a metodologia de ensaio (porcelana ou infra-estrutura em tração). Assim, a hipótese 4 foi confirmada.

5. Para um mesmo material, o conector com maior área de secção transversal produziu maiores valores de carga de fratura das PPFs, confirmando a hipótese 5.

6. A ciclagem mecânica não reduziu os valores de carga de fratura das PPFs, independente do material de infra-estrutura. $O$ tamanho de defeito crítico da infraestrutura dos grupos controle e dos grupos submetidos à ciclagem mecânica foi semelhante, sugerindo que o envelhecimento mecânico não foi capaz de provocar crescimento subcrítico de trincas nesses materiais cerâmicos. Portanto, a hipótese 6 foi rejeitada.

7. Em geral, o padrão de distribuição de tensões foi semelhante para os diferentes materiais de infra-estrutura e tamanho da área de secção transversal do conector. Dessa forma, a hipótese 7 foi rejeitada.

8. Foi observada influência do tipo de material de infra-estrutura no padrão macroscópico de fratura (fratura de conector, pôntico ou retentor) e no local da origem da fratura (superfície da porcelana, interface ou margem do retentor) das PPFs. Assim, a hipótese 8 foi aceita. Com relação à análise fractográfica das PPFs 
observou-se que o defeito crítico da infra-estrutura foi de superfície e que seu tamanho (c) foi semelhante para todos os sistemas cerâmicos, indicando maior influência do método de confeç̧ão do que da microestrutura do material na população de defeitos que originaram a fratura. Além disso, as informações obtidas através do teste in vitro foram qualificadas pela análise fractográfica e pela AEF, portanto podem ser utilizadas para estimar o comportamento clínico dos sistemas cerâmicos estudados.

9. Algumas considerações foram feitas em relação ao comportamento mecânico dos corpos-de-prova em forma de barra e de PPF:

a) o tamanho do defeito crítico do material de infra-estrutura foi semelhante para os corpos-de-prova em forma de barra (grupo monolítico) e os de PPF, indicando que diferentes metodologias de confecção de corpo-de-prova induziram uma população de defeitos semelhante;

b) os valores de tensão de fratura do material de infra-estrutura foram semelhantes para os dois tipos de corpos-de-prova, sugerindo que o processo de sinterização da camada de porcelana não teve influência nas propriedades mecânicas dessas cerâmicas;

c) diferentes padrões de fratura foram observados para os corpos-de-prova em camadas e para as PPFs.

Portanto, a hipótese experimental 9 foi parcialmente confirmada. 


\section{REFERÊNCIAS ${ }^{1}$}

American Society for Testing and Materials. B962-08 Standard test methods for density of compacted or sintered powder metallurgy (PM) products using Archimede's principle. In: Book of Standards; 2008.

American Society for Testing and Materials. C 1322-02a, Standard Practice for Fractography and Characterization of Fracture Origins in Advanced Ceramics. In: Annual Book of Standards; 2003.

American Society for Testing and Materials. C 1368-00, Standard test method for determination of slow crack growth parameters of advanced ceramics by constant stress rate flexural testing at ambient temperature. In: Annual Book of ASTM; 2001a.

American Society for Testing and Materials. C 1421-01. Standard test method for determination of fracture toughness of advanced ceramics at ambient temperature. In: Annual Book of ASTM; 2001b.

American Society for Testing and Materials. E 494-95, Standard practice for measuring ultrasonic velocity in materials. In: Annual Book of ASTM; 2001c.

Andersson M, Oden A. A new all-ceramic crown. A dense-sintered, high-purity alumina coping with porcelain. Acta Odontol Scand 1993;51(1):59-64.

Anstis GR, Chantikul P, Lawn BR, Marshall DB. A critical evaluation of indentation techniques for measuring fracture toughness: indirect crack measurements. J Am Ceram Soc 1981;64(9):533-38.

Anusavice KJ, DeHoff PH, Hojjatie B, Gray A. Influence of tempering and contraction mismatch on crack development in ceramic surfaces. J Dent Res 1989;68(7):1182-7.

Anusavice KJ, Tsai YL. Stress distribution in ceramics crown froms as a function of thickness, elastic modulus, and suporting substrate. In: Bumgardner JD PA, editor. Proceedings of the Sixteenth Southern Biomedical Engineering Conference; 1997; Biloxi, MS: IEEE; 1997. p. 264-67.

Apholt W, Bindl A, Luthy H, Mormann WH. Flexural strength of Cerec 2 machined and jointed InCeram-Alumina and InCeram-Zirconia bars. Dent Mater 2001;17(3):260-7.

\footnotetext{
${ }^{1}$ De acordo com Estilo Vancouver.
} 
Att W, Grigoriadou M, Strub JR. ZrO2 three-unit fixed partial dentures: comparison of failure load before and after exposure to a mastication simulator. J Oral Rehabil 2007;34(4):282-90.

Barinov SM, Ivanov NV, Orlov SV, Shevchenko VJ. Influence of environment on delayed failure of alumina ceramics. J Eur Ceram Soc 1998;18:2057-63.

Beuer F, Edelhoff D, Gernet W, Sorensen JA. Three-year clinical prospective evaluation of zirconia-based posterior fixed dental prostheses (FDPs). Clin Oral Investig 2009;13(4):445-51.

Beuer F, Steff B, Naumann M, Sorensen JA. Load-bearing capacity of all-ceramic three-unit fixed partial dentures with different computer-aided design (CAD)/computer-aided manufacturing (CAM) fabricated framework materials. Eur $\mathrm{J}$ Oral Sci 2008;116(4):381-6.

Bonfante E. Confiabilidade e modos de fratura de próteses parciais fixas implantosuportadas metalocerâmicas e em zircônia [tese]. Bauru: Universidade de São Paulo; 2009.

Bottino MA, Salazar-Marocho SM, Leite FP, Vasquez VC, Valandro LF. Flexural strength of glass-infiltrated zirconia/alumina-based ceramics and feldspathic veneering porcelains. J Prosthodont 2009;18(5):417-20.

Callister Jr WD. Ciência e engenharia de materiais: uma introdução. 5 ed. Rio de Janeiro: LTC - Livros Técnicos e Científicos Editora S.A.; 2002.

Cattell MJ, Clarke RL, Lynch EJ. The transverse strength, reliability and microstructural features of four dental ceramics--Part I. J Dent 1997;25(5):399-407.

Cazzato A, Faber KT. Fracture energy of glass-alumina interfaces via the bimaterials bend test. J Am Ceram Soc 1997;80(1):181-88.

Cehreli MC, Kokat AM, Akca K. CAD/CAM Zirconia vs. slip-cast glass-infiltrated Alumina/Zirconia all-ceramic crowns: 2-year results of a randomized controlled clinical trial. J Appl Oral Sci 2009;17(1):49-55.

Cesar PF, Soki FN, Yoshimura HN, Gonzaga CC, Styopkin V. Influence of leucite content on slow crack growth of dental porcelains. Dent Mater 2008;24(8):1114-22.

Cesar PF, Yoshimura HN, Miranda Junior WG, Okada CY. Correlation between fracture toughness and leucite content in dental porcelains. J Dent 2005;33(9):721-9. 
Chantikul P, Anstis GR, Lawn BR, Marshall DB. A critical evaluation of indentation techniques for measuring fracture toughness: II, strength method. J Am Ceram Soc 1981;64(9):539-43.

Cheung KC, Darvell BW. Sintering of dental porcelain: effect of time and temperature on appearance and porosity. Dent Mater 2002;18(2):163-73.

Chevalier J, Gremillard L. The tetragonal-monoclinic transformation in zirconia: lessons learned and future trends. J Am Ceram Soc 2009;92(9):1901-20.

Chevalier J, Olagnon C, Fantozzi G. Subcritical crack growth in 3Y-TZP ceramics: atatic and cyclic fatigue. J Am Ceram Soc 1999;82(11):3129-38.

Chevalier J, Olagnon C, Fantozzi G, Bernard C. Crack propagation behavior of YTZP ceramics. J Am Ceram Soc 1995;78(7):1889-94.

Chitmongkolsuk S, Heydecke G, Stappert C, Strub JR. Fracture strength of allceramic lithium disilicate and porcelain-fused-to-metal bridges for molar replacement after dynamic loading. Eur J Prosthodont Restor Dent 2002;10(1):15-22.

Chong KH, Chai J, Takahashi Y, Wozniak W. Flexural strength of In-Ceram alumina and In-Ceram zirconia core materials. Int J Prosthodont 2002;15(2):183-8.

Christel P, Meunier A, Heller M, Torre JP, Peille CN. Mechanical properties and short-term in-vivo evaluation of yttrium-oxide-partially-stabilized zirconia. J Biomed Mater Res 1989;23(1):45-61.

Cottom BA, Mayo MJ. Fracture toughness of nanocrystalline $\mathrm{ZrO}_{2}-3 \mathrm{~mol} \% \mathrm{Y}_{2} \mathrm{O}_{3}$ determined by Vickers indentation. Scripta Mater 1996;34:809-14.

Crisp RJ, Cowan AJ, Lamb J, Thompson O, Tulloch N, Burke FJ. A clinical evaluation of all-ceramic bridges placed in UK general dental practices: first-year results. $\mathrm{Br}$ Dent J 2008;205(9):477-82.

Curtis AR, Wright AJ, Fleming GJ. The influence of simulated masticatory loading regimes on the bi-axial flexure strength and reliability of a Y-TZP dental ceramic. J Dent 2006;34(5):317-25.

De Aza AH, Chevalier J, Fantozzi G, Schehl M, Torrecillas R. Crack growth resistance of alumina, zirconia and zirconia toughened alumina ceramics for joint prostheses. Biomaterials 2002;23(3):937-45. 
De Jager N, de Kler M, van der Zel JM. The influence of different core material on the FEA-determined stress distribution in dental crowns. Dent Mater 2006;22(3):234-42.

de Kler M, de Jager N, Meegdes M, van der Zel JM. Influence of thermal expansion mismatch and fatigue loading on phase changes in porcelain veneered $\mathrm{Y}$-TZP zirconia discs. J Oral Rehabil 2007;34(11):841-7.

Della Bona A. Bonding to ceramics: scientific evidences for clinical dentistry. $1^{\circ}$ ed. São Paulo: Artes Médicas; 2009.

Della Bona A, Anusavice KJ, DeHoff PH. Weibull analysis and flexural strength of hot-pressed core and veneered ceramic structures. Dent Mater 2003;19(7):662-9.

Della Bona A, Donassollo TA, Demarco FF, Barrett AA, Mecholsky JJ, Jr. Characterization and surface treatment effects on topography of a glass-infiltrated alumina/zirconia-reinforced ceramic. Dent Mater 2007;23(6):769-75.

Della Bona A, Kelly JR. The clinical success of all-ceramic restorations. J Am Dent Assoc 2008;139 Suppl:8S-13S.

Della Bona A, Mecholsky JJ, Barrett AA, Griggs JA. Characterization of glassinfiltrated alumina-based ceramics. Dent Mater 2008;24(11):1568-74.

Della Bona A, Mecholsky JJ, Jr., Anusavice KJ. Fracture behavior of lithia disilicateand leucite-based ceramics. Dent Mater 2004;20(10):956-62.

Della Bona A, van Noort R. Shear vs. tensile bond strength of resin composite bonded to ceramic. J Dent Res 1995;74(9):1591-6.

DeLong R, Douglas WH. Development of an artificial oral environment for the testing of dental restoratives: bi-axial force and movement control. J Dent Res 1983;62(1):32-6.

Denry I, Kelly JR. State of the art of zirconia for dental applications. Dent Mater 2008;24(3):299-307.

Deville S, Chevalier J, Gremillard L. Influence of surface finish and residual stresses on the ageing sensitivity of biomedical grade zirconia. Biomaterials 2006;27(10):2186-92. 
Edelhoff D, Florian B, Florian W, Johnen C. HIP zirconia fixed partial dentures-clinical results after 3 years of clinical service. Quintessence Int 2008;39(6):459-71.

Fairhurst CW, Lockwood PE, Ringle RD, Twiggs SW. Dynamic fatigue of feldspathic porcelain. Dent Mater 1993;9(4):269-73.

Filser F, Kocher P, Weibel F, Luthy H, Scharer P, Gauckler LJ. Reliability and strength of all-ceramic dental restorations fabricated by direct ceramic machining (DCM). Int J Comput Dent 2001;4(2):89-106.

Fischer $\mathrm{H}$, Weber M, Marx R. Lifetime prediction of all-ceramic bridges by computational methods. J Dent Res 2003;82(3):238-42.

Fischer J, Grohmann P, Stawarczyk B. Effect of zirconia surface treatments on the shear strength of zirconia/veneering ceramic composites. Dent Mater J 2008;27(3):448-54.

Fischer J, Stawarczyk B, Hammerle $\mathrm{CH}$. Flexural strength of veneering ceramics for zirconia. J Dent 2008;36(5):316-21.

Fischer J, Stawarzcyk B, Trottmann A, Hammerle CH. Impact of thermal misfit on shear strength of veneering ceramic/zirconia composites. Dent Mater 2009;25(4):419-23.

Fleming GJ, Shaini FJ, Marquis PM. An assessment of the influence of mixing induced variability on the bi-axial flexure strength of dentine porcelain discs and the implications for laboratory testing of porcelain specimens. Dent Mater 2000;16(2):114-9.

Fleming GJ, Shelton RM, Marquis PM. The influence of clinically induced variability on the bi-axial fracture strength of aluminous core porcelain discs. J Dent 1999;27(8):587-94.

Fleming GJ, Dickens M, Thomas LJ, Harris JJ. The in vitro failure of all-ceramic crowns and the connector area of fixed partial dentures using bilayered ceramic specimens: the influence of core to dentin thickness ratio. Dent Mater 2006;22(8):771-7.

Fleming GJ, El-Lakwah SF, Harris JJ, Marquis PM. The effect of core:dentin thickness ratio on the bi-axial flexure strength and fracture mode and origin of bilayered dental ceramic composites. Dent Mater 2005;21(2):164-71. 
Fréchette VD. Failure analysis of brittle materials. Advances in Ceramics. Westerville, $\mathrm{OH}$ : American Ceramic Society; 1990.

Giordano RA, 2nd, Pelletier L, Campbell S, Pober R. Flexural strength of an infused ceramic, glass ceramic, and feldspathic porcelain. J Prosthet Dent 1995;73(5):411-8.

Gonzaga CC. Crescimento de trinca subcrítico em cerâmicas odontológicas: efeito do material (microstrutura) e do método de ensaio [tese]. São Paulo: Universidade de São Paulo; 2007.

Gonzaga CC, Yoshimura HN, Cesar PF, Miranda WG, Jr. Subcritical crack growth in porcelains, glass-ceramics, and glass-infiltrated alumina composite for dental restorations. J Mater Sci Mater Med 2009;20(5):1017-24.

Griffith AA. The phenomena of rupture and flow in solids. Philos Trans R Soc 1920;221:163-98.

Guazzato M, Albakry M, Ringer SP, Swain MV. Strength, fracture toughness and microstructure of a selection of all-ceramic materials. Part I. Pressable and alumina glass-infiltrated ceramics. Dent Mater 2004b;20(5):441-8.

Guazzato M, Albakry M, Ringer SP, Swain MV. Strength, fracture toughness and microstructure of a selection of all-ceramic materials. Part II. Zirconia-based dental ceramics. Dent Mater 2004a;20(5):449-56.

Guazzato M, Albakry M, Swain MV, Ironside J. Mechanical properties of In-Ceram Alumina and In-Ceram Zirconia. Int J Prosthodont 2002;15(4):339-46.

Guazzato M, Proos K, Quach L, Swain MV. Strength, reliability and mode of fracture of bilayered porcelain/zirconia (Y-TZP) dental ceramics. Biomaterials 2004c;25(20):5045-52.

Guazzato M, Quach L, Albakry M, Swain MV. Influence of surface and heat treatments on the flexural strength of Y-TZP dental ceramic. J Dent 2005;33(1):9-18.

Gupta PK, Jubb NJ. Post-indentation slow growth of radial cracks in glasses. J Am Ceram Soc 1981;64:C112-4.

Hannink RHJ, Kelly PM, Muddle BC. Transformation toughening in zirconiacontaining ceramics. J Am Ceram Soc 2000;83(3):461-87. 
Heffernan MJ, Aquilino SA, Diaz-Arnold AM, Haselton DR, Stanford CM, Vargas MA. Relative translucency of six all-ceramic systems. Part I: core materials. J Prosthet Dent 2002a;88(1):4-9.

Heffernan MJ, Aquilino SA, Diaz-Arnold AM, Haselton DR, Stanford CM, Vargas MA. Relative translucency of six all-ceramic systems. Part II: core and veneer materials. J Prosthet Dent 2002b;88(1):10-5.

Heuer $\mathrm{AH}$, Claussen N, Kriven WM, Ruhle M. Stability of tetragonal $\mathrm{ZrO}_{2}$ particles in ceramic matrices. J Am Ceram Soc 1982;65:642-50.

Heuer AH, Lange FF, Swain MV, Evans AG. Transformation toughening: an overview. J Am Ceram Soc 1986;69:i-iv.

Hickel R, Roulet JF, Bayne S, Heintze SD, Mjor IA, Peters M, et al. Recommendations for conducting controlled clinical studies of dental restorative materials. Clin Oral Investig 2007;11(1):5-33.

Hidaka O, Iwasaki M, Saito M, Morimoto T. Influence of clenching intensity on bite force balance, occlusal contact area, and average bite pressure. J Dent Res 1999;78(7):1336-44.

Holmes DC, Haganman CR, Aquilino SA, Diaz-Arnold AM, Stanford CM. Finite element stress analysis of IMZ abutment designs: development of a model. J Prosthodont 1997;6(1):31-6.

Hsueh CH, Luttrell CR, Becher PF. Analyses of multilayered dental ceramics subjected to biaxial flexure tests. Dent Mater 2006;22(5):460-9.

Hsueh CH, Thompson GA, Jadaan OM, Wereszczak AA, Becher PF. Analyses of layer-thickness effects in bilayered dental ceramics subjected to thermal stresses and ring-on-ring tests. Dent Mater 2008;24(1):9-17.

Hulbert S, Bokros J, Hench L, Wilson J, Heimke G. Ceramics in clinical applications, past, present and future. In: Vincenzinc P, editor. High tech ceramics. Amsterdam: Elsevier Science; 1987. p. 3-27.

International Organization for Standardization. 6872 Dentistry - Ceramic Materials. In; 2008.

Irwin GR. Analysis of stresses and strain near the end of crack transversing a plate. J Appl Mech 1957;24:361-4. 
Jemt T, Karlsson S, Hedegard B. Mandibular movements of young adults recorded by intraorally placed light-emitting diodes. J Prosthet Dent 1979;42(6):669-73.

Jung YG, Peterson IM, Kim DK, Lawn BR. Lifetime-limiting strength degradation from contact fatigue in dental ceramics. J Dent Res 2000;79(2):722-31.

Karlsson S. A clinical evaluation of fixed bridges, 10 years following insertion. J Oral Rehabil 1986;13(5):423-32.

Kaye B. Particle image analysis; 1998.

Kelly JR. Clinically relevant approach to failure testing of all-ceramic restorations. J Prosthet Dent 1999;81(6):652-61.

Kelly JR. Perspectives on strength. Dent Mater 1995;11(2):103-10.

Kelly JR, Tesk JA, Sorensen JA. Failure of all-ceramic fixed partial dentures in vitro and in vivo: analysis and modeling. J Dent Res 1995;74(6):1253-8.

Kilicarslan MA, Kedici PS, Kucukesmen HC, Uludag BC. In vitro fracture resistance of posterior metal-ceramic and all-ceramic inlay-retained resin-bonded fixed partial dentures. J Prosthet Dent 2004;92(4):365-70.

Kim JW, Covel NS, Guess PC, Rekow ED, Zhang Y. Concerns of hydrothermal degradation in CAD/CAM zirconia. J Dent Res 2010;89(1):91-5.

Kobayashi K, Kuwajima $\mathrm{H}$, Masaki T. Phase change and mechanical properties of $\mathrm{ZrO}_{2}-\mathrm{Y}_{2} \mathrm{O}_{3}$ solid electrolyte after aging. Solid State lonics 1981;4:489-95.

Kohorst P, Herzog TJ, Borchers L, Stiesch-Scholz M. Load-bearing capacity of allceramic posterior four-unit fixed partial dentures with different zirconia frameworks. Eur J Oral Sci 2007;115(2):161-6.

Kosmac T, Oblak C, Jevnikar P, Funduk N, Marion L. The effect of surface grinding and sandblasting on flexural strength and reliability of Y-TZP zirconia ceramic. Dent Mater 1999;15(6):426-33.

Larsson C, Holm L, Lovgren N, Kokubo Y, Vult von Steyern P. Fracture strength of four-unit Y-TZP FPD cores designed with varying connector diameter. An in-vitro study. J Oral Rehabil 2007;34(9):702-9. 
Liu S, Chen I. Fatigue of yttria-stabilized zirconia: I, fatigue damage, fracture origins, and lifetime prediction. J Am Ceram Soc 1991;74(6):1197-205.

Lohbauer U, Kramer N, Petschelt A, Frankenberger R. Correlation of in vitro fatigue data and in vivo clinical performance of a glassceramic material. Dent Mater 2008;24(1):39-44.

Lucas LC, Lemons JE. Biodegradation of restorative metallic systems. Adv Dent Res 1992;6:32-7.

Luthardt RG, Holzhuter M, Sandkuhl O, Herold V, Schnapp JD, Kuhlisch E, et al. Reliability and properties of ground Y-TZP-zirconia ceramics. J Dent Res 2002;81(7):487-91.

Luthy H, Filser F, Loeffel O, Schumacher M, Gauckler LJ, Hammerle CH. Strength and reliability of four-unit all-ceramic posterior bridges. Dent Mater 2005;21(10):9307.

Magne P, Perakis N, Belser UC, Krejci I. Stress distribution of inlay-anchored adhesive fixed partial dentures: a finite element analysis of the influence of restorative materials and abutment preparation design. J Prosthet Dent 2002;87(5):516-27.

McLaren EA, White SN. Glass-infiltrated zirconia/alumina-based ceramic for crowns and fixed partial dentures. Pract Periodontics Aesthet Dent 1999;11(8):985-94; quiz 96.

McLean JW. The alumina reinforced porcelain jacket crown. J Am Dent Assoc 1967;75(3):621-8.

McLean JW, Hughes TH. The reinforcement of dental porcelain with ceramic oxides. Br Dent J 1965;119(6):251-67.

Mecholsky JJ. Fractography: determining the sites of fracture initiation. Dent Mater 1995b;11(2):113-6.

Mecholsky JJ. Fracture mechanics principles. Dent Mater 1995a;11(2):111-2.

Meyenberg $\mathrm{KH}$, Luthy $\mathrm{H}$, Scharer $\mathrm{P}$. Zirconia posts: a new all-ceramic concept for nonvital abutment teeth. J Esthet Dent 1995;7(2):73-80. 
Michalske TA, Freiman SW. Molecular mechanism for stress corrosion in vitreous silica. J Am Ceram Soc 1983;66:284-88.

Molin MK, Karlsson SL. Five-year clinical prospective evaluation of zirconia-based Denzir 3-unit FPDs. Int J Prosthodont 2008;21(3):223-7.

Morena R, Beaudreau GM, Lockwood PE, Evans AL, Fairhurst CW. Fatigue of dental ceramics in a simulated oral environment. J Dent Res 1986;65(7):993-7.

Motta AB, Pereira LC, da Cunha AR, Duda FP. The influence of the loading mode on the stress distribution on the connector region of metal-ceramic and all-ceramic fixed partial denture. Artif Organs 2008;32(4):283-91.

Oh WS, Anusavice KJ. Effect of connector design on the fracture resistance of allceramic fixed partial dentures. J Prosthet Dent 2002;87(5):536-42.

Ohlmann B, Rammelsberg P, Schmitter M, Schwarz S, Gabbert O. All-ceramic inlayretained fixed partial dentures: preliminary results from a clinical study. J Dent 2008;36(9):692-6.

Oilo M, Gjerdet NR, Tvinnereim HM. The firing procedure influences properties of a zirconia core ceramic. Dent Mater 2008;24(4):471-5.

Pallis K, Griggs JA, Woody RD, Guillen GE, Miller AW. Fracture resistance of three all-ceramic restorative systems for posterior applications. J Prosthet Dent 2004;91(6):561-9.

Palmqvist S, Swartz B. Artificial crowns and fixed partial dentures 18 to 23 years after placement. Int J Prosthodont 1993;6(3):279-85.

Papanagiotou HP, Morgano SM, Giordano RA, Pober R. In vitro evaluation of lowtemperature aging effects and finishing procedures on the flexural strength and structural stability of Y-TZP dental ceramics. J Prosthet Dent 2006;96(3):154-64.

Petrovic JJ, Dirks RA, Jacobson LA, Mendiratta MG. Effects of residual stresses on fracture from controlled surface flaws. J Am Ceram Soc 1976a;59(3-4):177-78.

Petrovic JJ, Wills RR, Mendiratta MG. Controlled surface flaw initiated fracture in reaction-bonded Si3N4. J Mater Sci 1976b;11(7):1330-34. 
Piconi C, Maccauro G. Zirconia as a ceramic biomaterial. Biomaterials 1999;20(1):125.

Pinto MM, Cesar PF, Rosa V, Yoshimura HN. Influence of $\mathrm{pH}$ on slow crack growth of dental porcelains. Dent Mater 2008;24(6):814-23.

Pjetursson BE, Sailer I, Zwahlen M, Hammerle $\mathrm{CH}$. A systematic review of the survival and complication rates of all-ceramic and metal-ceramic reconstructions after an observation period of at least 3 years. Part I: Single crowns. Clin Oral Implants Res 2007;18 Suppl 3:73-85.

Plengsombut K, Brewer JD, Monaco EA, Jr., Davis EL. Effect of two connector designs on the fracture resistance of all-ceramic core materials for fixed dental prostheses. J Prosthet Dent 2009;101(3):166-73.

Probster L. Four year clinical study of glass-infiltrated, sintered alumina crowns. J Oral Rehabil 1996;23(3):147-51.

Proeschel PA, Morneburg T. Task-dependence of activity/ bite-force relations and its impact on estimation of chewing force from EMG. J Dent Res 2002;81(7):464-8.

Quinn GD. Fractography of ceramics and glasses. Washington: National Institute of Standards and Technology; 2007.

Quinn GD, Kübler JJ, Gettings RJ. Fracture toughness of advanced ceramics by the surface crack in flexure (SCF) method: a VAMAS round robin. VAMAS Technical Report. Gaithersburg, MD: National Institute of Standards and Techonogy; 1994. Report No.: 17.

Quinn JB, Quinn GD, Kelly JR, Scherrer SS. Fractographic analyses of three ceramic whole crown restoration failures. Dent Mater 2005;21(10):920-9.

Raigrodski AJ. Clinical and laboratory considerations for the use of CAD/CAM YTZP-based restorations. Pract Proced Aesthet Dent 2003;15(6):469-76; quiz 77.

Raigrodski AJ. Contemporary materials and technologies for all-ceramic fixed partial dentures: a review of the literature. J Prosthet Dent 2004;92(6):557-62.

Raigrodski AJ, Chiche GJ. The safety and efficacy of anterior ceramic fixed partial dentures: A review of the literature. J Prosthet Dent 2001;86(5):520-25. 
Randall PN. Plain strain crack toughness testing of high strength metallic materials. In: Jr BWF, E SJ, editors. ASTM STP 410. Philadelphia: American Society for Testing and Materials; 1966. p. 88-126.

Rekow ED, Harsono M, Janal M, Thompson VP, Zhang G. Factorial analysis of variables influencing stress in all-ceramic crowns. Dent Mater 2006;22(2):125-32.

Ritter JE. Critique of test methods for lifetime predictions. Dent Mater 1995b;11(2):147-51.

Ritter JE. Engineering design and fatigue failure of brittle materials. In: Bradt RC, Hasselman DPH, Lange FF, editors. Fracture Mechanics of Ceramics. New York: Plenum Press; 1978. p. 667-86.

Ritter JE. Predicting lifetimes of materials and material structures. Dent Mater 1995a;11(2):142-6.

Ritter JE, Vigedomine M, Breder K, Jakus K. Dynamic fatigue of indented soda-lime glass as a function of temperature. J Mater Sci 1985;28:2868-72.

Rizkalla AS, Jones DW. Mechanical properties of commercial high strength ceramic core materials. Dent Mater 2004;20(2):207-12.

Rosa V, Yoshimura HN, Pinto MM, Fredericci C, Cesar PF. Effect of ion exchange on strength and slow crack growth of a dental porcelain. Dent Mater 2009;25(6):736-43.

Rosentiel SF, Porter SS. Apparent fracture toughness of all-ceramic crown systems. J Prosthet Dent 1989;62(5):529-32.

Rosentritt M, Behr M, Gebhard R, Handel G. Influence of stress simulation parameters on the fracture strength of all-ceramic fixed-partial dentures. Dent Mater 2006;22(2):176-82.

Rosentritt M, Behr M, van der Zel JM, Feilzer AJ. Approach for valuating the influence of laboratory simulation. Dent Mater 2009;25(3):348-52.

Sailer I, Feher A, Filser F, Gauckler LJ, Luthy H, Hammerle CH. Five-year clinical results of zirconia frameworks for posterior fixed partial dentures. Int J Prosthodont 2007a;20(4):383-8. 
Sailer I, Feher A, Filser F, Luthy H, Gauckler LJ, Scharer P, et al. Prospective clinical study of zirconia posterior fixed partial dentures: 3-year follow-up. Quintessence Int 2006;37(9):685-93.

Sailer I, Pjetursson BE, Zwahlen M, Hammerle $\mathrm{CH}$. A systematic review of the survival and complication rates of all-ceramic and metal-ceramic reconstructions after an observation period of at least 3 years. Part II: Fixed dental prostheses. Clin Oral Implants Res 2007b;18 Suppl 3:86-96.

Salazar Marocho SM, Studart AR, Bottino MA, Bona AD. Mechanical strength and subcritical crack growth under wet cyclic loading of glass-infiltrated dental ceramics. Dent Mater 2010;26(5):483-90.

Scherrer SS, de Rijk WG. The fracture resistance of all-ceramic crowns on supporting structures with different elastic moduli. Int J Prosthodont 1993;6(5):462-7.

Scherrer SS, Kelly JR, Quinn GD, Xu K. Fracture toughness (KIc) of a dental porcelain determined by fractographic analysis. Dent Mater 1999;15(5):342-8.

Scherrer SS, Quinn GD, Quinn JB. Fractographic failure analysis of a Procera AllCeram crown using stereo and scanning electron microscopy. Dent Mater 2008;24(8):1107-13.

Scherrer SS, Quinn JB, Quinn GD, Wiskott HW. Fractographic ceramic failure analysis using the replica technique. Dent Mater 2007;23(11):1397-404.

Seghi RR, Sorensen JA. Relative flexural strength of six new ceramic materials. Int J Prosthodont 1995;8(3):239-46.

Sjolin R, Sundh A, Bergman M. The Decim system for the production of dental restorations. Int J Comput Dent 1999;2(3):197-207.

Sorensen JA, Cruz M, Mito WT, Raffeiner O, Meredith HR, Foser HP. A clinical investigation on three-unit fixed partial dentures fabricated with a lithium disilicate glass-ceramic. Pract Periodontics Aesthet Dent 1999;11(1):95-106; quiz 08.

Sorensen JA, Kang SK, Torres TJ, Knode H. In-Ceram fixed partial dentures: threeyear clinical trial results. J Calif Dent Assoc 1998;26(3):207-14.

Studart AR, Filser F, Kocher P, Luthy H, Gauckler LJ. Cyclic fatigue in water of veneer-framework composites for all-ceramic dental bridges. Dent Mater 2007;23(2):177-85. 
Suarez MJ, Lozano JF, Paz Salido M, Martinez F. Three-year clinical evaluation of In-Ceram Zirconia posterior FPDs. Int J Prosthodont 2004;17(1):35-8.

Sundh A, Molin M, Sjogren G. Fracture resistance of yttrium oxide partially-stabilized zirconia all-ceramic bridges after veneering and mechanical fatigue testing. Dent Mater 2005;21(5):476-82.

Sundh A, Sjogren G. Fracture resistance of all-ceramic zirconia bridges with differing phase stabilizers and quality of sintering. Dent Mater 2006;22(8):778-84.

Swain MV. Unstable cracking (chipping) of veneering porcelain on all-ceramic dental crowns and fixed partial dentures. Acta Biomater 2009;5(5):1668-77.

Taskonak B, Griggs JA, Mecholsky JJ, Jr., Yan JH. Analysis of subcritical crack growth in dental ceramics using fracture mechanics and fractography. Dent Mater 2008b;24(5):700-7.

Taskonak B, Yan J, Mecholsky JJ, Jr., Sertgoz A, Kocak A. Fractographic analyses of zirconia-based fixed partial dentures. Dent Mater 2008a;24(8):1077-82.

Teixeira EC, Piascik JR, Stoner BR, Thompson JY. Dynamic fatigue and strength characterization of three ceramic materials. J Mater Sci Mater Med 2007;18(6):121924.

Ten Cate JM, Duijsters PP. Alternating demineralization and remineralization of artificial enamel lesions. Caries Res 1982;16(3):201-10.

Thompson GA. Determining the slow crack growth parameter and Weibull twoparameter estimates of bilaminate disks by constant displacement-rate flexural testing. Dent Mater 2004;20(1):51-62.

Thompson GA. Influence of relative layer height and testing method on the failure mode and origin in a bilayered dental ceramic composite. Dent Mater 2000;16(4):235-43.

Thompson JY, Anusavice KJ. Effect of surface etching on the flexure strength and fracture toughness of Dicor disks containing controlled flaws. J Dent Res 1994;73(2):505-10.

Thompson JY, Anusavice KJ, Naman A, Morris HF. Fracture surface characterization of clinically failed all-ceramic crowns. J Dent Res 1994;73(12):1824-32. 
Tinschert J, Natt G, Hassenpflug S, Spiekermann H. Status of current CAD/CAM technology in dental medicine. Int J Comput Dent 2004;7(1):25-45.

Tinschert J, Natt G, Mautsch W, Augthun M, Spiekermann H. Fracture resistance of lithium disilicate-, alumina-, and zirconia-based three-unit fixed partial dentures: a laboratory study. Int J Prosthodont 2001;14(3):231-8.

Tinschert J, Natt G, Spiekermann H, Schulze KA. Lifetime of Alumina and Zirconia Ceramics Used for Crown and Bridge Restorations. J Biomed Mater Res Part B: Appl Biomater 2007;80B:317-21.

Tinschert J, Schulze KA, Natt G, Latzke P, Heussen N, Spiekermann H. Clinical behavior of zirconia-based fixed partial dentures made of DC-Zirkon: 3-year results. Int J Prosthodont 2008;21(3):217-22.

Tinschert J, Zwez D, Marx R, Anusavice KJ. Structural reliability of alumina-, feldspar-, leucite-, mica- and zirconia-based ceramics. J Dent 2000;28(7):529-35.

Uo M, Sjogren G, Sundh A, Watari F, Bergman M, Lerner U. Cytotoxicity and bonding property of dental ceramics. Dent Mater 2003;19(6):487-92.

Vult von Steyern P, Carlson P, Nilner K. All-ceramic fixed partial dentures designed according to the DC-Zirkon technique. A 2-year clinical study. J Oral Rehabil 2005;32(3):180-7.

Weibull W. A statistical theory of the strength of materials. Ing Vetensk Akad Proc 1939;151:1-45.

White SN, Caputo AA, Vidjak FM, Seghi RR. Moduli of rupture of layered dental ceramics. Dent Mater 1994;10(1):52-8.

White SN, Miklus VG, McLaren EA, Lang LA, Caputo AA. Flexural strength of a layered zirconia and porcelain dental all-ceramic system. J Prosthet Dent 2005;94(2):125-31.

Wiederhorn SM. Influence of water vapor on crack propagation in soda-lime-glass. J Am Ceram Soc 1967;50:407-14.

Wiskott HW, Nicholls JI, Belser UC. Stress fatigue: basic principles and prosthodontic implications. Int J Prosthodont 1995;8(2):105-16. 
Witek SR, Butler EP. Zirconia particles coarsening and the effect of zirconia additions on the mechanical properties of certain commercial aluminas. J Am Ceram Soc 1986;69:523-29.

Wolfart S, Ludwig K, Uphaus A, Kern M. Fracture strength of all-ceramic posterior inlay-retained fixed partial dentures. Dent Mater 2007;23(12):1513-20.

Yilmaz $\mathrm{H}$, Aydin $\mathrm{C}$, Gul BE. Flexural strength and fracture toughness of dental core ceramics. J Prosthet Dent 2007;98(2):120-8.

Yoshimura HN, Cesar PF, Miranda WG, Gonzaga CC, Okada CY, Goldenstein H. Fracture toughness of dental porcelains evaluated by IF, SCF, and SEPB methods. Am Ceram Soc 2005;88(6):1680-83.

Young W, Budynas R. Roark's formulas for stress and strain. 7 ed: McGraw-Hill; 2002.

Zeng K, Oden A, Rowcliffe D. Evaluation of mechanical properties of dental ceramic core materials in combination with porcelains. Int J Prosthodont 1998;11(2):183-9.

Zeng K, Oden A, Rowcliffe D. Flexure tests on dental ceramics. Int J Prosthodont 1996;9(5):434-9.

Zhu Q, With G, Dortmans LJMG, Feenstra F. Subcritical crack growth behavior of Al2O3-glass dental composites. J Biomed Mater Res Part B: Appl Biomater 2003;65B:233-8. 